\title{
GILBERTO IGARASHI
}

\section{Contribuições para a implementação de um barramento de processo segundo a Norma IEC 61850-9}

Tese apresentada à Escola Politécnica da Universidade de São Paulo para obtenção do título de Doutor

São Paulo

2016 


\section{GILBERTO IGARASHI}

\section{Contribuições para a implementação de um barramento de processo segundo a Norma IEC 61850-9}

Tese apresentada à Escola Politécnica da Universidade de São Paulo para obtenção do título de Doutor

Área de Concentração: Departamento de Engenharia de Energia e Automação Elétricas (PEA)

Orientador: Prof. Dr. Josemir Coelho Santos

São Paulo

2016 
Este exemplar foi revisado e corrigido em relação à versão original, sob responsabilidade única do autor e com a anuência de seu orientador.

São Paulo,21 de janeiro de 2016.

Assinatura do autor:

Assinatura do orientador:

Catalogação-na-publicação

Igarashi, Gilberto

CONTRIBUICOÕES PARA A IMPLEMENTAÇÃO DE UM BARRAMENTO DE PROCESSO SEGUNDO A NORMA IEC 61850-9 / G. Igarashi -- versão corr. -- São Paulo, 2016. $228 \mathrm{p}$.

Tese (Doutorado) - Escola Politécnica da Universidade de São Paulo. Departamento de Engenharia de Energia e Automação Elétricas.

1.instrumentação elétrica 2.redes de comunicação de dados I.Universidade de São Paulo. Escola Politécnica. Departamento de Engenharia de Energia e Automação Elétricas II.t. 
À minha amada esposa. 


\section{AGRADECIMENTOS}

À Deus e a minha família.

Ao Prof. Dr. Josemir Coelho Santos, pela orientação, atenção, compreensão, disposição e paciência.

A todos os colegas do Laboratório de Sensores Ópticos, em especial a Shigueru, Thiago, Raul, Gleison, Sandra e Jonas, pela amizade e auxílios valiosos.

A minha amada esposa Patricia, por sua presença, compreensão, companheirismo e incentivo.

A todos os professores e funcionários da Engenharia Elétrica da Escola Politécnica da Universidade de São Paulo, que de algum modo colaboraram durante a minha permanência nesta universidade.

À CAPES, FUSP e Comissão de Pesquisa do PEA pelo apoio financeiro concedido, possibilitando a participação em congressos regionais e internacionais.

À Pextron Controles Eletrônicos Ltda, em especial aos colegas do Departamento de Engenharia de Produto e aos membros da Diretoria, pelo apoio no desenvolvimento deste trabalho.

Ao Instituto Federal de Educação, Ciência e Tecnologia de São Paulo, pelo incentivo para capacitação concedido.

Ao Prof. Dr. Alexandre Brincalepe Campo, que desde o início de minha carreira acadêmica sempre me inspirou e me motivou. 


\section{RESUMO}

Desde seu lançamento, em 2002, a Norma IEC 61850 vem evoluindo para se tornar o padrão adotado nos Sistemas de Automação de Subestações. Dentre seus vários aspectos, destacamse os serviços de tempo real, que permitem a implementação de funções de automação e de proteção dentro da subestação através da troca de mensagens específicas entre Dispositivos Eletrônicos Inteligentes através de um barramento digital de rede de dados. O objetivo central deste trabalho é explorar algumas das questões que envolvem a implementação de uma classe de serviços de tempo real: a transmissão de valores amostrados através de Serviços SMV, definidos pela Norma IEC 61850-9. Primeiramente, apresenta-se um breve resumo das principais características da Norma IEC 61850 que possibilitam o atendimento dos três requisitos por ela estabelecidos como base: a interoperabilidade entre dispositivos de diferentes fabricantes, a versatilidade na configuração e reconfiguração do Sistema de Automação da Subestação, e a possibilidade de implementação de novas tecnologias. Em seguida, explora-se com maior profundidade todos os aspectos relevantes à implementação dos Serviços SMV. Devido à complexidade deste assunto, o autor propõe abordá-lo sob a ótica de cinco tópicos interdependentes: variações da Norma IEC 61850-9, confiabilidade do barramento de processo, sincronismo de tempo, análise da qualidade da medição e segurança cibernética. Com base nos resultados apresentados neste estudo, propõem-se duas plataformas, um protótipo de Transformador de Potencial Óptico e um protótipo de Relé de Proteção Diferencial para transformadores de potência, com o objetivo de explorar alguns dos aspectos pertinentes à implementação de um barramento de processo de acordo com a Norma IEC 61850-9. Também foram realizados testes de geração e transmissão de mensagens contendo valores de amostras de tensão/corrente do sistema elétrico (denominadas de $S V$ Messages) com a finalidade de implementá-las de fato e avaliar as ferramentas de mercado disponíveis. Por fim foi proposto um modelo para a simulação do sistema de potência em conjunto com a rede de comunicação utilizando o programa Matlab/Simulink. O autor espera que este trabalho contribua para esclarecer os vários conceitos envolvidos na implementação do barramento de processo definido pela Norma IEC 61850-9, auxiliando na pesquisa e no desenvolvimento de novas ferramentas e dispositivos, e no aprimoramento da Norma IEC 61850.

Palavras chave: Norma IEC 61850-9. Transformadores para Instrumentos Ópticos. Proteção diferencial para transformador de potência. 


\begin{abstract}
Since its introduction, in 2002, the IEC 61850 Standard has been evolved to become the standard adopted in Substation Automation Systems. Among its various aspects it can be highlighted the real-time services, which allows the implementation of automation and protection functions within the substation by exchanging specific messages between Intelligent Electronic Devices via a digital data bus network. The main objective of this text is to explore some issues about the implementation of one class of real-time services: the transmission of sampled values through SMV Services, defined by IEC 61850-9 Standard. First, it is presented a brief summary of the main features of IEC 61850 Standard which allows it to meet the three main requirements on this standard: interoperability between devices from different manufacturers, versatility in configuration and reconfiguration of Substation Automation System, and possibility of implementation of new technologies. Next, it is explored, with more details, all aspects involved in the implementation of SMV Services. Due to the complexity of this subject, the author proposes approaches it from the perspective of five interdependent topics: variations of IEC 61850-9 Standard, process bus reliability, time synchronism, analysis of measurement quality, and cyber security. Based on results presented two platforms are proposed, an Optical Voltage Transformer prototype and a Differential Protection Relay prototype for power transformers, in order to explore some of aspects related to the implementation of a process bus according to IEC 61850-9 Standard. It was executed also some tests of generation and transmission of messages containing samples values of voltage/current from power system (referred as SV Messages) in order to implement them in fact, and to evaluate available market tools. At the end it is propoused a model for simulation of power system and network communication using Matlab/Simulink software. The author hopes this work may contribute to clarify the various concepts involved in the implementation of a process bus according to IEC 61850-9 Standard, aiding in research and development of new tools and devices, and improvement of IEC 61850 Standard.
\end{abstract}

Keywords: IEC 61850-9-2 Standard. Optical Instrument Transformer. Differential protection for power transformer. 


\section{LISTA DE ILUSTRAÇÕES}

Figura 1 - Arquitetura básica de um SAS.

Figura 2 - Esquema em árvore representando a estrutura de modelos de dados (simplificado)

Figura 3 - Exemplo de definição de um Logical Node (PIOC) ......................................... 26

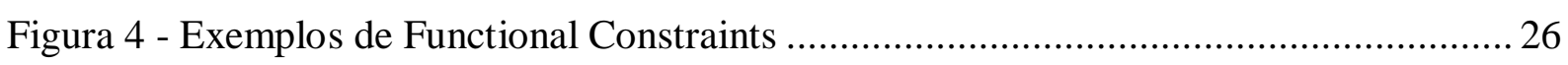

Figura 5 - Exemplo de DO expresso no formato de Common Data Class do tipo ACT.......... 27

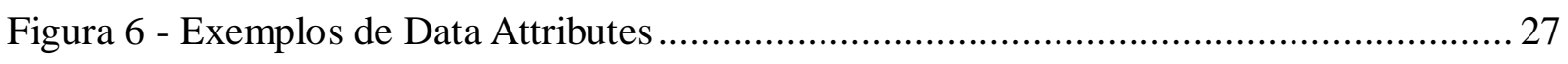

Figura 7 - Fragmento de um esquema UML utilizado pela Linguagem SCL ....................... 29

Figura 8 - Fragmento de código XML utilizado pela Linguagem SCL .............................. 29

Figura 9 - Modelo de referência para o processo de engenharia com a Linguagem SCL ....... 30

Figura 10 - Definição do tempo de transferência da mensagem, segundo a IEC 61850-5 ...... 32

Figura 11 - Diagrama de tempo do comando GSE quando nenhum evento está ocorrendo.... 33

Figura 12 - Diagrama de tempo do comando GSE na ocorrência de um evento .................... 34

Figura 13 - Diagrama básico de um barramento de processo de acordo com a Norma IEC

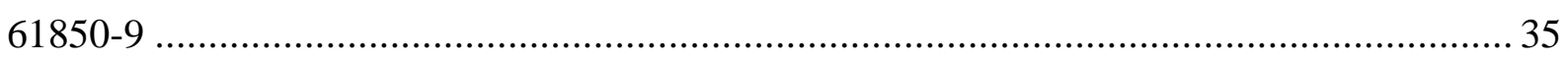

Figura 14 - Diagrama proposto que representa os cinco aspectos interdependentes para

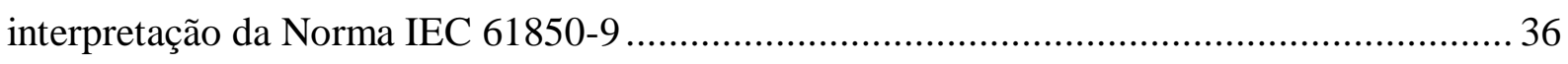

Figura 15 - Formato do frame ISO/IEC 8802-3 ........................................................ 37

Figura 16 - Concatenação de várias ASDUs, em conjunto com a APCI, formando uma APDU

Figura 17 - Conteúdo da ASDU (Dataset universal) baseado na especificação da Norma IEC 60044-8

Figura 18 - Exemplo de uma APDU codificada em ASN.1, com oito ASDUs concatenados . 40

Figura 19 - Codificação dos parâmetros segundo o padrão ASN.1 …................................. 41

Figura 20 - Dinâmica do contador smpCnt ........................................................... 41

Figura 21 - Exemplo de codificação de um Dataset de acordo com o documento IEC 61850-9- 
Figura 22 - Nomograma contendo análise da faixa dinâmica da corrente ............................ 44

Figura 23 - Atributos do campo Quality, de acordo com a Norma IEC 61850-7-3............... 46

Figura 24 - Arquitetura em anel (conexão em vermelho) .............................................. 48

Figura 25 - Arquitetura em anel com switch incorporado............................................ 48

Figura 26 - Arquitetura em anel utilizando Protocolo RSTP .......................................... 49

Figura 27 - Reorganização da arquitetura através do Protocolo RSTP................................. 50

Figura 28 - Exemplo de arquitetura redundante utilizando o Protocolo PRP......................... 50

Figura 29 - Frame com cabeçalho do Protocolo PRP. .................................................... 52

Figura 30 - Exemplo de arquitetura redundante utilizando o Protocolo HSR ........................ 53

Figura 31 - Frame com cabeçalho do Protocolo HSR .................................................. 54

Figura 32 - Perda de amostra no barramento de processo.............................................. 55

Figura 33 - Barramento de 1pps utilizado para sincronismo de tempo .............................. 56

Figura 34 - Estabelecimento da hierarquia mestre-escravo pelo Protocolo PTP ................... 57

Figura 35 - Procedimento básico para sincronismo de tempo utilizando o Protocolo PTP ..... 60

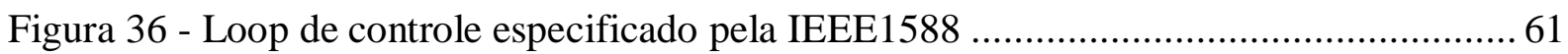

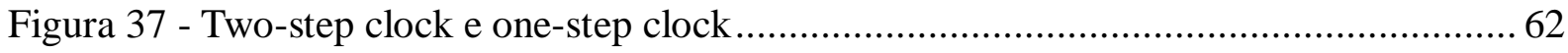

Figura 38 - Mecanismos para medição do tempo de propagação em um path ....................... 63

Figura 39 - Pontos onde podem haver geração do timestamp no Protocolo PTP.................... 63

Figura 40 - Exatidões ao longo do processo de distribuição do sinal de sincronismo no

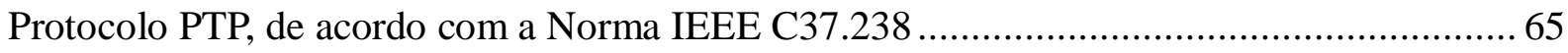

Figura 41 - Forma de onda, no padrão 1pps, gerado pelo dispositivo que define a base de

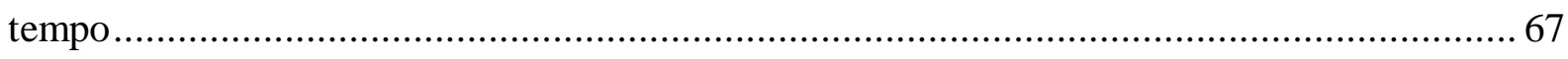

Figura 42 - Definição do atributo SmpSynch, de acordo com o modo de operação do IED ... 67

Figura 43 - Estrutura de teste básica para avaliação de TCs convencionais .......................... 69

Figura 44 - Diagrama básico de um TI com interface segundo a Norma IEC 61850-9 .......... 70

Figura 45 - Ilustração de máscara para especificação de resposta em frequência.................. 72 
Figura 46 - Arquitetura do sistema para avaliação do SV Message publicado pelo dispositivo testado

Figura 47 - Arquitetura proposta pela IEC 61869-9 para avaliação de erros

Figura 48 - Ponto de referência na SV Message onde é feita a medição do Maximum Delay

Time

Figura 49 - Diagrama em blocos do sistema de calibração proposto 76

Figura 50 - Configuração de rede utilizada para análise dos conceitos de QoS 77

Figura 51 - Cabeçalho IEEE 802.3Q inserido pela Norma IEC 61850-9 no frame Ethernet .. 80

Figura 52 - Exemplo de criptografia simétrica.... 84

Figura 53 - Exemplo de criptografia assimétrica. 85

Figura 54 - Fluxograma básico da Função Hash Criptográfica HMAC 87

Figura 55 - Frame não seguro (esquerda) e frame seguro definido pela IEC 62351-6 (direita), admitindo que ambos utilizem o Protocolo PRP para redundância 88

Figura 56 - Estrutura esperada para um TP óptico digital com interface IEC 61850-9-2....... 92

Figura 57 - Plataforma simplificada para avaliação do TP óptico com interface IEC 61850-9-2

Figura 58 - Diagrama com os modelos de interferômetros que podem ser utilizados no bloco Unidade Óptica ....

Figura 59 - Diagrama em blocos da Unidade de Processamento de Sinais 95

Figura 60 - Exemplo de sinal $\operatorname{Id}(\mathrm{t})$ 95

Figura 61 - Expansão, no domínio do tempo, do sinal $\mathrm{Vd}(\mathrm{t})$ no intervalo de tempo $\mathrm{T}_{2}$ 96

Figura 62 - Blocos CPU e Interface de Rede 97

Figura 63 - Protótipo do Interferômetro Recuperador 98

Figura 64 - Protótipos do Interferômetro Sensor de Alta Tensão 98

Figura 65 - Ilustração dos erros a serem avaliados 99

Figura 66 - Definição dos conceitos de erro e de precisão. 101

Figura 67: Diagrama de “Accuracy of synchronization” segundo a IEC 61850-9-2LE. 102 
Figura 68 - Instante de amostragem adotado

Figura 69 - Modulador eletro-óptico de amplitude transversal por efeito Pockels 106

Figura 70 - Função de transferência (T em função de V) do modulador eletro-óptico de amplitude transversal por efeito Pockels

Figura 71 - Função de transferência ( $\Gamma$ em função de $V$ ) do modulador eletro-óptico de amplitude transversal por efeito Pockels 107

Figura 72 - Sinal Vd(t) calculado 109

Figura 73- Sinal de alta tensão $\mathrm{V}_{1}(\mathrm{t})$ (linha contínua) e amostras calculadas (sinal discretizado)

Figura 74 - Sinal de alta tensão $\mathrm{V}_{1}(\mathrm{t})$ (linha contínua) e os erros calculados para cada amostra (sinal discretizado multiplicado por 10 para melhor visualização) para um ganho G igual a 54

Figura 75 - Sinal de alta tensão $\mathrm{V}_{1}(\mathrm{t})$ (linha contínua) e os erros calculados para cada amostra (sinal discretizado multiplicado por 10 para melhor visualização) para um ganho G igual a 55

Figura 76 - Somatória dos erros, de acordo com o ganho G ajustado

Figura 77 - Distribuição dos erros (sinal discretizado multiplicado por 10 para melhor visualização) para o ganho $\mathrm{G}$ igual a 54,77

Figura 78 - Requisitos de erro de relação (ratio error) e de atraso de fase (phase displacement), de acordo com a Norma IEC 61869-9

Figura 79 - Erros de relação calculados para cada harmônica (considerando a taxa de amostragem em 256 amostras/ciclo)

Figura 80 - Erros de atraso de fase calculados para cada harmônica (considerando a taxa de amostragem em 256 amostras/ciclo)

Figura 81 - Representação gráfica do fasor $\varepsilon_{(\mathrm{s})}$ (valor absoluto) 115

Figura 82 - Erros de relação para cada harmônica (considerando metodologia proposta) .... 118

Figura 83 - Erros de atraso de fase para cada harmônica (considerando metodologia proposta)

Figura 84 - Funcionamento básico da proteção diferencial de transformador na ocorrência de 
uma falha externa (a) e de uma falha interna (b)

Figura 85 - Exemplo de arquitetura para proteção diferencial digital de transformadores de potência

Figura 86 - Fluxograma que demonstra a sequência de algoritmos executados pelo bloco uP

Figura 87 - Exemplo de sistema elétrico com transformador trifásico e proteção diferencial

Figura 88 - Plano de atuação/restrição da proteção diferencial

Figura 89 - Representação dos diversos erros compensados no plano de atuação/restrição.. 129

Figura 90 - Exemplo de arquitetura utilizando barramento de processo digital com Merging Unit

Figura 91 - Fluxograma do algoritmo de proteção diferencial proposto

Figura 92 - Sistema proposto para validação do algoritmo de proteção diferencial

Figura 93 - Exemplo de esquema típico de parametrização do plano de atuação/restrição... 131

Figura 94 - Situações de falta testadas fora da zona de proteção: falta trifásica (a), falta dupla fase (b) e falta fase-terra (c)......

Figura 95 - Evolução da falta trifásica fora da zona de proteção no plano de atuação/restrição

Figura 96 - Evolução da falta dupla fase fora da zona de proteção no plano de atuação/restrição

Figura 97 - Falta fase-terra fora da zona de proteção

Figura 98 - Situações de falta testadas dentro da zona de proteção: falta trifásica (a), falta dupla fase (b) e falta fase-terra (c). 135

Figura 99 - Evolução da falta trifásica dentro da zona de proteção no plano de atuação/restrição ..... 136

Figura 100 - Evolução da falta dupla fase dentro da zona de proteção no plano de atuação/restrição

Figura 101 - Evolução da falta fase-terra dentro da zona de proteção no plano de atuação/restrição ..... 
Figura 102 - Representação gráfica dos efeitos da perda de sincronismo no plano de atuação/restrição

Figura 103 - Evolução da corrente Idiff para diversos valores de ppm

Figura 104 - Compensação da perda de sincronismo de tempo através do slope 1

Figura 105 - Estrutura utilizada para geração e avaliação de SV Messages

Figura 106 - Estrutura básica, de um frame Ethernet, utilizada na construção de SV Messages

Figura 107 - Descrição do campo APDU transmitido no frame básico da SV Message

Figura 108 - Tela do software Wireshark contendo a SV Message analisada 156

Figura 109 - Tela Configuration do software SVScout

Figura 110 - SV Messages disponíveis no barramento de processo capturadas pelo software SVScout.

Figura 111 - Formas de onda geradas a partir das SV Messages capturadas pelo software SVScout

Figura 112 - Tela do software Wireshark contendo a análise dos campos opcionais 160

Figura 113 - Tela do software Wireshark contendo a análise da SV Message com formato especificado para finalidade de medição

Figura 114 - Tela do software Wireshark versão 1.6.7 apresentando a análise detalhada do cabeçalho ASDU 164

Figura 115 - Tela do osciloscópio com os sinais medidos para estimativa do tempo de construção e transmissão da SV Message 166

Figura 116 - Frame Ethernet contendo o cabeçalho do Protocolo PRP. 167

Figura 117 - Tela do software Wireshark contendo a SV Message com Protocolo PRP 169

Figura 118 - Frame Ethernet contendo o cabeçalho do Protocolo HSR 170

Figura 119 - Tela do software Wireshark contendo a SV Message com Protocolo HSR 172

Figura 120 - Frame Ethernet contendo os cabeçalhos para segurança cibernética (Extended PDU)

Figura 121 - Descrição do campo Extension utilizado para os testes 
Figura 122 - Tela do software Wireshark apresentando a SV Message capturada contendo os campos e os cabeçalhos para segurança cibernética

Figura 123 - Diagrama do sistema de potência com barramento de processo IEC 61850-9-2

Figura 124 - Modelo proposto para a simulação do sistema de potência em conjunto com o

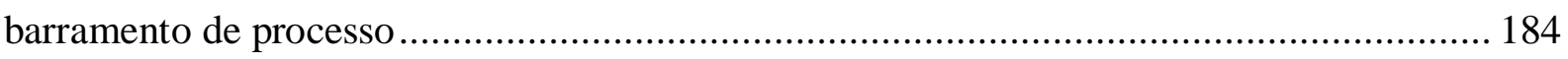

Figura 125 - Trecho do modelo desde a linha L1 até o transformador T1 ............................ 185

Figura 126 - Trecho do modelo entre o transformador T1 e o barramento B1 …................ 185

Figura 127 - Trecho do modelo entre o barramento B1 e o alimentador AL1 ..................... 186

Figura 128 - Trecho do modelo entre o barramento B1 e o alimentador AL2 …................. 186

Figura 129 - Trecho do modelo englobando IED1, IED2, IED3, SW1A e SW1B ............... 187

Figura 130 - Trecho do modelo englobando IED4, IED5, SW2A e SW2B ........................ 187

Figura 131 - Diagrama contendo os blocos que compõem o SAMU proposto..................... 189

Figura 132 - Black-box que representa o switch proposto.............................................. 190

Figura 133 - Diagrama geral dos blocos utilizados para o modelo de switch proposto ........ 190

Figura 134 - Diagrama contendo os blocos que compõem a entrada do switch proposto ..... 191

Figura 135 - Diagrama contendo os blocos utilizados para a construção do bloco LAN SW1

Figura 136 - Blocos responsáveis por implementar a dinâmica de queue do switch

Figura 137 - Blocos responsáveis por implementar o tempo de transmissão das mensagens 193

Figura 138 - Blocos reponsáveis por implementar o IED1 ........................................ 195

Figura 139 - Blocos responsáveis por implementar o IED2 ….................................. 197

Figura 140 - Resultados obtidos pelo Scope conectado nas entradas de corrente do SAMU1 e do SAMU2

Figura 141 - Resultados obtidos pelo Scope conectado nas saídas Out1 e Out2 do IED2 .... 199

Figura 142 - Resultados obtidos pelo Scope conectado no IED2 alterando o encaminhamento

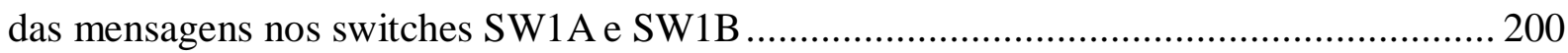

Figura 143 - Resultados obtidos pelo Scope conectado ao bloco Read Timer do IED2 ....... 201 
Figura 144 - Resultados obtidos pelo Scope conectado na saída MACCadd do bloco Get

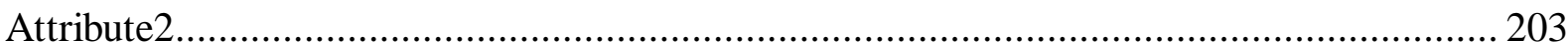

Figura 145 - Resultados obtidos pelo Scope conectado na saída MACCadd do bloco Get

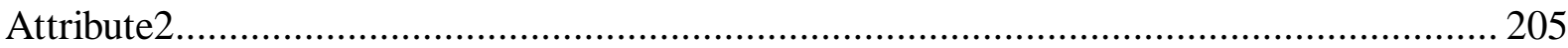

Figura 146 - Transformadores de Corrente Convencionais fabricados pela ABB ............... 217

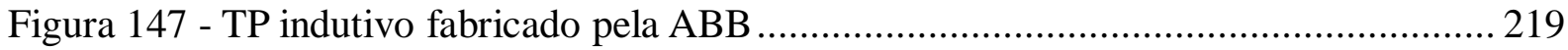

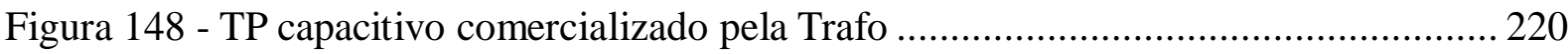

Figura 149 - Representação conceitual do efeito Faraday …........................................ 222

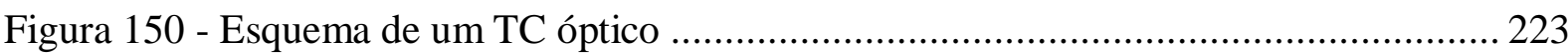

Figura 151 - Onda de luz plano polarizada propagando-se por um meio anisotrópico

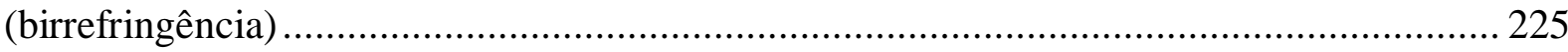

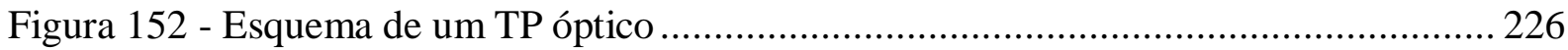

Figura 153 - Plataforma para Calibração em Campo.......................................................... 227 


\section{LISTA DE TABELAS}

Tabela 1 - Exatidão (accuracy) dos transformadores de corrente, segundo a norma IEC 600444.

Tabela 2 - Classes de performance para sincronismo de tempo, de acordo com a Norma IEC $61850-5$

Tabela 3 - Requisitos a serem atendidos na análise da magnitude, em função da frequência . 72

Tabela 4 - Exemplo de aplicação dos conceitos de accuracy e de erro

Tabela 5 - Performance classes dos TIs

Tabela 6 - Erros de relação e erros de fase para cada harmônica (considerando metodologia proposta)

Tabela 7 - Resultados das simulações para i(t) e ir(t)

Tabela 8 - Correntes da falta trifásica fora da zona de proteção

Tabela 9 - Correntes da falta dupla fase fora da zona de proteção

Tabela 10 - Correntes aplicadas para falta fase-terra fora da zona de proteção

Tabela 11 - Correntes aplicadas para falta trifásica dentro da zona de proteção

Tabela 12 - Correntes aplicadas para falta dupla fase dentro da zona de proteção 136

Tabela 13 - Correntes aplicadas para falta fase-terra dentro da zona de proteção. 137

Tabela 14 - Resultados da simulação para a frequência de $60 \mathrm{~Hz}$ 139

Tabela 15 - Resultados da simulação para a frequência de $50 \mathrm{~Hz}$ 140

Tabela 16 - Resultados da simulação com metade da potência nominal do transformador... 141

Tabela 17 - Resultado da simulação considerando drift de $\pm 100 \mathrm{ppm}$ 145

Tabela 18 - Resultados da simulação considerando drift de \pm 30 ppm 146

Tabela 19 - Faixas de endereços MAC recomendadas pela Norma IEC 61850-9-2 151

Tabela 20 - Resumo das características de SAMUs disponíveis no mercado 181

Tabela 21 - Exemplos de IEDs utilizados no nível de bay disponíveis no mercado 182

Tabela 22 - Resumo das características de switches disponíveis no mercado 182 


\section{SUMÁRIO}

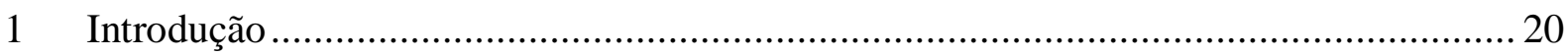

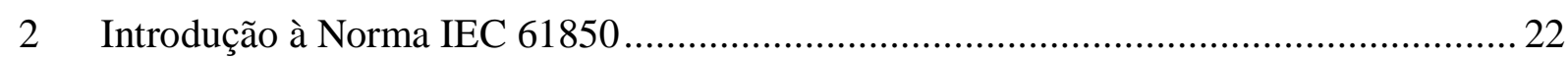

2.1 Breve Histórico Sobre a Automação de Subestações .............................................. 22

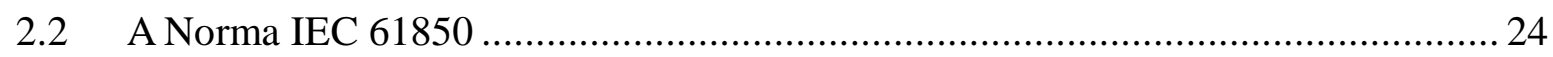

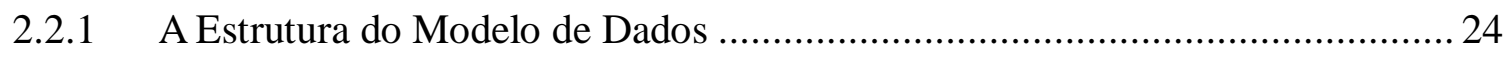

2.2.2 A Linguagem de Descrição da Configuração de Subestações ............................ 28

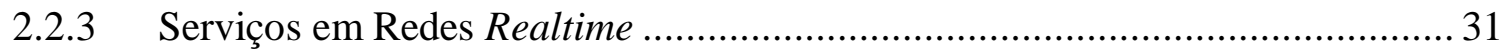

2.2.4 Mensagens GSE - As Mensagens GOOSE .................................................... 32

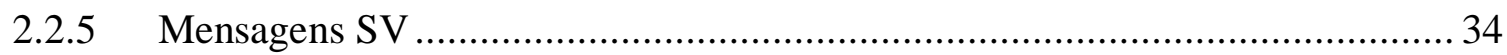

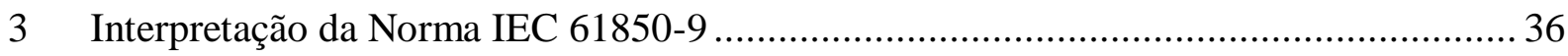

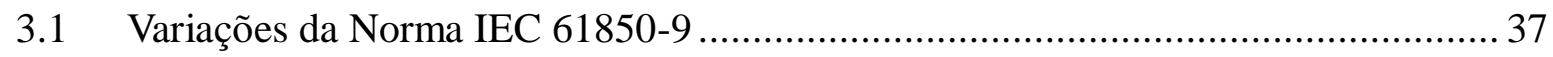

3.2 Confiabilidade do barramento de processo …………............................................ 47

3.3 Sincronismo de tempo através do barramento de rede …………….........................55

3.4 Análise da qualidade da medição disponibilizada no barramento de processo......... 68

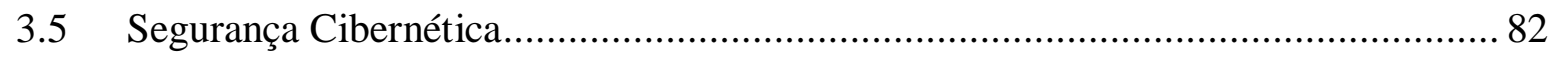

4 Proposta de Plataforma de Transformador de Potencial Óptico Digital com interface IEC

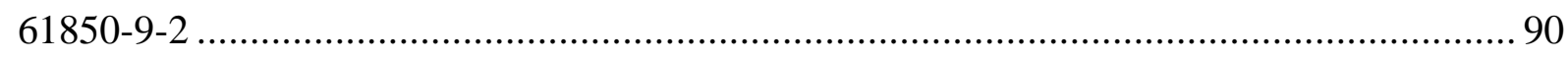

4.1 Plataforma de TP óptico digital com interface IEC 61850-9-2 …………….......... 90

4.2 Avaliação dos erros da plataforma de TP óptico digital proposta …………………. 99

5 Proposta de Plataforma de Relé Diferencial para a Proteção de Transformadores de Potência com interface IEC 61850-9-2 ........................................................................ 120

5.1 Simulação das amostras enviadas no barramento de processo................................. 121

5.2 Algoritmo de proteção diferencial para transformadores de potência ..................... 124

5.3 Comportamento da proteção diferencial considerando a perda de sincronismo de tempo no barramento de processo.................................................................................... 139

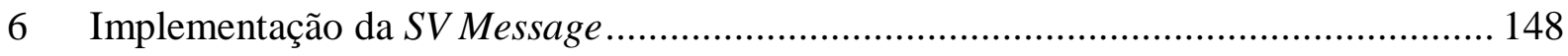

6.1 Implementação do frame básico da SV Message .................................................. 150 
6.2 Implementação da SV Message em conjunto com os Protocolos PRP/HSR para redundância de rede.

6.3 Implementação da SV Message em conjunto com a Norma IEC 62351-6 para segurança cibernética

7 Simulação de barramento de processo IEC 61850-9-2 utilizando Matlab/Simulink

7.1 Conceitos gerais envolvendo a simulação de sistemas de potência em conjunto com barramento de processo IEC 61850-9-2.

7.2 Proposta de sistema de potência com barramento de processo IEC 61850-9-2 para simulação.

7.2.1 IEDs de interface do barramento de processo

7.2.2 IEDs presentes no nível de bay

7.2.3 Switches presentes no barramento de processo

7.3 Modelo proposto para a simulação do sistema de potência em conjunto com o

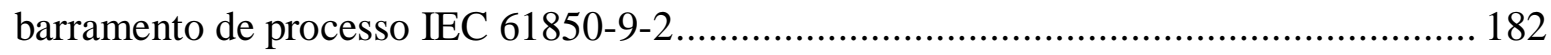

7.3.1 Diagrama unifilar do sistema de potência proposto .................................... 185

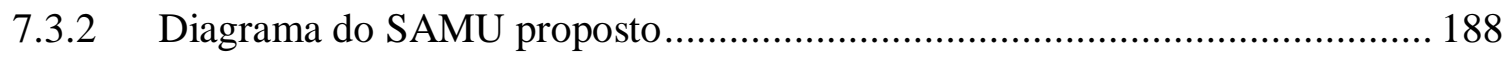

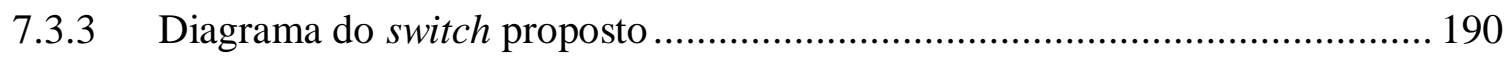

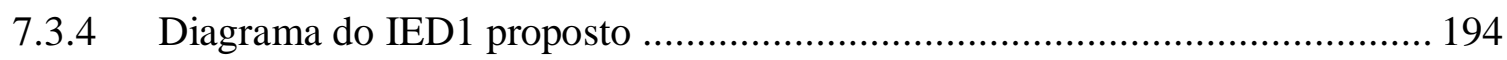

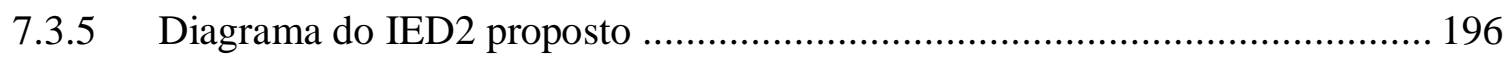

7.4 Simulações realizadas no modelo proposto ............................................... 198

7.4.1 Transmissão dos valores amostrados .......................................................... 198

7.4.2 Avaliação do tempo de transmissão das SV Messages................................... 200

7.4.3 Processamento de prioridade das mensagens pelos switches ........................ 201

7.4.4 Atraso nas mensagens de maior prioridade devido às mensagens de baixa prioridade

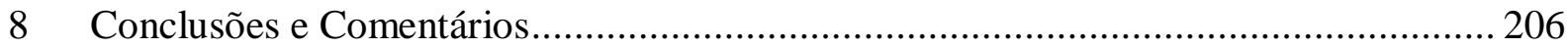

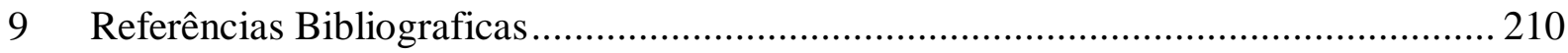

Anexo 1: Introdução aos Transformadores para Instrumentos com Tecnologia Não-

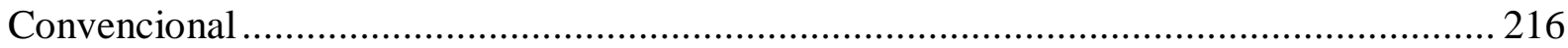




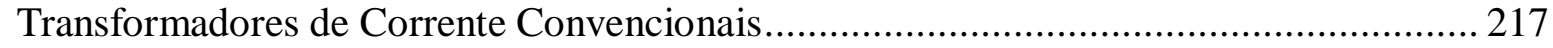

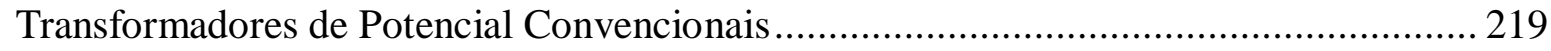

Transformadores de Corrente Não Convencionais ................................................... 221

Transformadores de Potencial Não Convencionais ................................................... 224

Anexo 2: Processo Pretendido para Calibração em Campo de Transformadores para

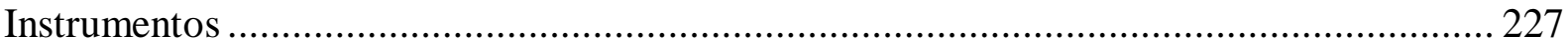




\section{Introdução}

A Norma IEC 61850, cuja primeira edição foi lançada em 2002, é o resultado do empenho de pesquisadores e fabricantes de equipamentos das mais diversas áreas com o objetivo de implementar um Sistema de Automação de Subestação que garanta três requisitos principais: interoperabilidade entre equipamentos de diferentes fabricantes, versatilidade para a configuração e reconfiguração dos equipamentos, e a possibilidade de implementação de novas tecnologias. Dentre os vários recursos que a norma oferece, destacam-se os serviços de tempo real do tipo Generic Substation Event (Serviços GSE) e do tipo Sampled Measured Values (Serviços SMV), que permitiram a implementação de funções de automação e proteção através de mensagens transmitidas através de um barramento de rede digital para comunicação de dados. Este trabalho tem como objetivo explorar os Serviços SMV especificados pela Norma IEC 61850-9, que permitem a transmissão de valores de tensão e corrente, amostrados por Transformadores de Instrumentos, através de Sample Value Messages (SV Messages).

O Capítulo 2 traz um breve resumo da Norma IEC 61850, destacando as principais características que tornam possível o cumprimento dos requisitos de interoperabilidade, de liberdade de configuração e de implementação de novas tecnologias e o diagrama unifilar utilizado como referência para o desenvolvimento das contribuições propostas pelo autor para a implementação de um barramento de processo de acordo com a Norma IEC 61850-9.

No Capítulo 3 são apresentados os resultados de um extenso trabalho de pesquisa e estudo que abrangem os diversos aspectos necessários para a implementação de um barramento de processo segundo a Norma IEC 61850-9. O autor propõe que o assunto seja abordado sob a ótica de cinco aspectos distintos e interdependentes: variações da Norma IEC 61850-9 (que trata da análise das variações de implementação dos Serviços SMV propostas pela Norma IEC 61850-9-1 e pela Norma IEC 61850-9-2), confiabilidade do barramento de processo (que trata da não interrupção dos serviços de tempo real em situações de falha no barramento de rede de dados), sincronismo de tempo (que trata dos assuntos relacionados ao sincronismo temporal das amostras), análise da qualidade da medição (que trata dos aspectos que envolvem a avaliação da medição disponibilizada pelos serviços de tempo real) e segurança cibernética (que trata das medidas de segurança adotadas no barramento de processo contra ataques 
cibernéticos).

No Capítulo 4 é apresentado a proposta de uma Plataforma de Transformador de Potencial (TP) óptico digital com interface IEC 61850-9-2 integrada.

No Capítulo 5 é apresentado a proposta de uma Plataforma de Relé de Proteção Diferencial para Transformadores de Potência com interface IEC 61850-9-2, com o objetivo de avaliar os efeitos da perda do sinal de sincronismo de tempo no funcionamento da unidade diferencial.

No Capítulo 6 foram feitas simulações de envio de SV Messages com o objetivo de aprofundar e de aplicar os conceitos apresentados, além de avaliar ferramentas comerciais disponíveis para a análise destas mensagens.

No Capítulo 7 é proposto um modelo para a simulação do sistema de potência em conjunto com o barramento de comunicação de dados utilizando ferramentas do software Matlab/Simulink.

O autor espera que os trabalhos desenvolvidos atendam boa parte dos requisitos necessários para a implementação de um barramento de processo, contribuindo para o desenvolvimento de novas tecnologias e de novos equipamentos. Os resultados obtidos serão aplicados no projeto de um protótipo de TP óptico digital em desenvolvimento no Laboratório de Sensores Ópticos (LSO) da Escola Politécnica da Universidade de São Paulo (EPUSP). 


\section{Introdução à Norma IEC 61850}

\subsection{Breve Histórico Sobre a Automação de Subestações}

Todas as subestações possuem algum tipo de automação, cuja complexidade depende da sua estrutura e da sua importância no sistema elétrico no qual estão inseridas. No passado, utilizavam-se dispositivos secundários eletromecânicos puramente analógicos e simples ligações elétricas que enviavam sinais de comando entre estes dispositivos. $\mathrm{O}$ desenvolvimento da eletrônica, num primeiro momento, permitiu a modernização desses equipamentos secundários, utilizando-se de tecnologias eletrônicas analógicas. Posteriormente, com a evolução dos sistemas digitais, houve nova modernização dos equipamentos secundários, que passaram a se utilizar de tecnologias eletrônicas digitais, possibilitando o desenvolvimento dos Dispositivos Eletrônicos Inteligentes (Intelligent Electronic Devices - IEDs) para a implementação de Sistemas de Automação de Subestação (Substation Automation System - SAS). Estes IEDs trocam informações entre si utilizando redes de comunicação, transmitindo dados na forma digital segundo regras definidas em protocolos de comunicação.

De forma geral, pode-se organizar os dispositivos que compõem um SAS em diferentes níveis, cada um com uma função específica, e classificá-los em nível de processo, de bay e de subestação, conforme ilustra a Figura 1. A interligação dos diversos níveis é feita através dos barramentos de rede de comunicação de forma digital (comunicação serial com protocolo implementado) ou convencional (sinais analógicos). Estes barramentos são divididos em dois tipos: de subestação e de processo. 


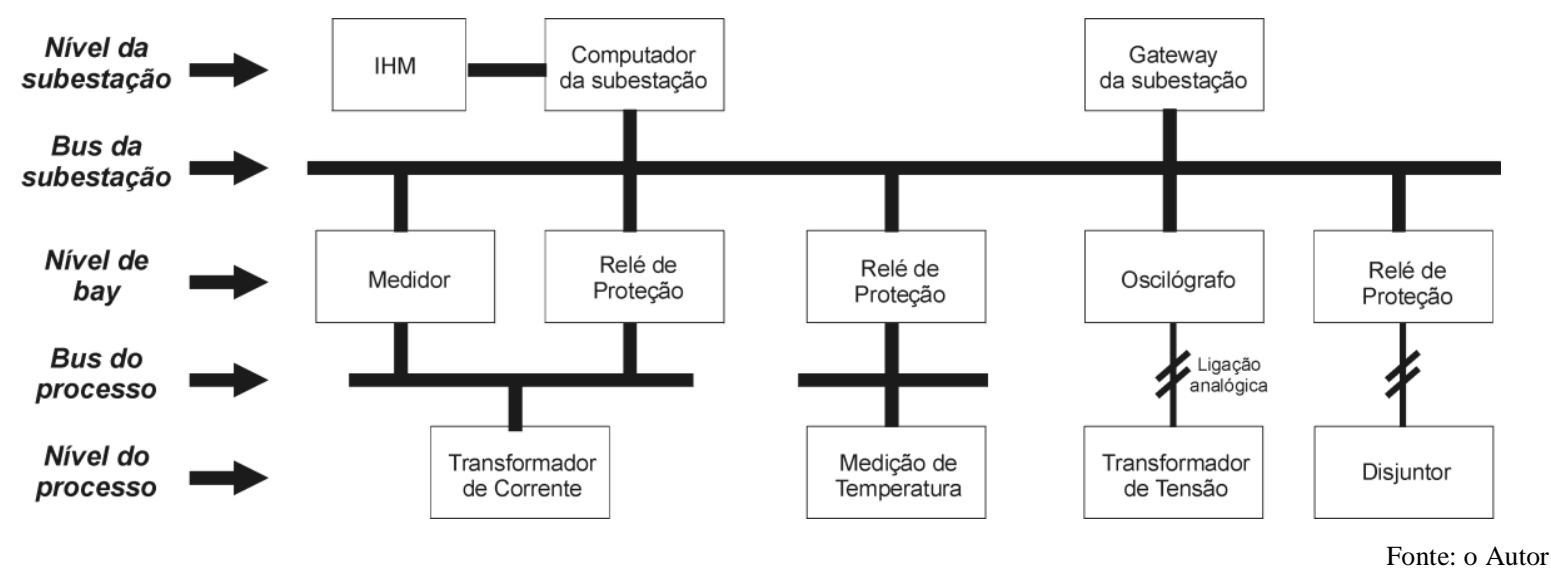

Num primeiro momento, os principais fabricantes e pesquisadores do setor desenvolveram seus próprios protocolos de comunicação com a intenção de interligar tais equipamentos, o que gerou a oferta de diversos protocolos no mercado, como o DNP3, o Modbus-RTU, o Profibus e o Fieldbus.

Embora a configuração mostrada na Figura 1 ofereça a estrutura de comunicação necessária para a operação de um SAS, ela também trouxe uma série de restrições.

A maior parte desses protocolos não é capaz de trocar informações diretamente entre si ou de operar em conjunto num mesmo barramento físico de rede. Muitos deles também são proprietários, oferecendo alguma forma de restrição, seja para o acesso de documentação sobre seu funcionamento ou para a operação no barramento. Este fato implica, por exemplo, na instalação de diversos gateways para conversão de protocolos, o que acaba por tornar a instalação, a operação e a manutenção da rede mais complexas.

Nem todos os sinais trocados entre os IEDs foram digitalizados, como por exemplo, os sinais de intertravamento entre relés de proteção, os sinais de trip gerados por um relé de proteção para um disjuntor ou o sinal contendo a medida da corrente elétrica feita por um Transformador de Corrente (TC) para ser enviado a um oscilógrafo. Isso implica na utilização de diversos cabos para a transmissão destes sinais, ainda na forma analógica, em conjunto com o barramento de rede digital.

Com a evolução da tecnologia digital, desenvolveram-se equipamentos e conceitos de proteção e automação digitais. Alguns conceitos, para serem implementados, obrigam o uso de diversos protocolos num mesmo SAS, seja porque nenhum deles oferece todas as funções necessárias ou porque não possuem liberdade para expansões. 
No nível de processo do SAS, o desenvolvimento de novos Transformadores para Instrumentos (TIs) utilizando tecnologias não convencionais de medição trouxe inúmeros avanços se comparados aos dispositivos baseados em tecnologias convencionais. Infelizmente, tais dispositivos carecem de uma interface padronizada capaz de oferecer todas essas vantagens no momento de entregar sua medição para o barramento de processo, obrigando o fabricante do transformador a utilizar interfaces proprietárias ou especiais.

Este cenário demonstra, portanto, a necessidade e a oportunidade de se estabelecer um padrão de comunicação que atenda os requisitos citados.

\subsection{A Norma IEC 61850}

A Norma IEC 61850 [2], que teve sua primeira versão editada em 2002, surgiu como resultado da colaboração dos principais pesquisadores e fabricantes do setor, os quais já vinham discutindo anteriormente uma solução nesse sentido na $\mathrm{UCA}^{\circledR}$ International Users Group. Seus três principais objetivos são: a interoperabilidade entre diferentes dispositivos, a facilidade de configuração e reconfiguração do SAS e a versatilidade para implementação de novas tecnologias que futuramente venham a ser desenvolvidas. Para atender estes requisitos, a norma estabeleceu um padrão de dados e realizou uma virtualização dos diferentes dispositivos encontrados em uma subestação, segundo conceitos de modelagem voltada a objetos. Em seguida, as funções em uma subestação foram definidas de forma abstrata e, na sequência, foram mapeadas sempre que possível em protocolos abertos e de uso no mercado. Por fim, foram estabelecidos os processos de engenharia para desenvolvimento do SAS e os critérios básicos de tempo de execução das funções. Pode-se afirmar, portanto, que a Norma IEC 61850 não é somente um modelo de protocolo, pois visa estabelecer uma padronização de todo o processo de desenvolvimento do SAS.

\subsubsection{A Estrutura do Modelo de Dados}

Uma das formas mais empregadas para visualizar a estrutura do modelo de dados e objetos 
previstos na Norma IEC 61850 é uma estrutura em árvore, semelhante a um esquema de diretórios de um sistema operacional para computadores. A Figura 2, a seguir, mostra um exemplo de um trecho de estrutura deste tipo. Nela, podem-se destacar os seguintes itens:

- Intelligent Electronic Device (IED): representa o dispositivo físico inteligente que pode conter um ou mais Dispositivos Lógicos (Logical Devices);

- Logical Device (LD): representa um dispositivo lógico que pode conter um ou mais Nós Lógicos (Logical Nodes);

- Logical Node (LN): é um objeto lógico, definido pela Norma IEC 61850-7-4, que contém dados (Data Objects) e serviços (Services) associados utilizados para implementar uma determinada função no SAS. São identificados por uma sigla de quatro letras maiúsculas, sendo que a primeira identifica sua classe de natureza. Quando inseridos na estrutura de dados, são acompanhados por um índice numérico no final, para que seja possível diferenciar dois nós lógicos do mesmo tipo contidos num mesmo IED. Exemplos: P para proteção, portanto, PIOC1 (proteção de sobrecorrente instantânea $n^{\circ}$ 1) e PDIF2 (proteção diferencial no 2). Um LN é definido através de uma tabela de definições, conforme ilustra a Figura 3.

Figura 2 - Esquema em árvore representando a estrutura de modelos de dados (simplificado)

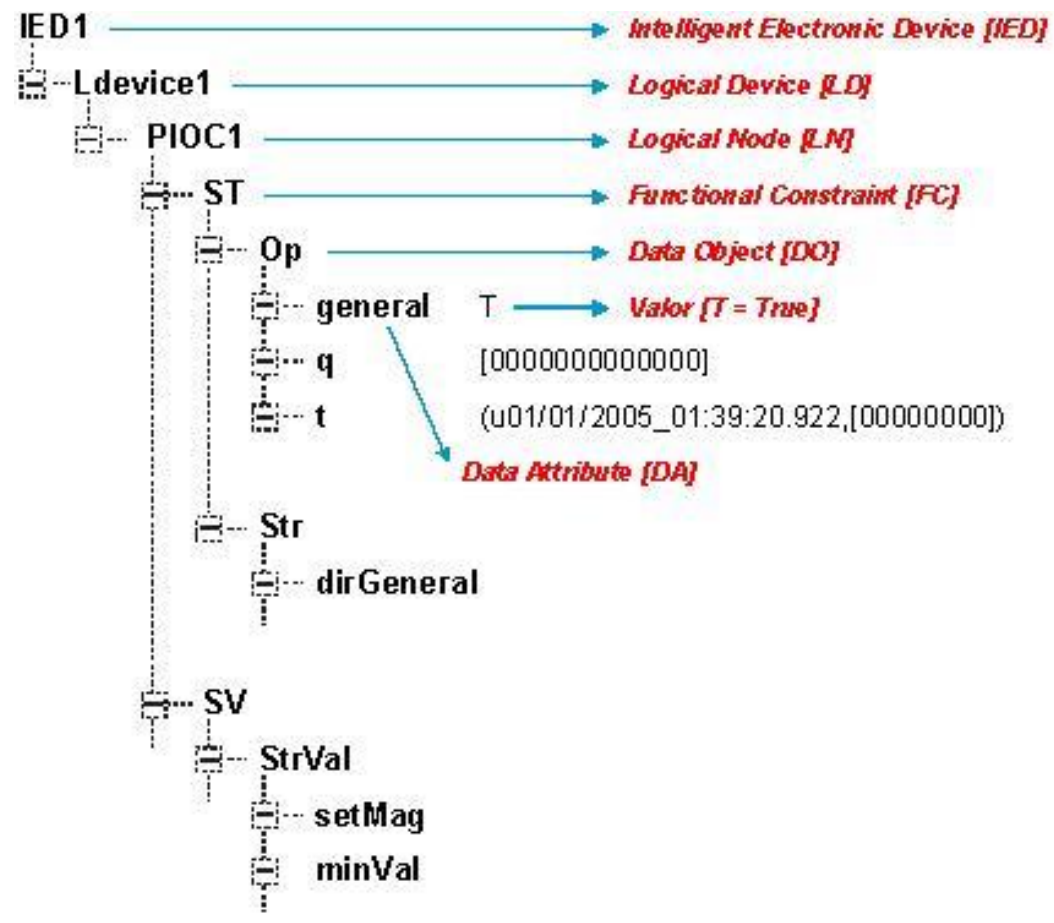


Figura 3 - Exemplo de definição de um Logical Node (PIOC)

\begin{tabular}{|c|c|c|c|c|}
\hline \multicolumn{5}{|c|}{ PIOC class } \\
\hline Attribute Name & Attr. Type & Explanation & $\mathbf{T}$ & $\mathrm{M} / \mathrm{O}$ \\
\hline LNName & & Shall be inherited from Logical-Node Class (see IEC 61850-7-2) & & \\
\hline \multicolumn{5}{|l|}{ Data } \\
\hline \multicolumn{5}{|c|}{ Common Logical Node Information } \\
\hline & & LN shall inherit all Mandatory Data from Common Logical Node Class & & M \\
\hline OpCntRs & INC & Resetable operation counter & & $\mathrm{O}$ \\
\hline \multicolumn{5}{|l|}{ Status Information } \\
\hline Str & $A C D$ & Start & & $\mathrm{O}$ \\
\hline Op & ACT & Operate & & M \\
\hline \multicolumn{5}{|l|}{ Settings } \\
\hline StrVal & ASG & Start Value & & $\mathrm{O}$ \\
\hline
\end{tabular}

Fonte: Norma IEC 61850

- Functional Constraints (FC): representam as categorias nas quais os Data Attributes estão classificados. São definidos pela Norma IEC 61850-7-2 e expressos por uma sigla de duas letras maiúsculas. Exemplos: ST (informação de status) e MX (medições). A Figura 4 apresenta uma tabela contendo exemplos de FCs.

Figura 4 - Exemplos de Functional Constraints

\begin{tabular}{|c|c|c|c|c|c|}
\hline \multicolumn{6}{|c|}{ Functional constraint (FC) } \\
\hline & Semantic & Services allowed & $\begin{array}{l}\text { Initial values/storage/ } \\
\text { explanation }\end{array}$ & $D^{a}$ & $\mathrm{CB}^{\mathrm{b}}$ \\
\hline ST & $\begin{array}{l}\text { Status } \\
\text { information }\end{array}$ & $\begin{array}{l}\text { DataAttribute shall represent a status } \\
\text { information whose value may be read, } \\
\text { substituted, reported, and logged but shall not } \\
\text { be written }\end{array}$ & $\begin{array}{l}\text { Initial value of the DataAttribute } \\
\text { shall be taken from the process }\end{array}$ & $\mathrm{x}$ & \\
\hline MX & $\begin{array}{l}\text { Measurands } \\
\text { (analogue } \\
\text { values) }\end{array}$ & $\begin{array}{l}\text { DataAttribute shall represent a measurand } \\
\text { information whose value may be read, } \\
\text { substituted, reported, and logged but shall not } \\
\text { be written }\end{array}$ & $\begin{array}{l}\text { Initial value of the DataAttribute } \\
\text { shall be taken from the process }\end{array}$ & $\mathrm{x}$ & \\
\hline $\mathrm{CO}$ & Control & $\begin{array}{l}\text { DataAttribute shall represent a control } \\
\text { information whose value may be operated } \\
\text { (control model) and read }\end{array}$ & N.a. & $\mathrm{x}$ & \\
\hline SP & Setpoint & $\begin{array}{l}\text { DataAttribute shall represent a set-point } \\
\text { information whose value may be controlled } \\
\text { (control model) and read. Values controlled } \\
\text { shall become effective immediately }\end{array}$ & $\begin{array}{l}\text { Initial value of the DataAttribute } \\
\text { shall be as configured; value shall } \\
\text { be non-volatile }\end{array}$ & $\mathrm{x}$ & $\mathrm{x}$ \\
\hline
\end{tabular}

Fonte: Norma IEC 61850

Data Objects (DO): representam os atributos contidos nos Nós Lógicos. Os Data Objects obedecem a formatos padronizados, chamados de Common Data Classes (CDC), definidos na Norma IEC 61850-7-3. Exemplo: dentro do Nó Lógico PIOC encontra-se o atributo Op (Operate), que é classificado como informação de status (Functional Constraint tipo ST). Este atributo segue a estrutura do Common Data Class tipo ACT. A Figura 5 apresenta uma tabela contendo um exemplo de DO tipo ACT. 
Figura 5 - Exemplo de DO expresso no formato de Common Data Class do tipo ACT.

\begin{tabular}{|c|c|c|c|c|c|}
\hline \multicolumn{6}{|l|}{ ACT class } \\
\hline $\begin{array}{c}\text { Attribute } \\
\text { Name }\end{array}$ & Attribute Type & FC & TrgOp & Value/Value Range & $\mathrm{M} / \mathrm{O} / \mathrm{C}$ \\
\hline DataName & \multicolumn{4}{|c|}{ Inherited from Data Class (see IEC 61850-7-2) } & \\
\hline \multicolumn{6}{|c|}{ DataAttribute } \\
\hline \multicolumn{6}{|c|}{ status } \\
\hline general & BOOLEAN & ST & dchg & & M \\
\hline phsA & BOOLEAN & ST & dchg & & $\mathrm{O}$ \\
\hline phsB & BOOLEAN & ST & dchg & & $\mathrm{O}$ \\
\hline phsC & BOOLEAN & ST & dchg & & $\mathrm{O}$ \\
\hline neut & BOOLEAN & ST & dchg & & $\mathrm{O}$ \\
\hline$q$ & Quality & ST & qchg & & M \\
\hline $\mathrm{t}$ & TimeStamp & ST & & & M \\
\hline \multicolumn{6}{|c|}{ configuration, description and extension } \\
\hline operTm & TimeStamp & $\mathrm{CF}$ & & & 0 \\
\hline d & VISIBLE STRING255 & DC & & Text & $\mathrm{O}$ \\
\hline $\mathrm{dU}$ & UNICODE STRING255 & DC & & & $\mathrm{O}$ \\
\hline cdcNs & VISIBLE STRING255 & EX & & & AC_DLNDA_M \\
\hline cdcName & VISIBLE STRING255 & EX & & & AC_DLNDA_M \\
\hline dataNs & VISIBLE STRING255 & EX & & & AC_DLN_M \\
\hline \multicolumn{6}{|l|}{ Services } \\
\hline \multicolumn{6}{|c|}{ As defined in Table 13} \\
\hline
\end{tabular}

Fonte: Norma IEC 61850

- Data Attributes (DA): representam os dados propriamente ditos e são definidos pelas Normas IEC 61850-7-2 e IEC 61850-7-3. Existem vários tipos, cada qual com um formato específico para um determinado tipo de variável a ser expressa. Como exemplo, pode-se citar que as variáveis que possuem somente dois estados (de natureza booleana) utilizam o tipo BOOLEAN e que as variáveis utilizadas para expressar a qualidade de um determinado dado utilizam o tipo Quality. A Figura 6 demonstra uma tabela contendo exemplos de DAs.

Figura 6 - Exemplos de Data Attributes

\begin{tabular}{|c|c|c|c|}
\hline \multicolumn{4}{|c|}{ BasicTypes } \\
\hline Name & Value range & Remark & Used by \\
\hline BOOLEAN & & & $\begin{array}{l}\text { IEC } 61850-7-3 \\
\text { IEC } 61850-7-2\end{array}$ \\
\hline INT8 & -128 to 127 & & $\begin{array}{l}\text { IEC } 61850-7-3 \\
\text { IEC } 61850-7-2\end{array}$ \\
\hline INT16 & -32768 to 32767 & & $\begin{array}{l}\text { IEC } 61850-7-3 \\
\text { IEC } 61850-7-2\end{array}$ \\
\hline INT24 & -8388608 to 8388607 & for TimeStamp type & IEC $61850-7-2$ \\
\hline INT32 & -2 147483648 to 2147483647 & & $\begin{array}{l}\text { IEC } 61850-7-3 \\
\text { IEC } 61850-7-2\end{array}$ \\
\hline INT128 & $-2 * * 127$ to $(2 * * 127)-1$ & Required for counters & IEC $61850-7-3$ \\
\hline INT8U & $\begin{array}{l}\text { Unsigned integer, } \\
0 \text { to } 255\end{array}$ & & $\begin{array}{l}\text { IEC } 61850-7-3 \\
\text { IEC } 61850-7-2 \\
\end{array}$ \\
\hline INT16U & $\begin{array}{l}\text { Unsigned integer, } \\
0 \text { to } 65535\end{array}$ & & $\begin{array}{l}\text { IEC } 61850-7-3 \\
\text { IEC } 61850-7-2\end{array}$ \\
\hline
\end{tabular}

Fonte: Norma IEC 61850 Os Data Attributes de um IED podem ser representados de duas formas: notação baseada no padrão MMS da Norma IEC 61850-8-1 ou na notação baseada no padrão ACSI da Norma IEC 61850-7-2. Exemplo: para representar o dado "general", pertencente ao nó lógico PIOC2, 
que por sua vez está inserido no dispositivo lógico Ldevice1, as seguintes notações são possíveis:

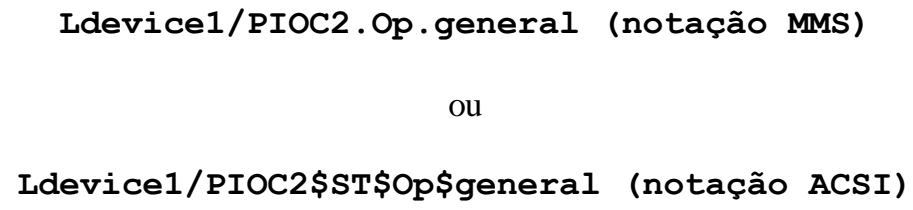

\subsubsection{A Linguagem de Descrição da Configuração de Subestações}

Para garantir a interoperabilidade entre os IEDs de uma subestação, foi necessário estabelecer um formato padronizado para representar toda a estrutura de modelo de dados do SAS, contendo todos os links de comunicação existentes entre os IEDs, de modo a garantir a compatibilidade na troca de informações entre IEDs e entre as ferramentas de engenharia (programas) de diferentes fabricantes, utilizadas no projeto de um SAS.

Para tanto, definiu-se uma linguagem padronizada de configuração de subestações chamada Linguagem de descrição da Configuração da Subestação (ou Linguagem SCL), que tem como bases a Linguagem XML (versão 1.0) e a Linguagem UML. O âmbito da Linguagem SCL, conforme definido na Norma IEC 61850-6, é claramente restrito aos seguintes aspectos:

- Especificação funcional do sistema de automação da subestação;

- Descrição das configurações dos IEDs;

- Descrição do diagrama unifilar da subestação.

Para isso, definiram-se:

- Um modelo de objetos que descreva os IEDs, suas conexões de comunicação e a sua distribuição na subestação; e

- Um formato padronizado para descrever como este modelo de objetos deve ser representado em arquivos que serão trocados entre as ferramentas de engenharia.

Dessa forma, foram estruturados todos os componentes que descrevem um SAS (níveis de tensão, transformadores, IEDs, nós lógicos, etc.) e como eles se relacionam, através de 
esquemas estabelecidos através da Linguagem UML baseados em conceitos de modelagem orientada a objetos, conforme ilustra a Figura 7, a seguir.

Figura 7 - Fragmento de um esquema UML utilizado pela Linguagem SCL

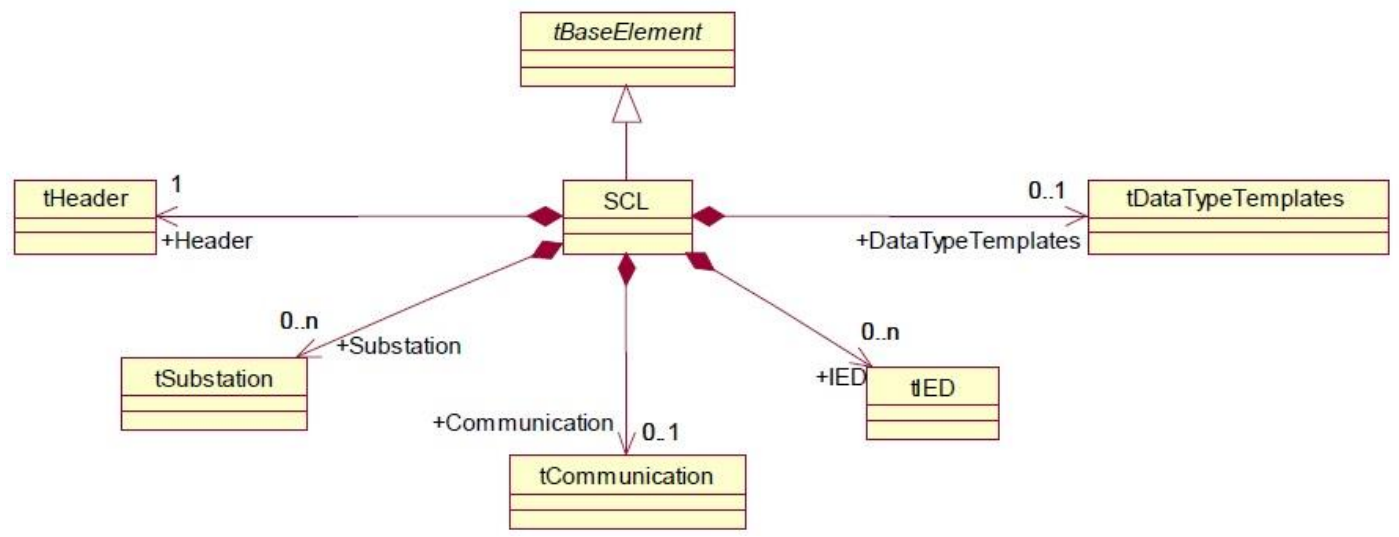

Fonte: Norma IEC 61850

Definido o modelo de objetos, o próximo passo foi codificá-lo em um formato de arquivo padronizado a ser utilizado pelas ferramentas de engenharia, utilizando a Linguagem XML, conforme ilustra a Figura 8.

Figura 8 - Fragmento de código XML utilizado pela Linguagem SCL

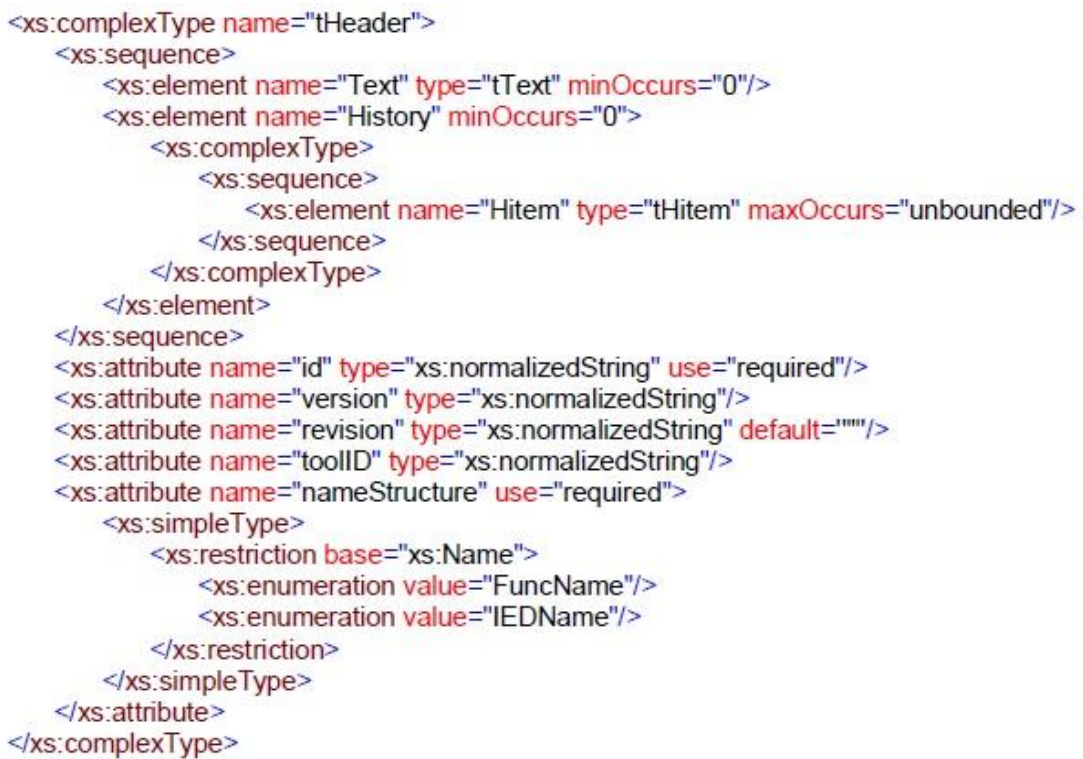

Fonte: Norma IEC 61850

De posse dos esquemas UML definidos, com todos os elementos gerados em XML que o compõem, é possível criar os Arquivos de Descrição SCL, compostos por estes elementos. Os Arquivos de Descrição SCL criados podem ser, basicamente, de quatro tipos:

- Descrição das características do IED (sua extensão é ICD); 
- Descrição de especificação do sistema (sua extensão é SSD);

- Descrição de configuração da subestação (sua extensão é SCD);

- Descrição do IED configurado (sua extensão é CID).

A Figura 9 ilustra o processo de engenharia pretendido com o uso da Linguagem SCL.

Figura 9 - Modelo de referência para o processo de engenharia com a Linguagem SCL

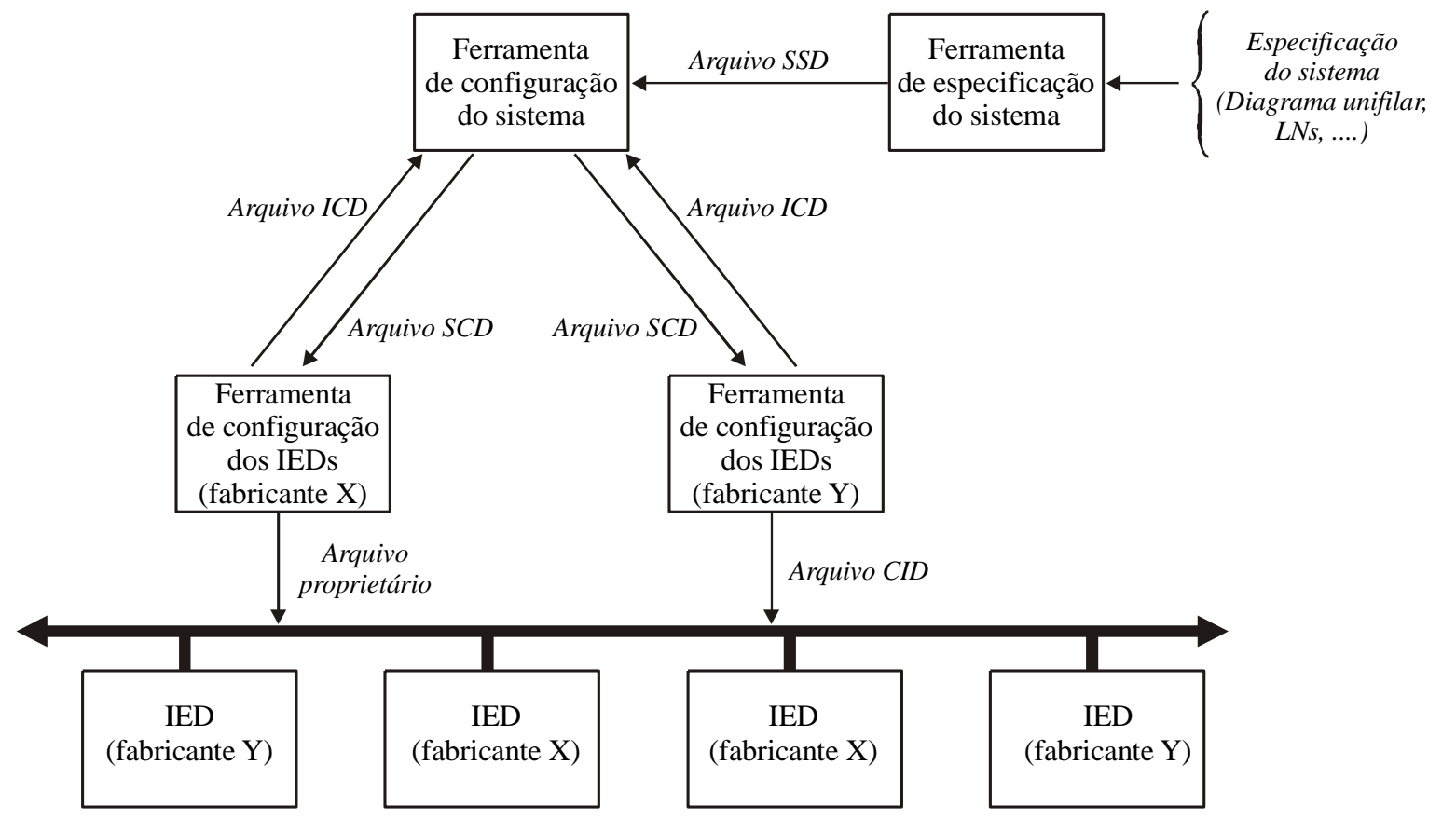

Fonte: o Autor

Nesta figura, destacam-se:

- Ferramenta de Configuração do IED: é uma ferramenta específica do fabricante do equipamento capaz de gerar arquivos de configuração específicos do IED ou configurar o IED. É importante observar que um IED somente poderá ser considerado compatível com a IEC 61850 se ele vier acompanhado por um arquivo ICD que descreva suas características, ou por uma ferramenta capaz de gerar o arquivo ICD (ferramenta de configuração do IED) e seja ou capaz de utilizar um arquivo SCD do sistema diretamente, ou ainda vir acompanhado de uma ferramenta capaz de importar o arquivo SCD e configurá-lo (ferramenta de configuração do IED).

- Ferramenta de Especificação do Sistema: é uma ferramenta capaz de gerar o arquivo que contenha as especificações da subestação (arquivo SSD) a partir de uma especificação do sistema (diagrama unifilar, nós lógicos utilizados, diagrama dos alimentadores, etc.). 
- Ferramenta de Configuração do Sistema: é uma ferramenta independente dos IEDs utilizados capaz de importar os arquivos ICDs de diversos IEDs e o arquivo SSD de especificação do sistema, os quais serão utilizados pelo engenheiro para construir as diversas informações do sistema que serão compartilhadas pelos diferentes IEDs. Esta ferramenta gera um arquivo SCD do sistema que será utilizado pelas ferramentas de configuração dos IEDs para configurar as características dos IEDs, de acordo com as funções projetadas na ferramenta de configuração do sistema. Opcionalmente, um arquivo no padrão CID pode ser criado para transferir as informações para os IEDs. Caso contrário, pode-se utilizar um arquivo de padrão proprietário do fabricante.

Novas expansões da Norma IEC 61850 estão em desenvolvimento e o processo de engenharia também vem sendo ampliado, prevendo, por exemplo, novas extensões de arquivos contendo informações para implementações de lógicas de proteção e automação entre subestações.

\subsubsection{Serviços em Redes Realtime}

Em se tratando de controle digital, é possível definir um sistema digital de tempo real como sendo um sistema computacional que deve reagir de forma satisfatória a estímulos oriundos do seu ambiente em prazos de tempo específicos, e não necessariamente instantâneos. Como o sistema a ser estudado é uma rede industrial, pode-se transportar este conceito e, portanto, definir uma Rede Realtime como sendo uma rede digital que oferece serviços executados em prazos de tempo específicos, e não necessariamente instantâneos.

A Norma IEC 61850-5 estabelece os tempos de execução específicos de cada função e os critérios básicos para sua medição. Uma das características importantes a se destacar é que a medição do tempo de transferência (transfer time) leva em consideração o tempo total de tratamento dos dados a serem transmitidos entre os IEDs, conforme se observa na Figura 10. 


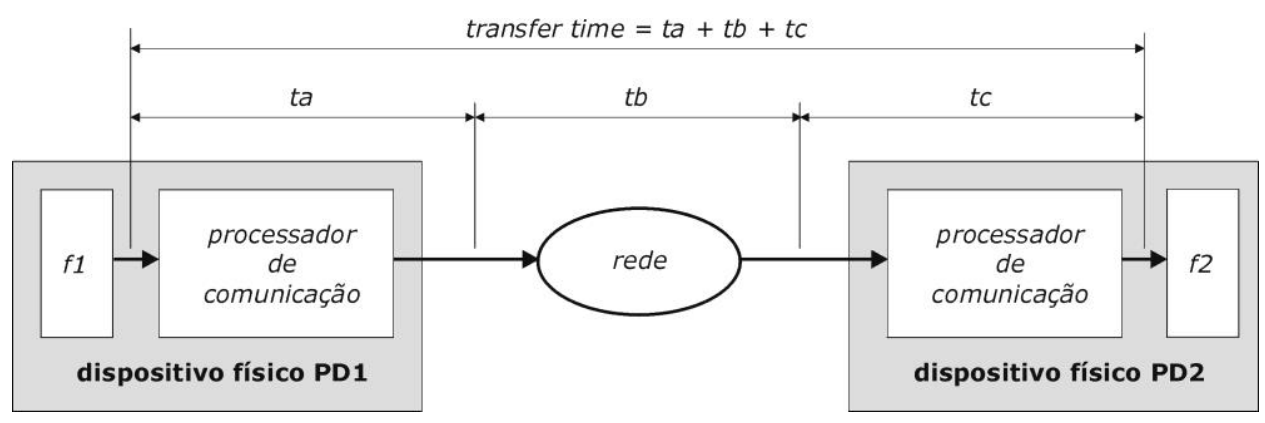

Fonte: adaptado Norma IEC 61850 Portanto, devem ser contabilizados o tempo necessário para encapsular os dados na pilha de protocolos antes de serem enviados pela interface de rede (intervalo ta), o tempo de processamento de todo e qualquer dispositivo que se encontra no barramento de rede, como switchs e bridges (intervalo $t b$ ), e o tempo requerido pelo receptor para desencapsular, extrair e tratar os dados da pilha de protocolos da mensagem recebida (intervalo $t c$ ). Este parâmetro é denominado tempo de transferência (transfer time) de uma mensagem.

Os diversos tipos de mensagens e suas respectivas classes de performance especificadas na Norma IEC 61850-5 estão mapeados diretamente nos protocolos apresentados na Norma IEC 61850-8-1. Dentre os vários serviços mapeados, este trabalho dará enfoque às mensagens baseadas nos Modelos GSE (Generic Substation Event) e no Modelo SV (Sample Values), que possuem alta performance e tempos de execução críticos.

\subsubsection{Mensagens GSE - As Mensagens GOOSE}

As Mensagens GSE, baseadas no Modelo GSE, são uma classe de mensagens rápidas utilizadas para a troca de sinais de comando entre IEDs. Estes sinais, anteriormente, eram transmitidos por conexões a fio e sinais elétricos analógicos (por exemplo, sinais de bloqueio de uma unidade de proteção e sinal de contato de alarme de um relé). Estes comandos são utilizados para implementar diversas lógicas de controle e de proteção, como função de proteção de falha de disjuntor, esquema de transferência de barramentos, lógica de religamento de disjuntores, intertravamentos, posição do comutador de tap do transformador de potência e lógicas adaptativas de proteção.

Para estas mensagens, a Norma IEC 61850-5 estabelece as seguintes classes de performance: 
- Classe P1: com transfer time na ordem de 1/2 ciclo (definido como $10 \mathrm{~ms}$ );

- Classe P2: com transfer time abaixo de $1 / 4$ ciclo (definido como menor que $3 \mathrm{~ms}$ );

- Classe P3: com transfer time abaixo de 1/4 ciclo (definido como menor que $3 \mathrm{~ms}$ );

Existem dois tipos de Mensagens GSE: as Mensagens GSSE (Generic Substation State Events) e as Mensagens GOOSE (Generic Object Oriented Substation Events). As Mensagens GSSE são baseadas em mensagens de protocolos desenvolvidos anteriormente à Norma IEC 61850 (como o UCA 2.0) e possuem um set de dados restrito. As Mensagens GOOSE foram desenvolvidas em conjunto com o processo de elaboração da Norma IEC 61850 e possuem um set de dados configurável, com maior versatilidade. Seu modo de transmissão é multicast, o que significa que o receptor da mensagem não necessita confirmar ao transmissor o recebimento, ou processamento, da mensagem.

A dinâmica das Mensagens GSE se desenvolve, resumidamente, da seguinte forma: admitindo um primeiro cenário onde exista um IED com unidade de sobrecorrente (nó lógico PIOC), se nenhum evento estiver ocorrendo (ou seja, não há curto-circuito que provoque um sinal de trip por sobrecorrente), o IED transmitirá periodicamente o valor das variáveis dentro da Mensagem GSE através da rede segundo um tempo Tmax (denominado Time Allow to Leave - TAL), conforme ilustra a Figura 11. A Mensagem GSE é representada pelo retângulo negro. Supõe-se, neste exemplo, que o único dado a ser transmitido seja o pick up da unidade de sobrecorrente deste IED.

Figura 11 - Diagrama de tempo do comando GSE quando nenhum evento está ocorrendo

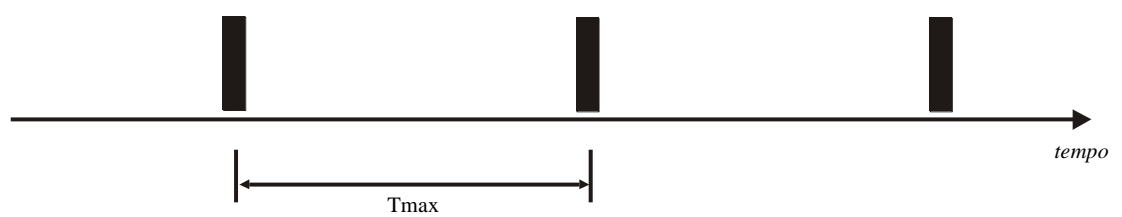

Fonte: o Autor No instante que ocorrer uma falha que sensibilize esta unidade de sobrecorrente, sua variável pick up irá mudar de valor. Neste momento, o IED percebe a mudança e passa imediatamente a enviar a Mensagem GSE com o novo valor, desta vez repetindo o envio num curto período de tempo Tmin, conforme demonstrado na Figura 12. Este intervalo entre as Mensagens GSE vai sendo incrementado de forma gradativa até retornar ao período de tempo Tmax. 
Figura 12 - Diagrama de tempo do comando GSE na ocorrência de um evento

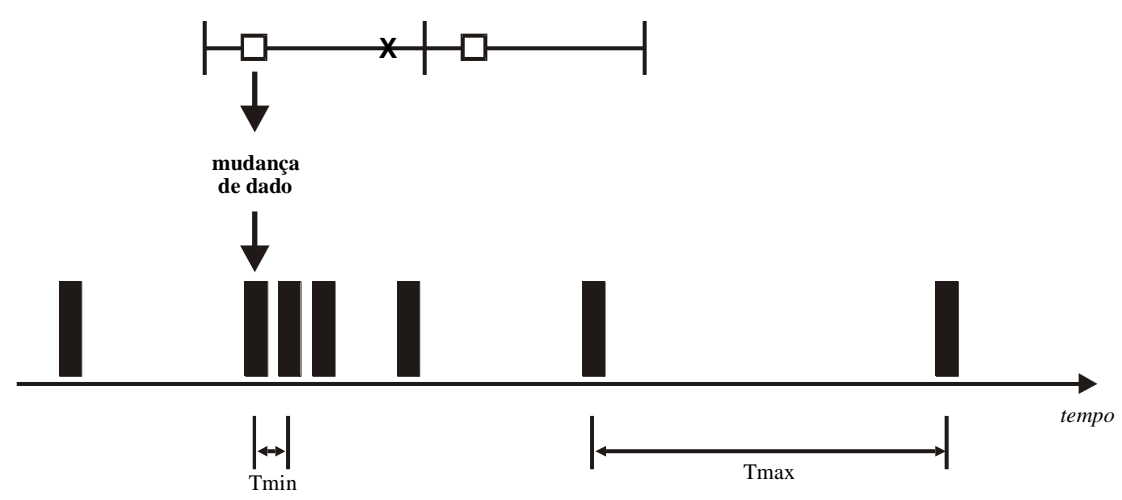

Fonte: o Autor

\subsubsection{Mensagens SV}

As Mensagens SV (Sample Value Messages, ou SV Messages), baseadas no Modelo SV definido pela Norma IEC 61850-9, são mensagens rápidas (tipo 4) e sua performance é definida em diferentes classes pela Norma IEC 61850-5, de acordo com a finalidade do valor medido (proteção, controle ou medição) e a taxa de amostragem. Seu funcionamento básico consiste em amostrar digitalmente a grandeza obtida de um transformador para instrumentos (tensão ou corrente) e transmitir este valor para os IEDs que irão utilizá-lo (relé, oscilógrafo, medidor, etc.) através de um barramento de rede de comunicação digital. Seu modo de transmissão é multicast e sua arquitetura segue o padrão publisher-subscriber, semelhante às Mensagens GSE, com a diferença de não utilizar a dinâmica de repetição de mensagens.

A Figura 13 representa um diagrama unifilar de uma subestação de distribuição típica com barramento de processo segundo a Norma IEC 61850-9. Ela sera utilizada como referência para o desenvolvimento das contribuições propostas pelo autor que serão apresentadas ao longo deste trabalho. 
Figura 13 - Diagrama básico de um barramento de processo de acordo com a Norma IEC 61850-9

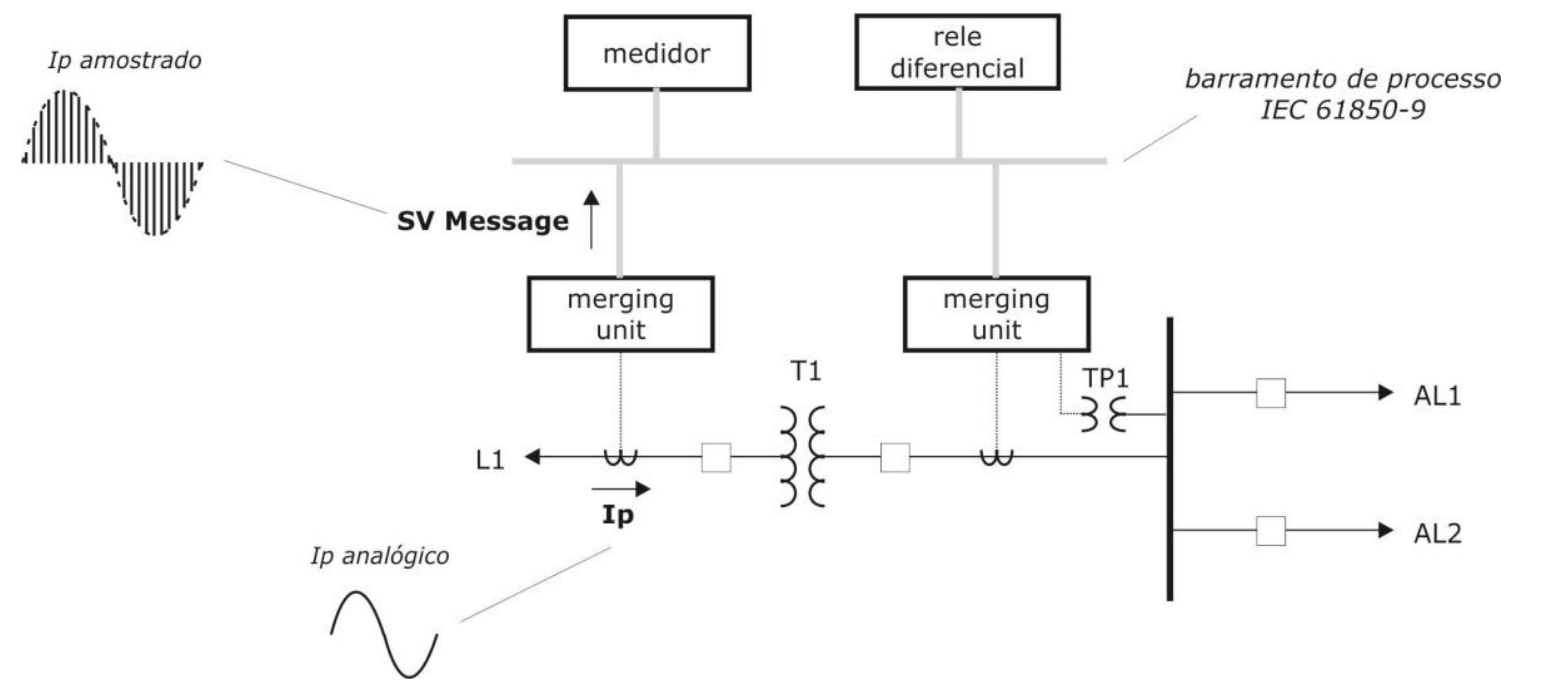

Fonte: o Autor

Para a SV Message com finalidade de proteção e/ou automação, a Norma IEC 61850-5 estabelece as seguintes classes de performance:

- Classe P1: com transfer time de até $10 \mathrm{~ms}$

- Classe P2: com transfer time de até $3 \mathrm{~ms}$;

- Classe P3: com transfer time de até 3 ms.

Não foram encontradas na Norma IEC 61850-5 informações a respeito do transfer time das SV Messages com finalidade de medição (classes de performance Classe M1, Classe M2 e Classe M3). 


\section{Interpretação da Norma IEC 61850-9}

Devido aos diversos aspectos que envolvem a implementação de um barramento de processo segundo a Norma IEC 61850-9, o autor realizou uma extensa pesquisa a respeito das normas e dos conceitos envolvidos. A conclusão deste estudo é a proposta apresentada neste capítulo, onde o assunto será abordado sob a ótica de cinco aspectos distintos e interdependentes: variações da Norma IEC 61850-9, confiabilidade do barramento de processo, sincronismo de tempo, análise da qualidade da medição e segurança cibernética [3] [4], conforme ilustra a Figura 14. Os resultados obtidos serão utilizados como base para as demais etapas deste trabalho. O autor espera que estes resultados auxiliem no esclarecimento e na divulgação da Norma IEC 61850, desmistificando os principais conceitos envolvidos (que, muitas vezes, são abordados de forma confusa e difusa por inúmeros trabalhos publicados) e contribuindo para o desenvolvimento de futuras pesquisas e produtos que envolvam o barramento de processo segundo a Norma IEC 61850-9.

Figura 14 - Diagrama proposto que representa os cinco aspectos interdependentes para interpretação da Norma IEC 61850-9

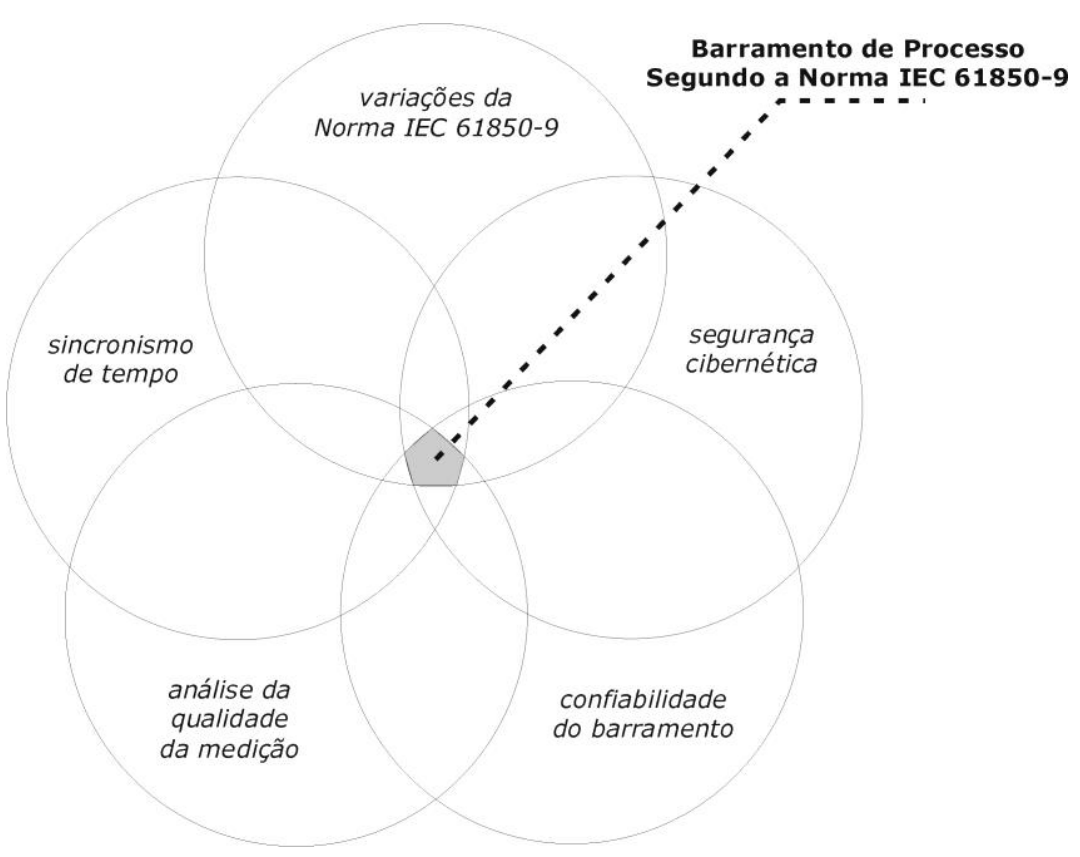

Fonte: o Autor 


\subsection{Variações da Norma IEC 61850-9}

A Norma IEC 61850-9 estabeleceu dois formatos distintos para a transmissão dos valores amostrados: a IEC 61850-9-1 e a IEC 61850-9-2. Ambos os formatos trabalham com a transmissão dos valores diretamente sobre o frame padrão IEC 8802-3 (também conhecido como padrão Ethernet), conforme demonstrado na Figura 15:

Figura 15 - Formato do frame ISO/IEC 8802-3

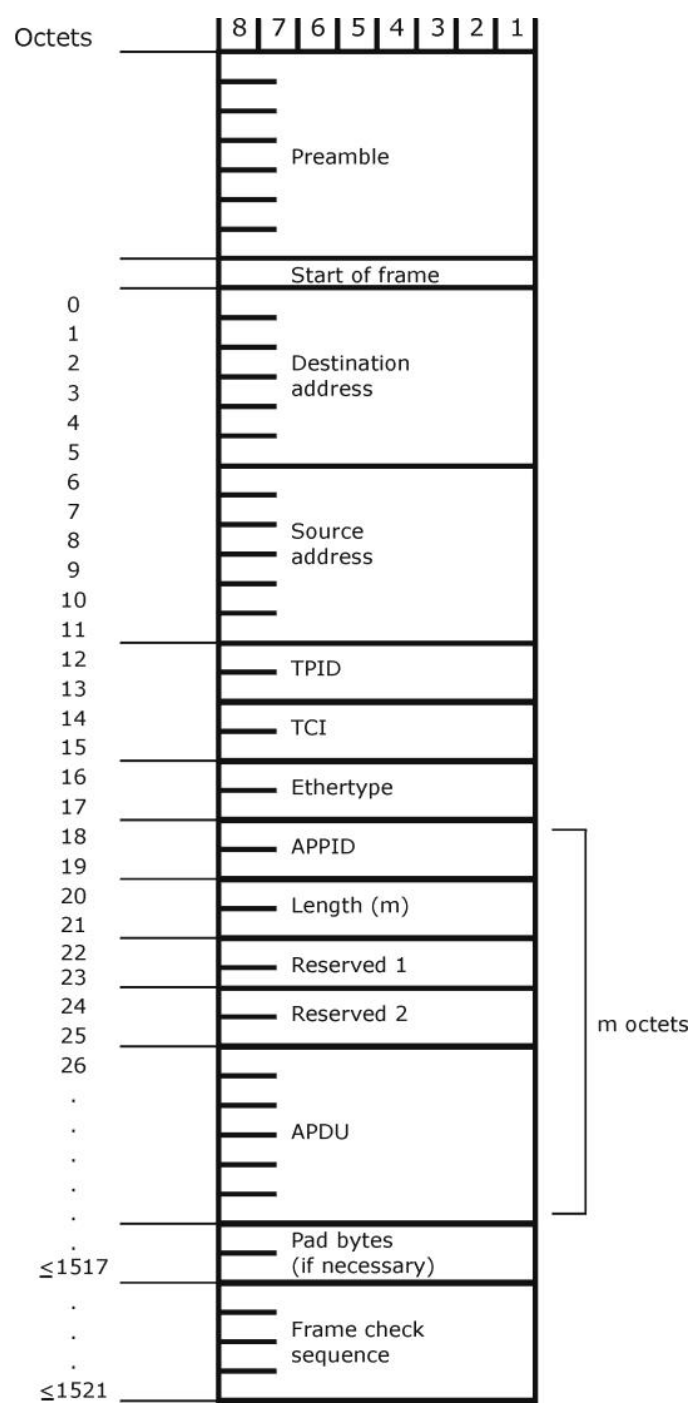

Fonte: o Autor

Os dados estão organizados em uma estrutura chamada Application Protocol Data Unit (APDU), composta por um cabeçalho chamado Application Protocol Control Information (APCI) e por uma estrutura de dados chamada Application Service Data Unit (ASDU), que contém os valores de tensão e corrente amostrados, conforme se observa na Figura 16, a 
seguir. Cada ASDU contém uma amostra dos valores de tensão e corrente. É permitido que uma APDU contenha mais de uma ASDU. Esta concatenação de ASDUs é um parâmetro de configuração do sistema que não é dinamicamente variável e deve ter seu valor préestabelecido no momento de elaboração do projeto com o objetivo de reduzir a complexidade de sua implementação.

Figura 16 - Concatenação de várias ASDUs, em conjunto com a APCI, formando uma APDU

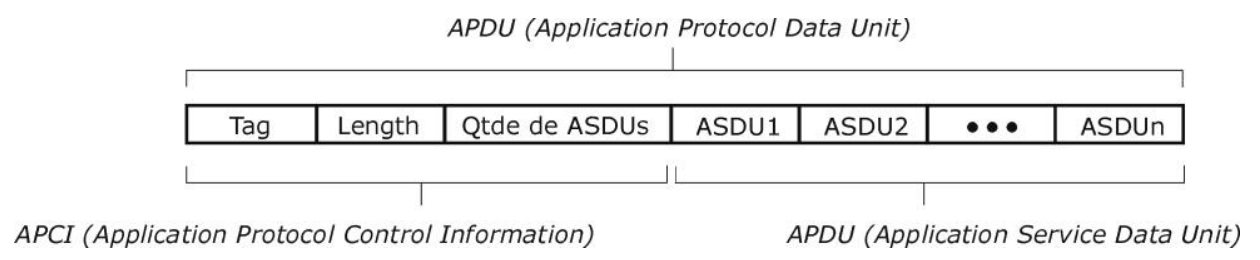

Fonte: o Autor A diferença entre os dois formatos reside, basicamente, na formatação do ASDU. Na Norma IEC 61850-9-1, seu formato é fixo, seguindo um Dataset universal estabelecido previamente na Norma IEC 60044-8 [5], conforme ilustrado na Figura 17. 


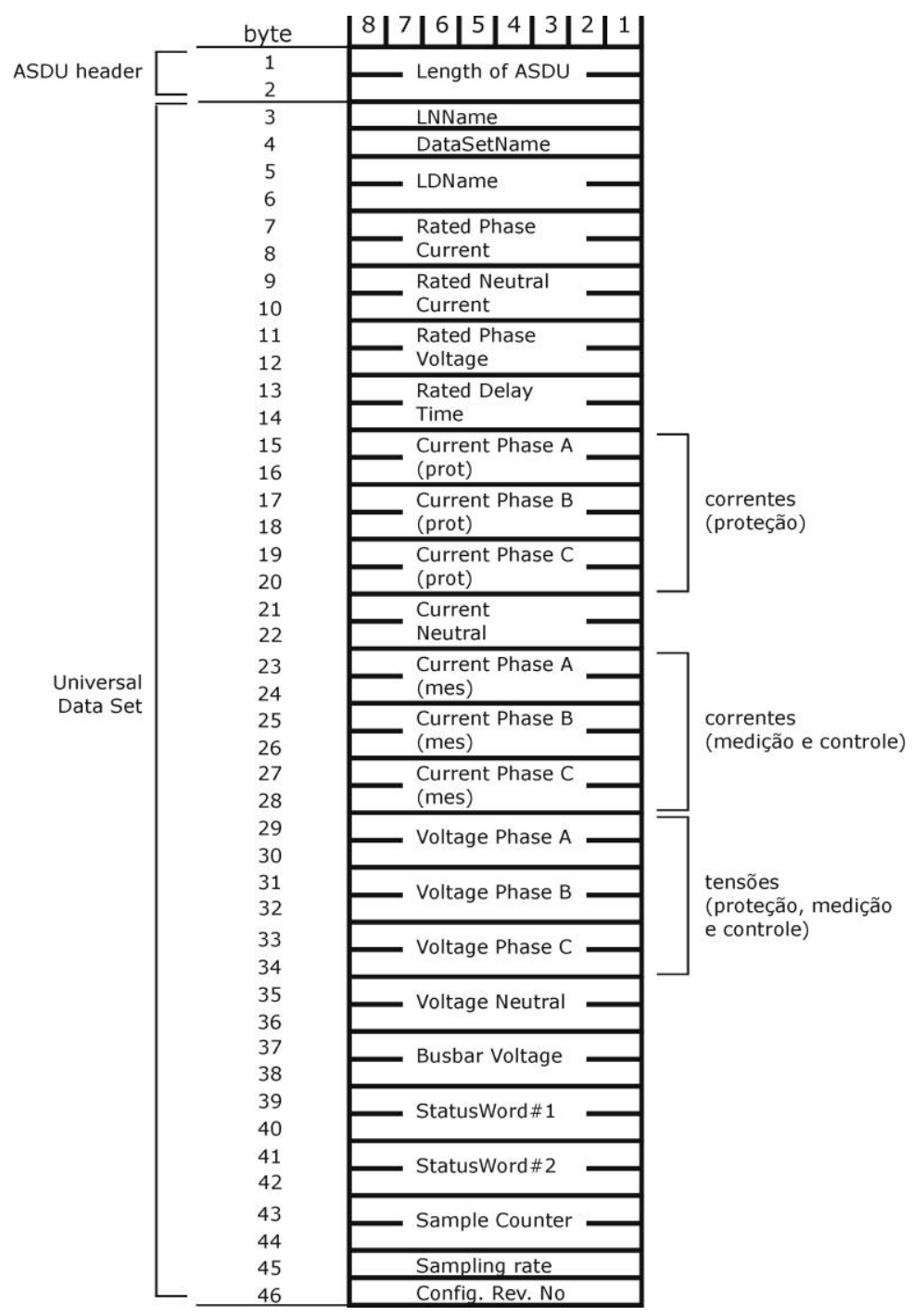

Fonte: o Autor

Observa-se que, neste caso, o ASDU prevê dois campos para expressar os valores de corrente: um para aplicações em proteção e outro para aplicações em medição, além de um campo para tensão. Esta distinção se deve ao fato de que, em operação normal, os valores de correntes são menores e necessitam de maior precisão, principalmente para fins de faturamento, portanto, necessitam de uma faixa dinâmica específica. Já numa situação de curto-circuito, as correntes são elevadas e, para que possam ser lidas sem ultrapassar o fim da escala adotada para fins de proteção, necessitam de outra faixa dinâmica. A tensão, em ambas as situações, não tem seu valor alterado significativamente, portanto, possui somente uma faixa dinâmica.

Já o padrão adotado pela IEC 61850-9-2 utiliza uma APDU codificada segundo o padrão ASN.1 (ISO/IEC 8825-1) [6], conforme se observa na Figura 18, a seguir. Neste exemplo, cada um dos oito ASDUs contém um Dataset configurável, o que o torna mais versátil em relação ao Dataset universal da Norma IEC 61850-9-1, pois este não pode ser personalizado 
de acordo com sua aplicação.

Figura 18 - Exemplo de uma APDU codificada em ASN.1, com oito ASDUs concatenados

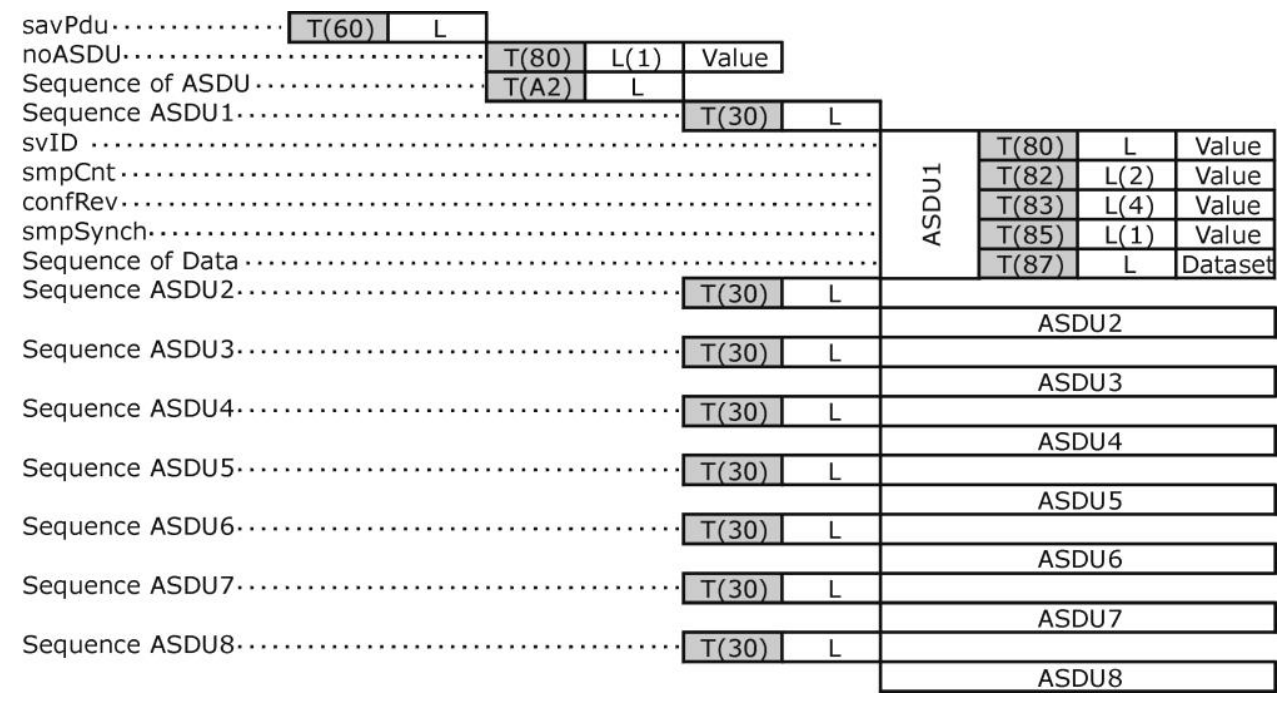

Fonte: o Autor

Cada um dos parâmetros é codificado em ASN.1, de acordo com a estrutura da Figura 19.

Uma excelente introdução sobre este padrão pode ser encontrada em [7]. Analisando a Figura

18, observa-se que um APDU é composto por vários parâmetros, cada um deles contendo:

- um campo Tag, identificado pela letra T e pela cor cinza, contém um byte que identifica o parâmetro;

- um campo Length, identificado pela letra L, contém a quantidade de bytes dos dados do parâmetro;

- um campo Value, identificado pela letra V, ou pela sigla values, pode conter os bytes de dados de um parâmetro (geralmente seu valor), ou um novo conjunto de parâmetros. 


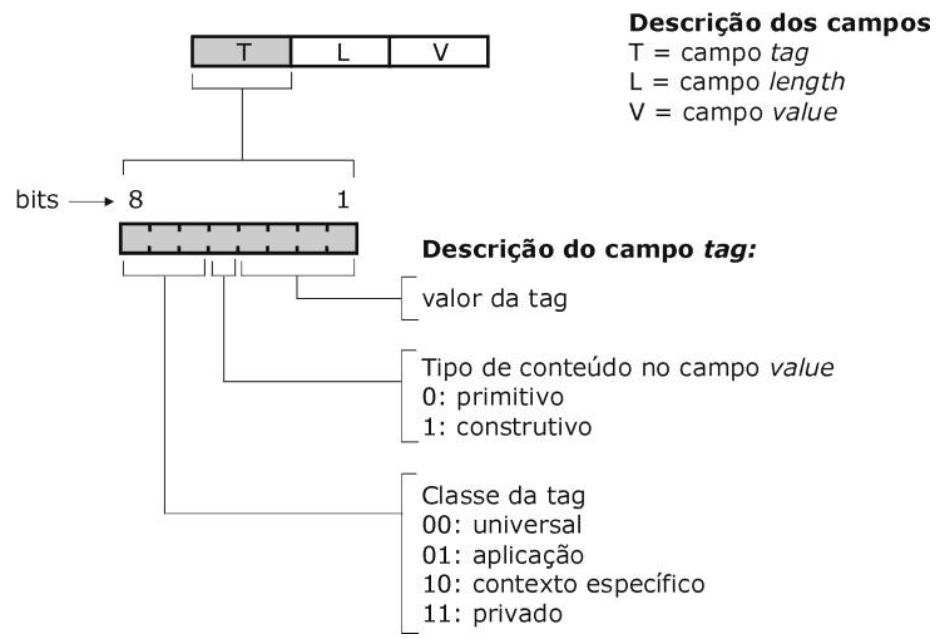

Fonte: o Autor

Dentre os diversos parâmetros, pode-se destacar o parâmetro smpCnt, que é um contador com o objetivo de identificar, de forma relativa no tempo, cada amostra enviada no barramento de processo. Seu mecanismo é ilustrado pelo exemplo da Figura 20. O contador é iniciado em zero na virada de cada novo segundo e incrementado sempre que uma nova amostra é feita. Para uma configuração de 80 amostras/ciclo, com frequência de rede de $50 \mathrm{~Hz}$, serão geradas $80 \times 50=4000$ amostras/segundo. Portanto, dentro de um intervalo de 1 segundo, a primeira amostra é identificada pelo número 0 e a última amostra é identificada pelo número 3999.

Figura 20 - Dinâmica do contador smpCnt

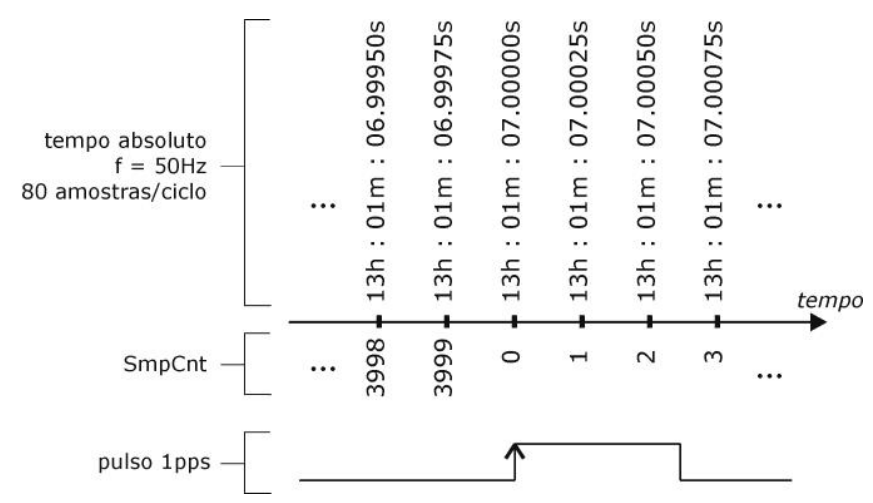

Fonte: o Autor Em 2004, a organização UCA, em conjunto com os principais pesquisadores e fabricantes de equipamentos do setor, desenvolveu um guia de implementação da Norma IEC 61850-9, conhecido como IEC 61850-9-2 Light Edition (IEC 61850-9-2LE) [8], onde foram definidas algumas diretivas com o objetivo de restringir as definições originalmente especificadas pela Norma IEC 61850-9 (que na prática mostraram-se muito abrangentes) e, desta forma, auxiliar na implementação da norma nos barramentos de processo das subestações. Dentre estas diretivas, podem-se destacar: 
- preferência pelo padrão definido pela Norma IEC 61850-9-2, ao invés do padrão definido pela Norma IEC 61850-9-1;

- definição de duas taxas para amostragem: 80 amostras/ciclo com uma ASDU por $S V$ Message (para aplicações de proteção), gerando um fluxo de 80 mensagens/ciclo, e 256 amostras/ciclo com oito ASDUs por SV Message (para aplicações de medição e qualidade de energia), gerando um fluxo de 32 mensagens/ciclo;

- pulso de 1pps, ou o padrão IRIG-B, como metodologias a serem utilizadas para o sincronismo de tempo entre IEDs.

A última edição da Norma IEC 61850-9-2 [21] já incorporou algumas destas sugestões.

Com base nestas especificações, a maior quantidade possível de amostras no intervalo de 1 segundo será atingida na configuração de 256 amostras/ciclo, com frequência de rede de 60 Hz, ou seja, 256 x $60=15360$ amostras. Portanto, um campo com tamanho de 2 bytes é suficiente para representar o parâmetro smpCnt. Analisando novamente a Figura 18, concluise que este parâmetro possui:

- valor 0x82 no campo ASN1.Tag, que identifica o parâmetro como sendo smpCnt;

- valor 0x02 no campo Length, pois 2 bytes são suficientes para expressá-lo;

- no campo value são inseridos os 2 bytes do contador smpCnt, referente à amostra transmitida.

Cada ASDU contém um Dataset com os valores relativos a uma amostra, conforme se observa na Figura 21. Neste exemplo, pode-se destacar a variável instMag.i, que possui codificação INT32 e expressa o valor instantâneo da corrente amostrada. De acordo com o documento IEC 61850-9-2LE e com a Norma IEC61850-9-2, Ed. 2 [21], esta codificação obedece ao formato 32 bits Big Endian - signed, e cada lsb (lowest significant bit - bit menos significativo) representa $1 \mathrm{~mA}$ da corrente primária do transformador para instrumentos, valor este, segundo o documento, suficiente para satisfazer a faixa dinâmica de todas as aplicações práticas de proteção, automação e medição. A Figura 22 apresenta um nomograma que ilustra esta análise. 
Figura 21 - Exemplo de codificação de um Dataset de acordo com o documento IEC 61850-9-2LE

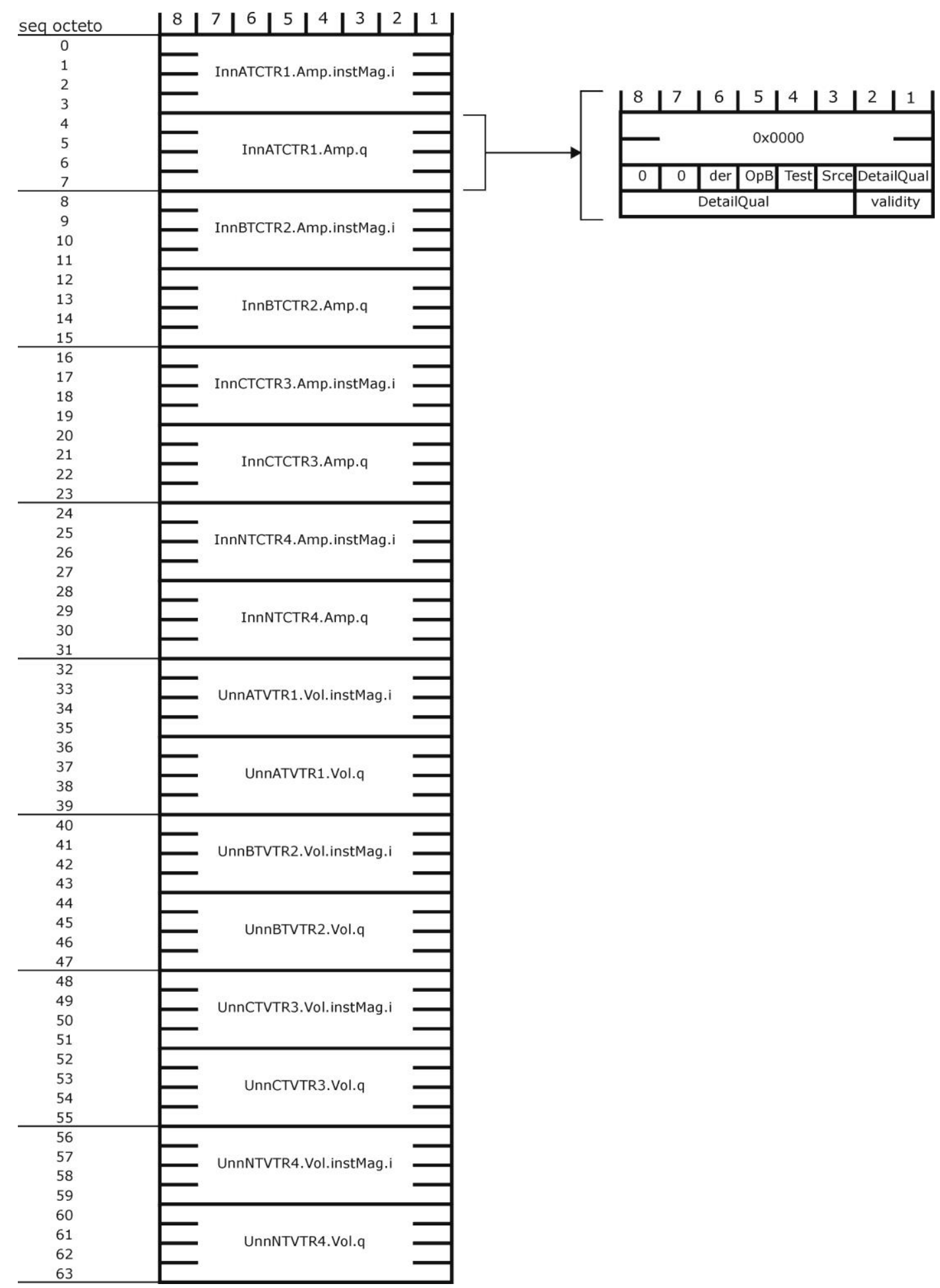

Fonte: o Autor 
Figura 22 - Nomograma contendo análise da faixa dinâmica da corrente

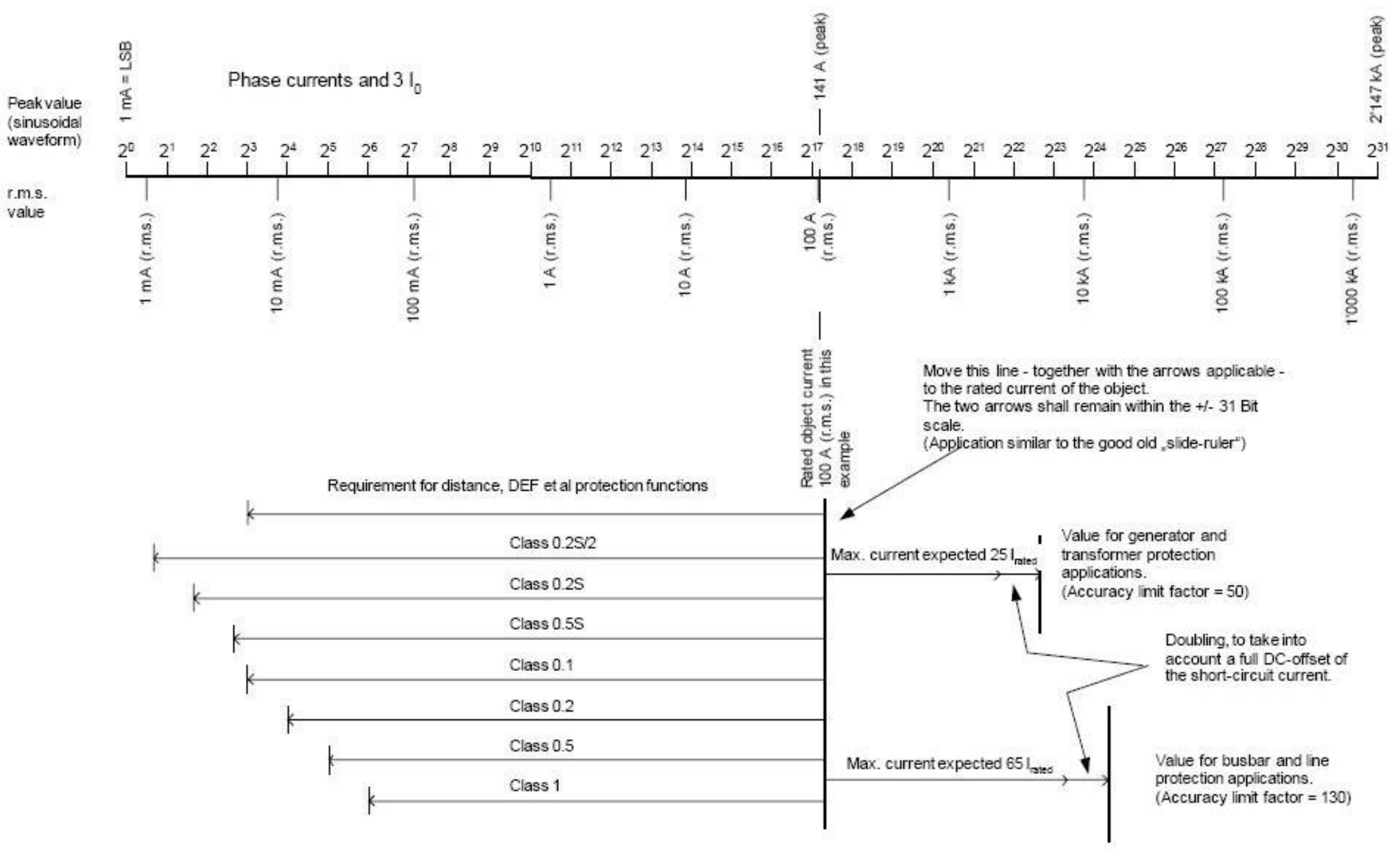

Fonte: IEC 61850-9-2 LE 
Com base na Tabela 1, o autor realizou a seguinte análise: neste exemplo, admite-se um TC com corrente primária nominal de trabalho de 100A eficazes, portanto, seu FLC (Full Load Current - Corrente de Carga) é igual a 100A. De acordo com a Tabela 1, a seguir, um transformador de instrumentos de classe $0.2 \mathrm{~S}$ deve apresentar um erro de medição de $0,75 \%$ quando aplicada uma corrente igual a 1\% de seu FLC (pior situação, com objetivo de avaliar sua exatidão). Esta classe de transformador de instrumentos é utilizada em aplicações de medição mais precisas, onde a corrente nominal secundária é $5 \mathrm{~A}$ e a faixa dinâmica se encontra entre $50 \mathrm{~mA}$ e $6 \mathrm{~A}[22]$.

Tabela 1 - Exatidão (accuracy) dos transformadores de corrente, segundo a norma IEC 60044-4

\begin{tabular}{|c|c|c|c|c|c|c|c|c|c|}
\hline \multirow[t]{2}{*}{$\begin{array}{l}\text { Accuracy } \\
\text { Class }\end{array}$} & \multicolumn{4}{|c|}{$\begin{array}{l}\text { Ratio Error } \\
\% \text { Reading }\end{array}$} & \multicolumn{4}{|c|}{$\begin{array}{l}\text { Phase Error } \\
\text { Minutes }\end{array}$} & \multirow{2}{*}{$\begin{array}{c}\text { Worst Case kW } \\
\text { Error } \\
\% \text { Reading } \\
5 \% \text { FLC } \\
\text { PF }=0.5\end{array}$} \\
\hline & $\begin{array}{c}100 \% \\
\text { FLC }\end{array}$ & $\begin{array}{l}20 \% \\
\text { FLC }\end{array}$ & $\begin{array}{l}5 \% \\
\text { FLC }\end{array}$ & $\begin{array}{l}1 \% \\
\text { FLC }\end{array}$ & $\begin{array}{l}100 \% \\
\text { FLC }\end{array}$ & $\begin{array}{l}20 \% \\
\text { FLC }\end{array}$ & $\begin{array}{l}5 \% \\
\text { FLC }\end{array}$ & $\begin{array}{l}1 \% \\
\text { FLC }\end{array}$ & \\
\hline 5 & 5 & & & & & & & & $N / A$ \\
\hline 3 & 3 & & & & & & & & $\mathrm{~N} / \mathrm{A}$ \\
\hline 1 & 1 & 1.5 & 3 & & 60 & 90 & 180 & & 11.9 \\
\hline 0.5 & 0.5 & .75 & 1.5 & & 30 & 45 & 90 & & 6.0 \\
\hline $0.5 \mathrm{~S}$ & 0.5 & 0.5 & 0.75 & 1.5 & 30 & 30 & 45 & 90 & 3.01 \\
\hline 0.2 & 0.2 & 0.35 & 0.75 & & 10 & 15 & 30 & & 2.25 \\
\hline $0.2 \mathrm{~S}$ & 0.2 & 0.2 & 0.35 & 0.75 & 10 & 10 & 15 & 30 & 1.10 \\
\hline 0.1 & 0.1 & 0.2 & 0.4 & & 5 & 8 & 15 & & 1.15 \\
\hline
\end{tabular}

Fonte: Norma IEC 60044-4 Analisando o limite inferior da faixa dinâmica, para se atingir uma precisão de $0,75 \%$, serão necessários 100/0,75 = 133 steps do conversor analógico digital. Como os valores de erro de medição são baseados em grandezas eficazes e o sinal de corrente possui ciclos positivos e negativos, a quantidade de steps necessária será $133 \times 2 \times \sqrt{2}=376$ steps. No caso de uma corrente igual a $1 \%$ do FLC, ou seja, $1 \%$ de $100 \mathrm{~A}=1 \mathrm{~A}$, serão necessários 376 steps, onde cada step equivale à $1 / 376=2,65 \mathrm{~mA}$. Portanto, utilizar uma codificação com $l s b$ de $1 \mathrm{~mA}$ atende a exatidão desejada.

No limite superior da faixa dinâmica, admitiu-se como pior caso 65 FLCs (proteção de barramento e de linhas), o que corresponde a uma corrente instantânea máxima de 65 x 100 x $\sqrt{2}= \pm 9192$ A. A corrente de curto-circuito pode, ainda, apresentar uma componente DC exponencial sobreposta, cuja magnitude depende do instante em que ocorreu o curto e da constante R/L do sistema de potência. Para efeito de análise, admitiu-se a pior situação, onde a corrente total atinja 2 x 65 FLCs. Neste caso, a corrente instantânea máxima a ser medida será de 2 × 9192 × $1000= \pm 18384000$ mA. A variável instMag.i tem tamanho máximo de $2^{31}$ $= \pm 2147483648 \mathrm{~mA}$, o que é suficiente para expressar esta magnitude de corrente. 
Conclui-se, portanto, que esta abordagem torna desnecessária a utilização de dois campos para expressar um mesmo valor de corrente (metodologia utilizada pelo Dataset da Norma IEC 61850-9-1), o que permite, inclusive levando em consideração a magnitude do sinal e a tecnologia utilizada para medição, o uso de um mesmo TC para aplicações de proteção e de medição.

Outra vantagem oferecida pela $S V$ Message é a possibilidade de especificar a qualidade de cada valor amostrado através de um campo Quality, segundo os critérios estabelecidos pela Norma IEC 61850-7-3.

Por exemplo, observando a Figura 21, o campo InnATCTR1.Amp.q (do tipo Quality) define os requisitos de qualidade da amostra inserida no campo InnATCTR1.Amp.instMag.i (do tipo INT32). A Figura 23, a seguir, traz um descritivo das funções de cada atributo do campo Quality.

Figura 23 - Atributos do campo Quality, de acordo com a Norma IEC 61850-7-3

\begin{tabular}{|c|c|c|c|}
\hline \multicolumn{4}{|c|}{ Quality Type Definition } \\
\hline Attribute Name & Attribute Type & Value/Value Range & $\mathrm{M} / \mathrm{O} / \mathrm{C}$ \\
\hline & PACKED LIST & & \\
\hline validity & CODED ENUM & good | invalid | reserved | questionable & M \\
\hline detailQual & PACKED LIST & & M \\
\hline overflow & BOOLEAN & & M \\
\hline outOfRange & BOOLEAN & & M \\
\hline badReference & BOOLEAN & & M \\
\hline oscillatory & BOOLEAN & & M \\
\hline failure & BOOLEAN & & M \\
\hline oldData & BOOLEAN & & M \\
\hline inconsistent & BOOLEAN & & M \\
\hline inaccurate & BOOLEAN & & M \\
\hline source & CODED ENUM & $\begin{array}{l}\text { process | substituted } \\
\text { DEFAULT process }\end{array}$ & $M$ \\
\hline test & BOOLEAN & DEFAULT FALSE & M \\
\hline operatorBlocked & BOOLEAN & DEFAULT FALSE & M \\
\hline
\end{tabular}

Fonte: Norma IEC 61850 Os atributos validity e detailQuality são inter-relacionados. $\mathrm{O}$ atributo validity informa se o campo InnATCTRI.Amp.instMag.i apresenta algum problema. Se não apresentar, terá seu valor setado como good. Caso contrário, terá seu valor setado como invalid ou questionable, e o seu problema será classificado de acordo com as opções definidas no atributo detailQual (overflow, outOfRange, badReference, oscillatory, failure, oldData, inconsistent e inaccurate).

Admitindo uma situação onde o valor amostrado seja maior do que o campo 
InnATCTR1.Amp.instMag.i é capaz de expressar, o atributo validity seria setado com o valor invalid e o atributo detailQual teria o atributo overflow setado com o valor TRUE. Isto contribui para a tomada de decisões mais precisas e confiáveis por parte do IED inscrito para receber esta SV Message.

Por fim, embora ambos os formatos trabalhem com transmissão de mensagens multicast, outra diferença entre eles é que a Norma IEC 61850-9-1 visa a transmissão de SV Messages através de um link unidirecional ponto a ponto, ou seja, de um IED para outro IED. Por outro lado, a Norma IEC 61850-9-2 objetiva a transmissão de SV Messages no formato multicast real, ou seja, de um IED para diversos IEDs.

\subsection{Confiabilidade do barramento de processo}

A Norma IEC 61850-9-2 define algumas alternativas de arquiteturas de barramento de processos recomendando, por exemplo, a segmentação do barramento de processo em barramentos individuais para cada bay e interconectando-os através de roteadores. A conexão física entre eles seria feita, inicialmente, com a utilização de um barramento Ethernet simples, e a Norma IEC 61850 não define mecanismos de redundância contra possíveis problemas que possam ocorrer no barramento, como por exemplo, a queima de um determinado switch da rede ou a desconexão acidental de um cabo da rede. Devido principalmente ao esforço dos fabricantes em querer aumentar a confiabilidade do barramento de rede frente a esses problemas, começaram a surgir no mercado diferentes soluções de implementação dos barramentos realtime (com arquiteturas, muitas vezes, específicas de um determinado fabricante), tanto no barramento da subestação quanto no barramento de processo. Tal fato aponta para a necessidade de se estabelecer uma arquitetura comum que se torne padrão, que não comprometa a interoperabilidade entre IEDs de diferentes fabricantes e que garanta confiabilidade para o barramento de rede.

Um exemplo de arquitetura encontrada é a interligação em anel entre os switches, conforme ilustra a Figura 24. Cada IED possui duas interfaces de rede, cada uma delas conectada a um diferente switch deste anel (conexões azuis). A informação transita pelo anel num determinado sentido (por exemplo, no sentido horário). Caso aconteça um problema em uma conexão entre 
o IED e um switch, o frame será enviado pela outra conexão. Caso ocorra um defeito em algum switch, o fluxo de dados se inverte quando chegar no switch defeituoso.

Figura 24 - Arquitetura em anel (conexão em vermelho)

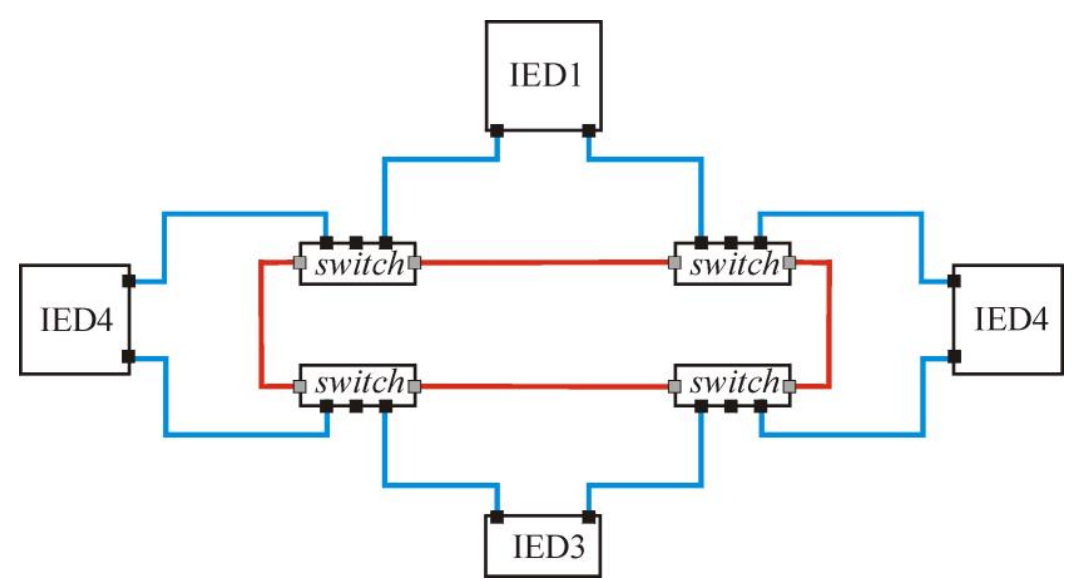

Fonte: o Autor

Em outro exemplo de arquitetura encontrada, remove-se a dupla conexão entre o IED e os switches e incorpora-se o switch diretamente no IED, conforme se verifica na Figura 25. Nesta configuração, o IED possui duas interfaces de rede e tais interfaces são interligadas formando um anel, que pode ou não utilizar a mesma lógica vista anteriormente para o restabelecimento do fluxo de dados quando uma determinada conexão do anel apresentar problemas.

Figura 25 - Arquitetura em anel com switch incorporado.

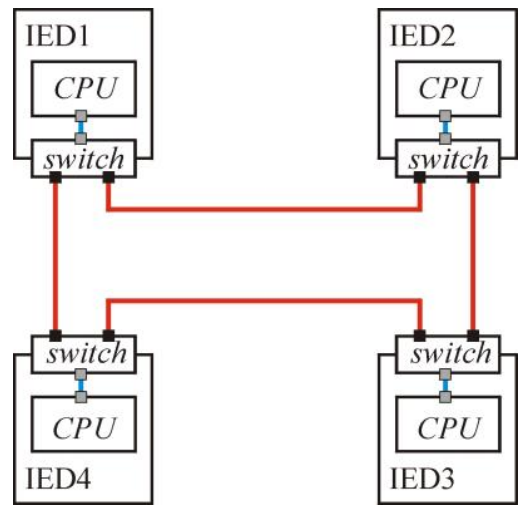

Fonte: o Autor

A arquitetura em anel também pode ser gerenciada utilizando o Protocolo RSTP (Rapid Spanning Tree Protocol) [9], que é uma opção aprimorada do Protocolo STP (Spanning Tree Protocol) e foi incorporada na Norma IEEE Std 802.1-D [10]. Sua função é remover loops em uma rede que ofereça mais de uma rota possível para transmitir uma determinada mensagem entre dois dispositivos, o que permite utilizar o Protocolo Ethernet como camada física. 
Na inicialização do sistema, o Protocolo RSTP realiza uma análise de todas as conexões existentes através da troca de mensagens entre os dispositivos, com o objetivo de comparar as diferentes prioridades elencadas a cada um deles. Este processo acaba por desabilitar algumas conexões redundantes e transformar a arquitetura da rede em uma árvore. Sua dinâmica pode ser analisada pelo exemplo da Figura 26, na qual foi desabilitada a conexão entre o IED1 e o IED4.

Figura 26 - Arquitetura em anel utilizando Protocolo RSTP

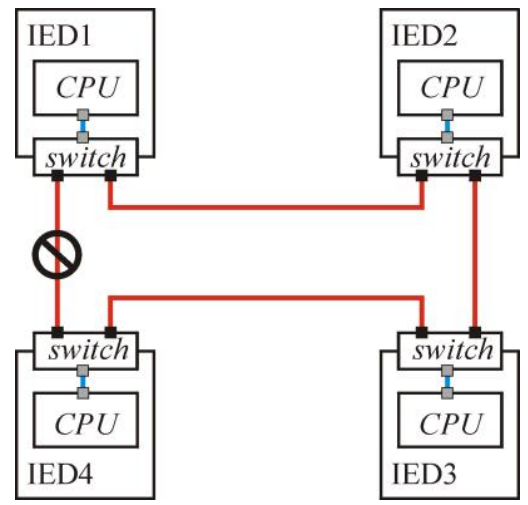

Fonte: o Autor O resultado é uma arquitetura de rede onde cada dispositivo se conecta a outro dispositivo somente por uma rota, sem riscos de loops. Este processo de avaliação das conexões é feito de forma periódica através da troca de mensagens tipo keep alive.

Caso ocorra um problema em alguma conexão habilitada, conforme demonstrado na Figura 27, o Protocolo RSTP perceberá a falha e reformulará as conexões. No caso ilustrado, a conexão entre o IED1 e o IED4 será reabilitada e desabilitada a conexão entre o IED2 e o IED3. Dependendo da complexidade da rede, este tempo de reconfiguração (denominado recovery time da rede) pode levar algumas dezenas de milisegundos até alguns segundos. 

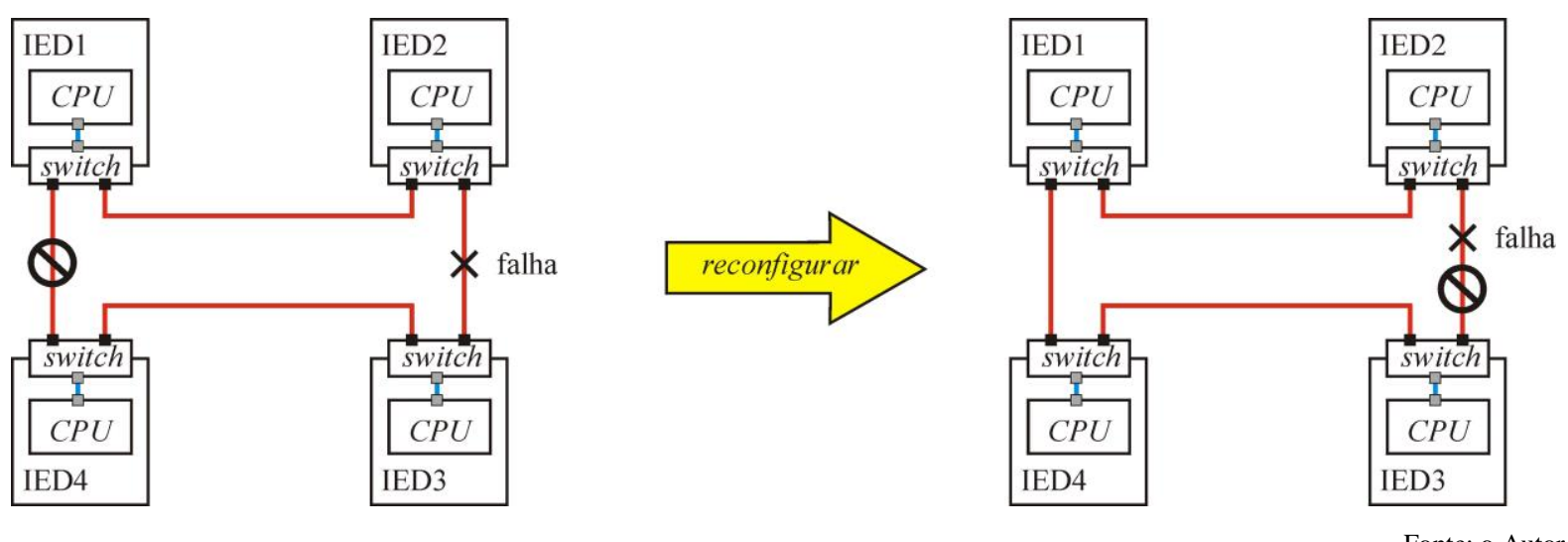

Embora esta solução ofereça uma confiabilidade aceitável na operação de um barramento de subestação sem grandes prejuízos (desde que o recovery time não seja elevado), o não funcionamento da rede por um período de dezenas de milisegundos é inaceitável para a operação de um barramento de processos, pois implica numa quantidade elevada de amostras não enviadas. Com o objetivo de solucionar este problema, outras arquiteturas foram estudadas. As mais promissoras são baseadas nas redundâncias de barramento oferecidas pelo Protocolo PRP (Parallel Redundancy Protocol) e pelo Protocolo HSR (High availability Seamless Redundancy Protocol) [9] [11], descritos na Norma IEC 62439-3 [13]. A Figura 28, a seguir, ilustra o funcionamento do Protocolo PRP.

Figura 28 - Exemplo de arquitetura redundante utilizando o Protocolo PRP.

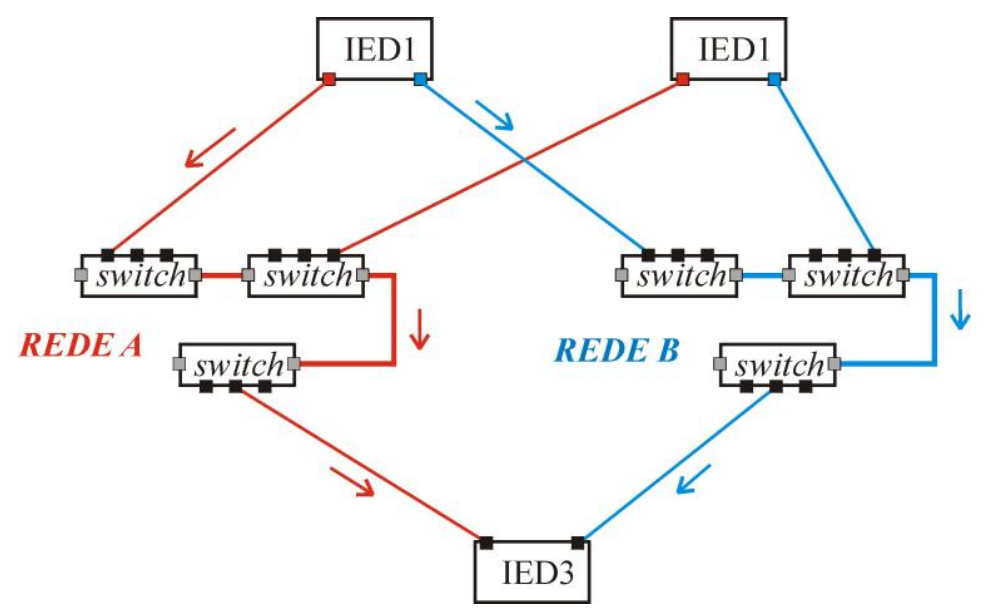

Fonte: o Autor

Nesta configuração, o barramento de rede, que pode ser uma conexão Ethernet simples com switches na configuração estrela, é duplicado (neste exemplo, nas redes A e B), e cada IED possui duas interfaces de rede com o mesmo endereço MAC, cada uma conectada em um dos barramentos de rede. Supondo que o IED1 deseje publicar uma SV Message e que o IED3 esteja inscrito para receber esta mensagem, primeiramente um cabeçalho do Protocolo PRP é 
adicionado após o conjunto de bytes referentes ao APDU, conforme ilustra a Figura 29. Neste cabeçalho é inserido um número de identificação da mensagem no campo Sequence number. Seu objetivo é permitir o gerenciamento da informação quando esta chegar nos IEDs programados para tratá-la. A seguir, o IED1 envia a mesma mensagem simultaneamente nas duas interfaces. Se não apresentar nenhuma irregularidade, a primeira mensagem que chegar no IED3 será aceita e a mensagem seguinte será desprezada. Para aumentar ainda mais a confiabilidade, propõe-se que, fisicamente, as conexões dos dois barramentos de rede sejam implementadas por diferentes caminhos dentro da subestação. É importante observar que o acréscimo de cabeçalho do Protocolo PRP eleva em 6 octetos o tamanho máximo possível do frame Ethernet (de 1521 octetos para 1527 octetos), o que exige o acréscimo correspondente no buffer de memória interna das interfaces de rede para que não ocorra perda dos últimos octetos por estouro de memória. 
Figura 29 - Frame com cabeçalho do Protocolo PRP.

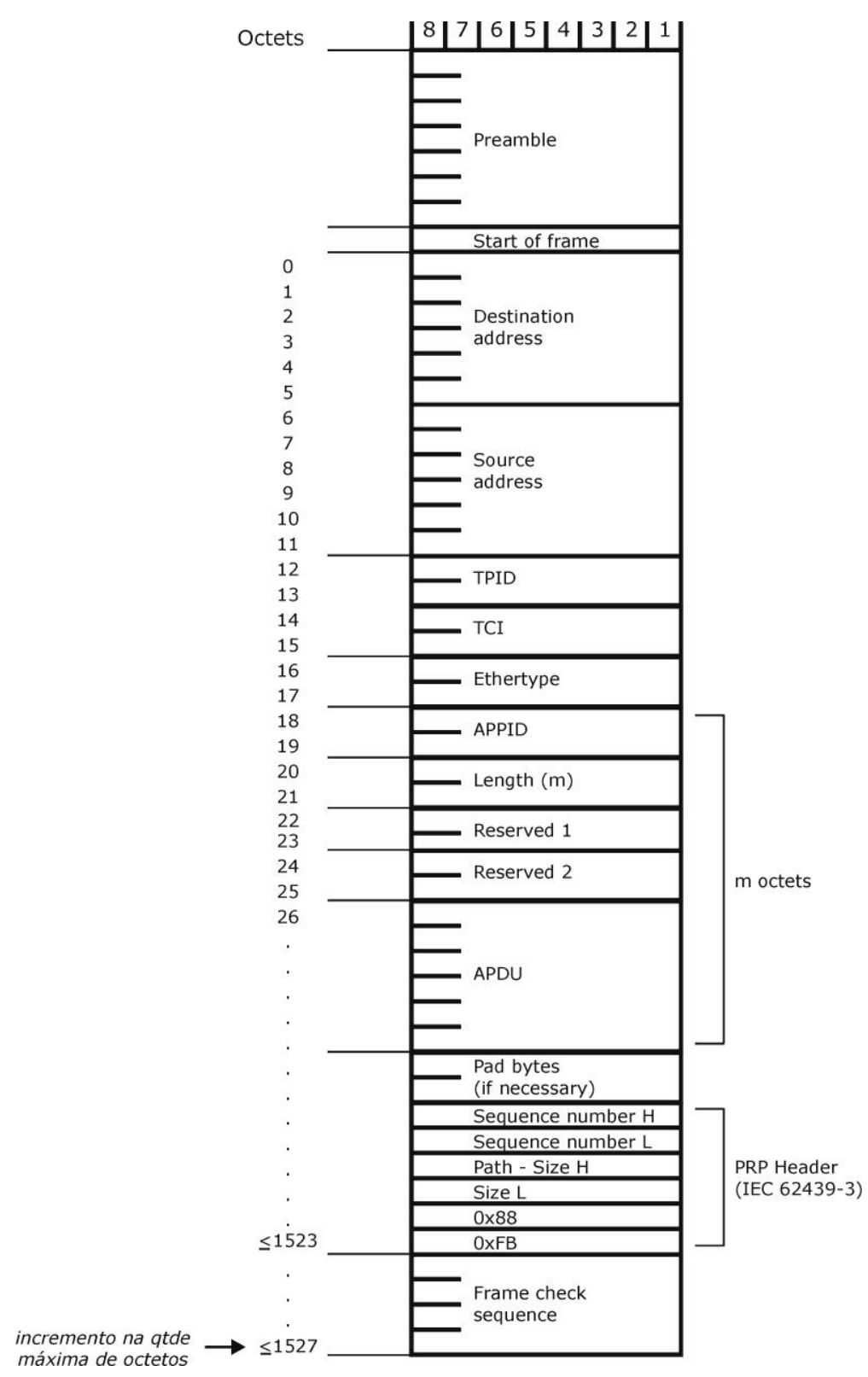

Fonte: o Autor Esta configuração oferece uma série de vantagens, como maior versatilidade para gerenciar o tráfego de rede (por exemplo, direcionando mensagens através de programação dos switches), simplicidade de arquitetura da rede e recovery time zero (não existe tempo de reconfiguração da rede caso ocorra uma falha em algum ponto de uma das redes). Em contrapartida, é necessário duplicar toda a estrutura de rede, o que acaba por elevar seu custo de implementação.

O Protocolo HSR trabalha na configuração em anel, conforme se observa na Figura 30: 


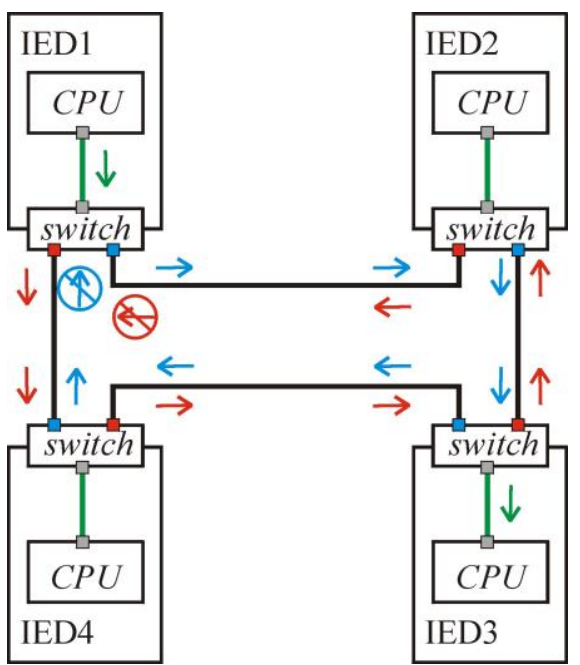

Fonte: o Autor

Supondo que o IED1 esteja publicando uma SV Message e que o IED3 esteja inscrito para receber esta mensagem, primeiramente, insere-se um cabeçalho do protocolo HSR, conforme ilustrado na Figura 31. Neste cabeçalho também existe um campo sequency number responsável por identificar a mensagem, com objetivo de anular sua circulação em loop no anel. A seguir, a mensagem é enviada simultaneamente em ambas as interfaces de rede, neste exemplo, representadas pelas cores vermelha e azul. A mensagem enviada pela interface vermelha do IED1 percorrerá a rota vermelha descrita até que retorne à interface de rede azul do IED1. Ao recebê-la, o Protocolo HSR analisa o cabeçalho, percebe que a mensagem está retornando e cessa a sua propagação, evitando que ela circule em loop. A mesma dinâmica ocorre com a mensagem enviada pela interface de rede azul.

Esta configuração oferece como vantagens recovery time zero e uma estrutura de rede com menor tamanho e custo, se comparado a uma estrutura de rede com Protocolo PRP que desempenhe a mesma função. Em contrapartida, ela requer a incorporação de um hardware de switch no IED, o que pode aumentar a latência na transmissão de mensagens pelo barramento de processo (pois uma mensagem terá de passar por diversos IEDs até chegar ao seu destino) e pode elevar o tráfego da rede devido à dinâmica de fluxo das mensagens em anel nos dois sentidos (sem possibilidade de redirecionamento de tráfego), o que deve ser levado em consideração no dimensionamento da rede. 


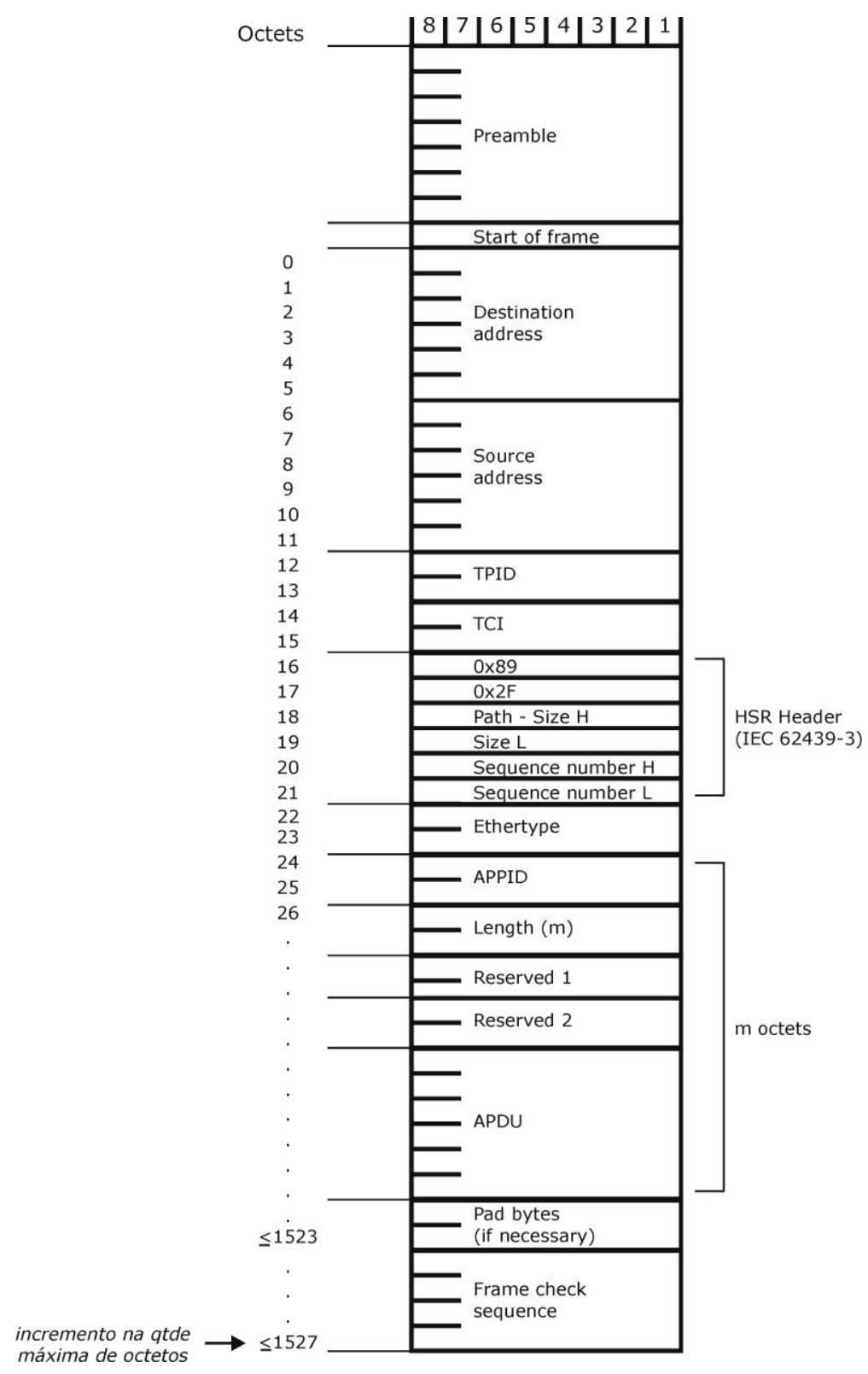

Fonte: o Autor Até o presente momento, a Norma IEC 61850-9-2 Ed2.0 [21] já incorporou em seu texto a recomendação pelo uso dos Protocolos PRP e HSR para a redundância do barramento de processo. Também foi elaborado o Technical Report IEC/TR 61850-90-4 [12], no qual é sugerido para os barramentos de processo recovey time igual a $0 \mathrm{~ms}$.

Ainda com relação ao aspecto de confiabilidade do barramento de processo, outro importante comentário a ser feito é sobre o tratamento que deve ser aplicado quando, por alguma razão, mesmo com a redundância do barramento de rede, ocorra a perda de alguma SV Message (por exemplo, devido a uma falha no processamento da mensagem em mais de um switch), conforme se observa na Figura 32. Neste exemplo, o IED3 inscrito para receber a mensagem 
publicada pelo IED1 terá em seu buffer interno de amostras uma lacuna sem o valor desta amostra. Atualmente, a forma como este problema será tratado não é contemplada pela Norma IEC 61850, ficando a cargo do desenvolvedor do IED determinar quais providências serão adotadas.

Figura 32 - Perda de amostra no barramento de processo

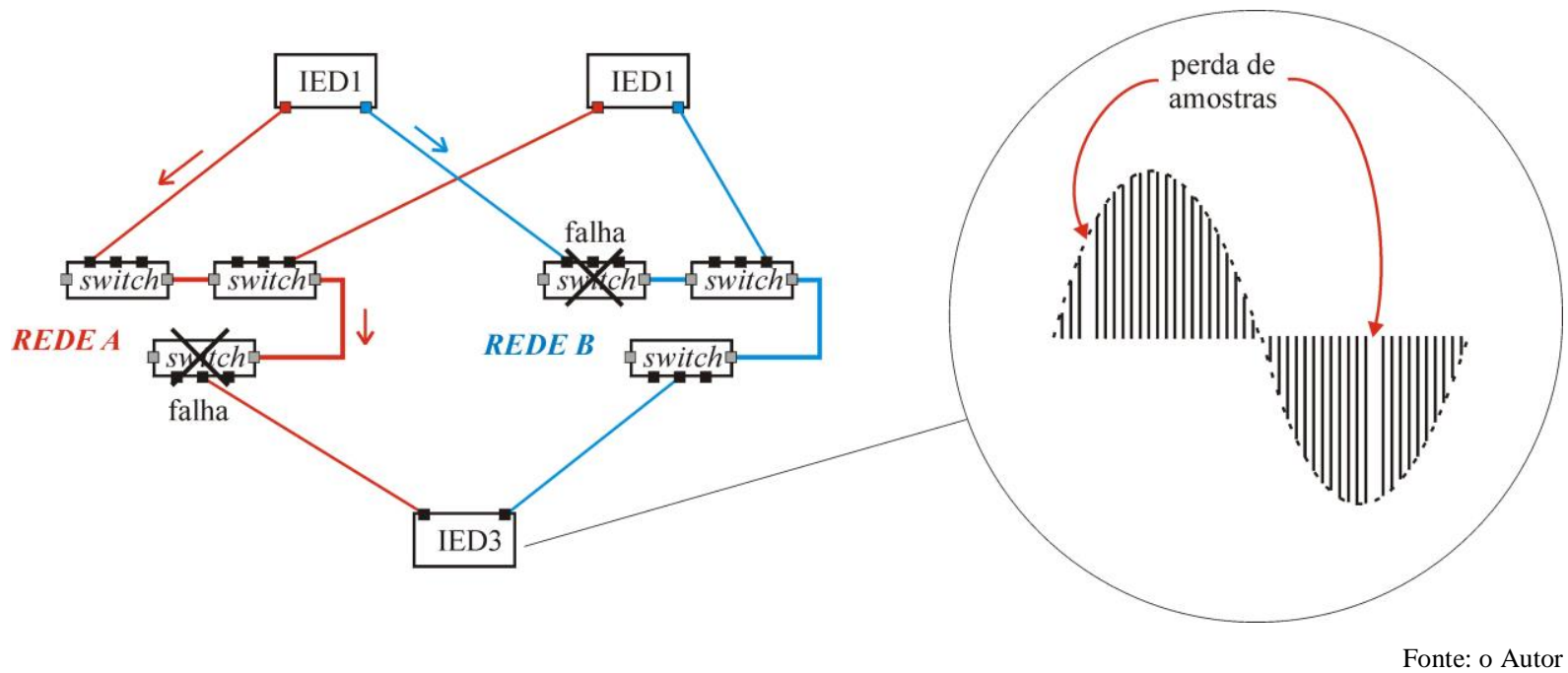

\subsection{Sincronismo de tempo através do barramento de rede}

O processo de sincronismo de tempo se refere à forma pela qual os IEDs que compõem um SAS irão realizar o sincronismo de seus relógios internos. Na maior parte das subestações atuais existe um barramento de rede específico para este fim, que segue o padrão IRIG-B ou o padrão 1 pulso por segundo (1pps). O sinal de sincronismo é gerado por um determinado dispositivo que, normalmente, utiliza um receptor de sinal GPS via satélite para obter sua referência de base de tempo. Cada dispositivo que necessite ser sincronizado possui uma entrada de rede específica para tal fim, de acordo com o padrão adotado.

Em sua primeira versão, a Norma IEC 61850 propôs a possibilidade de executar este processo de sincronismo utilizando os barramentos de subestação e de processo em conjunto com o Protocolo SNTP (Simple Network Time Protocol). Após sua edição, verificou-se que a precisão de tempo oferecida pelo protocolo SNTP, na ordem de alguns milissegundos, não atendia algumas aplicações do SAS, como os registros de oscilografia, a transmissão de valores amostrados no barramento de processo através da IEC 61850-9 e os sincrofasores. 
Os registros de oscilografia são muito utilizados para análise de falhas. Em algumas situações, é necessária a análise comparativa de registros de oscilografia de diversos pontos de um sistema de potência, os quais, portanto, necessitam ser sincronizados numa mesma base de tempo com extrema precisão.

Para a transmissão de valores amostrados, cada amostra precisa conter a informação do instante em que foi feita a amostragem para que esta possa ser precisamente comparada com amostras obtidas de diferentes pontos do sistema de potência em relação a uma mesma base de tempo. Por exemplo, em uma situação onde existam TCs instalados em ambos os enrolamentos de um transformador de potência e deseja-se executar uma função de proteção diferencial, caso as amostras do TC conectado ao primário apresentem um atraso de tempo da ordem de alguns milissegundos em relação ao TC conectado ao secundário, a proteção poderá atuar indevidamente.

O conceito de sincrofasores é baseado na medição precisa dos fasores de tensão e de corrente em pontos distintos de um sistema elétrico, o que torna possível a implementação de uma série de lógicas de controle e proteção (por exemplo, análise de estabilidade do sistema elétrico, detecção de ilhamento e funções de proteção diferencial de barramento de retaguarda). A medição é feita através de equipamentos específicos, chamados de Phasor Measurement Units (PMUs), que necessitam ser sincronizados com extrema precisão em uma mesma base de tempo.

Para a solução de algumas destas questões, o sincronismo individual de cada Merging Unit foi proposto inicialmente pelo documento IEC 61850-9-2LE através de uma rede específica operando com o formato 1pps, conforme ilustra a Figura 33. Desta forma, todos os dispositivos passam a ser sincronizados com precisão na ordem de microssegundos, mas ainda seria necessária a instalação de uma rede específica para tal finalidade.

\section{Figura 33 - Barramento de lpps utilizado para sincronismo de tempo}

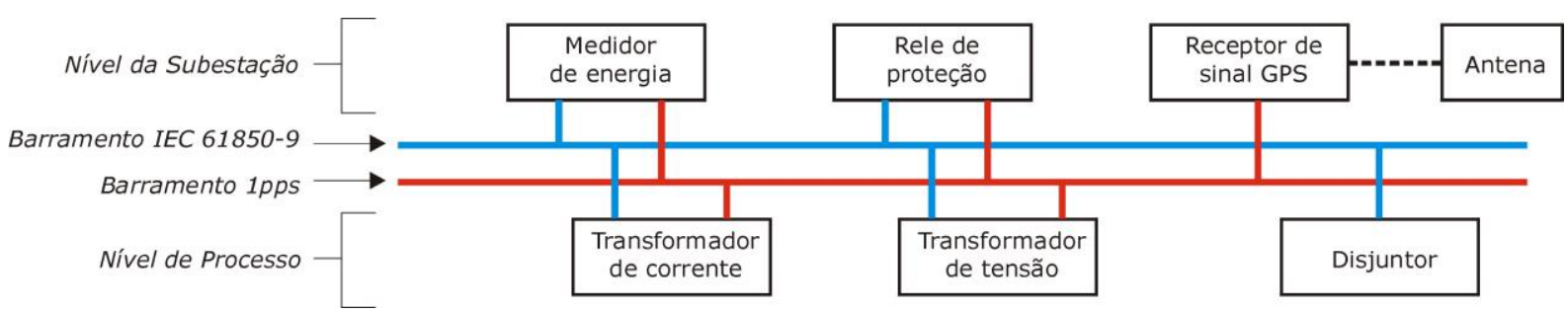

Fonte: o Autor

Mais recentemente, está em análise a proposta de utilização da Norma IEEE 1588v2 como 
padrão a ser adotado para o sincronismo de tempo. A Norma IEEE 1588 teve sua primeira versão editada em 2002, tendo sido melhorada em sua segunda versão editada em 2008 (conhecida como IEEE 1588v2) e posteriormente foi adotada como referência para a elaboração da Norma IEC 61588. Ela estabelece as regras para a operação do Protocolo PTP (Precision Time Protocol), cujo objetivo é prover mecanismos capazes de sincronizar, na ordem de até algumas dezenas de nanossegundos, o relógio interno de diversos dispositivos conectados a uma rede. Sua arquitetura trouxe uma série de vantagens com relação aos principais métodos de sincronismo de tempo utilizados até então, o que tem motivado sua implementação nas mais diversas áreas, como telecomunicações, automação e computação.

O processo de sincronismo através do Protocolo PTP é composto por duas fases: a primeira é o estabelecimento da hierarquia master-slave entre os dispositivos e seus ports de comunicação, e a segunda é a troca de mensagens para o sincronismo de tempo.

A primeira fase pode ser observada na Figura 34, apresentada a seguir.

Figura 34 - Estabelecimento da hierarquia mestre-escravo pelo Protocolo PTP

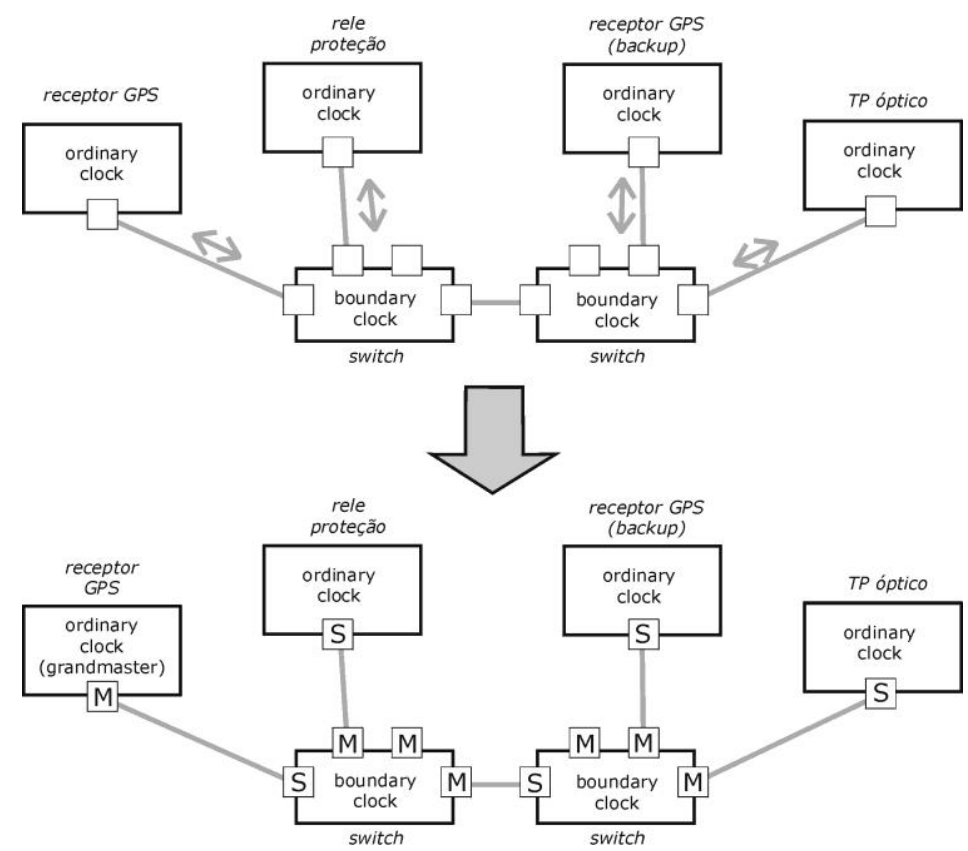

Fonte: o Autor

Cada dispositivo mantém internamente um dataset contendo vários parâmetros que expressam as características de seu relógio interno, como sua qualidade, sua estabilidade e seu nome de identificação. Nesta primeira fase, logo após a energização do sistema, cada dispositivo envia uma mensagem broadcast contendo seu dataset, denominada mensagem Announce (representada pelas setas bidirecionais), e receberá outras mensagens Announce contendo os 
datasets de outros dispositivos. Cada port de cada dispositivo, com base nos datasets recebidos, irá processar o Algoritmo BMC (Best Master Clock Algorithm). Primeiramente, avalia-se qual dispositivo possui a capacidade de ser a melhor referência de tempo. Este dispositivo recebe a denominação de grandmaster clock da rede e, geralmente, possui relógio interno com exatidão elevada constituído por oscilador com cristal de baixo erro, baixa deriva térmica e com sincronismo via satélite ligado ao Sistema de Posicionamento Global (GPS Global Positioning System). Como o algoritmo processado é o mesmo para todos os dispositivos, espera-se que eles cheguem à mesma conclusão, sem que seja necessário o envio de novas mensagens de negociação entre os dispositivos. Em seguida, cada port cruza as informações sobre qual dispositivo é o grandmaster clock e sobre quais mensagens Announce foram transmitidas e recebidas. Se ele transmitiu a mensagem Announce contendo o dataset do grandmaster clock, ele entra no estado de master clock daquele trecho (path) de rede e será a referência de tempo deste path. Caso ele tenha recebido a mensagem Announce contendo o dataset do grandmaster clock, ele entra no estado de slave clock daquele path e terá seu relógio interno sincronizado com relação ao master clock daquele path. Isto acaba por estabelecer uma hierarquia master-slave entre todos os ports de todos os dispositivos da rede. Este processo também é repetido tanto no momento de inclusão de um novo dispositivo com características que o habilitem a ser grandmaster clock, quanto no momento de exclusão de um dispositivo grandmaster clock.

$\mathrm{Na}$ segunda fase, realiza-se a troca de mensagens para sincronizar os relógios internos dos dispositivos. Neste processo, é necessário conhecer o instante no qual uma determinada mensagem foi transmitida e recebida em cada dispositivo. O registro deste instante é chamado timestamp. A Norma IEEE 1588v2 define duas classes de mensagens:

1) event messages: mensagens de evento que requerem a geração de timestamps precisos nos momentos de transmití-las e de recebê-las. São elas as mensagens Sync, Delay_Req, Pdelay_Req e Pdelay_Resp.

2) general messages: mensagens de uso geral que não requerem a geração de um timestamp preciso. São elas as mensagens Announce, Follow_Up, Delay_Resp, Pdelay_Resp_Follow_Up, Management e Signaling.

A Norma IEEE 1588v2 também define cinco tipos de dispositivos:

1) ordinary clock: possui somente um port, que pode assumir o estado de master clock ou de 
slave clock. Exemplos: receptor GPS, transformadores de instrumentos, relé de proteção, medidor, etc.;

2) boundary clock: é constituido por vários ports, cada um se comportando como o port de um dispositivo ordinary clock. Possui um relógio interno (local clock) que deve ser sincronizado. As mensagens recebidas por um port, relativas à sincronismo, definição da hierarquia master slave ou com fins de sinalização, não são encaminhadas para os demais ports; este encaminhamento acontece somente com as mensagens de gerenciamento. Geralmente é um elemento da rede, e não um dispositivo a ele conectado, para trocar dados e executar alguma lógica de automação. Exemplos: switches.

3) end-to-end transparent clock: encaminha todas as mensagens, sendo que, para as mensagens de evento, o resident time (tempo necessário para a mensagem atravessar o transparent clock) é contabilizado e registrado no campo correctionField das mensagens. Exemplos: bridges e roteadores.

4) peer-to-peer transparent clock: operam de forma semelhante ao dispositivo end-to-end transparent clock, com as seguintes diferenças:

- executa em cada port o peer delay mecanism, que tem por objetivo medir o delay de propagação de mensagens em um determinado link;

- somente corrige e encaminha as mensagens Sync e Follow_Up, sendo que, nesta correção, o campo correctionField é contabilizado com o resident time e o link delay do port receptor da mensagem Sync.

5) management node: dispositivo de gerenciamento da rede, geralmente utilizado para manutenção ou monitoração. Exemplos: notebook e interface homem máquina.

Seguindo o exemplo da Figura 34, após a definição da hierarquia master-slave, cada par de dispositivos, em cada path, irá executar o procedimento básico para sincronismo de tempo apresentado na Figura 35. Dois atrasos precisam ser compensados:

- o atraso referente à diferença de tempo entre o relógio interno do master clock e o relógio interno do slave clock (representado por Tms);

- o atraso referente à propagação da mensagem no path: do master clock para o slave clock 
(representado por Tmsd) e do slave clock para o master clock (representado por Tsmd).

Figura 35 - Procedimento básico para sincronismo de tempo utilizando o Protocolo PTP

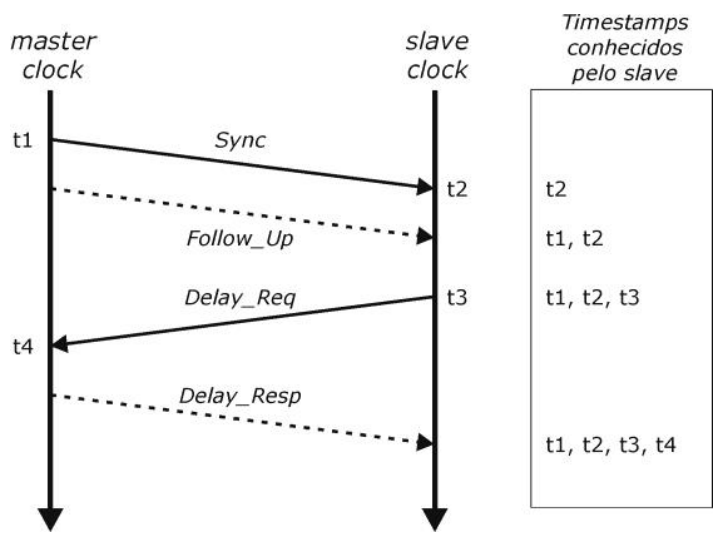

Fonte: o Autor

O procedimento básico para sincronismo de tempo compreende a seguinte sequência:

1) O master clock envia para o slave clock, no instante $t 1$, uma mensagem Sync. O timestamp t1 é armazenado. Esta mensagem chegará no slave clock no instante t2. Neste momento, o slave clock armazena o timestamp t2.

2) Em seguida, o master clock envia uma mensagem Follow_Up para o slave clock, contendo o timestamp t1. Assim que receber esta mensagem, o slave clock, de posse dos timestamps $t 1$ e $t 2$, calcula Tmsd de acordo com a Equação (1), demonstrada a seguir:

$$
\operatorname{Tmsd}=(\mathrm{t} 2+\mathrm{Tms})-\mathrm{t} 1
$$

3) Posteriormente, o slave clock envia para o master clock, no instante t3, uma mensagem Delay_Req. O timestamp t3 é armazenado. Esta mensagem chegará ao master clock no instante $\mathrm{t} 4$, gerando o timestamp $\mathrm{t} 4$.

4) Finalizando, o master clock envia o timestamp t4 para o slave clock através de uma mensagem Delay_Resp. Assim que receber esta mensagem, o slave clock, de posse dos timestamps $t 3$ e $t 4$, calcula Tsmd através da Equação (2) abaixo:

$$
\text { Tsmd }=\mathrm{t} 4-(\mathrm{t} 3+\mathrm{Tms})
$$

Admitindo que o tempo de transmissão de uma mensagem do master clock para o slave clock seja o mesmo que do slave clock para o master clock, obtemos Td (delay para transmissão da mensagem no path) através da Equação (3), abaixo: 


$$
\mathrm{Td}=\mathrm{Tmsd}=\mathrm{Tsmd}
$$

Substituindo a Equação (3) nas Equações (1) e (2) e somando-as, obtemos a Equação (4):

$$
\begin{gathered}
\mathrm{Td}=\mathrm{t} 2-\mathrm{t} 1+\mathrm{Tms} \\
\mathrm{Td}=\mathrm{t} 4-\mathrm{t} 3-\mathrm{Tms}+ \\
\mathrm{Td}=0,5 \times[(\mathrm{t} 2-\mathrm{t} 1)+(\mathrm{t} 4-\mathrm{t} 3)]
\end{gathered}
$$

Finalmente, podemos calcular $T m s$ substituindo $T d$ tanto na Equação (1), quanto na Equação (2). Por exemplo, substituindo a Equação (4) na Equação (1), obtemos Tms na Equação (5), abaixo:

$$
\text { Tms }=0,5 \times[\mathrm{t} 1-\mathrm{t} 2+\mathrm{t} 4-\mathrm{t} 3]
$$

Com o valor de Tms calculado, o passo seguinte é corrigir o relógio interno do slave clock. Neste ponto, a norma descreve duas situações:

1) caso a diferença de tempo seja elevada (por exemplo, superior a 1 segundo), aplica-se uma correção absoluta no relógio interno;

2) caso a diferença de tempo seja pequena, aplica-se uma mudança percentual no oscilador do relógio interno do slave clock, de forma a sincronizá-lo através da sintonia de seu oscilador. Segundo a IEEE 1588v2, um loop de controle deve ser implementado, onde o sinal de erro é obtido através da diferença entre os relógios internos do master clock e do slave clock (Tms) e é aplicado no ajuste do oscilador através de uma lógica de controle, conforme observamos na Figura 36. A lógica que vem oferecendo melhores resultados utiliza o controle ProporcionalIntegral-Derivativo (PID).

Figura 36 - Loop de controle especificado pela IEEE1588

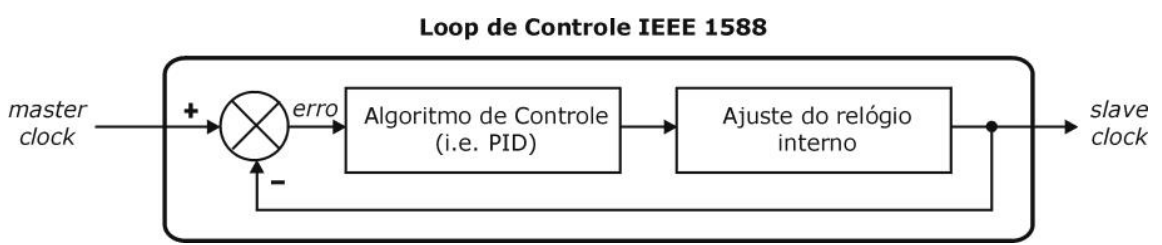

Fonte: o Autor Ainda com relação à troca de mensagens, a Norma IEEE 1588v2 especifica a possibilidade de eliminar as mensagens enviadas em sequência para transmissão do timestamp da mensagem anterior, desde que o dispositivo possua meios para tanto. Foram definidos dois dispositivos distintos, conforme Figura 37: 
two-step clock

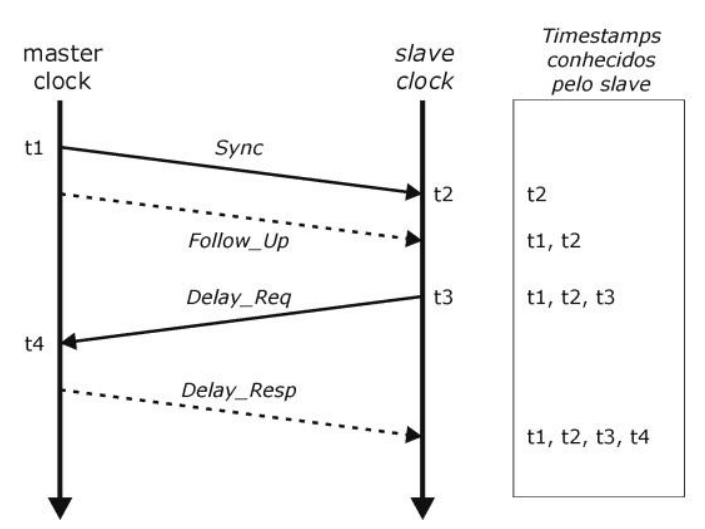

one-step clock

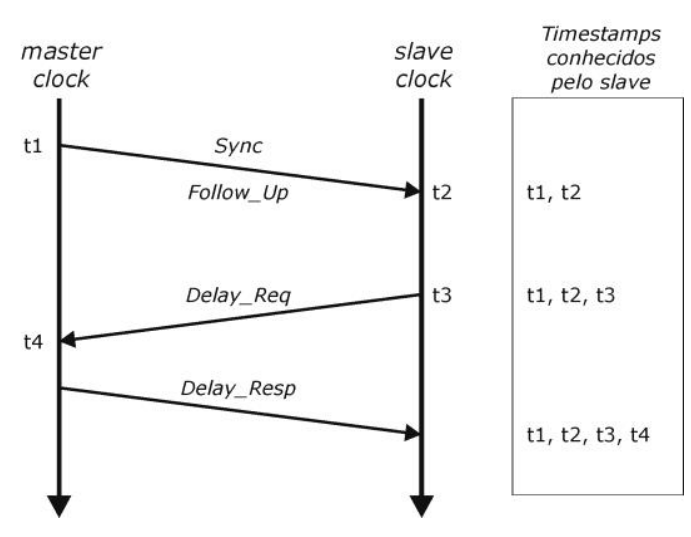

Fonte: o Autor

a) two-step clock: é um dispositivo que, para gerar e transmitir o timestamp de sua event message (neste exemplo, a mensagem Sync), utiliza primeiramente uma event message e, na sequência, uma general message (neste exemplo, a mensagem Follow_Up).

b) one-step clock: é um dispositivo capaz de, no momento de transmissão de sua event message (neste exemplo, a mensagem Sync), ler seu timestamp e inserí-lo na própria event message.

A Norma IEEE 1588v2 também prevê também que os dispositivos possam medir o atraso de propagação das mensagens em um determinado path através de dois mecanismos, de acordo com a Figura 38.

a) delay request-response mechanism: através de mensagens Sync (enviadas pelo master clock) e Delay_Req (enviadas pelo slave clock), o slave clock calcula o atraso de propagação;

b) peer delay mechanism: através de mensagens Pdelay_Req e Pdelay_Resp, onde tanto o master clock quanto o slave clock podem iniciar o processo, permitindo que ambos os dispositivos tenham a informação dos atrasos em seus paths utilizando somente duas mensagens, o que auxilia na redução do tempo em uma eventual reconfiguração da rede (caso a hierarquia master slave se altere) e na redução do tráfego de mensagens. 
Figura 38 - Mecanismos para medição do tempo de propagação em um path

delay request-response mechanism

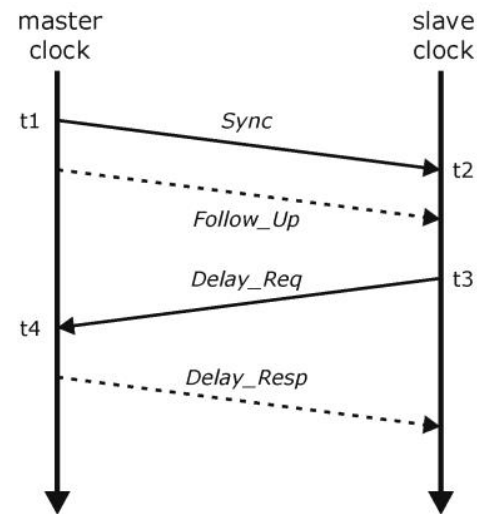

peer delay mechanism

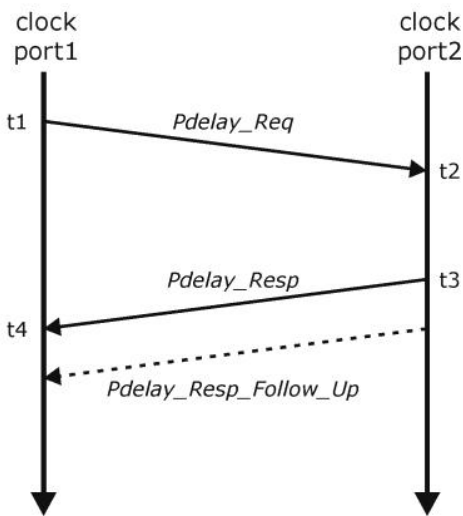

Fonte: o Autor

A geração dos timestamps, segundo a Norma IEEE 1588v2, é ilustrada pela Figura 39, a seguir.

Figura 39 - Pontos onde podem haver geração do timestamp no Protocolo PTP.

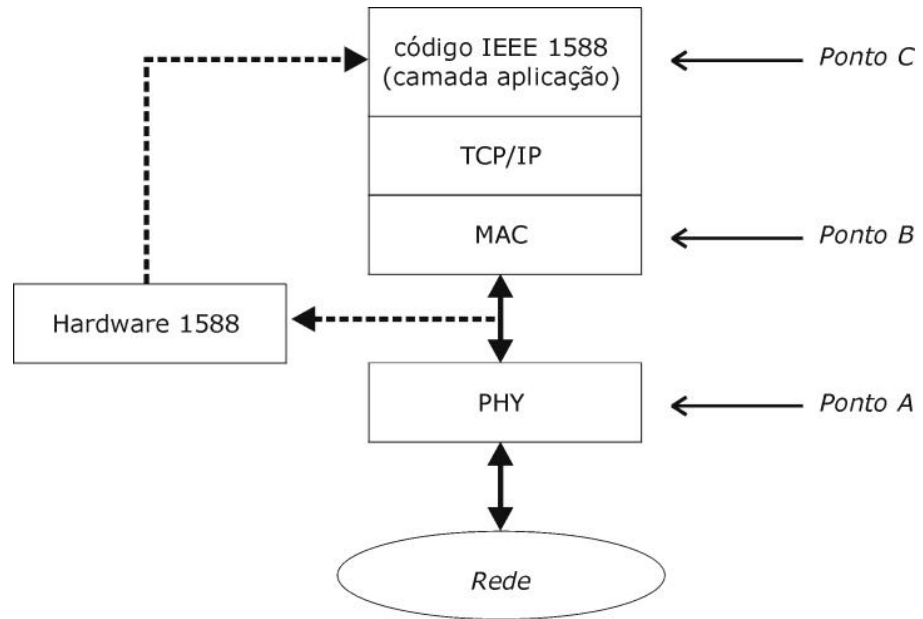

Fonte: o Autor

A implementação de uma interface de rede Ethernet exige, basicamente, três blocos: um bloco PHY (responsável pela geração do sinal físico que irá transmitir os bits que compõem uma mensagem, geralmente constituído por um conjunto formado por um circuito integrado e componentes magnéticos presentes no conector padrão RJ ou por um conjunto formado por circuito integrado e componentes optoeletrônicos, transmissor/receptor, para fibra óptica), um bloco MAC, responsável, dentre várias funções, por tratar o endereço MAC (Media Access Control) e a checagem de frame $\mathrm{CRC}$, e por um processador, que implementa a pilha do Protocolo PTP.

Como mostrado na Figura 39, a geração do timestamp pode ser realizada em três pontos da 
interface Ethernet:

a) Ponto A: através de um hardware específico junto ao bloco PHY, que oferece a melhor precisão (<10 ns) [23];

b) Ponto B: através de um hardware específico junto ao bloco MAC, que oferece uma precisão um pouco inferior (entre $10 \mathrm{~ns}$ e $10 \mu \mathrm{s}$ ) devido à imprecisão dos padrões utilizados para comunicação entre o bloco MAC e o processador (i.e. padrão MII, padrão RMII, etc.);

c) Ponto $C$ : através do firmware do Protocolo PTP, o que oferece menor precisão (>10 $\mu$ s).

O ponto de referência de uma mensagem onde se realiza a geração do timestamp está localizado entre o último bit do preâmbulo e o primeiro bit do header do frame Ethernet.

A Norma IEEE 1588v2 foi desenvolvida de forma a atender amplamente diversas aplicações que exigem sincronismo de tempo. Com o objetivo de auxiliar sua implementação nos SASs, foi elaborada a Norma IEEE C37.238 [24] [25], que contém um subset de parâmetros e de opções do Protocolo PTP, dentre os quais podem-se destacar:

a) permissão do uso de dispositivos two-step clock e one-step clock, com preferência para os dispositivos one-step clock;

b) intervalo fixo de $1 \mathrm{~s}$ entre as mensagens Sync;

c) permissão do uso do peer delay mechanism para medição de atraso em um path;

d) na primeira etapa, somente os dispositivos com capacidade para se tornarem grandmaster clock enviam mensagens Announce para estabelecimento da hierarquia master slave;

e) definição da performance na distribuição do sincronismo de tempo, com base em um cenário de 16 hops (qualquer conexão entre dispositivos de uma rede) com sobrecarga de $80 \%$ da rede, conforme ilustra a Figura 40 . Da precisão total de $\pm 1 \mu \mathrm{s}$, são permitidos para o grandmaster clock até $\pm 200 \mathrm{~ns}$, e para cada dispositivo de rede, até $\pm 50 \mathrm{~ns}$, restando até $\pm 50 \mathrm{~ns}$ para propagação do sinal nos hops. A Norma IEEE C37.288 define que o dispositivo final (neste exemplo, o IED que fará uso de seu clock sincronizado para executar função de automação/proteção do SAS) tem sua precisão estabelecida em função da performance de sua aplicação. 
Figura 40 - Exatidões ao longo do processo de distribuição do sinal de sincronismo no Protocolo PTP, de acordo com a Norma IEEE C37.238

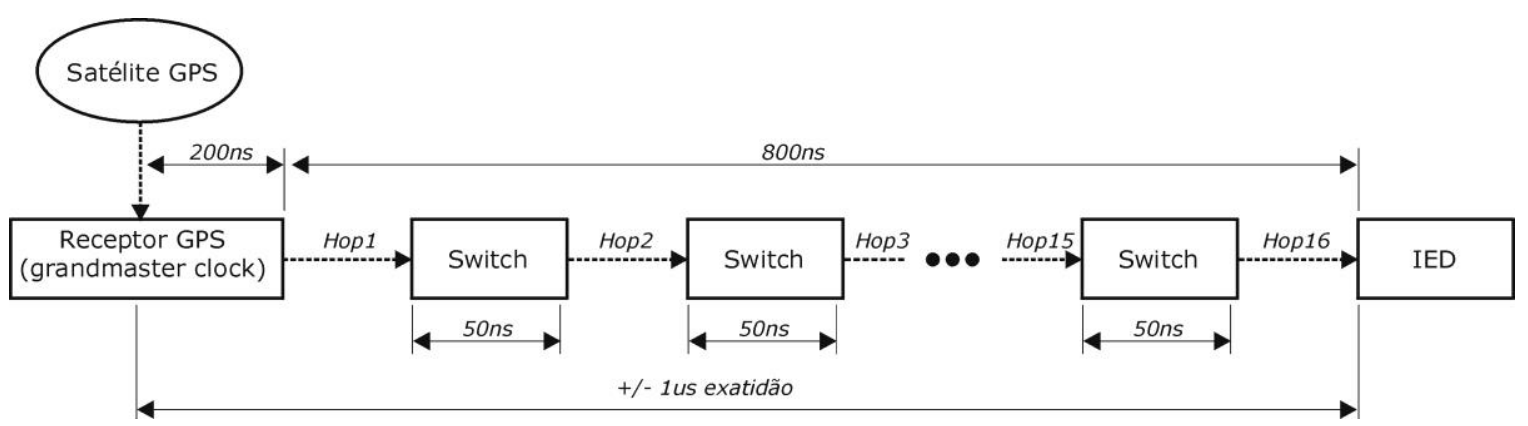

Fonte: o Autor

f) tratativas para conversão das escalas de tempo, pois muitos dispositivos presentes nos SASs atuais trabalham com escala de tempo no padrão UTC (Universal Time Coordinated), e a Norma IEEE 1588v2 utiliza como escala de tempo o padrão TAI (Temps Atomique International), exigindo a compensação de alguns aspectos, tais como a diferença de epochs (data definida pelo padrão como início da contagem de tempo) e os leap seconds (saltos de segundo para corrigir a diferença do tempo de rotação do planeta Terra com relação ao tempo obtido dos relógios atômicos de Césio).

Alguns aspectos, tais como a segurança do receptor GPS (comportamento frente a erros do sinal GPS emitidos pelo satélite em órbita), a possibilidade de distribuição do sincronismo de tempo via rede wireless (rede sem fio) e a segurança cibernética, foram apontados pela Norma IEEE C37.238 como tópicos a serem discutidos no futuro.

A Norma IEC 61850-5 estabelece classes de performance para as SV Messages enviadas no barramento de processo, conforme demonstrado na Tabela 2. Por exemplo, para um TI de performance class T4, medindo um sinal com frequência nominal de $50 \mathrm{~Hz}$, seu relógio interno deve ter uma precisão de $\pm 4 \mu \mathrm{s}$, o que equivale, aproximadamente, a um erro de 4 minutos de grau em sua fase.

Tabela 2 - Classes de performance para sincronismo de tempo, de acordo com a Norma IEC 61850-5

\begin{tabular}{|c|c|c|c|c|c|c|}
\hline $\begin{array}{l}\text { Time performance } \\
\text { class }\end{array}$ & Accuracy $(\mu s)$ & Refe & ice & $\begin{array}{c}\text { Phase angle } \\
50 \mathrm{~Hz}\end{array}$ & $\begin{array}{c}\text { Phase angle } \\
60 \mathrm{~Hz}\end{array}$ & $\begin{array}{l}\text { Fault location } \\
\text { (m) }\end{array}$ \\
\hline T3 & \pm 25 & P1 & & 27 & 32 & 7500 \\
\hline $\mathrm{T} 4$ & \pm 4 & $\mathrm{P} 2$ & M1 & 4 & 5 & 1200 \\
\hline T5 & \pm 1 & P3 & $\mathrm{M} 2 / 3$ & 1 & 1 & 300 \\
\hline
\end{tabular}

Por fim, a Norma IEC 61869-9, que se encontra em fase final de elaboração, define conceitos 
adicionais referentes ao processo de sincronismo. Dentre os conceitos definidos, o autor destaca os seguintes aspectos:

1) é preferível que o sincronismo seja feito pelo próprio barramento de rede através do Protocolo PTP; o formato 1pps pode ser disponibilizado para dispositivos já instalados;

2) a precisão de sincronismo de tempo desejada é de $\pm 1 \mu \mathrm{s}$, ou melhor (classe de performance T5, segundo a Norma IEC 61850-5);

3) são definidos dois tipos de estados para os dispositivos responsáveis por estabelecer a base de tempo utilizada como referência para sincronismo de tempo:

- global area clock: dispositivo cuja base de tempo fornecida está sincronizada com as bases de tempo definidas pelos laboratórios que mantém relógios segundo o padrão TAI ou segundo o padrão UTC. Como exemplos, podem ser citados os dispositivos sincronizados através do sistema GPS e os servidores de tempo do NIST (National Institure of Standards and Technology). Portanto, qualquer SV Message gerada a partir de um IED sincronizado por um dispositivo global area clock está sincronizada com qualquer outra SV Message também sincronizada por um dispositivo global area clock.

- local area clock: dispositivo cuja base de tempo fornecida não está sincronizada com relógios segundo o padrão TAI ou o padrão UTC. Portanto, um IED sincronizado por um local area clock pode apresentar um offset no seu relógio interno, se comparado com outro IED sincronizado por um global area clock. Em contrapartida, não apresentará nenhum offset se comparado com outro IED sincronizado pelo mesmo local area clock.

Desta forma, caso um receptor GPS seja utilizado como base de tempo para uma determinada rede, numa situação onde a recepção do sinal de satélite não apresente problemas, ele se encontraria no estado global area clock. Já numa situação onde, por exemplo, sua antena apresentasse problemas, ele se encontraria no estado local area clock.

A Norma IEC 61869-9 prevê ainda uma metodologia para que os IEDs sejam capazes de identificar o estado em que se encontra o dispositivo que fornece sua base de tempo. Caso o padrão adotado seja o pulso de $1 \mathrm{pps}$, ele obedece ao seguinte formato, representado pela Figura 41, a seguir. 
Figura 41 - Forma de onda, no padrão 1pps, gerado pelo dispositivo que define a base de tempo

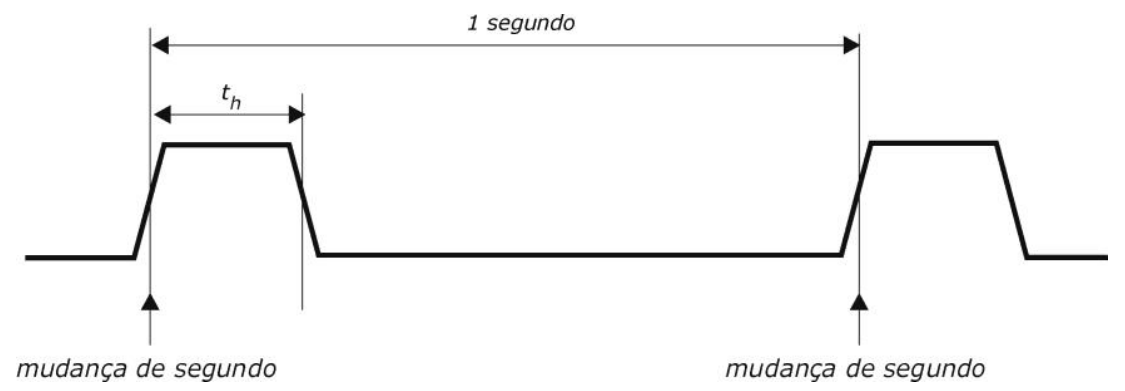

Fonte: o Autor Numa situação onde o dispositivo seja um global master clock, $t_{h}$ terá de ser superior a $5 \mu \mathrm{s}$. Caso o dispositivo seja um local area clock, $t_{h}$ terá de ser inferior a $1,1 \mu \mathrm{s}$. O intervalo de tempo entre $1,1 \mu$ s e $5 \mu$ s não deve ser utilizado.

Em sistemas onde a distribuição do sinal de sincronismo utilize o padrão definido pelo Protocolo PTP, as mensagens de sincronismo de tempo contêm um campo timeTraceable cujo valor será TRUE quando o dispositivo for um global master clock, e será FALSE quando o dispositivo for um local area clock.

4) um IED pode informar em sua SV Message, através do atributo SmpSynch, o estado em que se encontra o sincronismo de tempo da amostra enviada. $\mathrm{O}$ seu valor depende do modo em que o IED está operando, conforme ilustra a Figura 42.

Figura 42 - Definição do atributo SmpSynch, de acordo com o modo de operação do IED

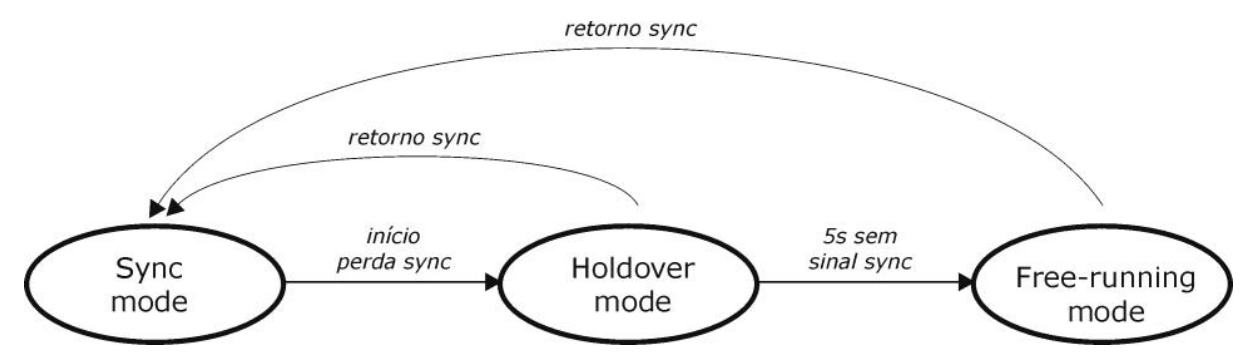

Fonte: o Autor - Sync mode: neste modo, o IED encontra-se com seu relógio interno sincronizado com a base de tempo da rede. Se estiver sincronizado com relação a um global area clock, o atributo SmpSynch será igual a 2. Se estiver sincronizado a um local area clock, é possível definir um número de 5 a 255, que identifica um conjunto de IEDs sincronizados pelo mesmo local area clock. Este número de identificação é informado pelo local area clock para os IEDs, e é transmitido no atributo SmpSynch somente se o Protocolo PTP for utilizado. Caso o padrão utilizado seja o 1pps (que não é capaz de transmitir este número de identificação), ou o número não seja informado via Protocolo PTP, o atributo SmpSynch será igual a 1. Embora a 
Norma IEC 61869-9 mencione que este número deve ser informado pelo local area clock aos IEDs por ele sincronizados, não foi identificado na Norma IEEE 1588v2 de que forma este número será transmitido.

- Holdover mode: neste modo, o sinal de sincronismo (via 1pps ou Protocolo PTP) começou a não ser recebido pelo IED. Ele continuará enviando suas SV Messages com o mesmo valor de SmpSynch que era utilizado enquanto se encontrava no modo Sync Mode. A Norma IEC 61869-9 especifica que o período de permanência em Holdover mode seja de, no mínimo, 5s.

- Free-running mode: caso o sinal de sincronismo não se restabeleça dentro do período de permanência em Holdover mode, o IED entra em Free-running mode, onde as amostras enviadas nas $S V$ Messages passam a ser sincronizadas pelo relógio interno do IED. Nessa situação, o atributo SmpSynch será igual a 0. Para operar neste modo, a Norma IEC 61869-9 define um desvio máximo admissível de \pm 100 ppm no relógio interno do IED.

\subsection{Análise da qualidade da medição disponibilizada no barramento de processo}

De acordo a Norma IEC 61850-9, os valores medidos por IEDs presentes no nível de processo são amostrados e transmitidos por SV Messages através do barramento de processo para IEDs presentes no nível de bay. Esta dinâmica define um novo cenário, que levou à necessidade de redefinição de novos requisitos a serem avaliados para análise da qualidade da medição e de novas plataformas para sua avaliação. O exemplo a seguir traz um resumo que ilustra o processo de teste de TIs convencionais e o processo de teste de NCITs com interface IEC $61850-9$

Nos TIs convencionais, o sinal medido em seu primário é disponibilizado em seu secundário na forma analógica. A Figura 43, a seguir, ilustra um exemplo de estrutura básica adotada para a avaliação da precisão e classe da exatidão de TCs convencionais. 


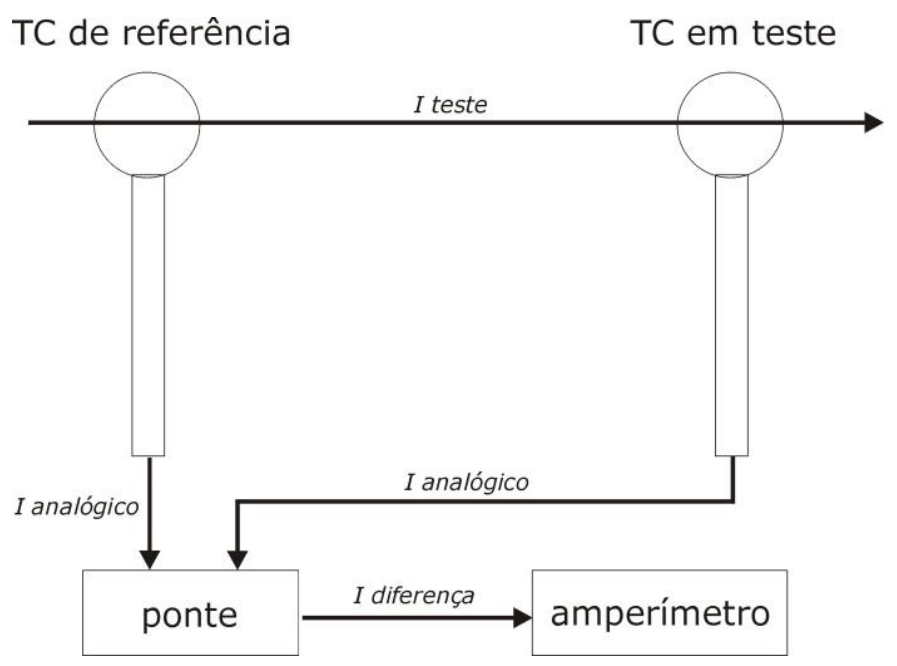

Fonte: o Autor

Nesta estrutura, uma mesma corrente de teste é injetada em ambos os TCs, gerando correntes em seus secundários na forma analógica, que serão aplicadas a um circuito em ponte cuja saída expressa a diferença, também na forma analógica, de ambos os sinais, que pode ser avaliada através de um amperímetro convencional com exatidão de acordo com a classe dos TCs avaliados.

Nos TCs com interface de acordo com a Norma IEC 61850-9, o sinal de corrente presente em seu primário é digitalizado, não havendo corrente de secundário, e o valor medido é inserido em uma $S V$ Message enviada através de uma interface digital de rede. O diagrama em blocos da Figura 44 representa os blocos básicos que podem compor um NCIT com interface segundo a Norma IEC 61850-9. A corrente Itest, através do bloco conversor Iteste para Isinal, é transformada em um sinal elétrico Isinal, de acordo com a tecnologia adotada. Em seguida o bloco microprocessador aciona o bloco conversor $A D$ em determinados instantes de tempo, de acordo com o sincronismo sinc enviado pelo bloco relógio interno, para gerar uma amostra digital de Isinal. De posse dessa amostra, o bloco microprocessador a encapsula em uma $S V$ Message segundo o padrão IEC 61850-9-2 e a envia para o barramento de processo através do bloco interface de rede. 


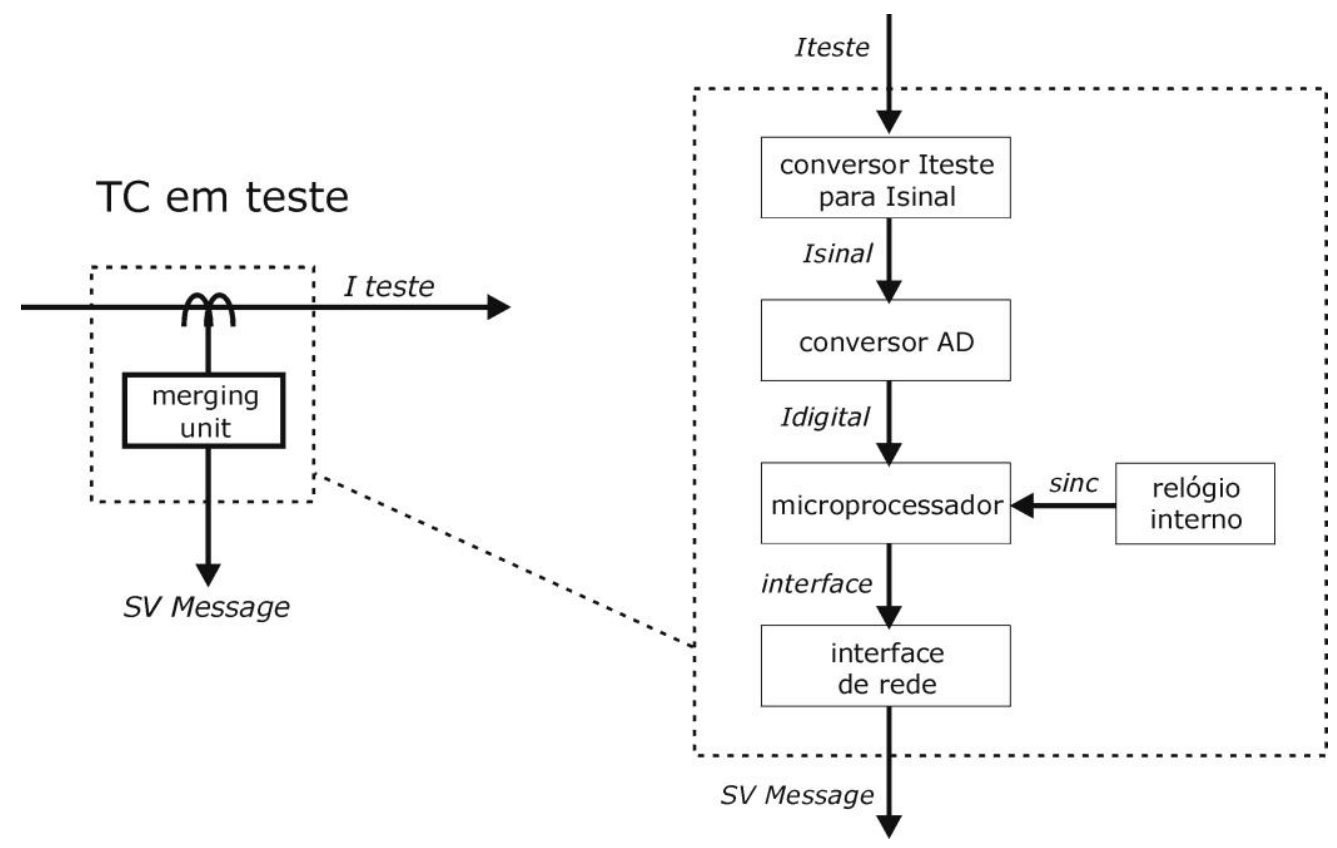

Historicamente, as principais normas internacionais utilizadas como padrão para a especificação de TCs e TPs disponíveis no mercado são referenciadas às normas da família IEC 60044. Esta família de normas, cuja última versão foi editada em 2002, chegou a propor algumas diretivas iniciais a serem aplicadas na definição de uma interface digital de TIs que substituiria as interfaces analógicas presentes até então. Atualmente está em processo de conclusão a elaboração da família de normas IEC 61869 [15], que irá abranger as mais recentes tecnologias desenvolvidas até o momento, inclusive a IEC 61850, e deve substituir a família de normas IEC 60044. Nesta nova família de normas já estão sendo abordados alguns aspectos relativos à medição disponibilizada no barramento de processo pelos transformadores para instrumentos, principalmente em relação aos modelos que utilizam tecnologias não convencionais de medição e que possuam interfaces eletrônicas.

Para a análise da qualidade da medição disponibilizada no barramento de processo, destacamse os seguintes assuntos:

\section{a) Análise da resposta harmônica}

No mercado, existem diversos dispositivos que utilizam o sinal vindo de TCs e TPs convencionais para a medição dos conteúdos harmônicos da corrente e da tensão, respectivamente, presentes no primário destes TIs. Embora alguns estudos apontem para aplicações de harmônicas acima de $5^{\text {a }}$ ordem, ainda não foram especificadas em nenhuma 
norma metodologias para avaliação da precisão da medição realizada pelos Tis e classificação de sua exatidão frente a sinais harmônicos, o que pode acarretar prejuízos na precisão do sinal presente na saída do transformador e, por consequência, em erros na interpretação por parte do dispositivo que utiliza o resultado dessa medição.

Além disso, em SASs com barramento de processo digital, a digitalização dos sinais de corrente, ou de tensão, é realizada pelo IED presente no nível de processo. O IED presente no nível de bay utilizará diretamente os valores amostrados para o processamento digital destes sinais, e deve respeitar o Teorema de Nyquist (a maior frequência do sinal a ser analisado deve ser inferior à metade da frequência de amostragem, para que não ocorra o efeito aliasing). Portanto, torna-se necessária a presença de um filtro anti-aliasing antes da etapa de digitalização, e o algoritmo digital executado pelo IED que receberá a SV Message deve estar casado com este filtro.

A Norma IEC 61869-9 começou a tratar sobre estes temas. A Figura 45, apresentada a seguir, ilustra uma proposta de máscara para especificação da resposta em frequência de TIs com interface IEC 61850-9. Através desta máscara obtêm-se informações importantes, como as harmônicas cujo TI é capaz de medir e a resposta em frequência de seu filtro anti-aliasing. 


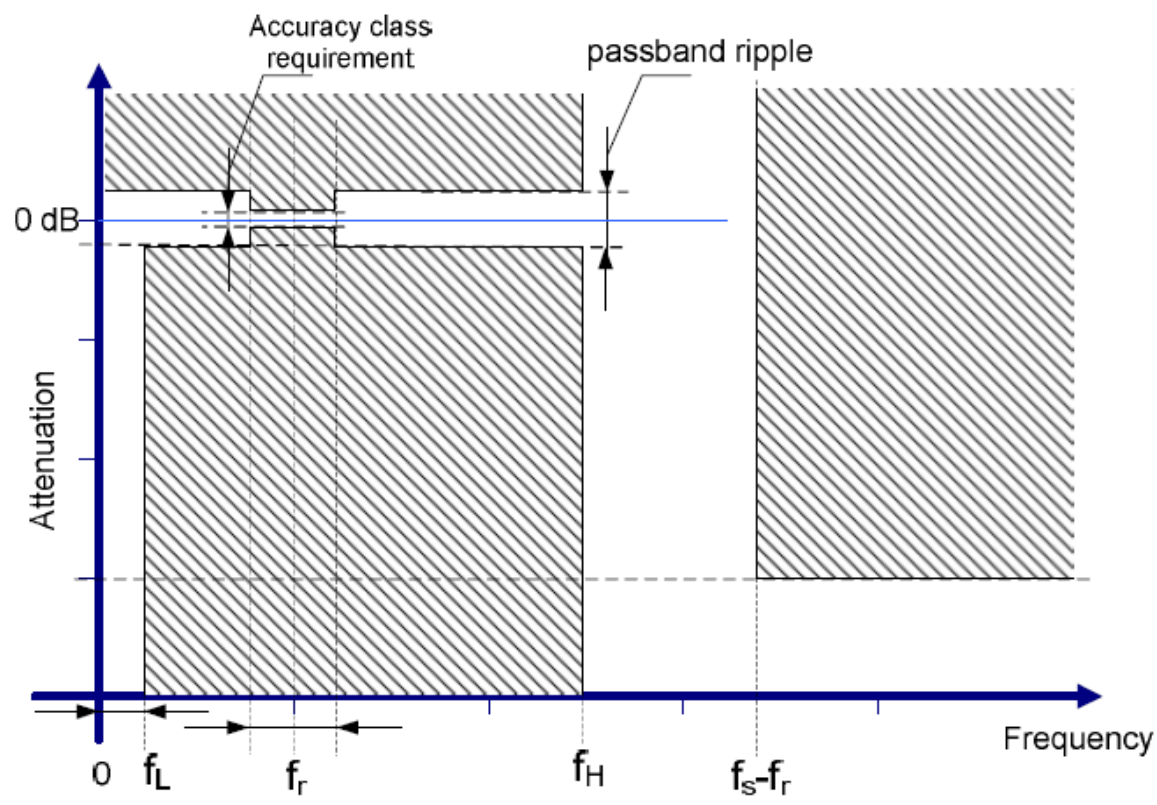

$\mathrm{f}_{\mathrm{r}}$ - rated frequency

$\mathrm{f}_{\mathrm{s}}$ - sampling frequency

$f_{L}-$ Low frequency roll-off

$f_{H}-$ High frequency roll-off

Fonte: Norma IEC 61869-9 (draft) A Tabela 3 apresenta uma proposta de tabela onde são especificados os requisitos que devem ser atendidos ao se analisar a variação da magnitude do sinal transmitido na SV Message de acordo com a frequência harmônica do sinal aplicado no primário do TI. O anexo E da Norma IEC 61869-9, ainda incompleto, proporá circuitos para a avaliação da resposta em frequência dos TIs.

Tabela 3 - Requisitos a serem atendidos na análise da magnitude, em função da frequência

\begin{tabular}{|c|c|c|c|c|c|c|}
\hline \multirow{2}{*}{$\begin{array}{l}\text { Accuracy } \\
\text { Class }\end{array}$} & \multicolumn{5}{|c|}{ Ratio error $(+/-)$ as a function of frequency (Percent) } & \multirow{2}{*}{$\begin{array}{l}\text { Anti } \\
\text { aliasing } \\
\text { filter } \\
\text { attenuation } \\
\text { (F } \geq \text { fs-fr) }\end{array}$} \\
\hline & $1 \mathrm{~Hz}$ & $\begin{array}{l}2^{\text {nd }} \text { to } 4^{\text {th }} \\
\text { harmonic }\end{array}$ & $\begin{array}{l}5^{\text {th }} \text { and } 6^{\text {th }} \\
\text { harmonic }\end{array}$ & $\begin{array}{l}7^{\text {th }} \text { to } 9^{\text {th }} \\
\text { harmonic }\end{array}$ & $\begin{array}{c}10^{\text {th }} \text { to } \\
13^{\text {th }} \\
\text { harmonic }\end{array}$ & \\
\hline $\begin{array}{c}\text { All } \\
\text { protection } \\
\text { classes }\end{array}$ & $+10 /-30 \%$ & $10 \%$ & $10 \%$ & - & - & $20 \mathrm{~dB}$ \\
\hline 1 & $+10 /-30 \%$ & $10 \%$ & $20 \%$ & $20 \%$ & $20 \%$ & $20 \mathrm{~dB}$ \\
\hline $0.5,0.5 \mathrm{~S}$ & $+5 /-30 \%$ & $5 \%$ & $10 \%$ & $20 \%$ & $20 \%$ & $26 \mathrm{~dB}$ \\
\hline $0.2,0.2 \mathrm{~S}$ & $+2 /-30 \%$ & $2 \%$ & $4 \%$ & $8 \%$ & $16 \%$ & $34 \mathrm{~dB}$ \\
\hline 0.1 & $+1 /-30 \%$ & $1 \%$ & $2 \%$ & $4 \%$ & $8 \%$ & $40 \mathrm{~dB}$ \\
\hline
\end{tabular}

Fonte: Norma IEC 61869-9 (draft) 


\section{b) Análise da precisão da medição}

A metodologia adotada para avaliação da precisão das medidas disponibilizadas pela interface de rede IEC 61850-9 ainda carece de definições mais precisas.

A Norma IEC 61850-10 estabelece uma metodologia muito superficial para testes das $S V$ Messages enviadas por um IED, conforme se observa na Figura 46. Um gerador de corrente/tensão gera os sinais que são aplicados no dispositivo testado. Menciona-se, sem maiores detalhes, um analisador de protocolos e um relógio mestre que sincroniza todo o processo.

Figura 46 - Arquitetura do sistema para avaliação do SV Message publicado pelo dispositivo testado

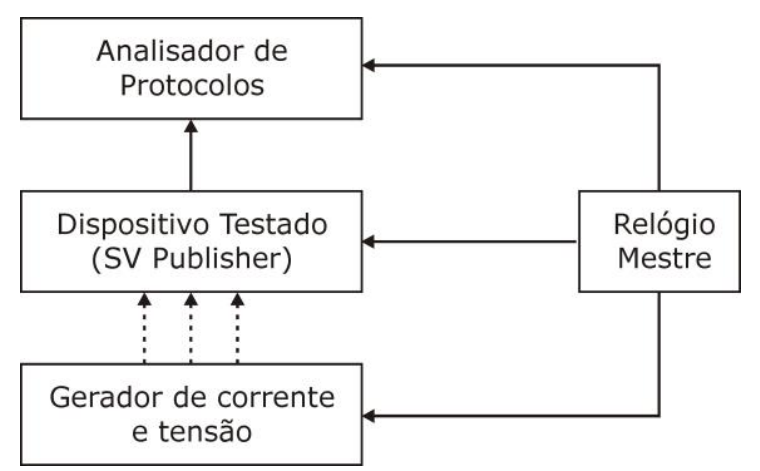

A Norma IEC 61869-9 avança muito neste sentido. Ela propõe, em seu anexo D, algumas plataformas para a avaliação dos erros. A Figura 47 ilustra umas destas plataformas. 


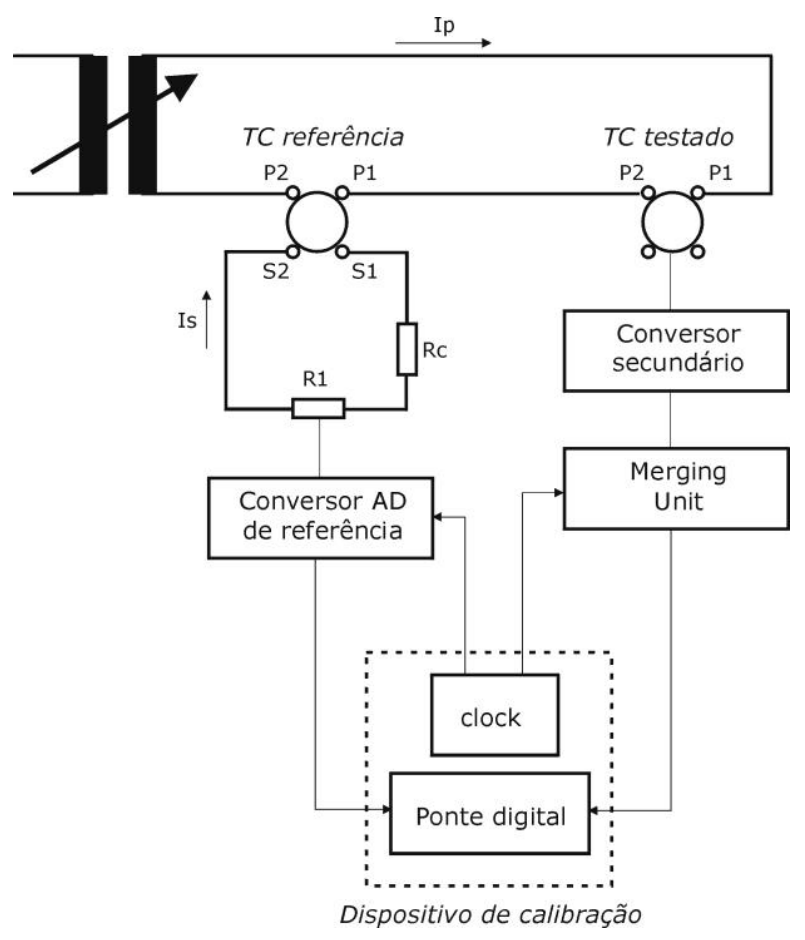

Fonte: o Autor Neste diagrama, a referência para avaliação de erros é obtida através de um TC referência em conjunto com um Conversor $A D$ de referência, que executa suas amostras de forma síncrona de acordo com um sinal gerado por um bloco clock. O IED em teste (neste diagrama, o conjunto TC testado + Conversor secundário + Merging Unit) também é sincronizado por um sinal gerado pelo bloco clock. As amostras geradas pelo Conversor AD de referência e pela Merging Unit são comparadas em um bloco Ponte digital. A norma propõe que este bloco utilize o algoritmo Discrete Fourier Transform (DFT) nas amostras recebidas para o cálculo do módulo e da fase da corrente de teste Ip para a avaliação dos erros.

A Norma IEC 61869-9 também define os conceitos de Delay Time e de Maximum Delay Time Requirement. Delay Time é o intervalo de tempo entre o instante em que o valor da tensão (ou corrente) está presente no primário do transformador de instrumentos e o instante em que a $S V$ Message, contendo o valor amostrado, é enviada pela interface de rede. O conceito de Maximum Delay Time Requirement, portanto, estabelece um limite máximo deste intervalo de tempo. A Norma IEC 61869-9, em conjunto com a Norma IEEE 1588v2, definem na $S V$ Message o ponto onde deve ser feita a medição do instante de tempo em que a mensagem é enviada, conforme demonstrado na Figura 48. Este ponto, denominado Message Timestamp Point, está localizado entre o byte de Start Frame Delimiter e o primeiro byte do destination address (endereço MAC de destino da SV Message). Para finalidade de proteção, o limite é de 
1,5 ms, para finalidade de medição, o limite é de $10 \mathrm{~ms}$, e para finalidade de ambos, este valor deve ser estabelecido pelo fabricante.

Figura 48 - Ponto de referência na SV Message onde é feita a medição do Maximum Delay Time

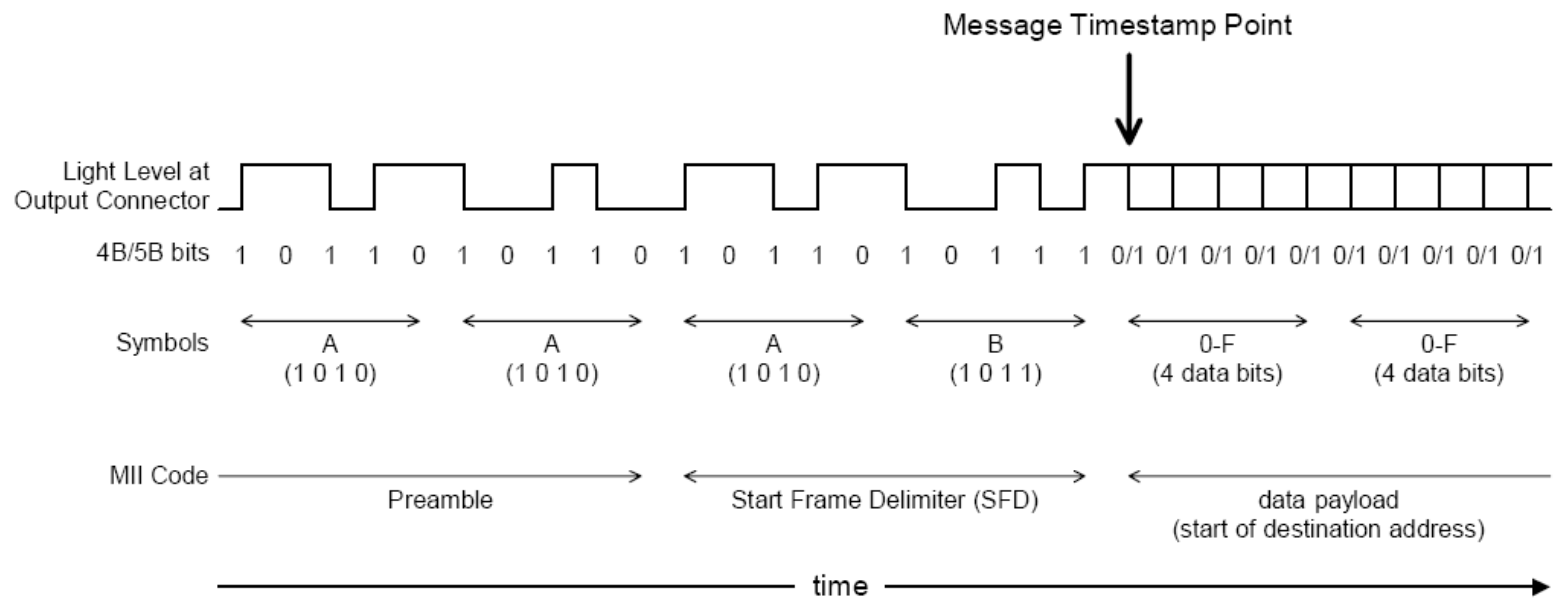

Fonte: Norma IEC 61869-9 (draft)

Poucos trabalhos foram publicados a respeito de metodologias e de plataformas para avaliação dos erros. Em [26] propõe-se um sistema para calibração, mas o artigo se concentra principalmente na apresentação daquele sistema e nas incertezas que podem ocorrer, sem mostrar resultados de medições por ele executadas.

Em [31] propõe-se um sistema para avaliação de Merging Units, onde um gerador de sinais, combinado com um amplificador, gera o sinal de teste a ser aplicado nos TIs. No secundário destes TIs estão presentes um sistema de aquisição de dados e a Merging Unit a ser avaliada, ambos sincronizados por um sinal de 1pps gerado por um receptor de satélite GPS. Um computador realiza a aquisição dos dados. Avaliações são propostas com base no valor RMS, na fase e no Total Vector Error - TVE (este último é um conceito utilizado em Phasor Measuring Unit - PMU). Também sugere-se uma comparação amostra a amostra e um teste dinâmico utilizando Transformadas de Clark e de Park. Vários detalhes relevantes não ficaram claros no artigo, como os equipamentos utilizados no sistema de avaliação e o algoritmo utilizado para o cálculo da fase. A medição do Maximum Delay Time não foi implementada.

Em [27] propõe-se outro sistema, conforme ilustra a Figura 49, a seguir. 
Figura 49 - Diagrama em blocos do sistema de calibração proposto

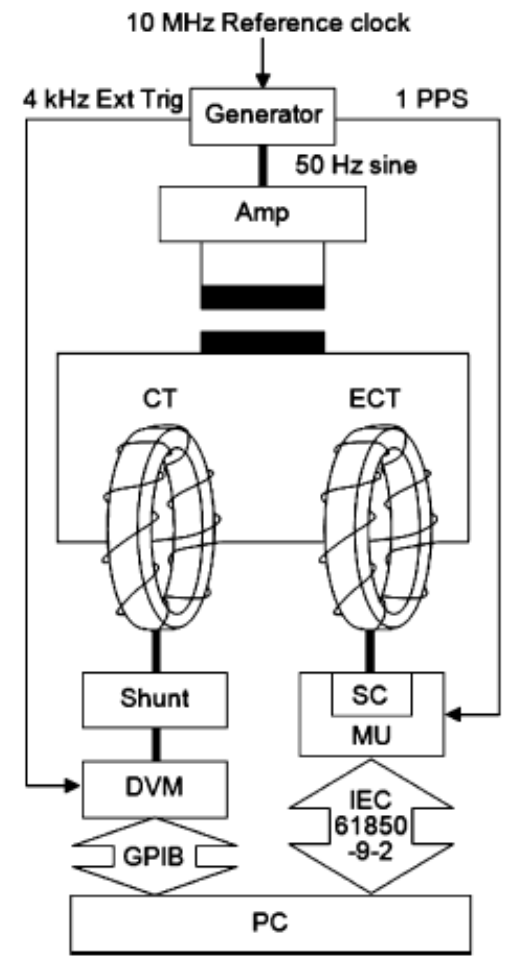

Fonte: YAMADA (2012)

Este sistema utiliza como referência um multímetro Agilent modelo 3458A (bloco DVM), capaz de digitalizar o sinal medido por um TC de referência. As amostras realizadas por este multímetro são sincronizadas com as amostras realizadas pelo conjunto Electronic Current Transformer/Merging Unit (ECT/MU) em avaliação através de um gerador de pulsos. Este gerador produz pulsos de $4 \mathrm{KHz}$ (para o disparo de amostras no multímetro a uma taxa de 80 amostras/ciclo de rede com frequência nominal de $50 \mathrm{~Hz}$ ) sincronizados com o pulso de 1pps (para sincronismo do relógio interno do conjunto ECT/MU). As amostras geradas são enviadas para um PC onde a amplitude e a fase da corrente aplicada para teste, medida simultaneamente pelo sistema de referência e pelo conjunto ECT/MU, são calculadas através de um algoritmo baseado na DFT, e são comparadas para a avaliação dos erros do conjunto ECT/MU. Neste sistema, ainda não foi implementada a avaliação do Maximum Delay Time.

\section{c) Quality of Service (QoS)}

Diferentes abordagens são utilizadas para definir o conceito de QoS. Após intensa pesquisa, o autor optou por abordar este conceito com base em [28], cuja descrição se apresentou mais coerente com o estudo do barramento de processo segundo a Norma IEC 61850-9, englobando os conceitos que serão destacados e analisados a seguir. 
Definem-se como QoS as formas de medir e de gerenciar a qualidade e a disponibilidade de uma rede. Existem no mercado duas configurações básicas de rede industriais que operam com o protocolo Ethernet:

- Switched Ethernet: onde os dispositivos são conectados entre si através de switches (e.g. IEC 61850, EtherNet/IP, Modbus TCP/IP);

- Non-Switched Ethernet: a conexão entre os dispositivos é em anel, sem a necessidade de switches (e.g. EtherCAT).

A Figura 50 ilustra uma configuração Switched Ethernet. Nesta configuração, uma mensagem pode ser endereçada na rede de três formas:

- Unicast: a mensagem é enviada de um dispositivo para outro dispositivo (e.g. mensagem MSG2, onde IED2 envia mensagem para IED3);

- Multicast: a mensagem é enviada de um dispositivo para um grupo de dispositivos (e.g. mensagem MSG1, onde IED1 envia uma mensagem para um determinado grupo de IEDs, neste caso, IED4 e IED5);

- Broadcast: a mensagem é enviada de um dispositivo para todos os dispositivos.

Figura 50 - Configuração de rede utilizada para análise dos conceitos de QoS

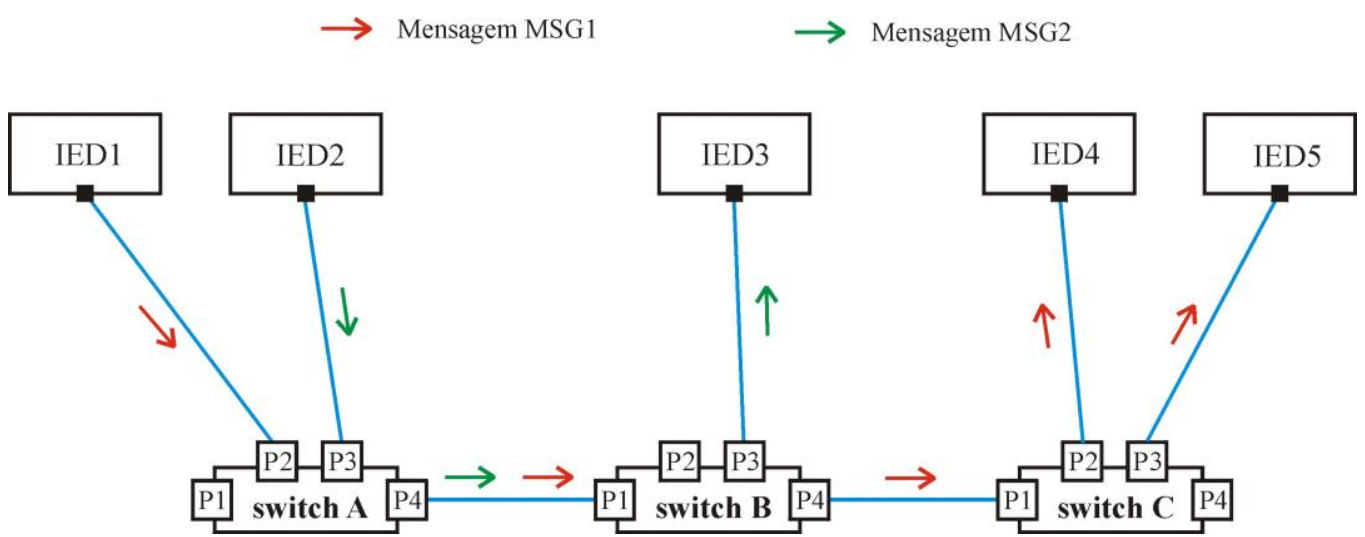

Fonte: o Autor Quando uma mensagem chega no port de um determinado switch, ela é inteiramente recebida, analisada e encaminhada para o(s) port $(s)$ correspondente(s). Todo este processo leva um determinado tempo para ser executado, denominado latency de um switch.

Em algumas situações, durante o processo de encaminhamento, é necessário que o switch armazene e trate em sua memória interna mais de uma mensagem. Por exemplo, no switch A, 
se as mensagens MSG1 e MSG2 forem recebidas simultaneamente, elas terão que ser armazenadas simultaneamente. A seguir, o switch tomará a decisão sobre qual (is) port $(s)$ as mensagens serão encaminhadas. Neste caso, como ambas serão encaminhadas para o port $\mathrm{P} 4$, o switch iniciará uma fila de mensagens a serem enviadas por este port (por exemplo, primeiro a mensagem MSG1 e, em seguida, a mensagem MSG2). Posteriormente, o port P4 enviará as mensagens nesta sequência. Outra situação seria o caso do switch A encaminhar a mensagem MSG1 para o port P4, mas este port já está enviando a mensagem MSG2. Nesta situação, o switch iniciará uma fila contendo a mensagem MSG1, aguardando a mensagem MSG2 ser transmitida. O processo de organização desta fila é denominado quеие de um switch.

Todo este procedimento exige que o switch possua uma memória interna para processar uma série de mensagens e criar as filas de mensagens de cada port. Esta memória tem um limite físico, estabelecido pelo projeto do switch. Caso este limite seja excedido, as mensagens recebidas, a partir deste momento, serão descartadas. Este fenômeno de perdas de mensagens é denominado packet loss de um switch.

Analisando agora o processo de envio da mensagem como um todo, o envio da mensagem MSG2 se inicia no IED2, passa pelos switches A e B e termina no IED3. Devido ao latency dos switches envolvidos (causado, por exemplo, pelo queue de cada um deles), o tempo total de transmissão da mensagem (denominado transmission delay da rede) pode variar, não sendo fixo. Este tempo pode, inclusive, ser infinito caso ocorra um packet loss em um determinado switch. Esta variação no transmission delay é denominada jitter da rede, e caracteriza o comportamento não determinístico da Ethernet, ou seja, não existe um tempo exato para a execução de uma determinada tarefa (neste caso, a transmissão da mensagem MSG2).

Cada mensagem ocupa um determinado tempo no barramento para ser transmitido. Por exemplo, supondo que no trecho de rede entre o IED2 e port P3, do switch A, a mensagem MSG2 tenha 1000 bytes ( 8000 bits), e se a velocidade do barramento neste trecho for 100 Mbits/s, isso determina uma capacidade máxima de transmissão (denominado bandwidth da rede) de até 100Mbits/s. O tempo ocupado para transmitir a mensagem MSG2 será de aproximadamente $80 \mu \mathrm{s}$. Se esta mensagem for enviada a uma taxa de 100 vezes por segundo, ela irá ocupar: 


$$
\begin{gathered}
8000 \times 100=0,8 \text { Mbits } \\
\text { ou } \\
\frac{8000 \times 100}{100 \times 10^{6}} \times 100 \%=0,8 \%
\end{gathered}
$$

Portanto, 0,8\% (ou 0,8 Mbits) do bandwidth deste trecho da rede estarão ocupados. Restam ainda 99,2\% (ou 99,2 Mbits) de banda teórica disponível para uso.

A implementação do barramento de processo segundo a Norma IEC 61850-9 gerou a necessidade de melhorar o não determinismo característico da rede Ethernet, devido aos vários fatores comentados acima, utilizando uma série de recursos de QoS não previstos inicialmente pelo protocolo Ethernet.

Um dos recursos foi utilizar mensagens multicast para a transmissão das SV Messages, sem exigir um reconhecimento de recepção da mensagem por parte do IED inscrito para recebê-la. Isso, por um lado, elevou o bandwidth da rede (por reduzir o fluxo de mensagens), mas a natureza multicast da mensagem faz com que esta se propague por todo o barramento de processo, ocupando o bandwidth de determinados trechos da rede sem necessidade. Para reduzir o tráfego de mensagens nesses trechos, a Norma IEC 61850-9 disponibilizou o uso do recurso VLAN (Virtual Local Area Network), definido pela Norma IEEE 802.3Q [29], o que gerou a inserção de um cabeçalho adicional de 4 bytes no frame Ethernet, conforme ilustra a Figura 51. Este recurso estabelece um número de identificação (chamado VID - VLAN Identifier) que engloba um determinado conjunto de IEDs. O switch encaminhará as mensagens com um determinado VID somente para os ports habilitados. Analisando o exemplo da Figura 50, admitindo que a mensagem MSG1 seja uma SV Message publicada pelo IED1 e que se deseje inscrever o IED4 e o IED5 para recebê-la, caso o recurso VLAN não seja utilizado, esta mensagem se propagará desnecessariamente por toda a rede. Estabelecendo o número 0x64 como o VID para a definição de uma VLAN, programa-se em cada switch quais IEDs pertencem a esta VLAN através da programação de cada port de cada switch (e.g. ports P2 e P4 do switch A pertencem a VLAN de VID número 0x64). Desta forma, a mensagem MSG1 se propagará somente nos trechos de rede necessários, melhorando o bandwidth disponível. Existem estudos [20] [28] que propõem o uso de outros protocolos, como o GARP Multicast Registration Protocol (GMRP) e o Multiple MAC Registration Protocol (MMRP), com a finalidade de estabelecer uma segmentação automática do barramento de processo em subredes, sem a necessidade de estabelecer a VLAN. Estes protocolos, basicamente, funcionam da seguinte forma: recorrendo novamente ao exemplo da 
Figura 50, supondo que o IED1 seja programado com um número que identifica a subrede à qual a sua SV Message pertence, o IED4 e o IED5 são inscritos para receber SV Messages que pertençam a subrede do IED1. O IED1 envia uma mensagem broadcast na rede informando que enviará SV Messages com este número. Todos os IEDs receberão esta mensagem e somente o IED4 e o IED5 responderão para o IED1, informando que estão inscritos para recebê-la. Cada switch, com base no port que recebeu a informação enviada pelo IED1 e nos ports que receberam as respostas do IED4 e do IED5, habilitará somente os ports necessários para a transmissão da SV Message.

Figura 51 - Cabeçalho IEEE 802.3Q inserido pela Norma IEC 61850-9 no frame Ethernet

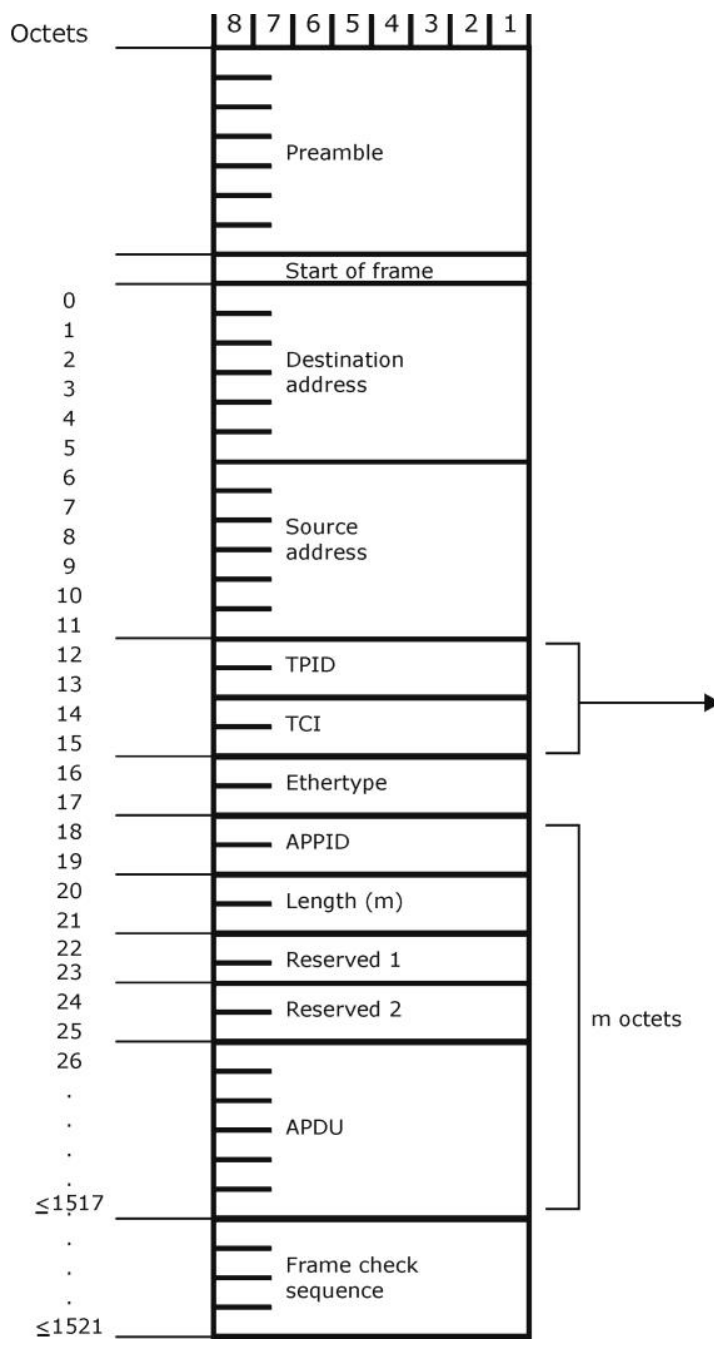

Fonte: o Autor Outro recurso utilizado pela Norma IEC 61850-9 é o de prioridade no tratamento das mensagens. O campo User priority da Norma IEEE 802.1Q, mostrado na Figura 51, estabelece uma faixa de números (que pode ser de 0 a 7) que definem diferentes níveis de prioridades para o processo de queue nos switches. Uma mensagem com User priority igual a 4 (definido como valor padrão para SV Messages, de acordo com [21]) tem maior prioridade 
que uma mensagem com User priority igual a 6. Recorrendo novamente ao exemplo da Figura 50, admitindo que a mensagem MSG1 seja uma SV Message (com User priority igual a 4) e que a mensagem MSG2 seja uma mensagem MMS (com User priority igual a 7), ambas as mensagens serão encaminhas pelo switch A para seu port $\mathrm{P} 4$; contudo, caso este port se encontre transmitindo uma outra mensagem será iniciado um processo de quеие pelo switch A, colocando a mensagem MSG1 antes da mensagem MSG2. Se antes de o port P4 acabar de transmitir a mensagem o switch A receber uma nova mensagem MSG1, o processo de queue do switch estabelecerá uma nova ordem, onde primeiro será transmitida a mensagem MSG1 recebida anteriormente, em seguida a nova mensagem MSG1, e por último a mensagem MSG2. É importante destacar, portanto, que o processo de prioridade altera o quеие de um switch, sem cancelar a transmissão de uma mensagem em curso, mesmo que esta mensagem seja de prioridade inferior. Portanto, o efeito de jitter da rede continuará a ocorrer, mas de forma minimizada. Isso deve ser levado em consideração na análise de tráfego da rede.

Como exemplo de análise de tráfego de rede, considere-se que um IED com finalidade de proteção envia SV Messages no barramento de processo a uma taxa de 80 amostras/ciclo, ou seja, admitindo uma frequência de rede elétrica de $60 \mathrm{~Hz}$, a cada $208 \mu$ s será enviada uma nova SV Message no barramento por essa IED. As mensagens do tipo MMS costumam ser longas, atingindo o limite máximo possível de um frame Ethernet (originalmente 1518 bytes, mais 4 bytes do padrão IEEE 802.1Q, 7 bytes de preamble e 1 byte de start of frame, totalizando 1530 bytes), o que, num barramento de $100 \mathrm{Mbits} / \mathrm{s}$, levará aproximadamente 122 $\mu$ s para ser transmitido. No exemplo da Figura 50, caso a mensagem MSG1 seja uma $S V$ Message, poderá ocorrer uma situação onde o port $\mathrm{P} 4$ do switch A inicie a transmissão de uma mensagem MMS assim que receber a mensagem MSG1. O mesmo pode acontecer com o port $\mathrm{P} 4$ do switch $\mathrm{B}$, o que ocasiona um atraso de $122 \mu$ s em cada switch, totalizando um jitter de $244 \mu$ s (sem levar em consideração o latency de cada switch). Portanto o IED4, inscrito para receber esta $S V$ Message, em um determinado momento, poderá ter de aguardar 244 us para recebê-la, o que supera o intervalo nominal de $208 \mu$ s e pode levá-lo a sinalizar um possível packet loss.

A prioridade das mensagens é estabelecida em um cabeçalho inserido diretamente no frame Ethernet que, de acordo com o modelo ISO/OSI, está localizado no nível 2. Esta metodologia é denominada layer 2 priority (prioridade no nível 2). Existe também a possibilidade de se aplicar uma dinâmica de prioridade no protocolo IP, localizado no nível 3 (denominada layer 
3 priority). Neste trabalho, essa dinâmica não será analisada, pois a SV Message é mapeada diretamente no nível 2 e não possui protocolo IP.

Neste cenário, é notável a importância da análise de QoS no projeto e na implementação de um barramento de processos. Uma pesquisa feita nas principais normas envolvidas revelou que as definições para esta análise ainda se encontram incompletas. A Norma IEC 61850 estabelece poucos requisitos para a execução de testes com a finalidade de avaliar o QoS de um determinado barramento de processo. A Norma IEC 61850-5 define classes de desempenho para o transfer time das SV Messages (conforme já abordado na seção 2.2.5). A Norma IEC 61869-9, ainda em fase de elaboração, estabelece que o IED responsável por enviar SV Messages não tenha sua performance prejudicada em uma situação de $100 \%$ de tráfego na recepção de mensagens. Existe ainda o relatório técnico TR IEC61850-90-4, em fase final de liberação, que definirá algumas recomendações a serem seguidas no projeto de barramentos de processo.

Com relação aos artigos elaborados sobre o tema, o autor destaca estudos sobre a simulação do tráfego de rede através de softwares específicos (como o software OMNeT) [32], estudos de redução de tráfego de rede utilizado VLAN e filtros multicast (através dos protocolos GMRP e MMRP) [30] [35] e estudos que apontaram algumas aplicações específicas que se mostraram restritivas à utilização do barramento de processo IEC 61850-9, como a proteção diferencial de barras em situações com elevado número de bays [33] (onde a elevada quantidade de $S V$ Messages ultrapassa o bandwidth da rede) e a localização de faltas utilizando ondas viajantes [34] (que exige uma elevada taxa de amostragem do sinal de tensão, superior a taxa de 256 amostras/ciclo).

\subsection{Segurança Cibernética}

Até meados da década de 90, os SASs utilizavam redes de comunicações isoladas baseadas em protocolos específicos para este fim (ex: MODBUS-RTU, Profibus, DNP3). O avanço da Norma IEC 61850 vem tornando os SASs cada vez mais integrados, utilizando como base tecnologias computacionais de alto desempenho já existentes e amplamente difundidas, sobretudo baseadas em Ethernet e TCP/IP, o que tornou o sistema mais exposto a ataques 
cibernéticos [16] [36]. Alguns exemplos de tipos de ataques que merecem destaque são o Ataque DoS, a Interceptação e o Vírus.

O Ataque DoS (Denial Of Service) consiste num envio massivo de requisições falsas a um determinado serviço de rede do sistema, que pode acabar consumindo seus recursos e degradando ou paralisando seu funcionamento.

A Interceptação (também denominada Man-In-The-Middle ou Replay Attack) consiste na interceptação dos dados que ali trafegam a partir da invasão e acesso aos dados trafegados na rede, seja para simples captura de senhas, para alteração dos valores dos dados trafegados (também denominado Tampering of Data) ou para os invasores se fazerem passar pelo dispositivo que realmente pertence à rede.

O Vírus é um software malicioso capaz de infectar sistemas computacionais causando danos diversos e, uma vez introduzidos, podem criar cópias e se espalhar por outros dispositivos.

Diversos ataques já foram pesquisados e simulados, demonstrando vulnerabilidades do barramento de processo [37] [38] [40]. A proteção contra estes e outros tipos de ataques envolve uma série de conceitos e estratégias, buscando resguardar a rede tanto fisicamente (através de dispositivos firewalls, cercas, cadeados, controle de acesso, etc.) quanto logicamente (através de softwares firewalls, antivírus, criptografia de dados, etc.).

Com o objetivo de estabelecer algumas diretrizes e recomendações quanto à segurança cibernética nos SASs, foram publicados, em 2007, os primeiros itens da Norma IEC 62351 [17]. Atualmente, esta norma ainda se encontra em fase de elaboração e deve ser proposta pelas novas versões da Norma IEC 61850 como padrão a ser seguido. A Norma IEC 62351-6 trata especificamente da segurança cibernética aplicada aos serviços realtime da Norma IEC 61850 (GOOSE Messages e SV Messages), contendo instruções sobre a criptografia aplicada nos dados a serem transmitidos. Antes de iniciar a discussão sobre algumas mudanças definidas pela norma, cabe introduzir alguns conceitos utilizados no campo da criptografia de dados.

A criptografia dos dados de uma mensagem consiste no transmissor codificar os dados, ou seja, alterar o valor dos dados contidos em uma mensagem segundo um algoritmo específico, de forma que somente um determinado receptor, ou um grupo de receptores, seja capaz de decifrar o conteúdo desta mensagem. De forma geral, o algoritmo de criptografia recebe como 
entradas os dados desta mensagem e uma senha numérica, chamada de chave (que é de posse do transmissor), e retorna uma sequência de dados que compõem a mensagem criptografada a ser transmitida. Após a transmissão da mensagem na rede e sua recepção pelo destinatário, este executa o algoritmo de descriptografia, que recebe como entradas os dados que compõem a mensagem criptografada e uma chave (que é de posse do receptor), e retorna como saída uma sequência de dados igual a mensagem transmitida inicialmente, antes de ser criptografada. É importante destacar que qualquer processo que altere os dados em favor da segurança irá demandar um acréscimo do tempo de processamento das mensagens pelos dispositivos de rede, o que deve ser levado em consideração para não prejudicar o seu desempenho. Basicamente, existem duas metodologias para criptografia de dados: a criptografia simétrica e a criptografia assimétrica.

A criptografia simétrica é aquela cuja chave utilizada para criptografar uma mensagem é a mesma utilizada para descriptografá-la, conforme ilustra a Figura 52. Neste exemplo, se o dispositivo B deseja receber mensagens criptografadas do dispositivo A, primeiramente ele envia uma chave através da rede e, a seguir, passa a receber as mensagens criptografadas segundo o algoritmo adotado. Utilizando a mesma chave enviada e a mensagem criptografada recebida, o algoritmo de descriptografia é capaz de decodificar a mensagem. Como exemplos de criptografia simétrica, podem ser citados o algoritmo AES e o algoritmo RC4.

Figura 52 - Exemplo de criptografia simétrica

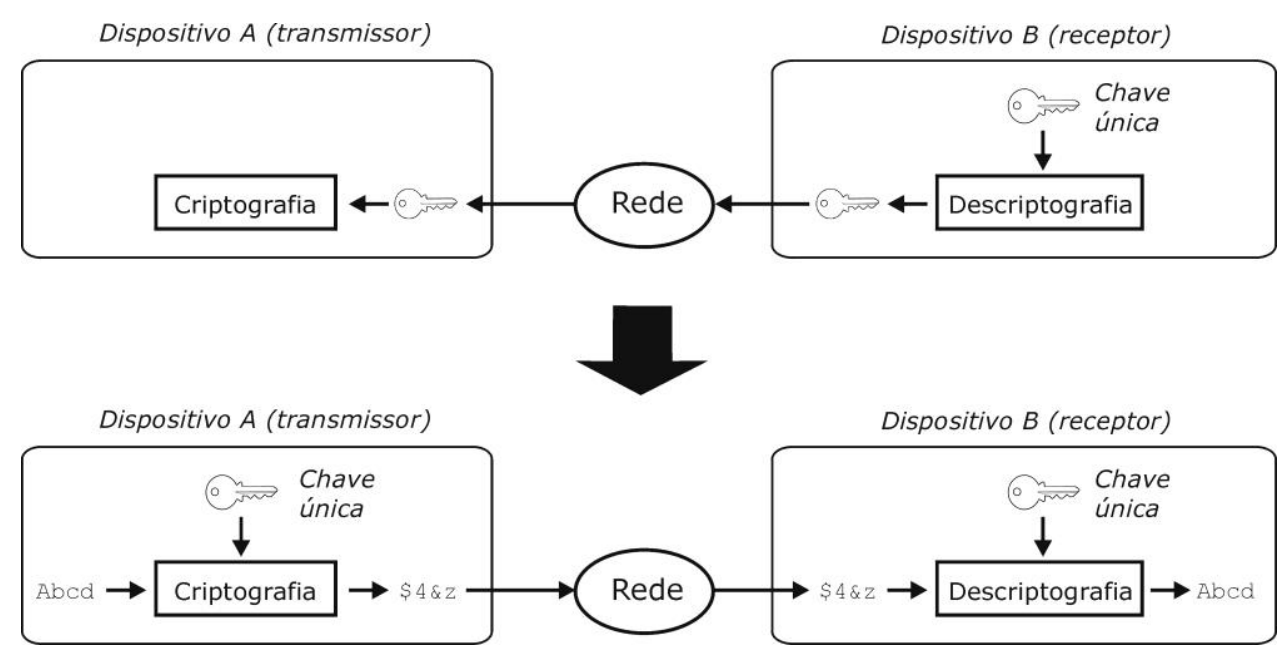

Fonte: o Autor A criptografia assimétrica é aquela cuja chave utilizada para criptografar uma mensagem (denominada chave privada) é diferente da chave utilizada para descriptografá-la (denominada chave pública), conforme ilustra a Figura 53, a seguir. 
Figura 53 - Exemplo de criptografia assimétrica

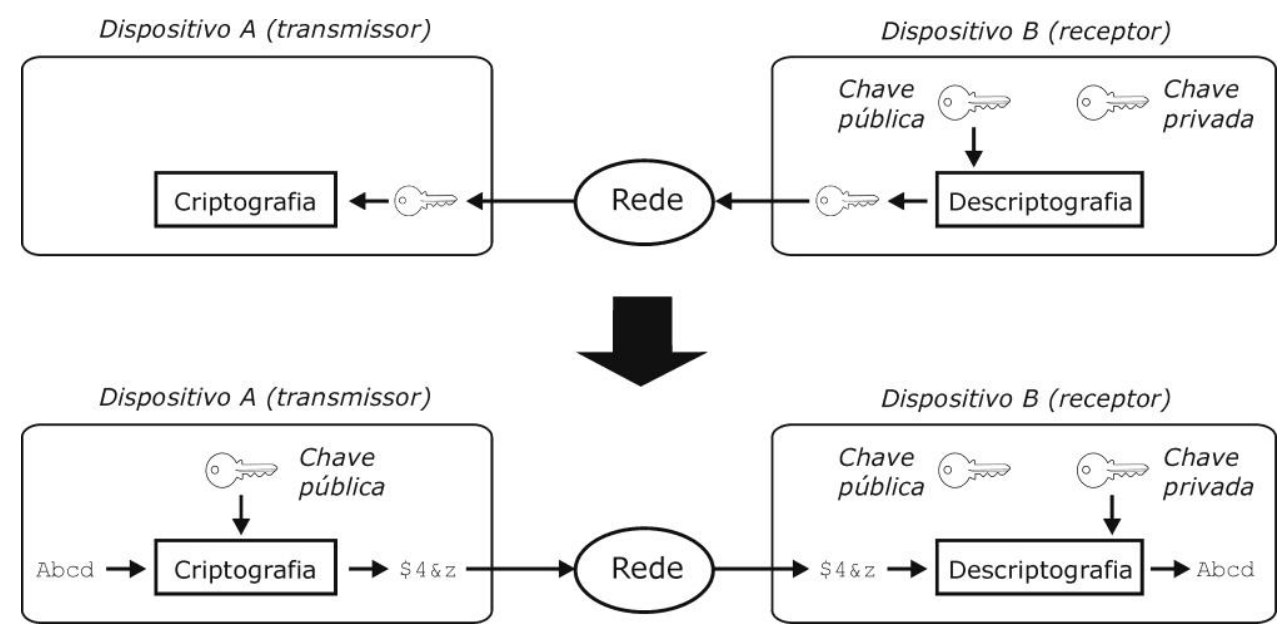

Fonte: o Autor

Neste exemplo, o dispositivo B possui duas chaves. Se o dispositivo B desejar receber mensagens criptografadas do dispositivo A, primeiramente ele envia sua chave pública. A seguir, o dispositivo A passa a enviar mensagens criptografadas segundo a chave pública recebida. Devido à lógica implementada nos algoritmos de criptografia/descriptografia, somente o dispositivo detentor da chave privada consegue decodificar a mensagem. Como exemplos de criptografia assimétrica, podem ser citados o algoritmo RSA e o algoritmo PGP.

A metodologia adotada para a distribuição da chave influencia diretamente no grau de segurança de um sistema, pois, no momento de transmissão dessa através da rede, qualquer dispositivo pode capturá-la e utilizá-la. Na criptografia simétrica, por exemplo, qualquer um que possua esta chave será capaz de decodificar as mensagens transmitidas. Já na criptografia assimétrica, somente o detentor da chave privada poderá decodificar as mensagens, o que a torna mais segura; entretanto, este método de criptografia tende a ser mais complexo e exigir maior tempo de processamento para execução. Resta ainda a possibilidade de um terceiro dispositivo que, querendo se passar pelo dispositivo B, envia uma falsa chave pública com o intuito de receber mensagens destinadas a ele. Para contornar este problema, as chaves podem ser distribuídas acompanhadas de certificados digitais, que contêm uma série de informações que garantem que ela foi realmente enviada pelo dispositivo B. O padrão X.509 é um exemplo de certificado digital muito utilizado para este fim.

Num primeiro momento, durante seu processo de elaboração, a Norma IEC 62351-6 propôs o uso de criptografia assimétrica segundo o padrão RSA para garantir a segurança dos dados transmitidos com o envio das chaves públicas através de certificados digitais segundo o padrão X.509 [40] [41]. Após a execução de testes por parte de alguns fabricantes e 
pesquisadores, algumas questões relévantes foram levantadas:

- Testes iniciais apontaram que o desempenho exigido pela Norma IEC 61850-5 (transfer time de 3 ms, para dispositivos de Classe P3) com o uso de criptografia assimétrica só seria atendido de forma aceitável com o auxílio de hardware dedicado para este fim.

- O uso de criptografia na transmissão das mensagens exige que todos os dispositivos da rede sejam capazes de criptografar/descriptografar dados; dispositivos incapazes de codificar/decodificar dados passariam a ser incompatíveis.

- A transmissão de chaves através de certificados exige, por parte de um dispositivo conectado ao barramento de processo e dos profissionais envolvidos com a configuração da rede, a habilidade de gerenciar diversos certificados emitidos pelos outros dispositivos também conectados. A execução de toda esta logística pode dificultar ainda mais o trabalho de configuração do barramento de processo, o que não seria interessante.

Para atender parte dessas questões, foi proposto, na primeira versão da Norma IEC 62351-6, o uso de uma assinatura digital obtida através de uma Função Hash Criptográfica, como forma de garantir a segurança e a integridade dos dados transmitidos. Este mecanismo é semelhante à criptografia simétrica, com algumas diferenças.

Assinatura digital é um esquema matemático no qual é gerada uma sequência numérica em função dos dados da mensagem a ser transmitida. Esta sequência numérica é utilizada para validar os dados que compõem uma mensagem recebida.

Função Hash (Hash Function) é uma modalidade de algoritmo capaz de receber, como entrada, uma sequência de dados de tamanho variável e convertê-la numa nova sequência de tamanho fixo.

A Função Hash Criptográfica (Cryptographic Hash Function) é uma modalidade de Função Hash utilizada para segurança de dados. Seu algoritmo para conversão de dados deve respeitar uma série de requisitos. Dentre eles, destaca-se a propriedade de Resistência à Colisão (Colision Resistant): não devem existir duas sequências de dados capazes de gerar uma mesma sequência de tamanho fixo. Esta característica permite sua utilização para testes de segurança e integridade dos dados. São exemplos de Função Hash Criptográfica os algoritmos MD5 e a família de funções SHA-2. A Função Hash Criptográfica definida pela 
Norma IEC 62351-6 é a Hashed Message Authentication Code (HMAC) do tipo SHA256, também denominada Keyed-Hash Message Authentication Code, especificada pela RFC 2401. Seu funcionamento básico é ilustrado pela Figura 54, a seguir.

Figura 54 - Fluxograma básico da Função Hash Criptográfica HMAC

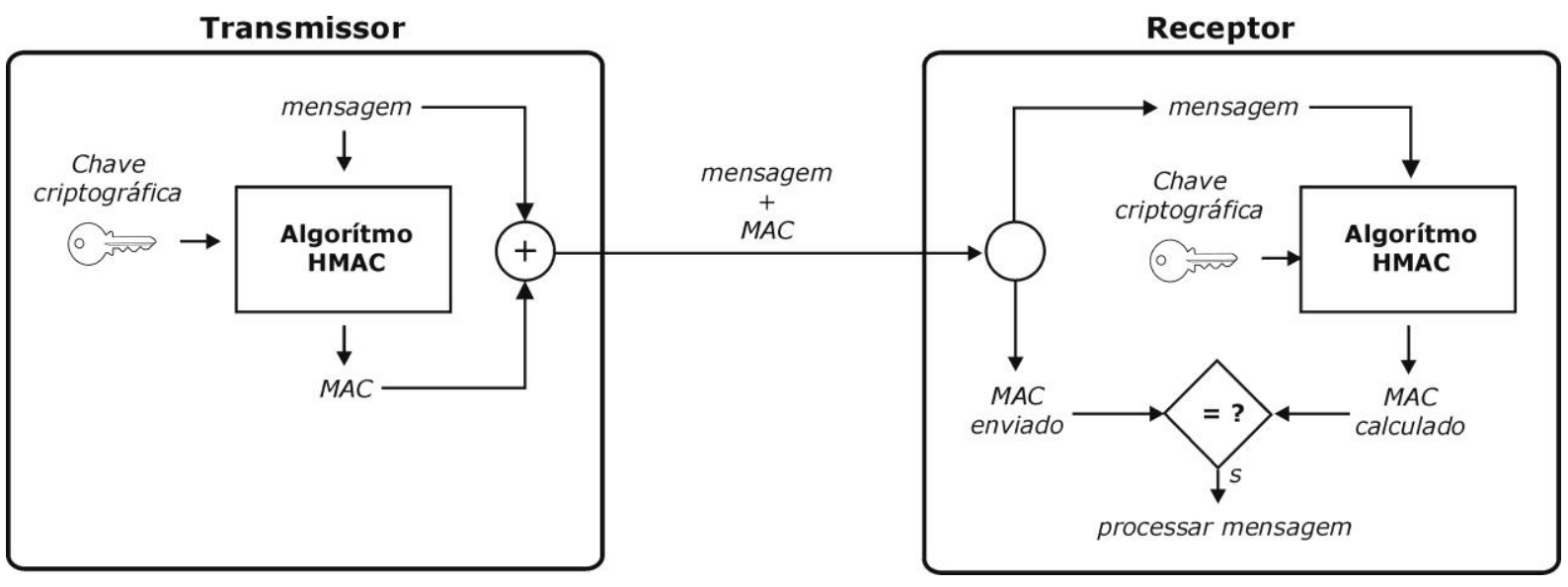

Fonte: o Autor O algoritmo HMAC, processado pelo transmissor, recebe como entradas a sequência de dados que compõem a mensagem a ser transmitida e uma chave criptográfica. Como saída, é gerada uma sequência de dados de tamanho fixo, denominada Message Authentication Code (MAC). Esta sequência é transmitida em conjunto com os dados da mensagem (que não sofrem criptografia). Ao receber a mensagem, o receptor, de posse da mesma chave criptográfica utilizada pelo transmissor, recalcula o MAC e o compara com o MAC recebido. Caso eles sejam iguais, a mensagem é considerada integra e segura, podendo ser processada normalmente.

Para permitir que todos os dispositivos, capazes ou não de processar o algoritmo HMAC, trabalhem num mesmo barramento de processo, garantindo a interoperabilidade do SAS, foi definido um novo formato de frame, denominado Extended PDU, tornando compatíveis o formato seguro e o formato não seguro utilizado até então. A Figura 55 demonstra as principais diferenças entre os dois formatos. 
Figura 55 - Frame não seguro (esquerda) e frame seguro definido pela IEC 62351-6 (direita), admitindo que ambos utilizem o Protocolo PRP para redundância
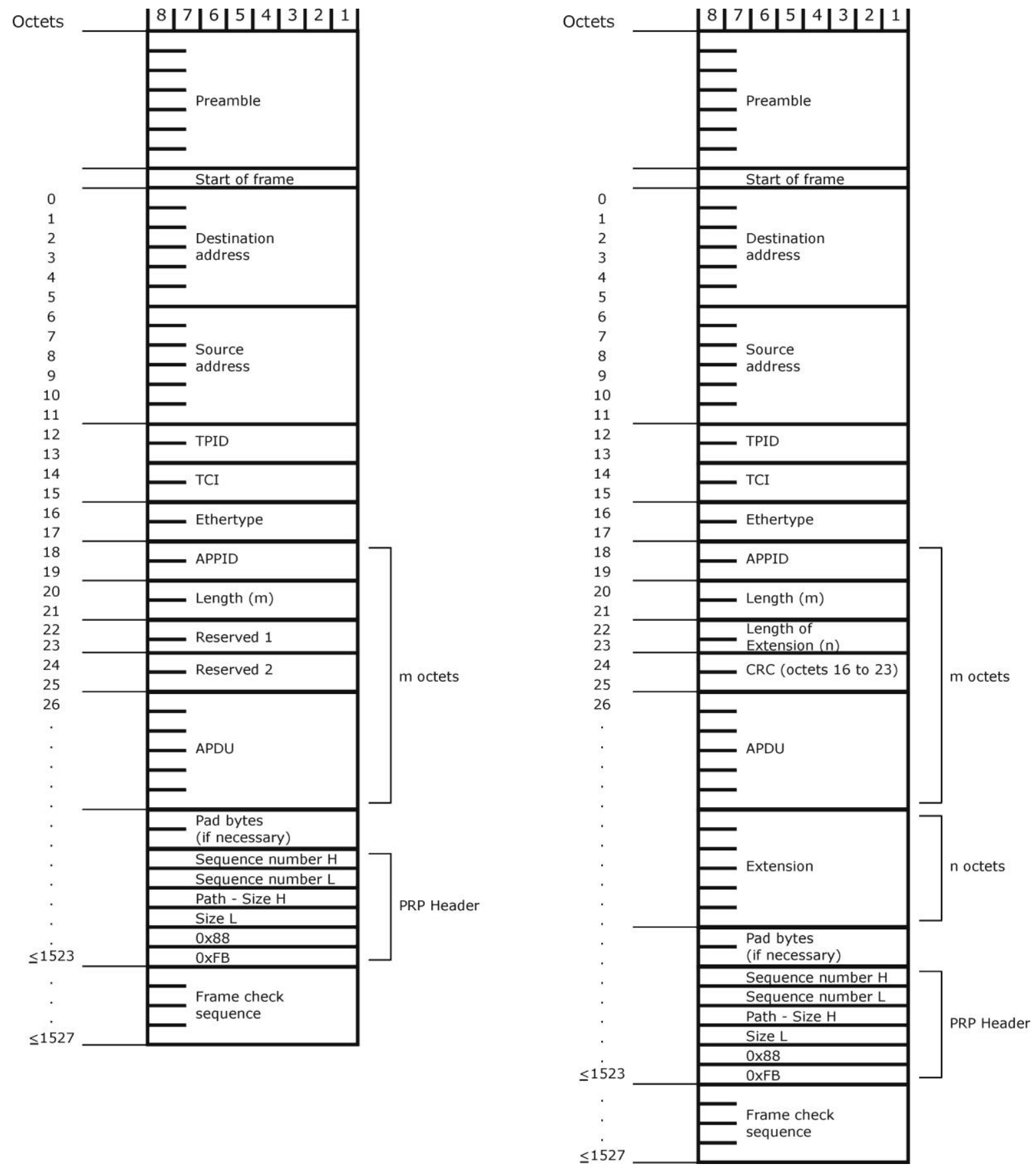

Fonte: o Autor

Basicamente, as mudanças ocorreram após o campo Length. O campo Reserved 1 foi substituído pelo campo Length of Extension. Seu valor é determinado contabilizando o número de octetos utilizados pelo campo Extension. O campo Reserved 2 foi substituído pelo campo $C R C$. Seu valor é determinado calculando o CRC dos octetos 16 ao 23. Em seguida, é inserido o APDU (já especificado pela Norma IEC 61850-9-2) e o campo Extension, que contém o MAC (calculado de acordo com o RFC 2401, considerando como entrada todos os octetos anteriores ao campo Extension). No final, são inseridos o campo Pad Bytes, o header 
do Protocolo PRP e o campo Frame Check Sequence, também já especificados pela Norma IEC 61850-9-2 e pela Norma IEC 62439-3. O APDU, que contém os dados das amostras de tensão/corrente, não é criptografado. Isso possibilita que tanto os dispositivos seguros (capazes de executar o algoritmo HMAC) quanto os não seguros possam interpretar os dados das amostras.

Além do uso de codificação dos dados, outras políticas complementares também podem ser utilizadas para melhorar a segurança do barramento de processo. Como exemplos, podem ser citados o uso de switches inteligentes (e.g. capazes de identificar mensagens geradas massivamente por um Ataque DoS e bloquear este fluxo de mensagens) [28] e a análise de timestamp seguro (e.g. campo SmpCnt codificado pelo algoritmo HMAC para identificar mensagens falsas, fora de sequência, geradas por um Replay Attack) [42] [43].

Restaram ainda assuntos importantes, tais como o gerenciamento dos certificados e a dinâmica para a distribuição das chaves, que atualmente estão em discussão e devem ser definidos na versão 2 da Norma IEC 62351-6. 


\section{Proposta de Plataforma de Transformador de Potencial Óptico Digital com interface IEC 61850-9-2}

Conforme se pode observar no diagrama unifilar da Figura 13 existem inúmeros TIs instalados em uma subestação. O uso de TIs ópticos no SAS traz uma série de vantagens em relação aos TIs convencionais, tais como: não saturação em altas correntes, melhor resposta à componente de corrente contínua, menor peso e garantia de isolação elétrica entre os circuitos primário e secundário, etc. $\mathrm{O}$ Anexo 1 deste trabalho apresenta um resumo das principais tecnologias envolvidas na construção de TIs convencionais e de TIs não convencionais.

A implementação do barramento de processo segundo a Norma IEC 61850-9, tanto para interface de TIs convencionais quanto para TIs ópticos, também apresenta inúmeras vantagens, se comparado ao barramento de processo convencional, tais como: garantia de isolação elétrica entre os circuitos primário e secundário, teste de integridade do barramento, possibilidade de redundância, sincronismo de tempo dos IEDs e interoperabilidade de equipamentos de diferentes fabricantes através da padronização do processo de transmissão dos valores medidos, etc.

Uma das vertentes tecnológicas pesquisadas pelo Laboratório de Sensores Ópticos (LSO) da Escola Politécnica da Universidade de São Paulo (EPUSP) é a medição de grandezas elétricas do sistema de potência (corrente e tensão) através de TIs baseados em princípios ópticos. A partir do interesse do autor em aprofundar seus estudos sobre o barramento de processo segundo a Norma IEC 61850-9 e dos projetos de TIs ópticos em desenvolvimento no laboratório, surgiu a iniciativa deste trabalho, que tem como objetivo agregar estas duas tecnologias de forma a aproveitar o melhor de cada uma delas para o desenvolvimento de um protótipo inovador de TP óptico digital com interface IEC 61850-9-2.

\subsection{Plataforma de TP óptico digital com interface IEC 61850-9-2}

A proposta de plataforma de TP óptico digital com interface IEC 61850-9-2 tem como base os trabalhos previamente desenvolvidos pelo LSO para o projeto de um protótipo de TP óptico 
que utiliza como base um Interferômetro de Luz Branca (White Light Interferometer - WLI) para a medição da tensão em Sistemas Elétricos de Potência (SEP).

De acordo com os resultados apresentados no Capítulo 3, podem-se destacar as seguintes recomendações que devem ser atendidas por um TI óptico com interface segundo a Norma IEC 61850-9:

- variações da Norma IEC 61850-9

O TI óptico deve atender o formato de comunicação definido pela Norma IEC 61850-9-2. Esta norma estabelece, por exemplo, duas taxas de amostragens possíveis: 80 amostras/ciclo com transmissão de uma amostra em cada SV Message (para fins de proteção) e 256 amostras/ciclo com transmissão de 8 amostras em cada $S V$ Message (para fins de medição). $\mathrm{O}$ padrão definido pela Norma IEC 61850-9-1 deverá ser descontinuado no futuro.

- confiabilidade do barramento de processo

O TI óptico deve implementar metodologias que permitam a redundância do canal de comunicação com recovery time zero. As tecnologias mais promissoras são as redundâncias oferecidas pelo Protocolo PRP (para implementações mais críticas e complexas, nas quais investimento maior se justifica) e pelo Protocolo HSR (para implementações menos complexas e sensíveis a custo).

- sincronismo de tempo através do barramento de processo

O TI óptico deve ser capaz de sincronizar seu relógio interno (e por consequência, os instantes nos quais realiza suas amostras) através do barramento de processo utilizando o Protocolo PTP definido pela Norma IEEE 1588v2. Os formatos 1pps e IRIG-B também podem ser aceitos, de forma que o TI óptico seja compatível com outros dispositivos instalados anteriormente.

- segurança cibernética

O TI óptico deve ser capaz de implementar as metodologias de assinatura digital estabelecidas pela Norma IEC 62351-6, utilizando função hash criptografada baseada no algoritmo HMAC. 
- análise da qualidade da medição disponibilizada no barramento de processo

A Norma IEC 61869, atualmente em fase final de elaboração, deverá substituir a Norma IEC 60044. Mais atualizada, ela definirá uma série de novos requisitos, sobretudo para os TIs eletrônicos, que até o momento não foram estabelecidos, como a avaliação de resposta harmônica, a análise de atrasos oriundos das tecnologias utilizadas no projeto dos TIs eletrônicos e a avaliação de erros de medições enviadas através de SV Messages. É interessante que a plataforma de TI óptico proposta atenda aos requisitos estabelecidos pelo draft desta norma, antecipando-se a futuras exigências.

Portanto, aliando essas recomendações aos resultados obtidos nos trabalhos apresentados em [44] [45], o diagrama da Figura 56 representa a estrutura esperada para um TP óptico digital com interface IEC 61850-9-2.

Figura 56 - Estrutura esperada para um TP óptico digital com interface IEC 61850-9-2

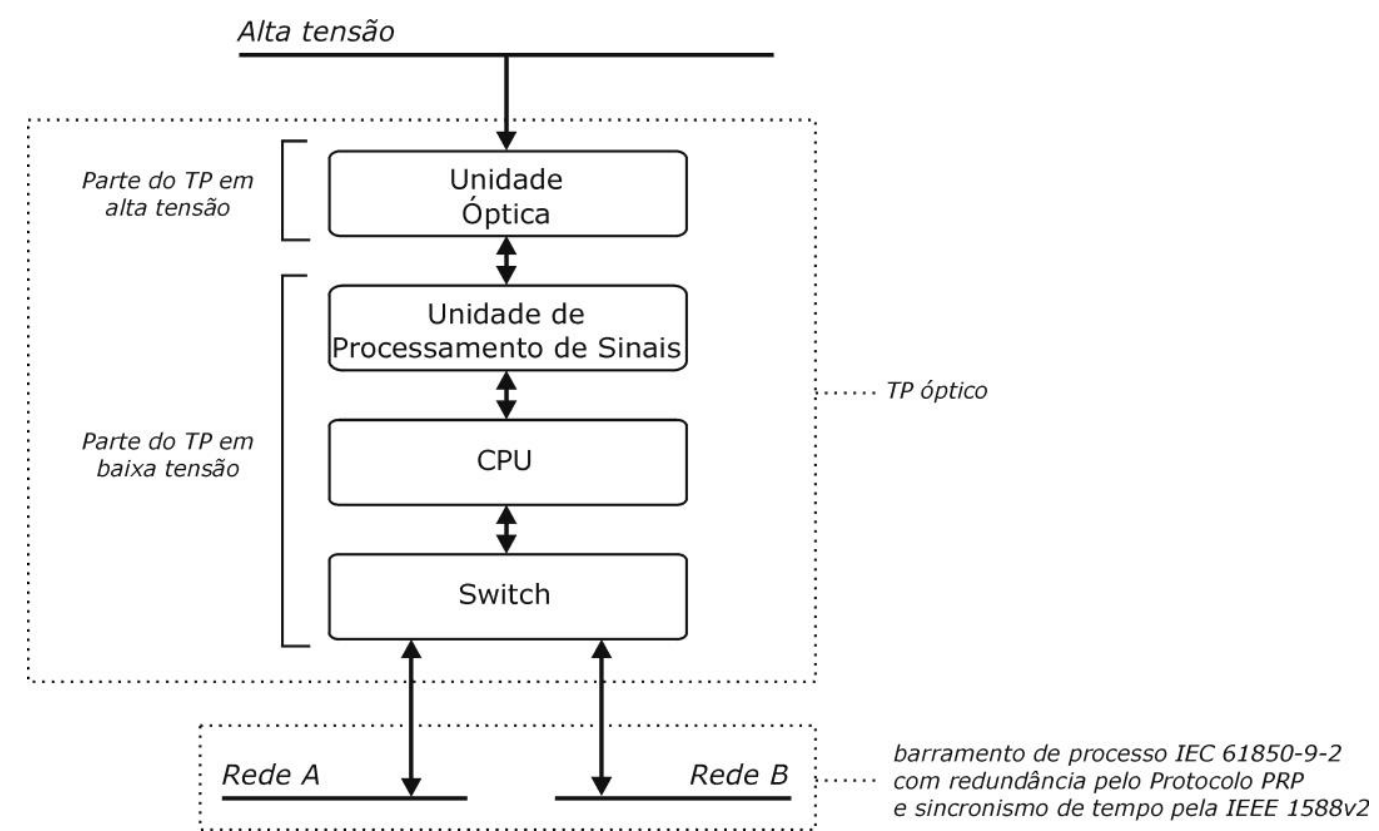

Fonte: o Autor

Para a estrutura apresentada na Figura 56, as principais características esperadas são:

- medição da alta tensão por princípios ópticos (neste caso, baseado na técnica WLI);

- um mesmo TP capaz de atender aos serviços de medição e de proteção;

- padrão de construção das mensagens no formato definido pela Norma IEC 61850-9-2 (utilizando APDU contendo ASDUs); 
- redundância do barramento de processo através dos Protocolos PRP/HSR;

- sincronismo de tempo através do barramento de processo segundo a Norma IEEE 1588v2;

- capacidade de amostragem do sinal de alta tensão de pelo menos 256 amostras/ciclo com taxa de transmissão de pelo menos 80 SV Messages/ciclo;

- análise da qualidade da medição disponibilizada baseada nos requisitos exigidos pela Norma IEC 61869-9;

- segurança dos dados através de assinatura digital baseada no algoritmo HMAC.

- barramento de processo utilizando fibra óptica em sua camada física.

Considerando que este trabalho caminha em conjunto com outro projeto também em desenvolvimento no LSO, que tem como objetivo a calibração de TIs in loco (o Anexo 2 apresenta um resumo desse projeto), será proposta uma plataforma simplificada, ilustrada pela Figura 57, que permitirá o estudo e a avaliação de algumas das principais tecnologias envolvidas, como a digitalização do processo óptico para medição da alta tensão, o sincronismo de tempo através do barramento de processo, os requisitos de tempo para medição e transmissão da amostra e a velocidade de execução do algoritmo de assinatura digital. O estudo destas tecnologias servirá como base para uma próxima etapa, em que será desenvolvido um TP óptico digital com as características apresentadas na Figura 56.

Figura 57 - Plataforma simplificada para avaliação do TP óptico com interface IEC 61850-9-2

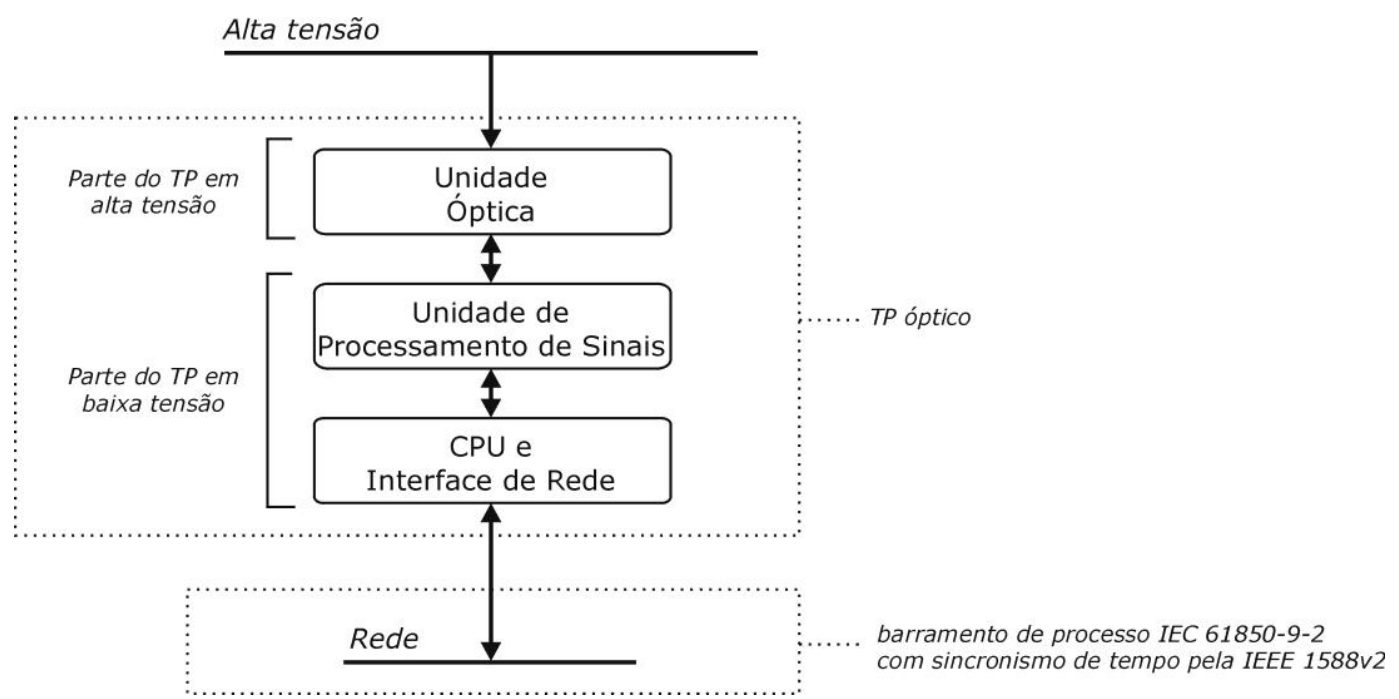

Fonte: o Autor

Outro ponto interessante a se destacar é que o bloco Unidade de Processamento de Sinais esta 
sendo projetado de forma que possa ser utilizado no bloco Unidade Óptica tanto um Interferômetro Sensor de Alta Tensão para a elaboração de um TP Óptico (baseado no Efeito Pockels) quanto um Interferômetro Sensor de Corrente para a elaboração de um TC Óptico (baseado no Efeito Faraday), conforme ilustra a Figura 58.

Figura 58 - Diagrama com os modelos de interferômetros que podem ser utilizados no bloco Unidade Óptica
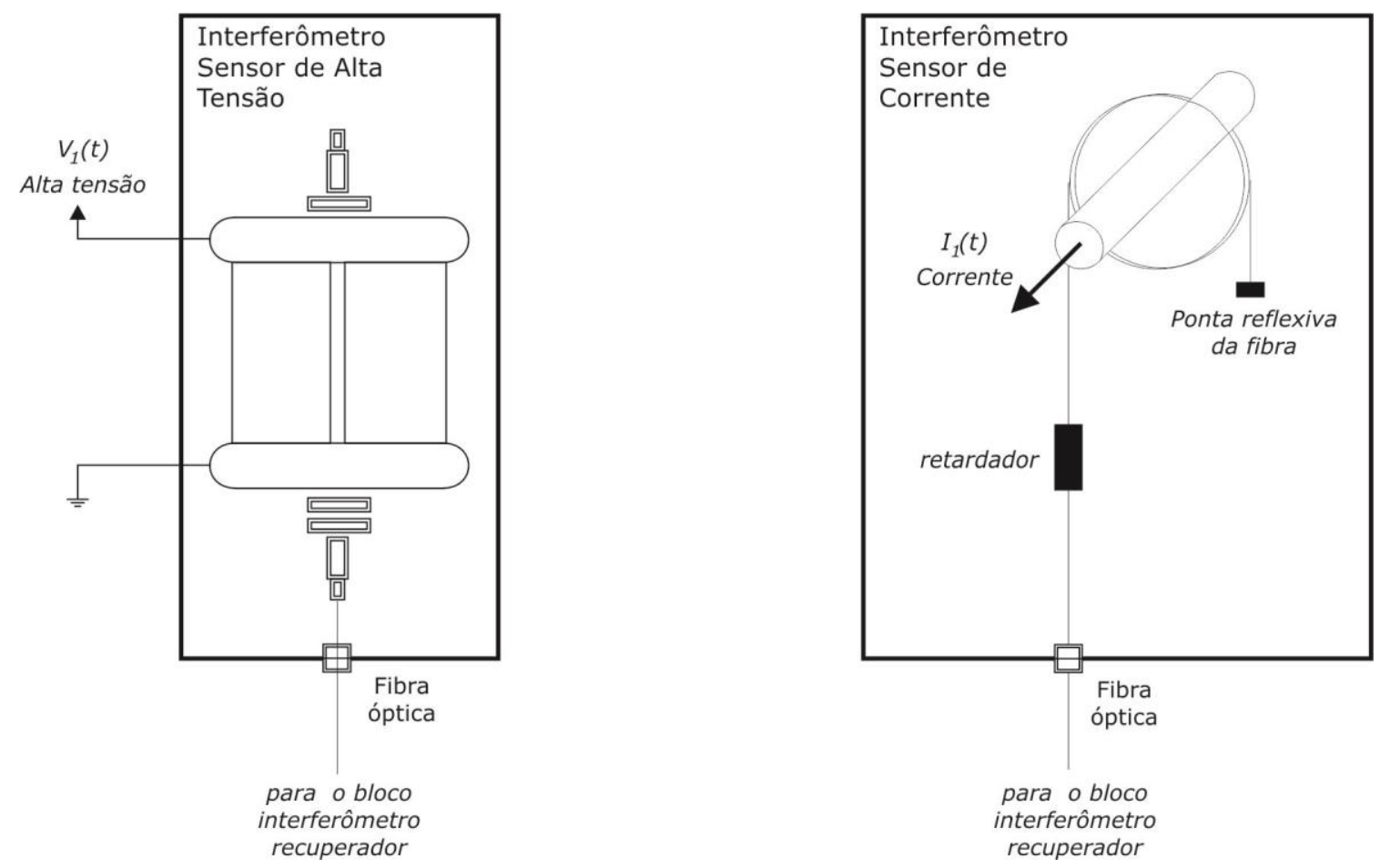

No projeto de TPs ópticos a alta tensão do sistema elétrico é aplicada no Interferômetro Sensor de Alta Tensão, presente no bloco Unidade Óptica. Este bloco consiste de um sensor Pockels, baseado em WLI, que modula o sinal óptico emitido por um Diodo Super Luminescente (Super Luminescent Diode - SLD) presente no bloco Unidade de Processamento de Sinais, conforme ilustrado na Figura 59, introduzindo uma diferença de caminho óptico (Optical Path Diference - OPD) entre duas componentes de polarização ortogonais deste sinal, de acordo com a forma de onda do sinal de alta tensão aplicado.

Em seguida, o sinal óptico tem sua OPD compensada por um segundo interferômetro (Interferômetro Recuperador) e é detectado por um Fotodetector (bloco DET), que converte o sinal óptico modulado para um sinal elétrico de corrente $I d(t)$ correspondente. 
Figura 59 - Diagrama em blocos da Unidade de Processamento de Sinais

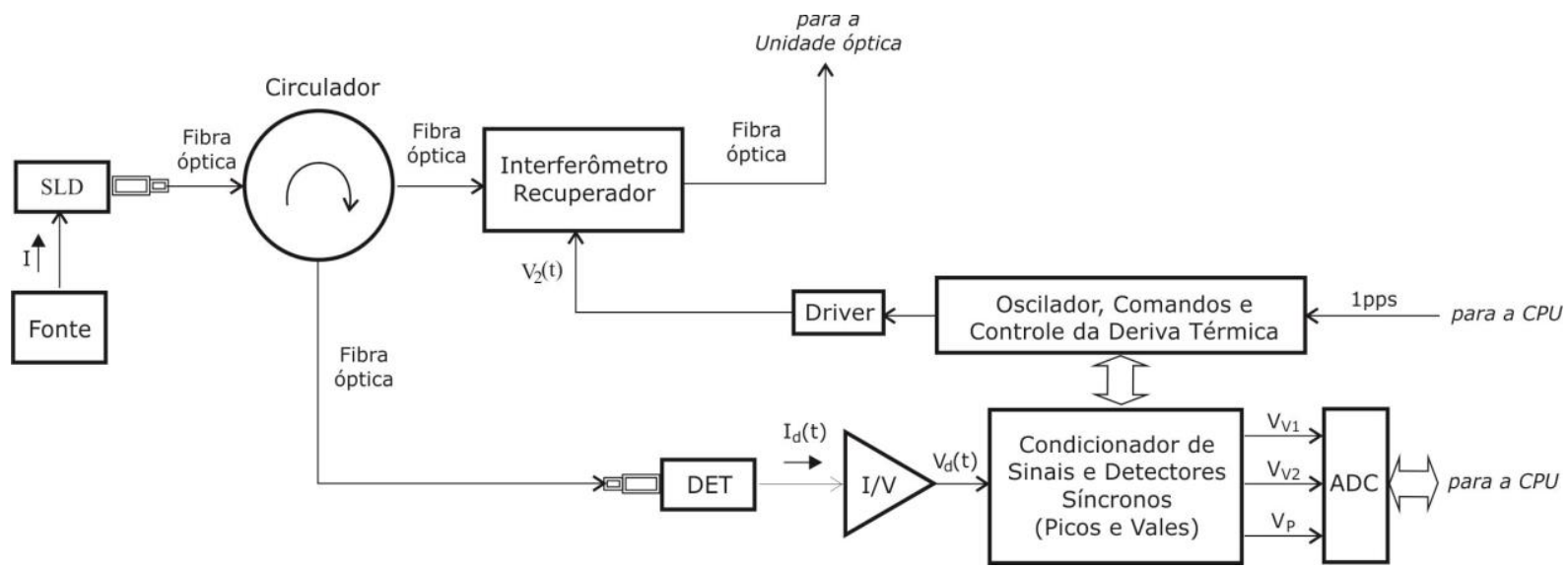

De acordo com [44] [45], o sinal $I d(t)$ pode ser expresso por:

Fonte: adaptado SANTOS (2009)

$$
I_{d}(t)=I_{d 0}\left\{1+\frac{1}{2} \cos \left[\phi_{1} \operatorname{sen} \omega_{1} t+\phi_{2} \operatorname{sen} \omega_{2} t\right]\right\}
$$

onde $\emptyset_{1}$ e $\emptyset_{2}$ são os atrasos de fase ópticos eletricamente introduzidos, respectivamente, pelo Interferômetro Sensor de Alta Tensão e pelo Interferômetro Recuperador. A Figura 60 apresenta um exemplo de sinal $I d(t)$ modulado por uma alta tensão senoidal aplicada no Interferômetro Sensor de Alta Tensão, considerando $\omega_{2}=16 \omega_{1}, \emptyset_{1}=0,5$ e $\emptyset_{2}=\pi / 2$, onde $\omega_{1}$ $=2 \pi \mathrm{f}_{1}, f_{1}$ é a frequência da alta tensão aplicada e $T_{1}=1 / \mathrm{f}_{1}$ é seu período. Similarmente, $\omega_{2}=$ $2 \pi \mathrm{f}_{2}$ e $T_{2}=1 / \mathrm{f}_{2}$.

Figura 60 - Exemplo de sinal Id(t)

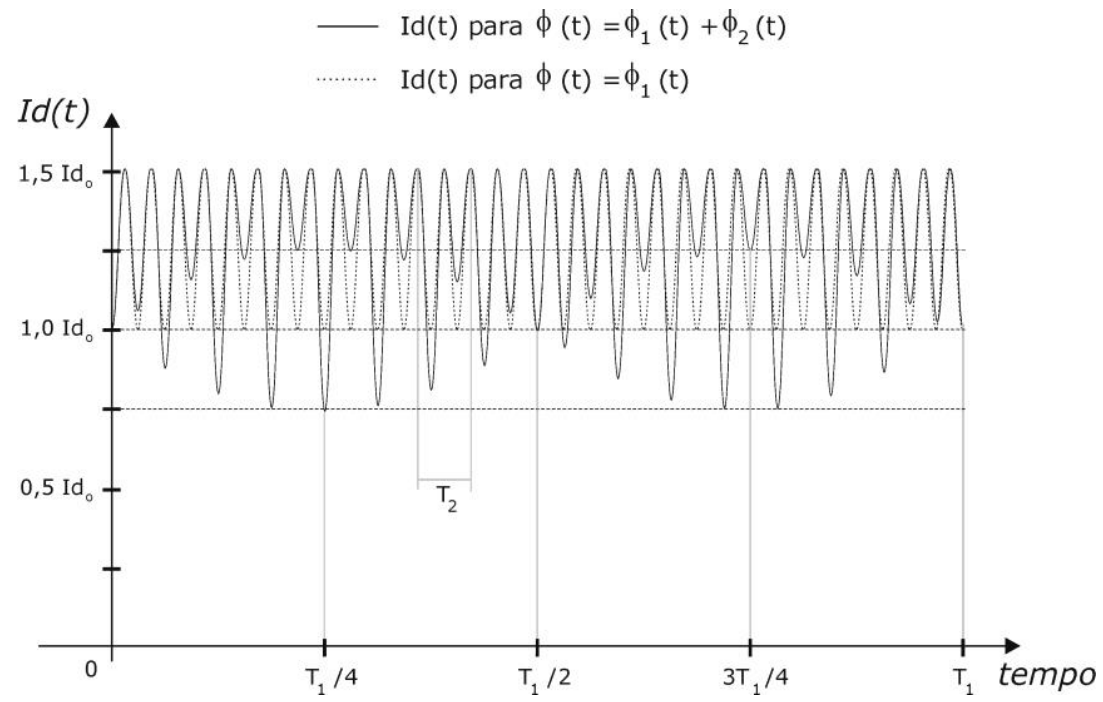

Fonte: adaptado SANTOS (2009)

O sinal $I d(t)$ é aplicado em um amplificador de transimpedância (bloco $I / V$ ), que converte o sinal de corrente $I d(t)$ em uma tensão $V d(t)$ correspondente. Seguindo as condições impostas 
em [44] [45], o sinal $V d(t)$ pode ser discretizado em amostras através da análise de um conjunto de valores de vales $\left(V_{V 1}\right.$ e $\left.V_{V 2}\right)$ e do valor de pico $\left(V_{P}\right)$ do sinal $V d(t)$, conforme mostra a Figura 61.

Figura 61 - Expansão, no domínio do tempo, do sinal $V d(t)$ no intervalo de tempo $T_{2}$

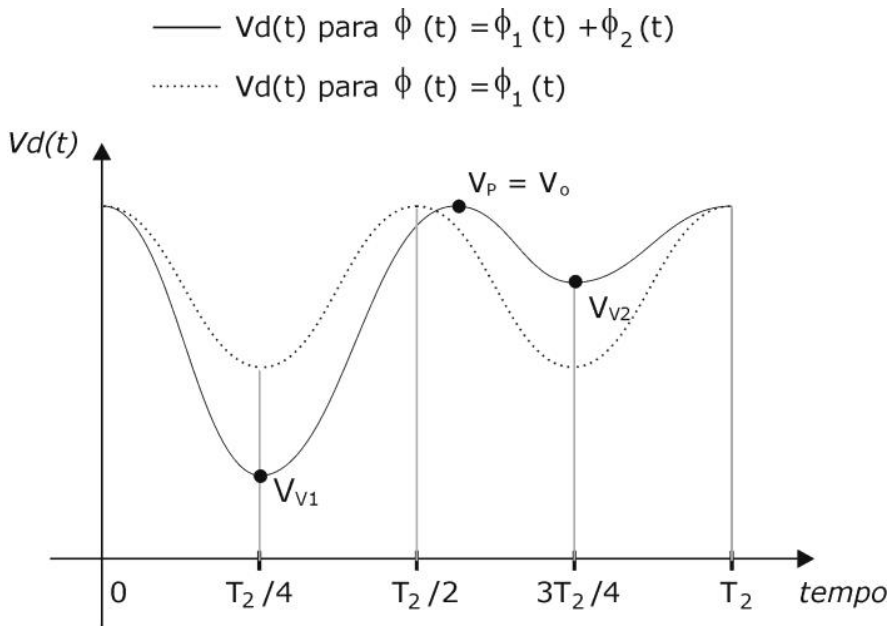

Fonte: adaptado SANTOS (2009)

Seguindo estas premissas, o valor da amostra de alta tensão pode ser obtido através da expressão:

$$
\left.\phi_{1}(\mathrm{t})\right|_{\phi_{2}=\pi / 2}=\operatorname{arcsen}\left(\frac{\mathrm{V}_{\mathrm{V} 2}-\mathrm{V}_{\mathrm{V} 1}}{\mathrm{~V}_{\mathrm{O}}}\right)
$$

Retornando à análise do diagrama em blocos da Figura 59, o bloco Oscilador, Comandos $e$ Controle da Deriva Térmica possui um oscilador interno termicamente estável, responsável por gerar o sinal elétrico $V_{2}(t)$ aplicado no bloco Interferômetro Recuperador. Este bloco também envia sinais de controle para os circuitos sample-and-hold presentes no bloco Condicionador de Sinais e Detectores Síncronos, de forma que eles possam amostrar de maneira síncrona as tensões $V_{V 1}, V_{V 2}$ e $V_{P}$. Antes de serem aplicados nos circuitos sample-andhold, as altas frequências do sinal $V d(t)$ são eliminadas por filtros anti-aliasing dentro do bloco Condicionador de Sinais e Detectores Síncronos. Posteriormente, as tensões $V_{V 1}, V_{V 2} \mathrm{e}$ $V_{P}$ são digitalizadas pelo conversor analógico digital presente no bloco $A D C$, de forma que possam ser tratadas pelo bloco CPU e Interface de Rede, ilustrados na Figura 62. Neste bloco, são calculadas as amostras dos valores da alta tensão primária medida, o sincronismo de tempo e o envio de mensagens pelo barramento de processo. Este bloco é constituído, basicamente, por um microcontrolador de alta performance com núcleo ARM Cortex-M4 (microcontrolador modelo STM32F407) e por circuitos eletrônicos responsáveis por implementar uma interface física de rede no padrão Ethernet, capaz de executar o sincronismo 
de tempo através do Protocolo PTP. O bloco I/O digital é constituído pelos ports do microcontrolador e faz a interface dos sinais digitais entre o bloco $C P U$ e o bloco $A D C$, de forma que a CPU controle o funcionamento do bloco $A D C$ e realize a leitura dos valores digitalizados de $V_{V 1}, V_{V 2}$ e $V_{P}$. A interface física de rede capaz de processar o Protocolo PTP foi elaborada com base nas propostas apresentadas em [46] e [47]. Ela implementa uma interface Ethernet single port auxiliada por hardware de sincronismo de tempo no padrão IEEE 1588v2 presente no ponto B (vide modelo apresentado pela Figura 39), sendo constituída por um bloco MAC responsável por gerar no hardware do microcontrolador um port de comunicação no padrão Ethernet, por um bloco Hardware 1588 responsável por auxiliar o microcontrolador no processo de sincronismo de tempo através do Protocolo PTP, e um bloco $P H Y$ responsável por modular os sinais digitais gerados pelo bloco MAC para os sinais elétricos necessários para que o bloco conector RJ45 consiga transmitir pelo barramento de processo os dados que compõem a SV Message.

\section{Figura 62 - Blocos CPU e Interface de Rede}

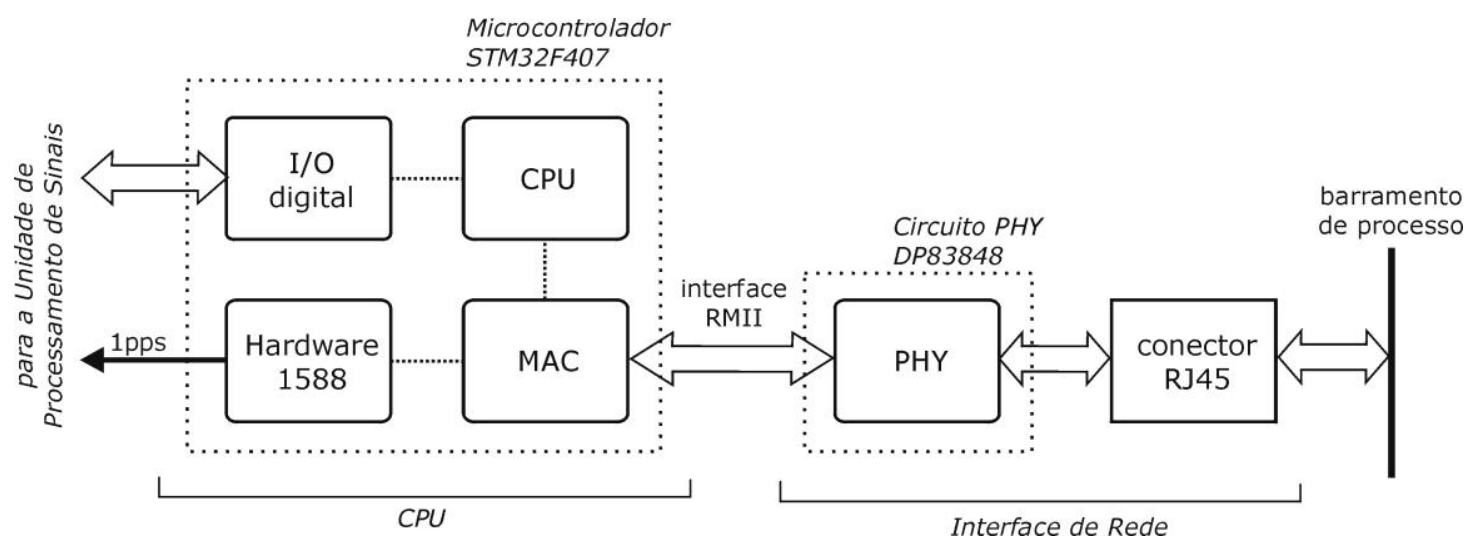

Fonte: o Autor

Uma vez que o processo de amostragem do sinal de alta tensão tem início no instante em que os circuitos sample-and-hold (presentes no bloco Unidade de Processamento de Sinais) executam suas amostras, que são disparadas de forma síncrona com o oscilador de alta precisão, é necessário sincronizar todo este processo de acordo com a base de tempo definida. Pelo fato do oscilador de alta precisão permitir ressincronismo via pulso externo no padrão 1pps e o microcontrolador escolhido possuir internamente um bloco Hardware 1588 com saída 1pps dedicada, este pulso será aplicado no oscilador de alta precisão para ressincronizálo. A taxa de amostragem pretendida para os testes iniciais é de 256 amostras/ciclo. Analisando as equações (1) e (2), conclui-se que o oscilador de alta precisão deve ser configurado com a mesma frequência definida para a taxa de amostragem, portanto, $15360 \mathrm{~Hz}$ (admitindo $60 \mathrm{~Hz}$ como frequência nominal da rede elétrica). 
Foram desenvolvidos no Laboratório de Sensores Ópticos, a partir dos trabalhos [44] e [45], os protótipos iniciais dos blocos Unidade Óptica e Unidade de Processamento de Sinais. A Figura 63, a seguir, apresenta uma imagem do protótipo do Interferômetro Recuperador.

Figura 63 - Protótipo do Interferômetro Recuperador

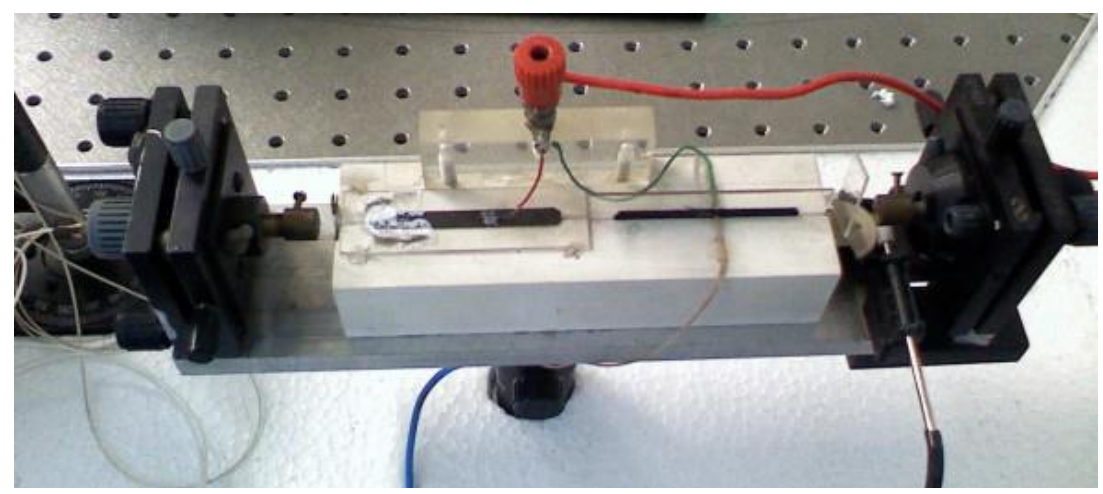

Fonte: SANTOS (2009)

A Figura 64 apresenta uma imagem do protótipo do Interferômetro Sensor de Alta Tensão.

Figura 64 - Protótipos do Interferômetro Sensor de Alta Tensão

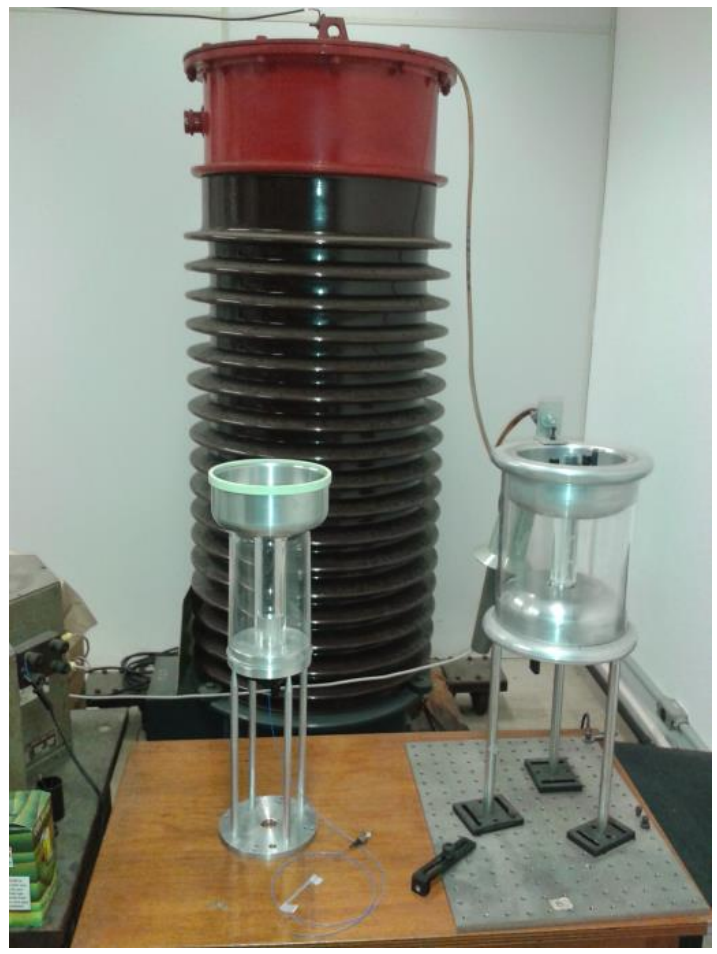




\subsection{Avaliação dos erros da plataforma de TP óptico digital proposta}

Para a plataforma de TP óptico, o autor propõe que os erros a serem avaliados possam ser classificados em duas categorias, conforme ilustra a Figura 65: o erro temporal da amostra $(\Delta \mathrm{t})$ e o erro de amplitude da $\operatorname{amostra}(\Delta \mathrm{Q})$.

Figura 65 - Ilustração dos erros a serem avaliados

TP em teste

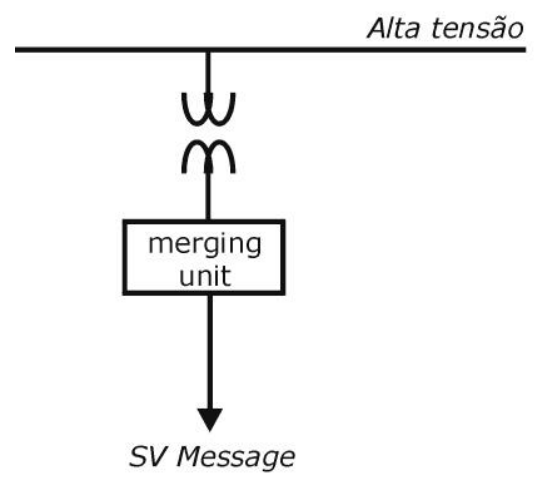

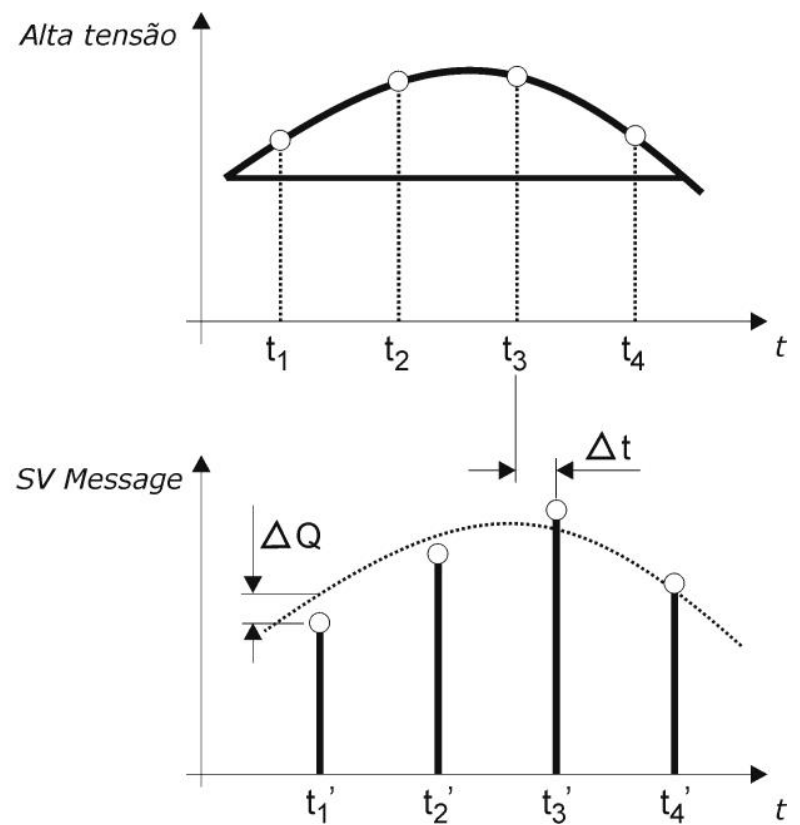

Fonte: o Autor O erro na amplitude da amostra decorre, principalmente, dos ganhos dos circuitos envolvidos, do atraso dos circuitos eletrônicos presentes antes da etapa de conversão analógica-digital, e das características do processo de conversão analógico-digital adotado.

O erro temporal de realização da amostra é devido, basicamente, ao efeito de três fatores somados:

Erro T1) erro de sincronismo do instante em que é realizada a amostra da alta tensão: este erro é causado pela diferença entre o ajuste do relógio interno e o sinal de sincronismo de tempo através do Protocolo PTP.

Erro T2) erro de atraso causado pelos circuitos eletrônicos envolvidos no processo de digitalização da amostra: os blocos Unidade Óptica e Unidade de Processamento de Sinais são compostos por circuitos eletrônicos (por exemplo, filtro anti-aliasing, circuito sampleand-hold e circuito fotodetector) que adicionam atrasos entre o sinal presente na sua entrada e 
na sua saída. Além deles, existe ainda um atraso inserido pelo tempo de trânsito da luz no enlace de fibras ópticas entre o SLD e o DET. Este atraso, contudo, é desprezível quando comparado com os citados anteriormente, desde que o comprimento do enlace não exceda algumas dezenas de metros.

Erro T3) erro de atraso devido ao tempo de processamento da amostra: após o valor ser amostrado nos circuitos sample-and-hold, existe um tempo de processamento desta amostra que se inicia no instante de sua digitalização pelo conversor $\mathrm{AD}$, passa pelo seu tratamento matemático e pelo processamento da pilha de protocolos por parte do microcontrolador, e termina com o envio da $S V$ Message pela interface de rede. Este tempo de processamento adiciona um atraso que deve ser considerado.

Antes de iniciar uma análise sobre como avaliar se a medição disponibilizada pela plataforma proposta atenderá aos requisitos necessários, cabe, neste ponto, uma discussão sobre a nomenclatura utilizada em algumas normas, com o intuito de esclarecer tais requisitos. De acordo com o Vocabulário Internacional de Metrologia [48], os seguintes conceitos são assim definidos:

- measurement accuracy (ou accuracy): expressa a exatidão de um valor, ou seja, o grau de concordância entre um valor medido e um valor verdadeiro de uma grandeza. $\mathrm{O}$ conceito de exatidão da medição não é expresso por um valor numérico, é um conceito qualitativo. Uma medida é considerada "mais exata" quando possui um erro menor.

- measurement precision (ou precision): expressa a precisão de um valor, ou seja, o grau de concordância entre indicações ou valores medidos obtidos por medições repetidas de um mesmo objeto ou objetos semelhantes, em condições definidas. A precisão da medição é normalmente expressa numericamente através de medidas de imprecisão, como desvio padrão, variância ou coeficiente de variação nas condições especificadas de medição.

- measurement error (ou error): expressa o erro de um valor, ou seja, o valor medido menos o valor de referência. $\mathrm{O}$ conceito de erro pode ser utilizado em situações onde exista um único valor de referência para cálculo do erro, o que ocorre quando uma calibração é feita utilizando como referência um padrão com incerteza de medição insignificante.

A seguir, a Figura 66 resume os conceitos apresentados. 


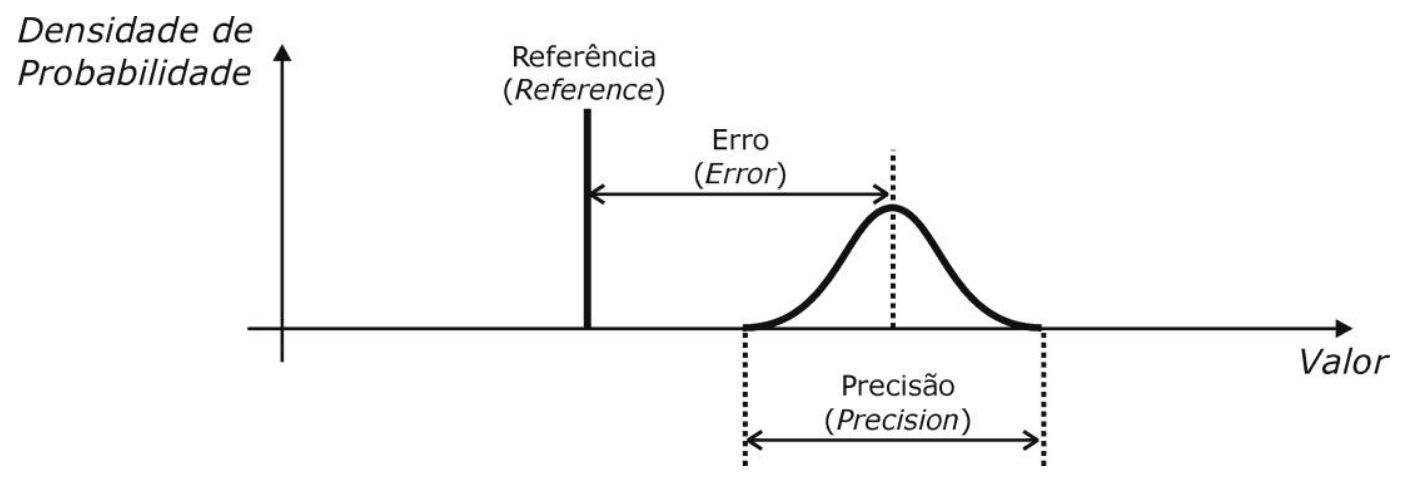

Fonte: o Autor A Tabela 4 demonstra um exemplo de aplicação dos conceitos de exatidão e de erro. Ela foi extraída da Norma IEC 60044-7 e estabelece os limites dos erros de relação e de atraso de fase da tensão medida para TIs de Potencial Eletrônicos a serviço da proteção. Analisando esta tabela, obtém-se a informação de que um dispositivo de accuracy class $3 P$ possui um limite de erro de $\pm 3 \%$ quando a ele é aplicada uma tensão acima de $5 \%$ do seu valor nominal. Já um dispositivo de accuracy class $6 P$ possui um limite de erro de $\pm 6 \%$ nas mesmas condições. O conceito de accuracy é utilizado aqui para representar, de forma qualitativa, que um dispositivo de accuracy class $3 P$ é mais exato (possui erro menor) que um dispositivo de accuracy class 6P. Os erros de cada accuracy class (ou classe de exatidão) são expressos numericamente em relação a uma referência.

Tabela 4 - Exemplo de aplicação dos conceitos de accuracy e de erro

\begin{tabular}{|c|c|c|c|c|c|c|c|c|c|}
\hline \multirow[t]{3}{*}{$\begin{array}{c}\text { Accuracy } \\
\text { class }\end{array}$} & \multicolumn{9}{|c|}{$\underset{\%}{U_{p} / U_{p n}}$} \\
\hline & \multicolumn{3}{|c|}{2} & \multicolumn{3}{|c|}{5} & \multicolumn{3}{|c|}{$x^{1)}$} \\
\hline & $\begin{array}{l}\boldsymbol{\varepsilon}_{\mathrm{u}} \\
\% \\
\pm\end{array}$ & $\begin{array}{c}\boldsymbol{\varphi}_{\mathbf{e}} \\
\text { minutes } \\
\pm\end{array}$ & $\begin{array}{c}\boldsymbol{\varphi}_{\mathbf{e}} \\
\text { centi- } \\
\text { radians } \\
\pm\end{array}$ & $\begin{array}{l}\boldsymbol{\varepsilon}_{\mathrm{u}} \\
\% \\
\pm\end{array}$ & $\begin{array}{c}\varphi_{\mathbf{e}} \\
\text { minutes } \\
\pm\end{array}$ & $\begin{array}{c}\boldsymbol{\varphi}_{\mathbf{e}} \\
\text { centi- } \\
\text { radians } \\
\pm\end{array}$ & $\begin{array}{l}\boldsymbol{\varepsilon}_{\mathbf{u}} \\
\% \\
\pm\end{array}$ & $\begin{array}{c}\varphi_{\mathbf{e}} \\
\text { minutes } \\
\pm\end{array}$ & $\begin{array}{c}\varphi_{\mathbf{e}} \\
\text { centi- } \\
\text { radians } \\
\pm\end{array}$ \\
\hline 3P & 6 & 240 & 7 & 3 & 120 & 3,5 & 3 & 120 & 3,5 \\
\hline $6 \mathrm{P}$ & 12 & 480 & 14 & 6 & 240 & 7 & 6 & 240 & 7 \\
\hline
\end{tabular}

a) Erro $T 1$

Fonte: Norma IEC 60044

A respeito do item T1, embora a Norma IEEE 1588v2 não especifique exatamente o procedimento para levantamento do erro de sincronismo, este pode ser verificado através da comparação entre o sinal da saída 1pps de um dispositivo receptor GPS (sinal de referência) e o sinal da saída 1pps do bloco Hardware 1588 utilizando, por exemplo, um osciloscópio [47] 
[49]. A Norma IEC 61850-5 define três classes de performance aplicadas para o sincronismo de tempo dos TIs, conforme Tabela 5.

Tabela 5 - Performance classes dos TIs

\begin{tabular}{|l|r|r|r|}
\hline $\begin{array}{c}\text { Time performance } \\
\text { class }\end{array}$ & Accuracy $(\mu \mathrm{s})$ & \multicolumn{2}{|c|}{ Reference } \\
\hline T3 & \pm 25 & P1 & \\
\hline T4 & \pm 4 & P2 & M1 \\
\hline T5 & \pm 1 & P3 & M2/3 \\
\hline
\end{tabular}

Fonte: Norma IEC 61850 As siglas P1, P2 e P3 representam as classes de exatidão utilizadas para classificar os TIs com finalidade de proteção. As siglas M1, M2 e M3 representam as classes de exatidão utilizadas para classificar os TIs com finalidade de medição.

O termo utilizado é accuracy, o que, segundo o Vocabulário Internacional de Metrologia, é um conceito qualitativo e não pode ser expresso numericamente. Portanto, as faixas de tolerância apresentadas pela norma não expressam o accuracy do TI. Os valores que estão mais próximos de representar este accuracy seriam, talvez, as classes de performance de tempo (time performance class T3, T4 e T5). A questão que surge é o que realmente expressam estes valores: a faixa de erro permitida ou a faixa de precisão permitida?

A resposta que parece ser mais plausível foi encontrada na definição do padrão de sincronismo de tempo através do pulso de 1pps, adotado antes do Protocolo PTP, no documento IEC 61850-9-2LE, conforme ilustrado na Figura 67.

Figura 67: Diagrama de "Accuracy of synchronization" segundo a IEC 61850-9-2LE

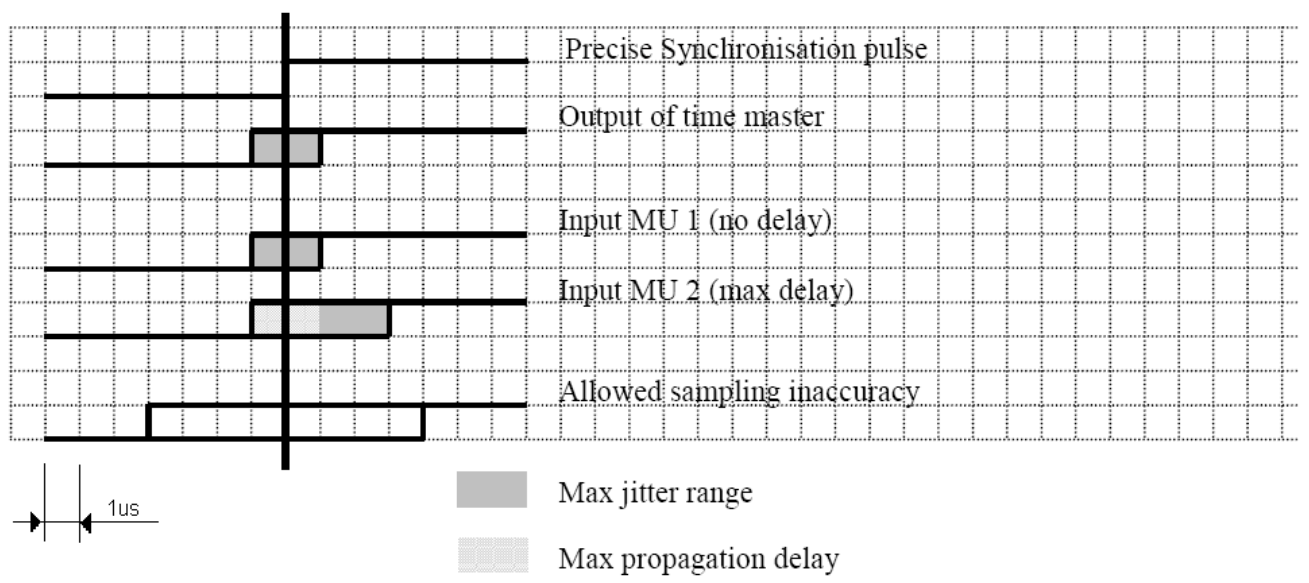

Fonte: IEC 61850-9LE 
Neste documento, menciona-se que a fonte do pulso de 1pps utilizado para sincronismo de tempo (time master) deve ter um accuracy de $\pm 1 \mu \mathrm{s}$. A transmissão deste pulso pode sofrer um atraso durante a sua transmissão de 0 a $2 \mu$ s, o que pode causar um jitter no receptor final de $\pm 2 \mu \mathrm{s}$. As amostras precisam ter seu timestamp com accuracy classe 4, conforme estabelecido pela Norma IEC 61850-5.

Novamente o termo accuracy é utilizado de forma questionável. Observa-se, entretanto, que o accuracy de $\pm 4 \mu$ s (gráfico allowed sampling inaccuracy) é estabelecido em relação a um pulso de 1pps de referência (gráfico precise synchronization pulse). A conclusão do autor é de que o pulso de 1 pps possui, na verdade, um precisão de $\pm 4 \mu$ s em relação à referência. Como o sincronismo de tempo através do Protocolo PTP pode ser checado através da comparação de pulsos no formato 1pps, é admissível, portanto, que o accuracy de $\pm 4 \mu$ s exigido pela Norma IEC 61850-5 seja analisado, na verdade, como um erro máximo de $\pm 4 \mu \mathrm{s}$ em relação a um pulso de 1 pps de referência.

O bloco CPU e Interface de Rede proposto utilizará o microcontrolador STM32F407, o hardware 1588 interno do microcontrolador e a pilha do Protocolo PTP proposto pela fabricante ST Microelectronics, o que, de acordo com [47], oferece um sincronismo de tempo com erro máximo dentro da faixa de $\pm 1 \mu$ s atendendo, no mínimo, à faixa de erro máximo de $\pm 4 \mu$ s exigido pela classe T4 da Norma IEC 61850-5, utilizada pelos TIs com finalidade de proteção classe P2, e pelos TIs com finalidade de medição classe M1. Isso favorece, portanto, a implementação de um único TI óptico com interface IEC 61850-9-2 habilitado para finalidades de proteção e medição.

\section{b) Erro $T 2$}

A respeito do item $\mathrm{T} 2$, atualmente não é especificado em norma como medir este erro diretamente. Analisando seus principais fatores geradores (atraso dos circuitos eletrônicos), o autor conclui que o efeito final é semelhante a um erro de atraso de fase entre o sinal presente no primário e o sinal presente no secundário de um TI convencional. Ou seja, este erro pode ser avaliado como um erro de fase entre o sinal presente no primário do TI e o sinal discretizado transmitido através das SV Messages.

Através do software MATLAB ${ }^{\circledR}$, foram desenvolvidas algumas simulações matemáticas com o objetivo de estimar o erro introduzido durante o cálculo das amostras da alta tensão medida. De acordo com a Equação (7), cada amostra é calculada através da análise de um conjunto de 
valores de vales e do valor de pico. Idealmente, cada amostra seria gerada sem nenhum erro em uma situação onde o valor da alta tensão medida não mudasse de valor no intervalo de tempo entre dois vales. Por exemplo, caso a frequência de oscilação fosse $15360 \mathrm{~Hz}$, este intervalo de tempo giraria em torno de $65.1 \mu$ s. Na prática, para um sinal de alta tensão variável no tempo, como o sinal senoidal da rede elétrica, isso não acontece, o que acaba por gerar um erro no cálculo das amostras. Para compensá-lo, duas hipóteses foram formuladas. A partir da aplicação de um sinal de alta tensão de referência para calibração do TI:

a) assume-se que a amostra calculada não possui erro de magnitude, mas que foi amostrada com um erro de tempo máximo na faixa de $\pm \Delta t$, se comparado com o instante de amostragem correto. Portanto, uma correção do instante de amostragem teria de ser realizada;

b) assume-se que a amostra calculada foi amostrada no instante correto, mas que tenha erro de magnitude. Portanto, uma correção de ganho $G$ da amostra teria de ser feita.

Para as simulações matemáticas realizadas neste trabalho, foi adotada a hipótese (b) com o objetivo de priorizar um melhor controle do instante de amostragem. Portanto, cada amostra calculada será corrigida por um ganho $G$, conforme Equação (8), a seguir:

$$
\left.\phi_{1}(\mathrm{t})\right|_{\phi_{2}=\pi / 2}=\mathrm{G} \times \operatorname{arcsen}\left(\frac{\mathrm{V}_{\mathrm{V} 2}-\mathrm{V}_{\mathrm{V} 1}}{\mathrm{~V}_{\mathrm{O}}}\right)
$$

Durante cada intervalo de tempo $T_{2}$ do sinal $V d(t)$ (que compreende um conjunto de dois vales $V_{V 1}$ e $V_{V 2}$ e um pico $V_{P}$ ), o instante de amostragem adotado é constante e igual a $T_{2} / 2$, conforme ilustra a Figura 68, a seguir. 


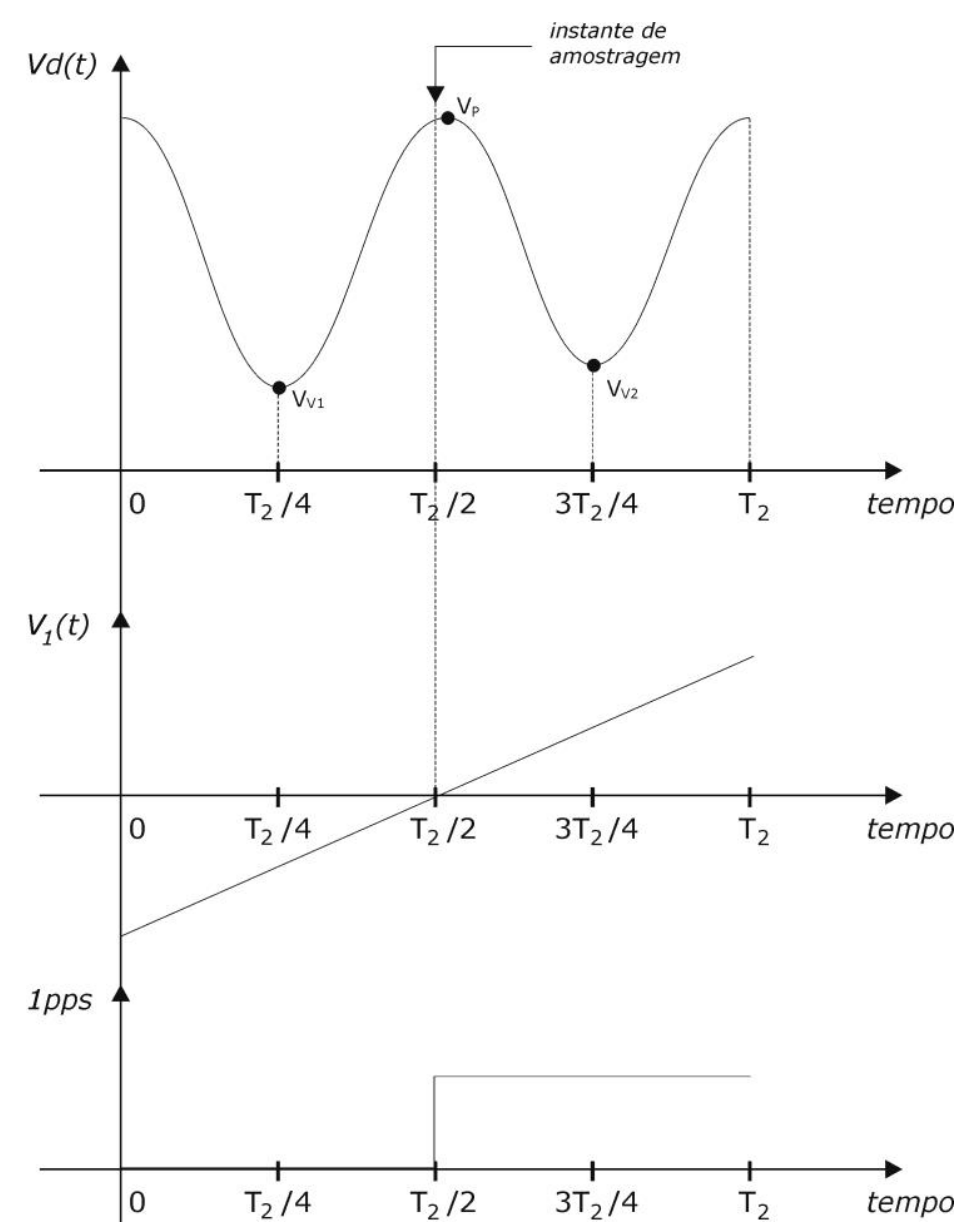

Fonte: o Autor Para que o erro possa ser minimizado e mensurado de forma adequada, será admitida também a hipótese de se utilizar como referência um sinal de alta tensão senoidal $V_{l}(t)$ sincronizado no tempo, com passagem pelo zero de seu semiciclo negativo para o semiciclo positivo no instante em que se inicia um novo segundo na base de tempo definido pelo padrão UTC. Nesta situação, é interessante que o sincronismo do oscilador de elevada precisão seja feito de tal forma que o instante de amostragem da primeira amostra deste sinal senoidal (o instante de sua primeira passagem pelo zero) coincida com o instante de amostragem apresentado na Figura 68. Em outras palavras, o instante $T_{2} / 2$ deve coincidir com a passagem pelo zero do sinal senoidal.

A definição do sinal de alta tensão $V_{l}(t)$ aplicado nas simulações tem como base a resposta do interferômetro sensor de alta tensão, cujo princípio de funcionamento é baseado no modulador eletro-óptico de amplitude transversal por efeito Pockels [45] da Figura 69. 
Figura 69 - Modulador eletro-óptico de amplitude transversal por efeito Pockels

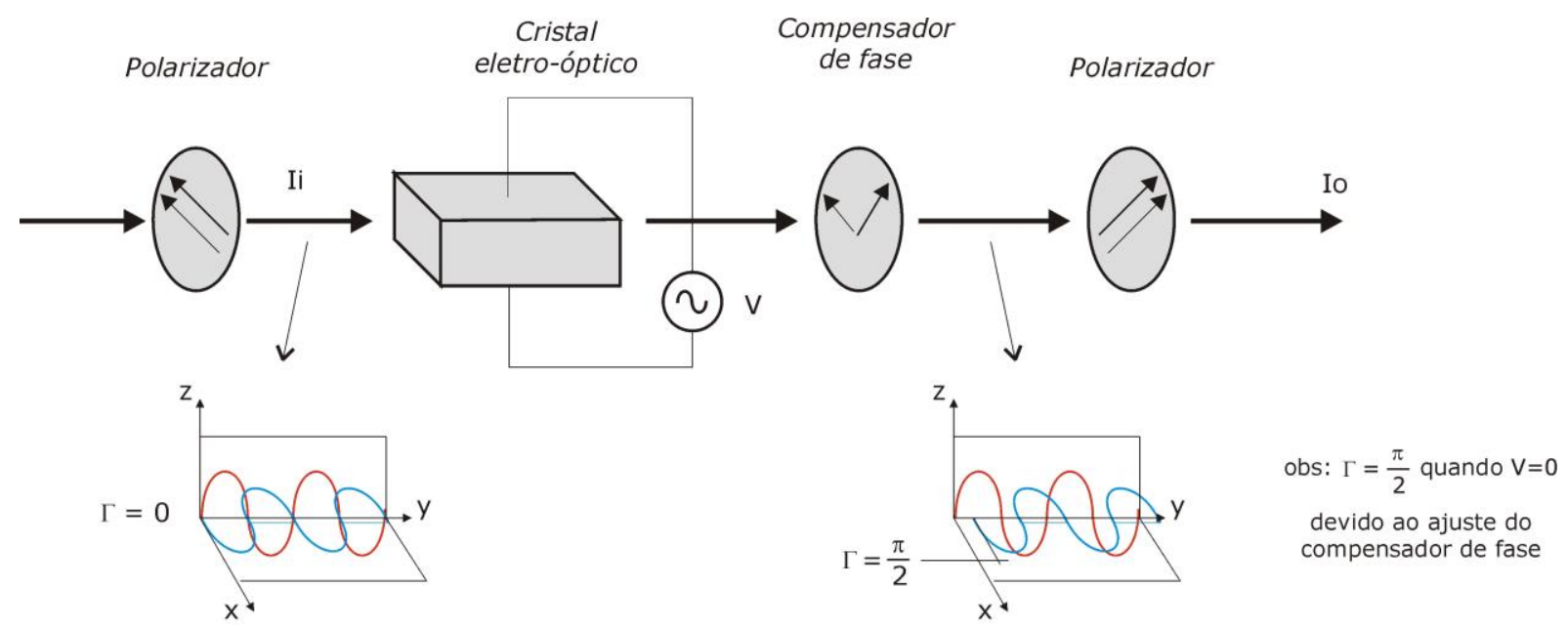

\section{Legenda:}

$\Gamma=$ atraso de fase relativo entre as componentes do campo elétrico

Ii = intensidade luminosa do feixe de luz de entrada

Io = intensidade luminosa do feixe de luz de saída

Fonte: o Autor

Nestas condições o Fator de Transmissão de Intensidade Luminosa $(T)$ deste conjunto pode ser expresso pela equação:

$$
\mathrm{T}=\frac{\mathrm{I}_{\mathrm{o}}}{\mathrm{I}_{\mathrm{i}}}=\operatorname{sen}^{2}\left(\frac{\Gamma}{2}\right)=\operatorname{sen}^{2}\left(\frac{\phi}{2}\right)=\operatorname{sen}^{2}\left(\frac{\pi}{4}+\frac{1}{2} \pi \frac{\mathrm{V}}{\mathrm{V}_{\pi}}\right)
$$

A Figura 70 ilustra a função de transferência ( $\mathrm{T}$ em função de $\mathrm{V}$ ) esperada para este modulador. 
Figura 70 - Função de transferência (T em função de V) do modulador eletro-óptico de amplitude transversal por efeito Pockels

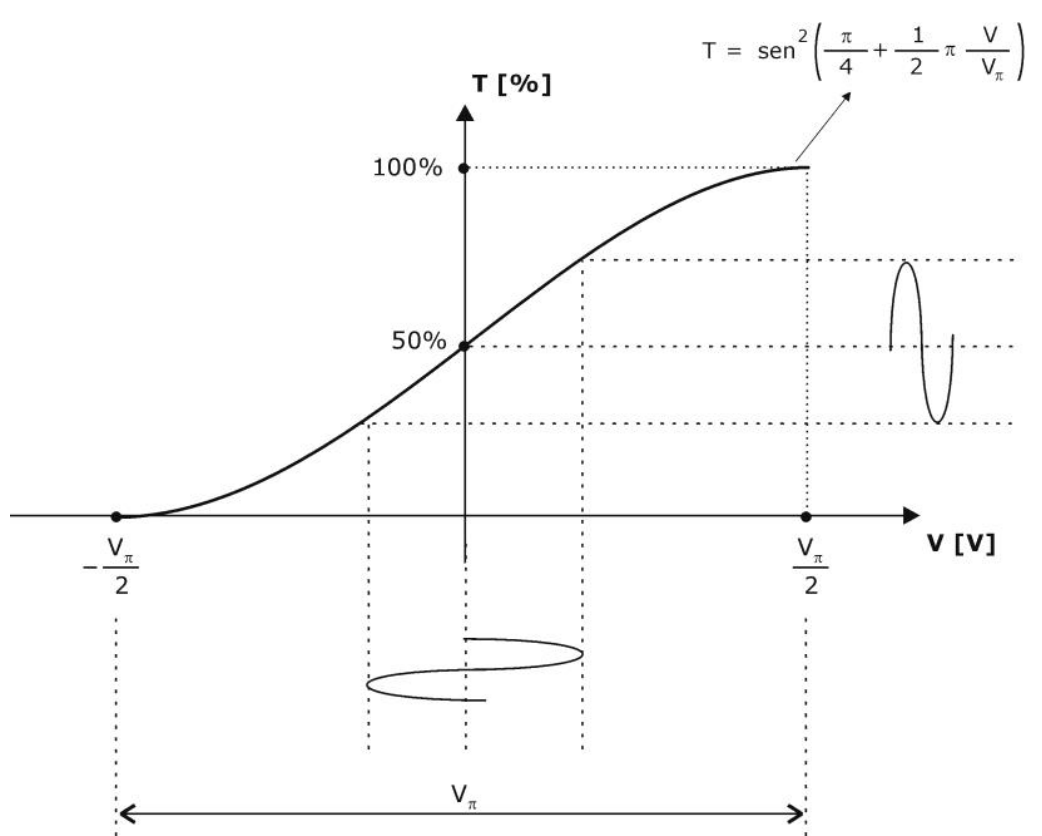

Fonte: o Autor

Pode-se também calcular $\Gamma$ em função da tensão aplicada, isolando o termo $\Gamma$ da Equação (9):

$$
\Gamma=\phi=\frac{\pi}{2}+\pi \frac{\mathrm{V}}{\mathrm{V}_{\pi}}
$$

A Figura 71 demonstra a função de transferência ( $\Gamma$ em função de $\mathrm{V})$ esperada.

Figura 71 - Função de transferência (Гem função de V) do modulador eletro-óptico de amplitude transversal por efeito Pockels

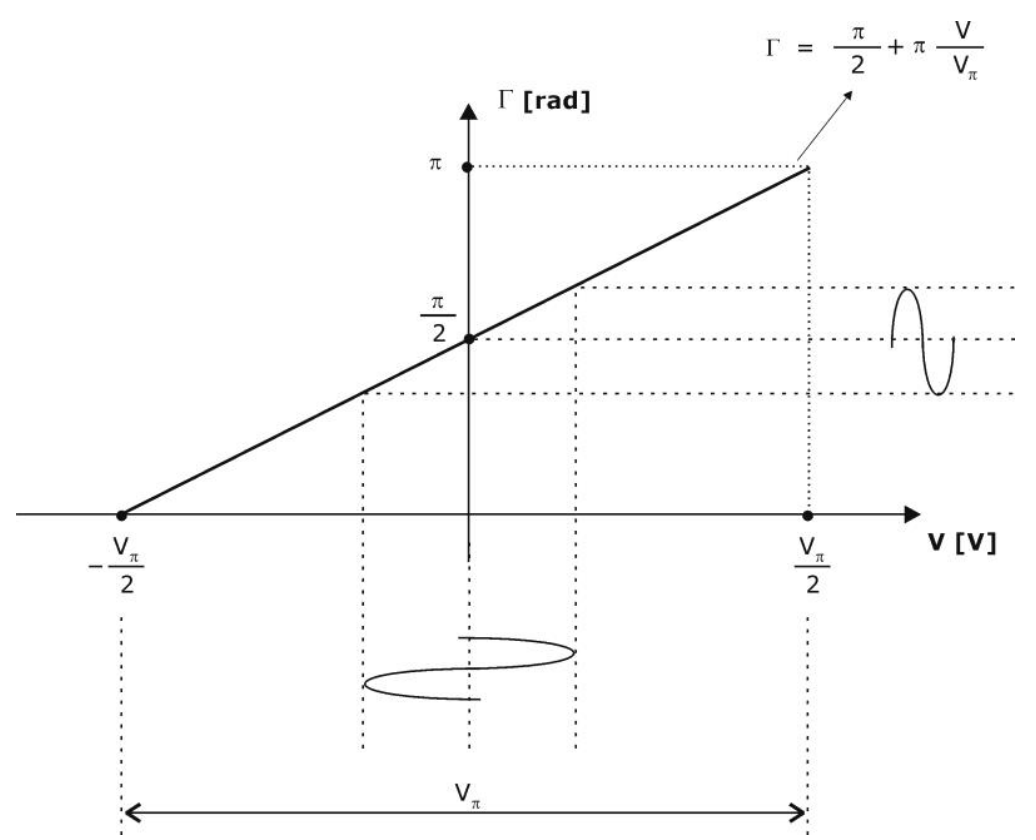

Define-se $V_{\pi}$ (tensão de meia onda) como sendo o valor da tensão, característico de cada 
configuração eletro-óptica, necessário para atrasar em $\pi$ radianos além do atraso natural induzido pelo compensador de fase.

Considerando $\phi$ como sendo o atraso de fase óptico induzido eletricamente pelo interferômetro sensor de alta tensão $\left(\phi=\phi_{1}\right), V_{l}$ como sendo a alta tensão aplicada no interferômetro sensor de alta tensão $\left(V=V_{l}\right)$ e respeitando as condições impostas em [45], em que não se utiliza compensador de fase, pode-se definir $\phi_{1}$ como sendo:

$$
\phi_{1}=\pi \frac{V_{1}}{V_{\pi}}
$$

Admitindo um exemplo hipotético onde o interferômetro sensor de alta tensão seja utilizado em um TP óptico de $69 \mathrm{KV}$, o valor pico a pico nominal deste TP óptico $\left(V_{P P}\right)$ será:

$$
\mathrm{V}_{\mathrm{PP}}=\frac{69 \mathrm{KV}}{\sqrt{3}} \times \sqrt{2} \times 2=112,67 \mathrm{KV}
$$

Considerando ainda que o interferômetro sensor de alta tensão tenha sido projetado de forma que a excursão do sinal de alta tensão corresponda a sua tensão de meia onda $\left(V_{P P}=V_{\pi}\right)$, temse que:

$$
\phi_{1}=\pi \frac{\mathrm{V}_{1}}{\mathrm{~V}_{\mathrm{PP}}}
$$

Com base na simulação da Figura 60 (onde o atraso de fase $\phi_{1}=0,5$ ) e na Equação (13) o valor de $V_{l}$ necessário para gerar este valor de atraso de fase será:

$$
0,5=\pi \frac{\mathrm{V}_{1}}{112,67 \mathrm{KV}} \longrightarrow \mathrm{V}_{1}(\mathrm{t})=17,93 \operatorname{sen} \omega_{1} \mathrm{t}[\mathrm{KV}]
$$

Esta condição (tensão aplicada bem menor do que $\mathrm{V}_{\pi}$ ) é tipicamente utilizada em sensores ópticos de tensão, pois se opera numa região bastante linear da curva de transferência ilustrada pela Figura 70.

A Figura 72, a seguir, apresenta o sinal $V d(t)$ calculado através da simulação no software MATLAB $^{\circledR}$ com base na Equação (6), nos valores propostos no exemplo da Figura 60, e na taxa de amostragem pretendida de 256 amostras/ciclo. 
Figura 72 - Sinal Vd(t) calculado

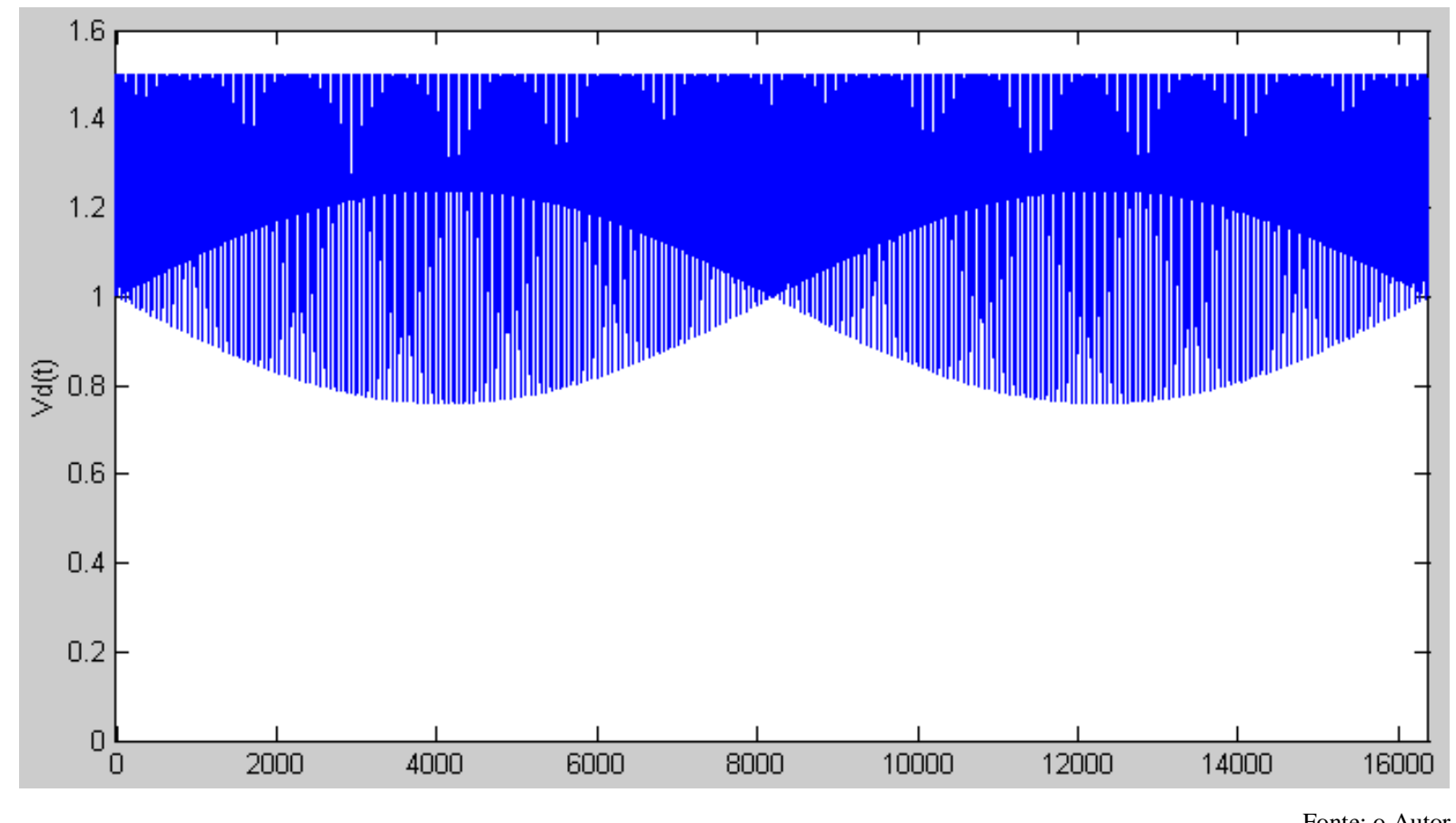

A Figura 73 ilustra o sinal de alta tensão $V_{l}(t)$ e as 256 amostras calculadas com base na Equação (8), admitindo ganho $G$ igual a 40 .

Figura 73- Sinal de alta tensão $V_{l}(t)$ (linha contínua) e amostras calculadas (sinal discretizado)

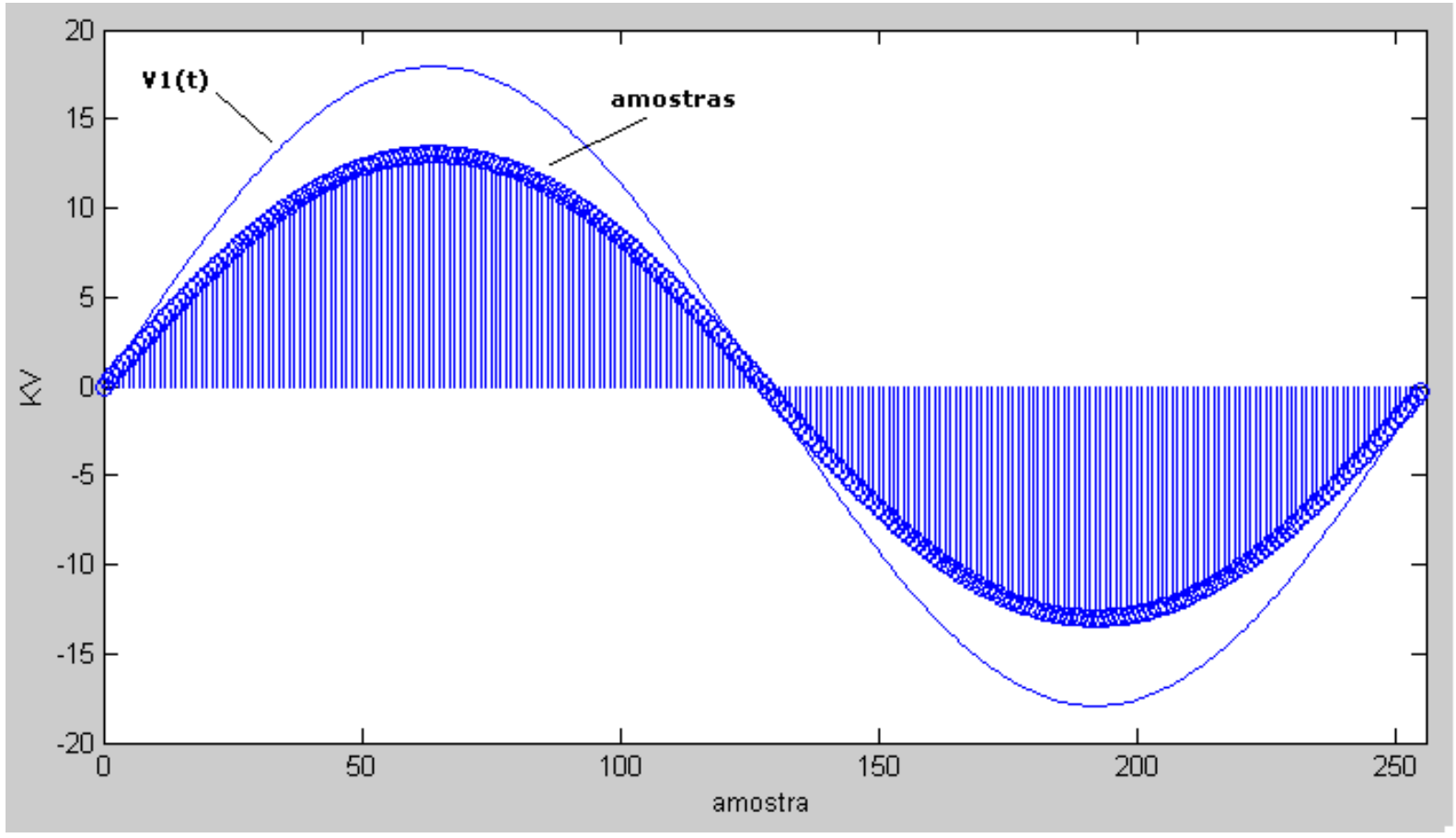

Fonte: o Autor

Os primeiros resultados mostraram que os valores de erro estimados entre cada amostra calculada e o sinal de referência $V_{l}(t)$ variam de acordo com o ganho $G$ ajustado, e sua 
distribuição não é linear. A Figura 74 demonstra os resultados dos erros de cada amostra admitindo um ganho $G$ igual a 54, e a Figura 75, para um ganho $G$ igual a 55. Em ambos os casos, os erros foram multiplicados por 10, para melhor visualização.

Figura 74 - Sinal de alta tensão $V_{l}(t)$ (linha contínua) e os erros calculados para cada amostra (sinal discretizado multiplicado por 10 para melhor visualização) para um ganho G igual a 54

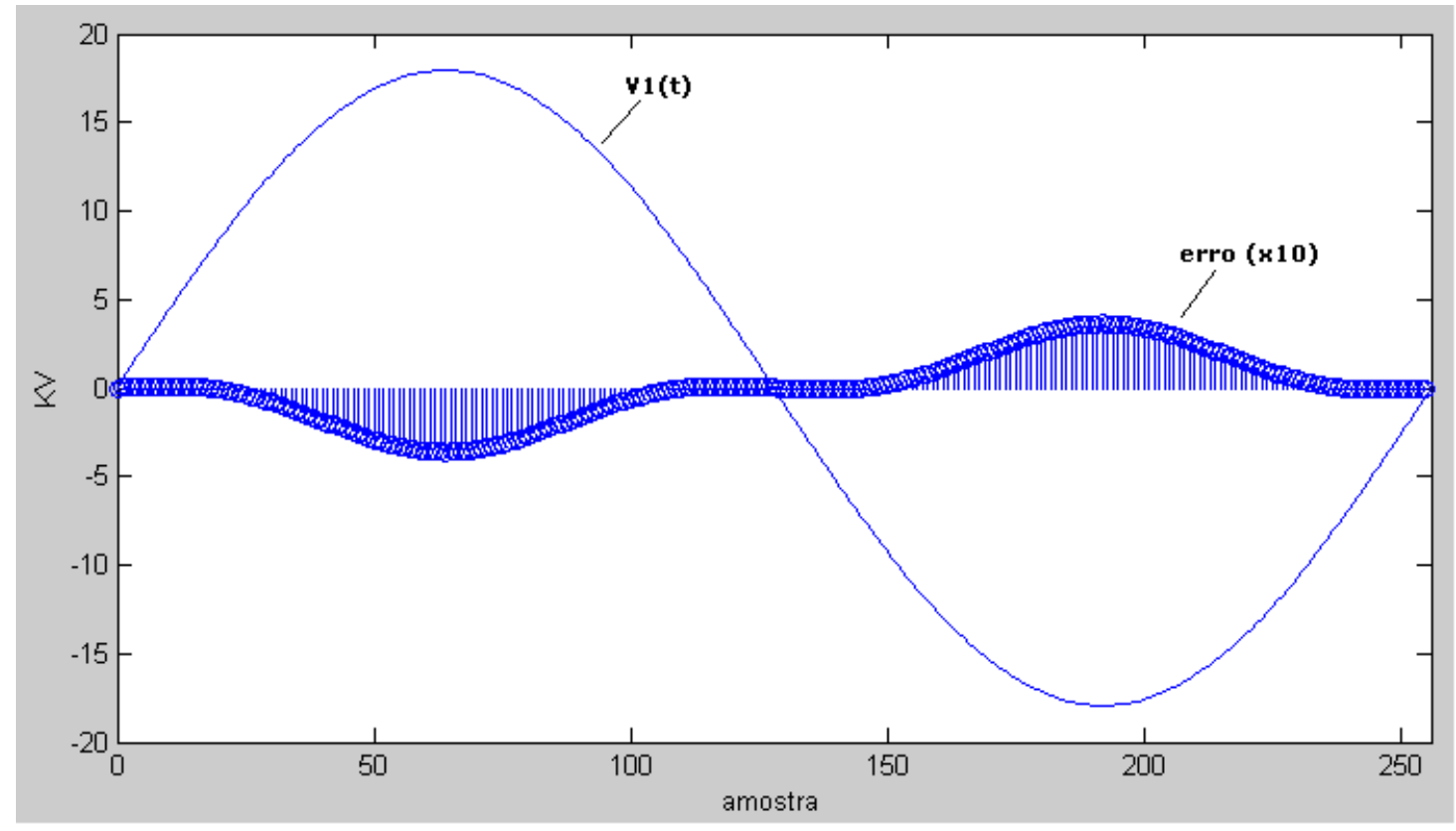

Fonte: o Autor

Figura 75 - Sinal de alta tensão $V_{l}(t)$ (linha contínua) e os erros calculados para cada amostra (sinal discretizado multiplicado por 10 para melhor visualização) para um ganho G igual a 55

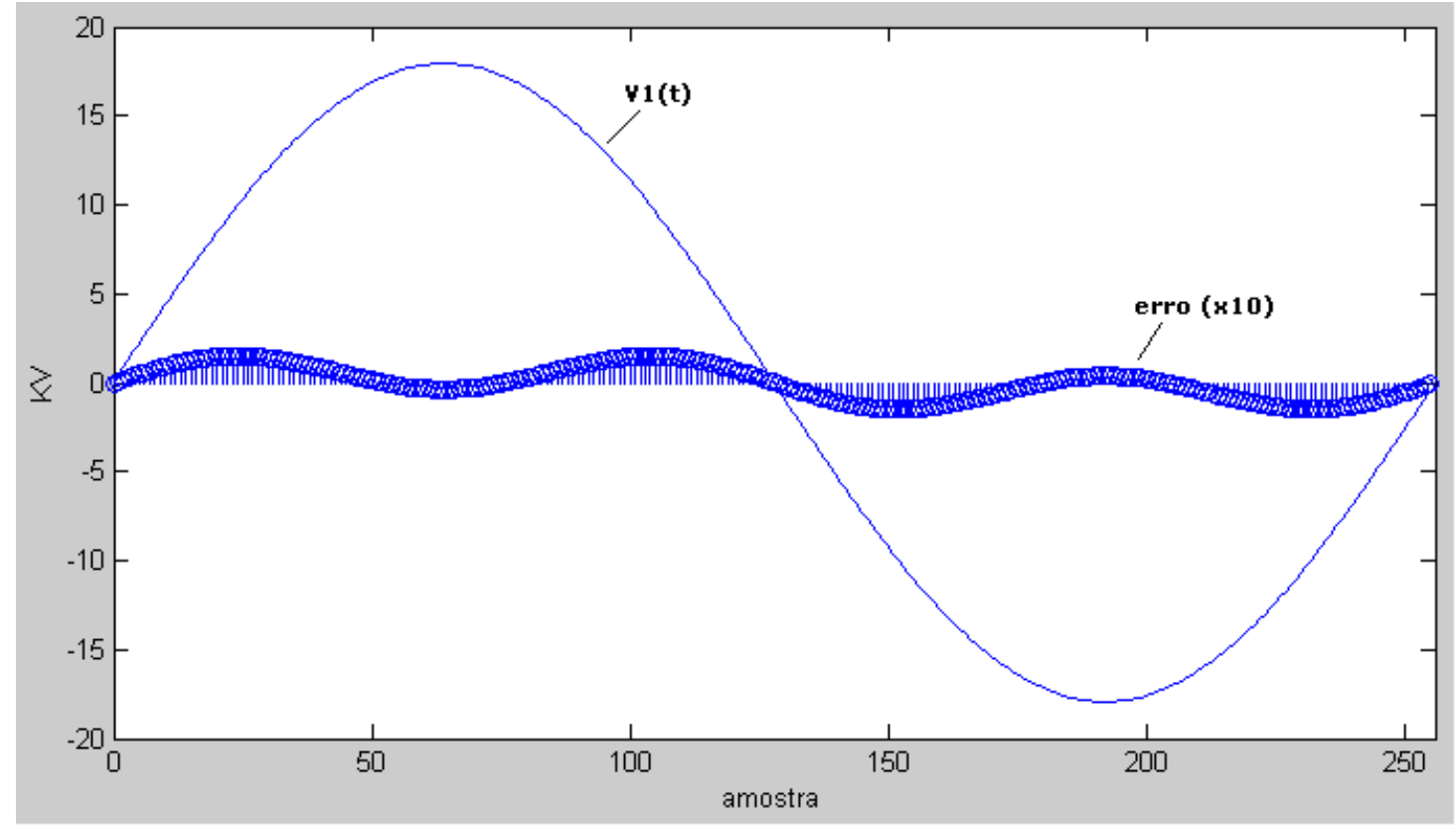

Fonte: o Autor

Buscando o melhor ajuste do ganho $G$ que minimize os erros de magnitude das amostras, o autor propõe neste trabalho a utilização de uma análise numérica baseada no Método dos 
Mínimos Quadrados, devido a excelente confiabilidade de sua metodologia de cálculo. A somatória dos erros quadráticos, acumulados por 256 amostras, geradas a partir de um sinal de alta tensão de referência, pode ser expressa por:

$$
\mathrm{S}=\sum_{\mathrm{i}=1}^{256}\left(\mathrm{y}_{\mathrm{i}}-\mathrm{G} \mathrm{x}_{\mathrm{i}}\right)^{2}
$$

onde $S$ é a somatória dos erros, $y_{i}$ é o valor teórico do sinal de alta tensão $V_{l}(t)$ medido, $x_{i}$ é o sinal $V d(t)$ amostrado e calculado segundo a Equação (8) e $G$ é o ganho ajustado. Para diversos valores de $G$, foram obtidos os seguintes valores de $S$, conforme se observa na Figura 76, a seguir.

Figura 76 - Somatória dos erros, de acordo com o ganho G ajustado

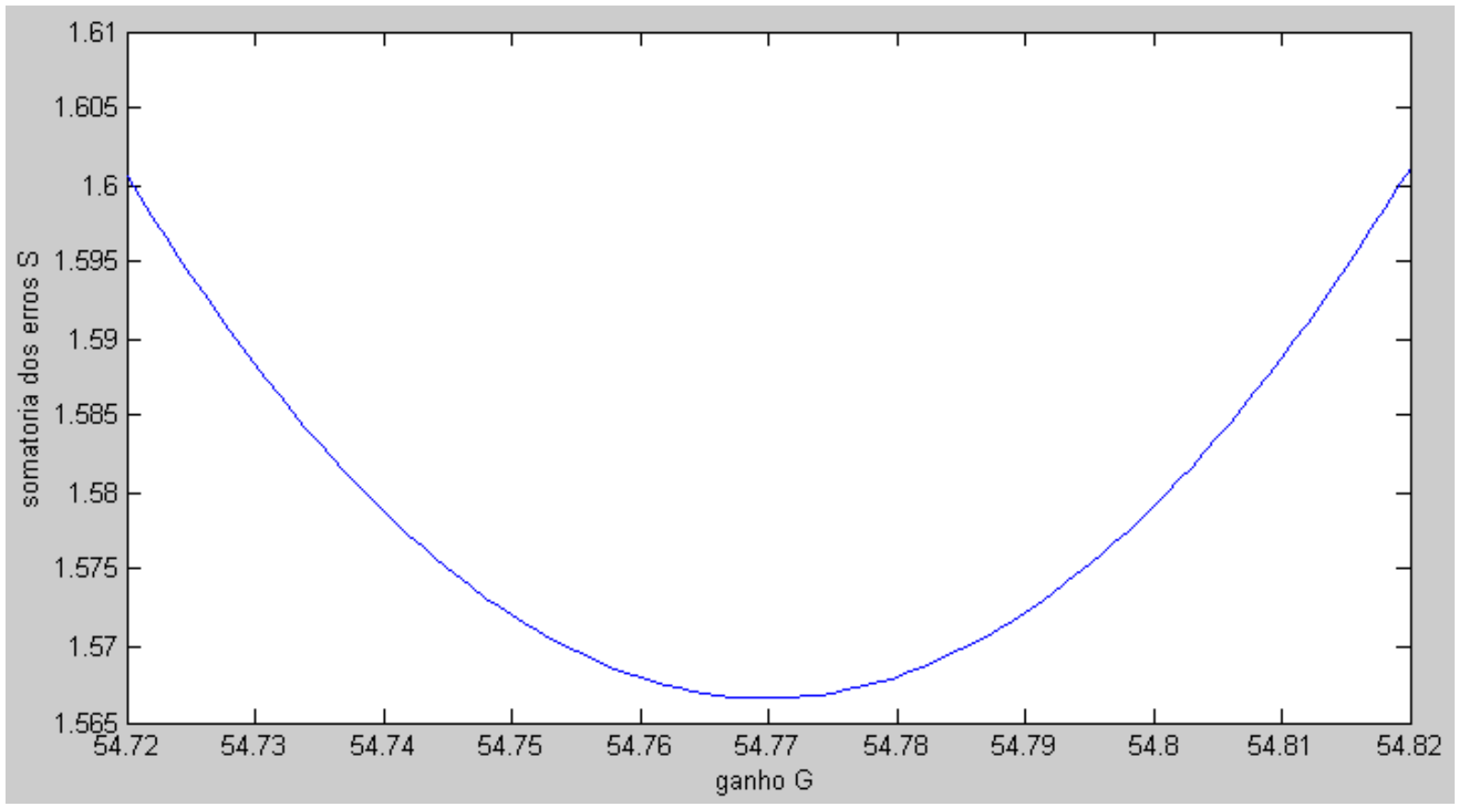

O melhor ajuste de $G$ ocorre quando:

$$
\frac{d \mathrm{~S}}{d \mathrm{G}}=\sum_{\mathrm{i}=1}^{256} 2\left(\mathrm{y}_{\mathrm{i}}-\mathrm{G} \mathrm{x}_{\mathrm{i}}\right)\left(-\mathrm{x}_{\mathrm{i}}\right)=0
$$

o que resultou em um valor de ganho de 54,77, aproximadamente. A Figura 77 ilustra a distribuição dos erros de cada amostra para o ganho calculado através do Método dos Mínimos Quadrados e taxa de amostragem de 256 amostras/ciclo. O sinal de alta tensão $V_{l}(t)$ é representado pela linha contínua e os erros calculados para cada uma das 256 amostras estão representados pelo sinal discretizado. Os erros foram multiplicados por 10 para melhor 
visualização.

Figura 77 - Distribuição dos erros (sinal discretizado multiplicado por 10 para melhor visualização) para o ganho G igual a 54,77

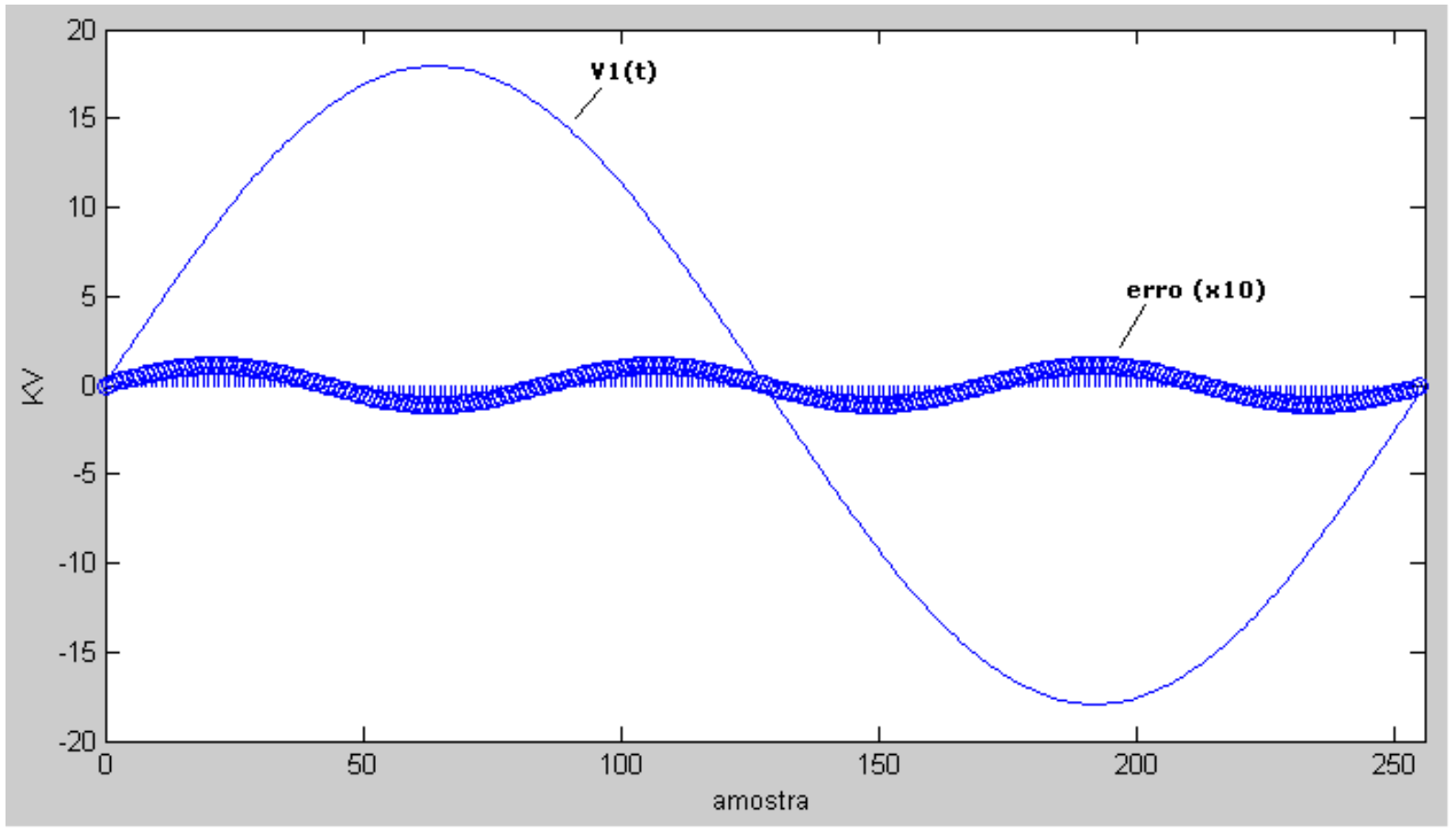

Fonte: o Autor

Conforme mencionado na seção 3.4 , não existe atualmente uma metodologia definida de como avaliar os erros de um sinal amostrado. A Norma IEC 61869-9, que se encontra em estágio final de elaboração, propõe que os erros de amplitude e de atraso de fase sejam representados através de um fasor $\varepsilon_{(s)}$, calculado pela Equação (17), a seguir:

$$
\vec{\varepsilon}_{(s)}=\frac{\frac{\sqrt{2}}{N} \sum_{n=0}^{N-1}\left(i_{X(s-n)}-i_{R(s-n)}\right) e^{2 \pi \sqrt{-1} k(s-n) / N}}{\sqrt{\frac{1}{N} \sum_{n=0}^{N-1}\left(i_{R(s-n)}\right)^{2}}} \times 100 \%
$$

sendo:

\begin{tabular}{|c|l|}
\hline$\varepsilon_{(s)}$ & $\begin{array}{l}\text { fasor que representa o erro de magnitude e o atraso de fase da Merging Unit, no } \\
\text { instante de tempo expresso por um } \operatorname{Smp} C n t \text { de valor } s\end{array}$ \\
\hline$i_{x(s)}$ & $\begin{array}{l}\text { valor da amostra obtida pelo TI em avaliação, contida nos campos AmpSv.instMag.i ou } \\
\text { VolSv.instMag.i na ASDU de sua } S V \text { Message, no instante de tempo expresso por um } \\
\text { SmpCnt de valor } s\end{array}$ \\
\hline$i_{R(s)}$ & $\begin{array}{l}\text { valor da amostra obtida pelo TI de referência, contida nos campos AmpSv.instMag.i ou } \\
\text { VolSv.instMag.i na ASDU de sua } S V \text { Message, no instante de tempo expresso por um } \\
\text { SmpCnt de valor } s\end{array}$ \\
\hline$N$ & $\begin{array}{l}\text { taxa de amostragem nominal igual a quantidade de amostras por segundo dividido pela } \\
\text { frequência fundamental (em Hz) }\end{array}$ \\
\hline$k$ & número da harmônica medida $(k>0$, e seu valor é 1 para a frequência fundamental) \\
\hline
\end{tabular}


O fasor $\varepsilon_{(s)}$ é calculado através do resultado da Transformada Discreta de Fourier de 1 Ciclo na forma exponencial do sinal resultante da diferença entre as amostras calculadas pelo TI em avaliação e as amostras obtidas através de um TI de referência, dividido pelo valor RMS do sinal de referência. O valor de seu módulo representa o erro de relação percentual e o valor de sua fase representa o erro de atraso de fase.

A Figura 78 ilustra os requisitos de erro de relação e de erro de atraso de fase exigidos pela Norma IEC 61869-9 para TIs com taxa de amostragem igual a $15360 \mathrm{~Hz}$ (256 amostras/ciclo para frequência nominal de rede de $60 \mathrm{~Hz}$ ) desde a frequência fundamental até a $50^{\mathrm{a}}$ harmônica.

Figura 78 - Requisitos de erro de relação (ratio error) e de atraso de fase (phase displacement), de acordo com a Norma IEC 61869-9

\begin{tabular}{|c|c|c|c|c|c|c|}
\hline \multirow{2}{*}{$\begin{array}{c}\text { Accuracy } \\
\text { Class }\end{array}$} & \multicolumn{3}{|c|}{$\begin{array}{c}\text { Ratio error }(+/-) \text { as a function of } \\
\text { frequency (Percent) }\end{array}$} & \multicolumn{3}{c|}{$\begin{array}{c}\text { Phase displacement (+ } /-) \text { as a } \\
\text { function of frequency (Degrees) }\end{array}$} \\
\cline { 2 - 7 } & $1 \mathrm{~Hz}$ & $\begin{array}{c}1^{\text {st }} \text { to } 2^{\text {nd }} \\
\text { harmonic }\end{array}$ & $\begin{array}{c}3^{\text {rd }} \text { to } 50^{\text {th }} \\
\text { harmonic }\end{array}$ & $0.1 \mathrm{~Hz}$ & $\begin{array}{c}1^{\text {st }} \\
\text { to } 2^{\text {nd }}\end{array}$ & $\begin{array}{c}3^{\text {rd }} \\
\text { harmonic } 50^{\text {th }} \\
\text { harmonic }\end{array}$ \\
\hline $\begin{array}{c}\text { All } \\
\text { accuracy } \\
\text { classes }\end{array}$ & $+1 /-30 \%$ & $1 \%$ & $5 \%$ & $+1 /-45^{\circ}$ & $1^{\circ}$ & $5^{\circ}$ \\
\hline
\end{tabular}

Fonte: Norma IEC 61869-9 (draft) A Figura 79 e a Figura 80, a seguir, representam, respectivamente, os erros de relação e os erros de atraso de fase calculados pela simulação no software MATLAB ${ }^{\circledR}$ da frequência fundamental até a $50^{\mathrm{a}}$ harmônica. Foram considerados $i_{X(S)}$ as amostras calculadas através da Equação $(8), i_{R(S)}$ as amostras obtidas do sinal de alta tensão $V_{l}(t), N$ igual a 256 e $k$ a harmônica desejada.

Uma primeira análise apontou que os erros de relação são atendidos para todas as harmônicas calculadas. Já os erros de atraso de fase não são atendidos, com seus valores permanecendo constantes em $-180^{\circ}$. 
Figura 79 - Erros de relação calculados para cada harmônica (considerando a taxa de amostragem em 256 amostras/ciclo)

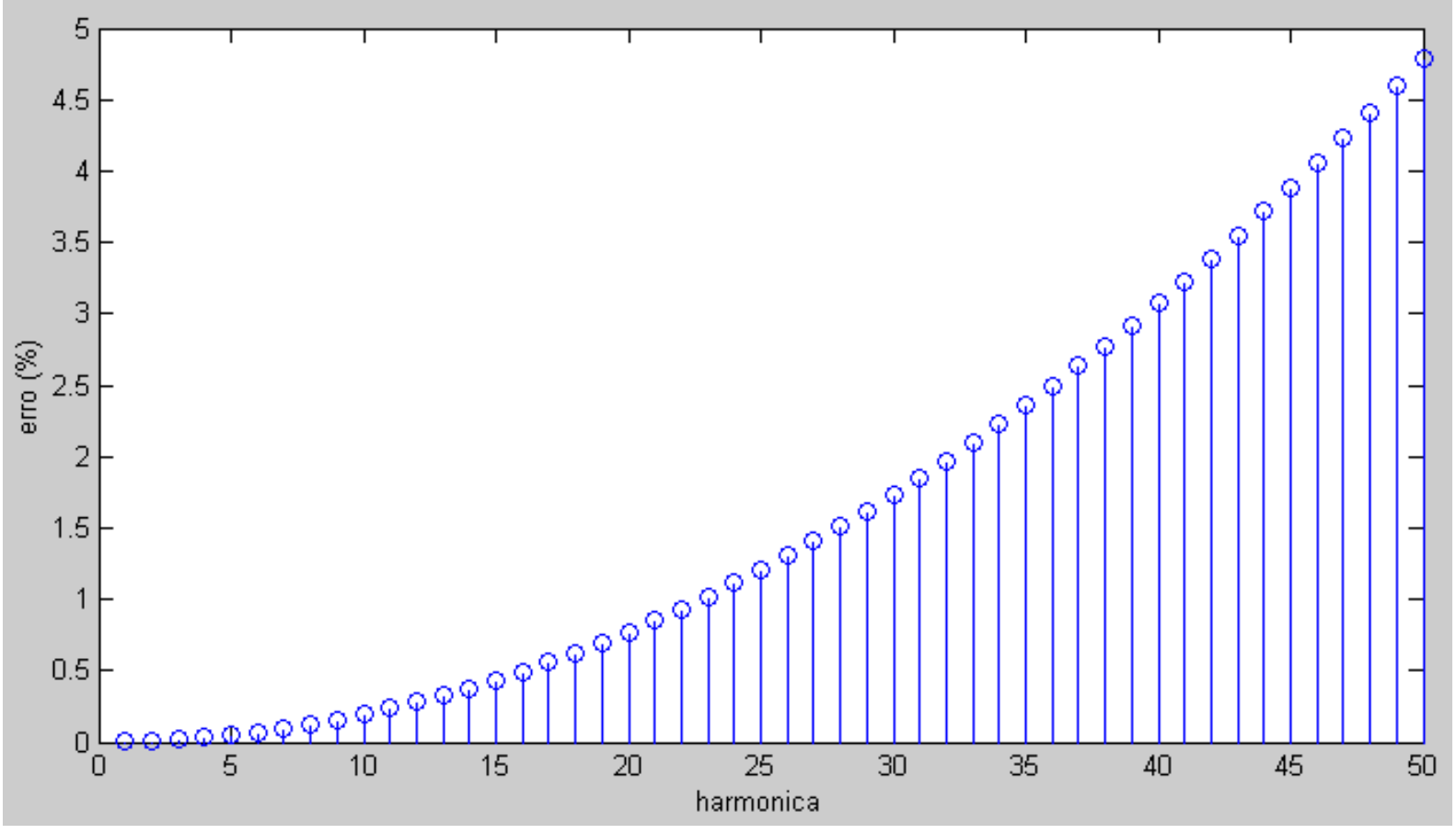

Fonte: o Autor

Figura 80 - Erros de atraso de fase calculados para cada harmônica (considerando a taxa de amostragem em 256 amostras/ciclo)

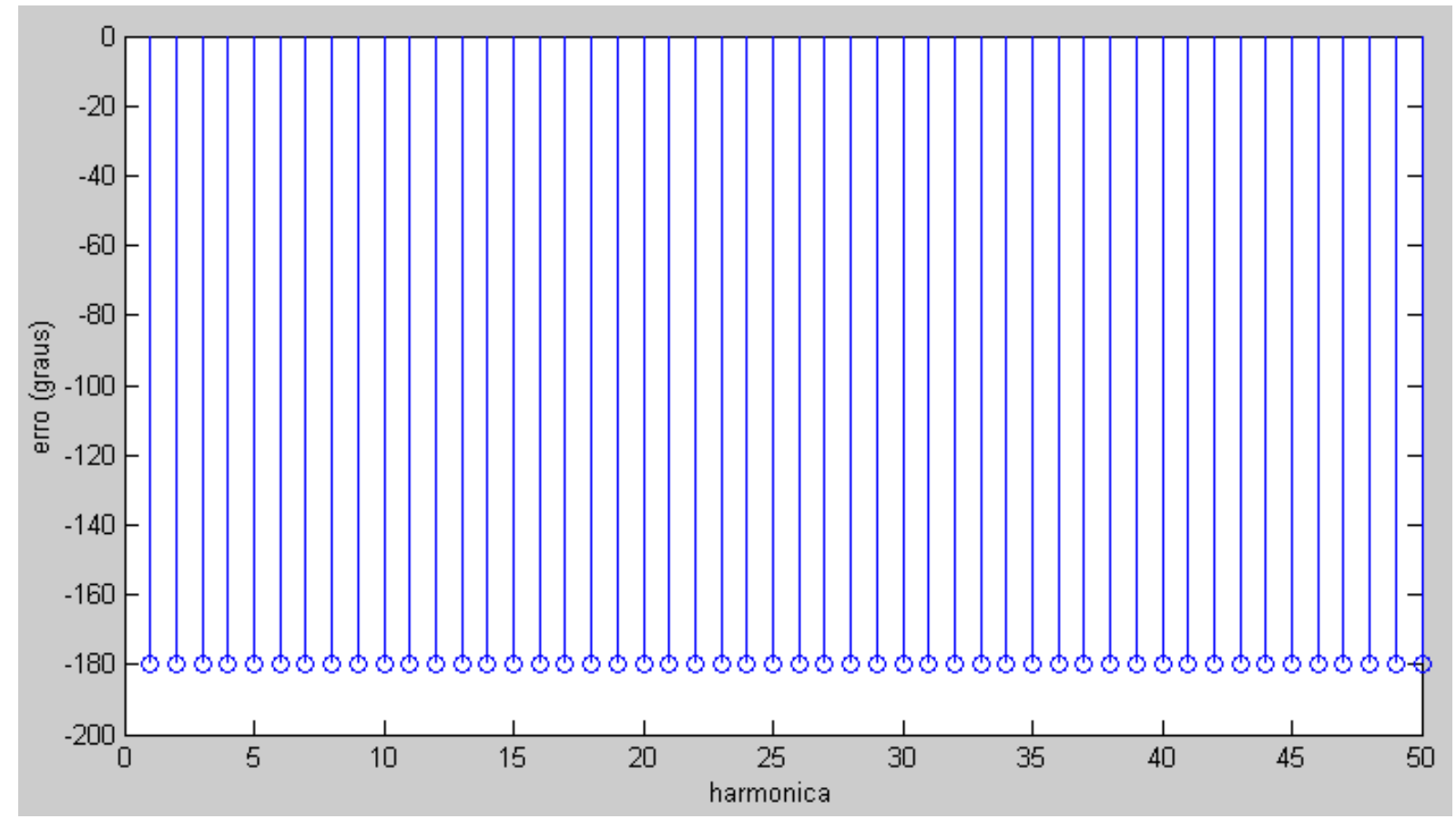

Fonte: o Autor

O autor, então, seguiu para uma análise mais detalhada sobre o cálculo do erro de relação e do erro de atraso de fase proposto. Analisando o termo superior da Equação (17): 


$$
\frac{\sqrt{2}}{N} \sum_{n=0}^{N-1}\left(i_{X(s-n)}-i_{R(s-n)}\right) e^{2 \pi \sqrt{-1} k(s-n) / N}
$$

pode-se concluir que o mesmo resultado pode ser alcançado aplicando-se a DFT separadamente nos sinais $i_{X(s)}$ e $i_{R(s)}$, de forma a obter um fasor de cada sinal e, em seguida, a diferença entre os seus fasores, ou seja:

$$
\frac{\sqrt{2}}{N} \sum_{n=0}^{N-1} i_{X(s-n)} e^{2 \pi \sqrt{-1} k(s-n) / N}-\frac{\sqrt{2}}{N} \sum_{n=0}^{N-1} i_{R(s-n)} e^{2 \pi \sqrt{-1} k(s-n) / N}
$$

Supondo um caso hipotético onde os sinais aplicados fossem, para uma frequência de rede $f$ igual a $60 \mathrm{~Hz}$, harmônica $k$ igual a 1 , e quantidade de amostras $N$ igual a 256:

$$
\begin{aligned}
& \mathrm{i}_{\mathrm{R}(\mathrm{s})}=10 \operatorname{sen}\left(2 \pi \mathrm{kft}+0^{\circ}\right) \\
& \mathrm{i}_{X(\mathrm{~s})}=9,8 \operatorname{sen}\left(2 \pi \mathrm{kft}+10^{\circ}\right)
\end{aligned}
$$

o valor do fasor $\varepsilon_{(s)}$ seria igual a $1,73\left\llcorner 101,58^{\circ} \mathrm{ou}\right.$, em valores percentuais, $17,3\left\llcorner 101,58^{\circ} \%\right.$. A Figura 81 ilustra graficamente o cálculo realizado pela Equação (18).

Figura 81 - Representação gráfica do fasor $\varepsilon_{(s)}$ (valor absoluto)

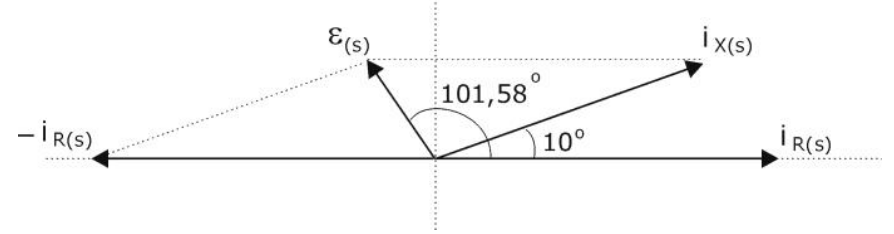

Fonte: o Autor

Conceitualmente, pode-se definir o erro de relação (ratio error) [5] de um TI como sendo a diferença entre a sua relação de transformação declarada e a sua relação de transformação real. Este erro acaba por causar uma diferença na magnitude do sinal de saída do TI.

Também é possível definir o erro de atraso de fase (phase displacement) [5] de um TI como sendo a diferença de fase entre o sinal presente em seu primário e o sinal presente em seu secundário.

Note que tanto o valor do módulo quanto o valor da fase do fasor $\varepsilon_{(s)}$ não expressam de forma direta, respectivamente, o erro de relação e o erro de atraso de fase entre os sinais $i_{R(s)}$ e $i_{X(s)}$. Portanto, para representar mais claramente o erro de relação e o erro de atraso de fase entre estes dois sinais, visando uma maior aderência com os conceitos acima apresentados, o autor 
sugere a seguinte metodologia:

Etapa 1) calcular individualmente o DFT dos sinais $i_{R(s)}$ e $i_{X(s)}$ :

$$
\begin{aligned}
& \mathrm{i}_{\mathrm{X}(\mathrm{s})}=\frac{\sqrt{2}}{\mathrm{~N}} \sum_{\mathrm{n}=0}^{\mathrm{N}-1} \mathrm{i}_{\mathrm{X}(\mathrm{s}-\mathrm{n})} \mathrm{e}^{2 \pi \sqrt{-1} \mathrm{k}(\mathrm{s}-\mathrm{n}) / \mathrm{N}} \\
& \mathrm{i}_{\mathrm{R}(\mathrm{s})}=\frac{\sqrt{2}}{\mathrm{~N}} \sum_{\mathrm{n}=0}^{\mathrm{N}-1} \mathrm{i}_{\mathrm{R}(\mathrm{s}-\mathrm{n})} \mathrm{e}^{2 \pi \sqrt{-1} \mathrm{k}(\mathrm{s}-\mathrm{n}) / \mathrm{N}}
\end{aligned}
$$

Etapa 2) calcular o erro de relação através da razão entre a diferença dos módulos de cada sinal e o módulo do sinal de referência:

$$
\text { erro de relação }=\frac{\left|i_{X(s)}\right|-\left|i_{R(s)}\right|}{\left|i_{R(s)}\right|} \times 100 \%
$$

Etapa 3) calcular o erro de atraso de fase através da diferença entre o valor da fase do fasor de referência e o valor da fase do fasor do sinal medido:

$$
\text { erro de atraso de fase }=\text { fase }\left(\mathrm{i}_{\mathrm{X}(\mathrm{s})}\right)-\text { fase }\left(\mathrm{i}_{\mathrm{R}(\mathrm{s})}\right)
$$

O uso da DFT para gerar os fasores de cada sinal é interessante, uma vez que a maioria dos algoritmos presentes nos dispositivos que irão receber as amostras enviadas através das $S V$ Messages (medidores, relés de proteção, PMUs, etc.) também utilizam a DFT, ou suas variações, para tratar e processar as amostras recebidas, o que torna os resultados da metodologia proposta mais próximos da resposta das aplicações finais.

Utilizando as Equações (22), (23), (24) e (25) para o exemplo hipotético apresentado, teremos:

Etapa 1) os fasores calculados seriam $\mathrm{i}_{\mathrm{R}(\mathrm{s})}=10\left\llcorner 0^{\circ}\right.$ e $\mathrm{i}_{\mathrm{X}(\mathrm{s})}=9,8\left\llcorner 10^{\circ}\right.$

Etapa 2) o erro de relação calculado seria:

$$
\text { erro de relação }=\frac{|9,8|-|10|}{|10|} \times 100 \%=-2 \%
$$

Etapa 3) o erro de atraso de fase calculado seria:

$$
\text { erro de atraso de fase }=10^{\circ}-0^{\circ}=10^{\circ}
$$


O cálculo, embora mais simples, apresenta resultados mais diretos, claros e com boa precisão. Aplicando esta metodologia para a plataforma de TP óptico proposta, com ganho $G$ igual a 54,77 , taxa de amostragem de 256 amostras/ciclo e frequência do oscilador de alta precisão de 256 vezes a frequência nominal da rede $(256 \times 60 \mathrm{~Hz}=15360 \mathrm{~Hz})$, foram obtidos os seguintes resultados de erro de relação e de erro de atraso de fase mostrados pela Tabela 6, pela Figura 82 e pela Figura 83, a seguir.

Tabela 6 - Erros de relação e erros de fase para cada harmônica (considerando metodologia proposta)

\begin{tabular}{|c|c|c|}
\hline $\begin{array}{c}\text { Harm } \\
(\mathbf{k})\end{array}$ & $\begin{array}{c}\text { Erro de } \\
\text { relação [\%] }\end{array}$ & $\begin{array}{c}\text { Erro de fase } \\
{\left[{\mathrm{x} 10^{-12}}^{-12} \text { graus }\right]}\end{array}$ \\
\hline 1 & $-0,0035$ & 0,0000 \\
\hline 2 & $-0,0093$ & 0,0000 \\
\hline 3 & $-0,0189$ & 0,0000 \\
\hline 4 & $-0,0324$ & 0,0000 \\
\hline 5 & $-0,0498$ & 0,0000 \\
\hline 6 & $-0,0711$ & 0,0000 \\
\hline 7 & $-0,0962$ & 0,0000 \\
\hline 8 & $-0,1252$ & 0,0142 \\
\hline 9 & $-0,1580$ & $-0,0142$ \\
\hline 10 & $-0,1947$ & 0,0142 \\
\hline 11 & $-0,2352$ & $-0,0711$ \\
\hline 12 & $-0,2796$ & 0,0000 \\
\hline 13 & $-0,3279$ & 0,0000 \\
\hline 14 & $-0,3800$ & 0,0000 \\
\hline 15 & $-0,4359$ & 0,0000 \\
\hline 16 & $-0,4957$ & 0,0142 \\
\hline 17 & $-0,5593$ & 0,0000 \\
\hline 18 & $-0,6268$ & 0,0000 \\
\hline 19 & $-0,6981$ & 0,0000 \\
\hline 20 & $-0,7732$ & 0,0142 \\
\hline
\end{tabular}

\begin{tabular}{|c|c|c|}
\hline $\begin{array}{c}\text { Harm } \\
\text { (k) }\end{array}$ & $\begin{array}{c}\text { Erro de } \\
\text { relação [\%] }\end{array}$ & $\begin{array}{c}\text { Erro de fase } \\
{\left[\mathrm{x10}^{-12} \text { graus] }\right]}\end{array}$ \\
\hline 21 & $-0,8500$ & $-0,0284$ \\
\hline 22 & $-0,9350$ & $-0,1137$ \\
\hline 23 & $-1,0216$ & 0,0568 \\
\hline 24 & $-1,1120$ & $-0,0426$ \\
\hline 25 & $-1,2063$ & 0,0000 \\
\hline 26 & $-1,3043$ & 0,0000 \\
\hline 27 & $-1,4062$ & 0,0000 \\
\hline 28 & $-1,5118$ & 0,0142 \\
\hline 29 & $-1,6213$ & 0,0142 \\
\hline 30 & $-1,7345$ & 0,0000 \\
\hline 31 & $-1,8515$ & 0,0000 \\
\hline 32 & $-1,9724$ & 0,0142 \\
\hline 33 & $-2,0969$ & $-0,1279$ \\
\hline 34 & $-2,2253$ & 0,0000 \\
\hline 35 & $-2,3574$ & $-0,0284$ \\
\hline 36 & $-2,4932$ & $-0,0426$ \\
\hline 37 & $-2,6328$ & 0,0000 \\
\hline 38 & $-2,7762$ & $-0,0284$ \\
\hline 39 & $-2,9233$ & 0,0000 \\
\hline 40 & $-3,0741$ & 0,0284 \\
\hline
\end{tabular}

\begin{tabular}{|c|c|c|}
\hline $\begin{array}{c}\text { Harm } \\
(\mathbf{k})\end{array}$ & $\begin{array}{c}\text { Erro de } \\
\text { relação [\%] }\end{array}$ & $\begin{array}{c}\text { Erro de fase } \\
{\left[\mathbf{x 1 0}^{-12} \text { graus] }\right.}\end{array}$ \\
\hline 41 & $-3,2287$ & 0,0000 \\
\hline 42 & $-3,3869$ & 0,0000 \\
\hline 43 & $-3,5489$ & 0,0000 \\
\hline 44 & $-3,7146$ & $-0,1847$ \\
\hline 45 & $-3,8839$ & 0,0284 \\
\hline 46 & $-4,0570$ & 0,1421 \\
\hline 47 & $-4,2337$ & 0,0000 \\
\hline 48 & $-4,4141$ & 0,0000 \\
\hline 49 & $-4,5982$ & $-0,0142$ \\
\hline 50 & $-4,7859$ & 0,0142 \\
\hline
\end{tabular}


Figura 82 - Erros de relação para cada harmônica (considerando metodologia proposta)

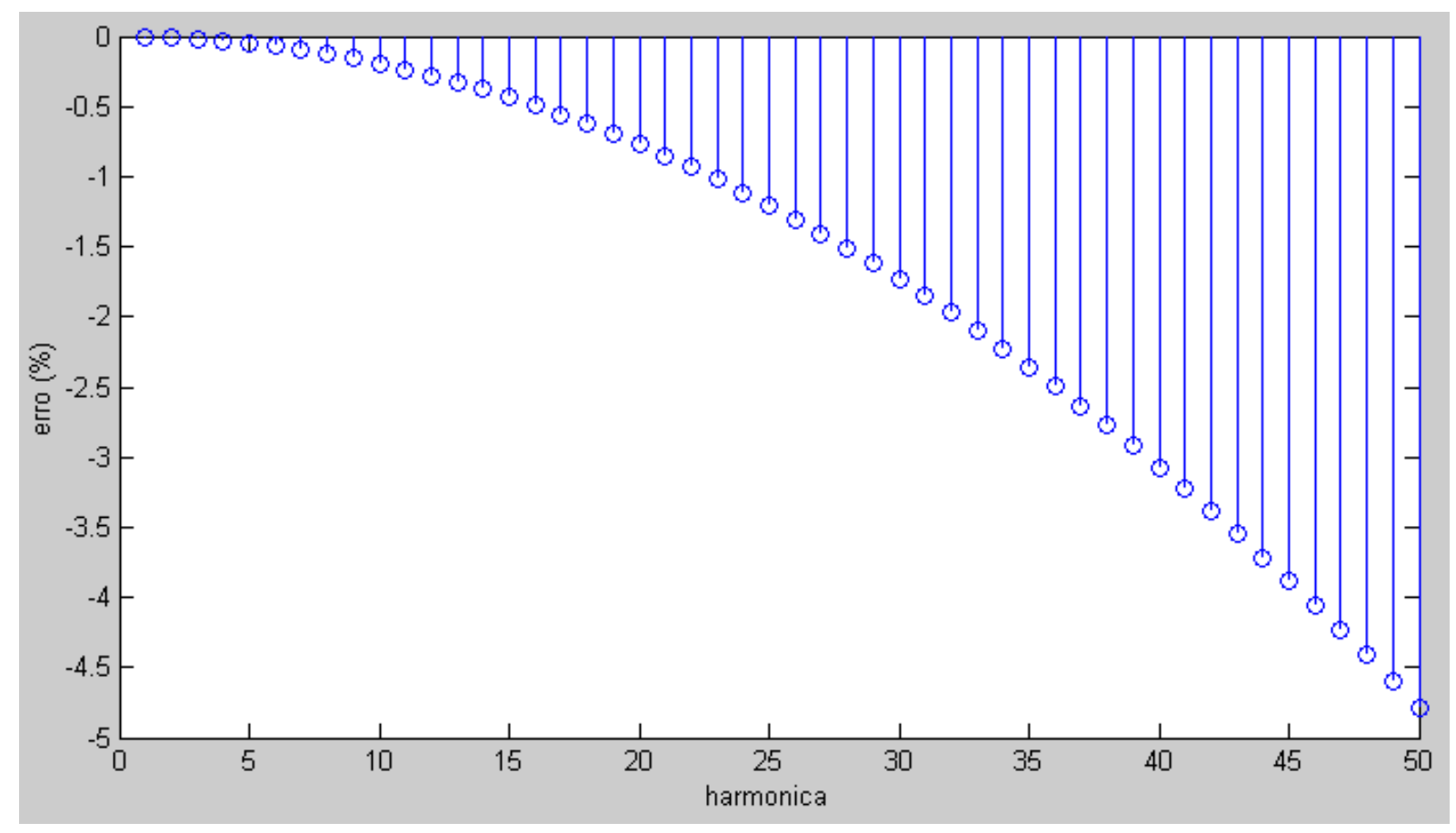

Fonte: o Autor

Figura 83 - Erros de atraso de fase para cada harmônica (considerando metodologia proposta)

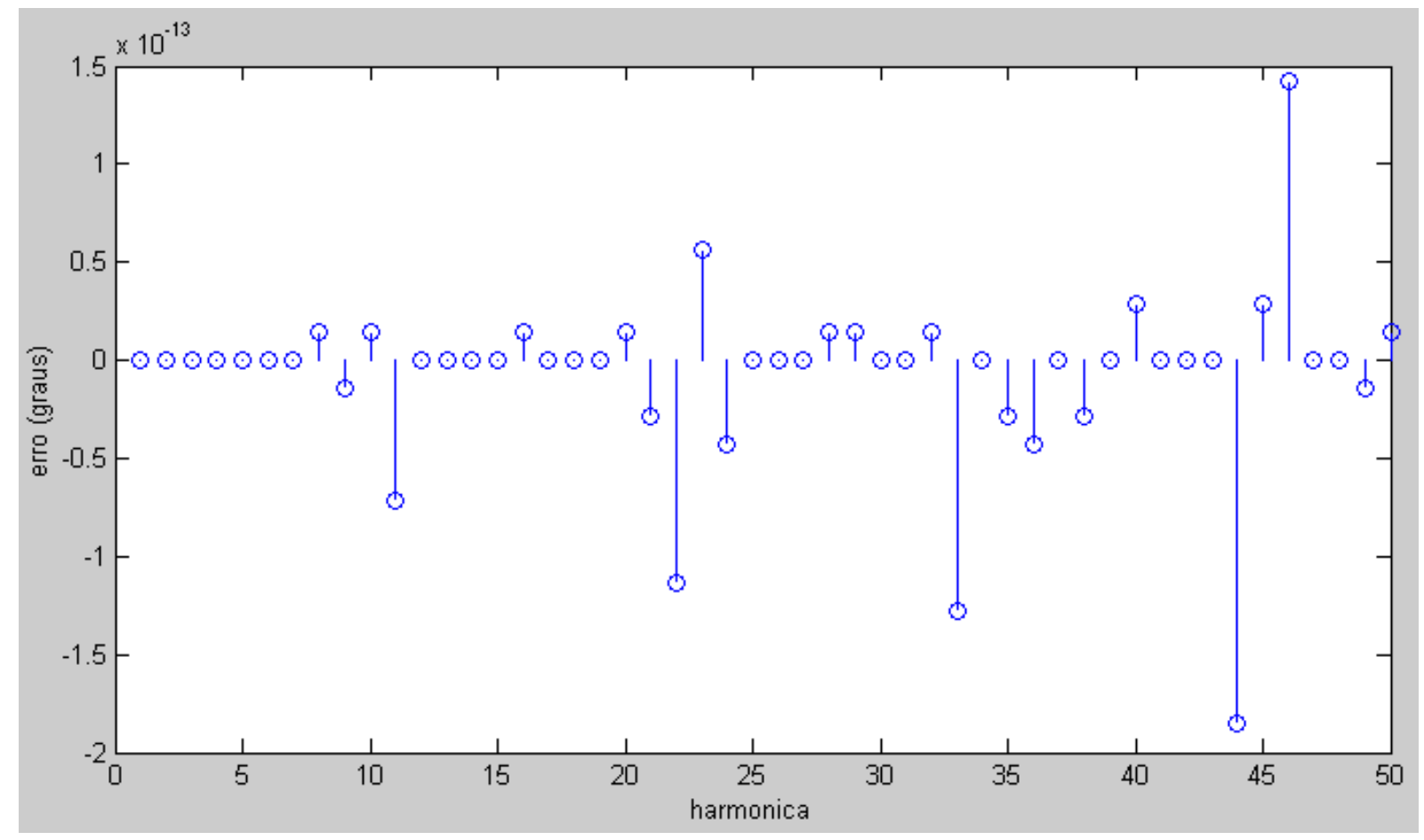

Fonte: o Autor

Comparando os resultados obtidos com os requisitos exigidos pela Norma IEC 61869-9 (apresentados na Figura 78), observa-se que tanto os requisitos de erro de relação quanto os requisitos de erro de atraso de fase, foram atendidos, para todas as harmônicas. Cabe neste 
ponto, portanto, uma sugestão do autor para uma possível revisão na norma a respeito da metodologia de cálculo destes erros.

Por fim, a Norma IEC 61869-9 ainda cita outro índice para estimar o erro de um TI, denominado composite error $\left(\varepsilon_{c}\right)$. Ele expressa a relação entre o valor RMS do sinal resultante da diferença entre as amostras do TI de referência e as amostras do TI avaliado, e o valor RMS do sinal de referência, ou seja:

$$
\vec{\varepsilon}_{c(s)}=\sqrt{\frac{\sum_{n=0}^{N-1}\left(i_{X(s-n)}-i_{R(s-n)}\right)^{2}}{\sum_{n=0}^{N-1}\left(i_{R(s-n)}\right)^{2}}} \times 100 \%
$$

O valor de $\varepsilon_{c}$ para o ganho $G$ calculado, na frequência fundamental, foi igual a $0,62 \%$. Infelizmente, ainda não foram definidos no draft da Norma IEC 61869-9 os requisitos exigidos para este tipo de erro.

\section{c) Erro T3}

A respeito do item T3, também não é especificado em norma como este erro deve ser medido. Um requisito que pode ser utilizado para avaliar este item de forma indireta é o conceito de Maximum Delay Time Requirement, apresentado na seção 3.4, que estabelece um limite de Delay Time de 1,5 ms (para finalidades de proteção), de $10 \mathrm{~ms}$ (para finalidades de medição) e um limite especificado pelo fabricante para aplicações que envolvam as duas finalidades. Este último limite especificado se encaixa com a proposta do protótipo de TP óptico digital. Portanto, será estabelecido como meta inicial o melhor desempenho (Delay Time de 1,5 ms) que, certamente, atenderá todas as finalidades de aplicação. Testes iniciais do protótipo de TP óptico mostraram um atraso da ordem de $500 \mu$ s entre o sinal presente no primário e o sinal presente na entrada do bloco $A D C$, o que resulta num tempo disponível de $1 \mathrm{~ms}$, aproximadamente, para processamento e envio da $S V$ Message. Resultados obtidos em testes realizados para a geração e a transmissão de SV Messages serão apresentados no Capítulo 6. 


\section{Proposta de Plataforma de Relé Diferencial para a Proteção de Transformadores de Potência com interface IEC 61850-9-2}

O objetivo desta parte do trabalho é analisar como os valores amostrados enviados através do barramento de processo para um relé de proteção diferencial para transformadores de potência, ilustrado no diagrama unifilar da Figura 13, podem interferir na operação deste relé em uma situação de perda de sincronismo de tempo das amostras.

Para isso, o autor desenvolveu dois algoritmos. Numa primeira etapa, elaborou-se um algoritmo capaz de simular as sequências de valores amostrados gerados. Posteriormente, cada sequência foi aplicada em um segundo algoritmo, elaborado para simular o funcionamento de uma função de proteção diferencial para transformadores de potência. Depois de validar a sequência de valores e o algoritmo de proteção diferencial, realizou-se uma simulação de drift dos relógios internos dos IEDs responsáveis por enviar os valores amostrados no barramento de processo para a avaliação dos efeitos da perda de sincronismo de tempo na operação do relé de proteção diferencial. 


\subsection{Simulação das amostras enviadas no barramento de processo}

A Norma IEC 61850-9-2 define que a corrente medida no primário de um TC seja transmitida no barramento de processo amostrando e digitalizando seu valor instantâneo de acordo com taxas de amostragens previamente estabelecidas (80 amostras/ciclo para fins de proteção ou 256 amostras/ciclo para fins de medição). As amostras podem ser realizadas pelo próprio TC ou através de uma Merging Unit conectada no secundário do TC. Cada amostra, ou uma sequência de valores de amostras, é inserida em uma $S V$ Message e enviada no formato multicast através do barramento de processo para os demais IEDs. Cada amostra precisa ser sincronizada no tempo para que possa ser utilizada sem problemas por estes IEDs. Atualmente, os padrões definidos para distribuição do sincronismo de tempo são o formato 1pps e o formato IRIG-B. A Norma IEC 61869-9, que está em fase final de elaboração, irá propor o uso do Protocolo PTP para a distribuição do sincronismo de tempo através do próprio barramento de rede. A representação do instante de amostragem de cada uma das

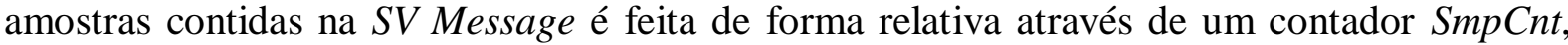
conforme mostrado na Figura 20.

Ainda segundo a Norma IEC 61850-9-2, em um cenário onde ocorra a perda do sinal de sincronismo de tempo, a transmissão de SV Messages pelos IEDs não deve cessar. Nesta situação, cada IED do nível de processo, responsável por gerar estas mensagens, deve passar a utilizar seu relógio interno como base de tempo para controlar os instantes de amostragens e o contador SmpCnt. Devido à maioria dos IEDs utilizarem tecnologia digital microprocessada, estes relógios internos são, geralmente, baseados em um oscilador a cristal, que possui um erro na sua frequência de oscilação especificado em partes por milhão (ppm). Por exemplo, um oscilador cujo erro declarado seja $\pm 20 \mathrm{ppm}$ (precisão semelhante aos dos relógios a quartzo encontrados no mercado) implica que, a cada novo segundo, o instante de tempo no qual a amostra é feita poderá ter um erro de até \pm 20 us. Portanto, a amostragem ideal $i(t)$, sem erro de sincronismo de tempo, e a amostra real $\operatorname{ir}(t)$, com erro de sincronismo de tempo, podem ser expressas, respectivamente, pelas Equações (27) e (28), onde Ip é o valor de pico da corrente primária, $\omega$ a velocidade angular, $D f$ o valor do erro em ppm e $\theta$ a defasagem do sinal. 


$$
\begin{gathered}
i(t)=I_{p} \operatorname{sen}(\omega t+\theta) \\
i_{r}(t)=I_{p} \operatorname{sen}\left[\omega t\left(1+\frac{D_{f}}{1000000}\right)+\theta\right]
\end{gathered}
$$

A Tabela 7 demonstra os resultados obtidos para as primeiras 16 amostras no início de cada novo segundo, a partir de simulações de um IED com sinal de sincronismo e de um IED sem sinal de sincronismo, ambos medindo a mesma corrente. Para esta simulação, considerou-se uma corrente primária Ip igual a $100 \sqrt{ } 2 \mathrm{~A}$ com passagem pelo zero no instante $t$ igual a zero segundos, frequência da rede elétrica em $50 \mathrm{~Hz}$, defasagem $\theta$ igual a zero, taxa de amostragem de 16 amostras por ciclo e erro $D f$ de $+20 \mathrm{ppm}$.

Analisando os resultados, pode-se concluir que, a cada novo segundo, um IED sincronizado no tempo apresenta exatamente os mesmos valores em suas 16 primeiras amostras. Em contrapartida, um IED sem sincronismo de tempo apresenta uma pequena variação nos valores de suas amostras. Esta variação é semelhante ao efeito de uma onda senoidal, cujo atraso $\theta$ aumenta de forma gradativa com o passar do tempo, embora a corrente primária medida por ambos os IEDs seja a mesma e com atraso $\theta$ igual a zero. 
Tabela 7 - Resultados das simulações para $i(t)$ e $\operatorname{ir}(t)$

\begin{tabular}{|c|}
\hline SmpCnt \\
\hline 0 \\
\hline 1 \\
\hline 2 \\
\hline 3 \\
\hline 4 \\
\hline 5 \\
\hline 6 \\
\hline 7 \\
\hline 8 \\
\hline 9 \\
\hline 10 \\
\hline 11 \\
\hline 12 \\
\hline 13 \\
\hline 14 \\
\hline 15 \\
\hline
\end{tabular}

\begin{tabular}{|c|c|c|}
\hline $\begin{array}{c}\mathbf{t} \\
(\mathbf{m s})\end{array}$ & $\begin{array}{c}\mathbf{i}(\mathbf{t}) \\
(\mathbf{A})\end{array}$ & $\begin{array}{c}\mathbf{i r}(\mathbf{t}) \\
(\mathbf{A})\end{array}$ \\
\hline 0,00 & 0,00 & 0,00 \\
\hline 1,25 & 54,11 & 54,11 \\
\hline 2,50 & 100,00 & 100,00 \\
\hline 3,75 & 130,65 & 130,65 \\
\hline 5,00 & 141,42 & 141,42 \\
\hline 6,25 & 130,65 & 130,65 \\
\hline 7,50 & 100,00 & 100,00 \\
\hline 8,75 & 54,11 & 54,11 \\
\hline 10,00 & 0,00 & 0,00 \\
\hline 11,25 & $-54,11$ & $-54,11$ \\
\hline 12,50 & $-100,00$ & $-100,00$ \\
\hline 13,75 & $-130,65$ & $-130,65$ \\
\hline 15,00 & $-141,42$ & $-141,42$ \\
\hline 16,25 & $-130,65$ & $-130,65$ \\
\hline 17,50 & $-100,00$ & $-100,00$ \\
\hline 18,75 & $-54,11$ & $-54,11$ \\
\hline & & \\
\hline & & \\
\hline & & \\
\hline & & \\
\hline & & \\
\hline & & \\
\hline & & \\
\hline & & \\
\hline & & \\
\hline
\end{tabular}

\begin{tabular}{|c|c|c|}
\hline $\begin{array}{c}\mathbf{t} \\
(\mathbf{m s})\end{array}$ & $\begin{array}{c}\mathbf{i}(\mathbf{t}) \\
(\mathbf{A})\end{array}$ & $\begin{array}{c}\mathbf{i r}(\mathbf{t}) \\
(\mathbf{A})\end{array}$ \\
\hline 1000,00 & 0,00 & 0,88 \\
\hline 1001,25 & 54,11 & 54,94 \\
\hline 1002,50 & 100,00 & 100,62 \\
\hline 1003,75 & 130,65 & 130,99 \\
\hline 1005,00 & 141,42 & 141,41 \\
\hline 1006,25 & 130,65 & 130,31 \\
\hline 1007,50 & 100,00 & 99,36 \\
\hline 1008,75 & 54,11 & 53,29 \\
\hline 1010,00 & 0,00 & $-0,89$ \\
\hline 1011,25 & $-54,11$ & $-54,94$ \\
\hline 1012,50 & $-100,00$ & $-100,63$ \\
\hline 1013,75 & $-130,65$ & $-130,99$ \\
\hline 1015,00 & $-141,42$ & $-141,41$ \\
\hline 1016,25 & $-130,65$ & $-130,30$ \\
\hline 1017,50 & $-100,00$ & $-99,35$ \\
\hline 1018,75 & $-54,11$ & $-53,28$ \\
\hline & & \\
\hline & & \\
\hline & & \\
\hline & & \\
\hline & & \\
\hline 100
\end{tabular}

\begin{tabular}{|c|c|c|}
\hline $\begin{array}{c}\text { t } \\
(\mathbf{m s})\end{array}$ & $\begin{array}{c}\mathbf{i}(\mathbf{t}) \\
(\mathbf{A})\end{array}$ & $\begin{array}{c}\mathbf{i r}(\mathbf{t}) \\
(\mathbf{A})\end{array}$ \\
\hline 2000,00 & 0,00 & 1,77 \\
\hline 2001,25 & 54,11 & 55,75 \\
\hline 2002,50 & 100,00 & 101,25 \\
\hline 2003,75 & 130,65 & 131,32 \\
\hline 2005,00 & 141,42 & 141,41 \\
\hline 2006,25 & 130,65 & 129,96 \\
\hline 2007,50 & 100,00 & 98,73 \\
\hline 2008,75 & 54,11 & 52,46 \\
\hline 2010,00 & 0,00 & $-1,78$ \\
\hline 2011,25 & $-54,11$ & $-55,76$ \\
\hline 2012,50 & $-100,00$ & $-101,25$ \\
\hline 2013,75 & $-130,65$ & $-131,33$ \\
\hline 2015,00 & $-141,42$ & $-141,41$ \\
\hline 2016,25 & $-130,65$ & $-129,96$ \\
\hline 2017,50 & $-100,00$ & $-98,72$ \\
\hline 2018,75 & $-54,11$ & $-52,45$ \\
\hline Fonte: 0 Autor \\
\hline
\end{tabular}




\subsection{Algoritmo de proteção diferencial para transformadores de potência}

Por muitos anos, a função de proteção diferencial vem sendo utilizada com sucesso para a proteção de transformadores de potência. Seus princípios básicos de operação são bem documentados [51]. De forma geral, ela consiste na medição e análise da diferença entre as correntes normalizadas presentes no primário (Ip) e no secundário (Is) de um transformador de potência, conforme ilustra a Figura 84, a seguir.

Figura 84 - Funcionamento básico da proteção diferencial de transformador na ocorrência de uma falha externa (a) e de uma falha interna $(b)$

(a)

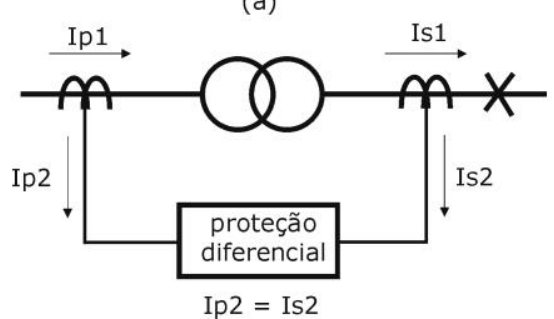

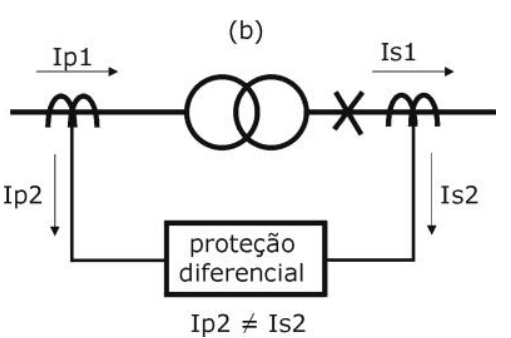

Fonte: o Autor Analisando a situação (a), se a falha acontecer fora da zona de proteção, definida neste caso entre os TCs de primário e de secundário do transformador de potência, a corrente Ipl irá se elevar na mesma proporção que a corrente $I s 1$, tornando a diferença entre elas próxima de zero, o que não sensibiliza a proteção diferencial. Já na situação (b), na ocorrência de uma falha dentro da zona de proteção, haverá uma diferença considerável entre as correntes Ipl e Is 1 , o que acabará por sensibilizar a proteção diferencial.

Antes que as correntes possam efetivamente ser comparadas, elas precisam, primeiramente, ser normalizadas, corrigindo os seguintes aspectos:

- relação de transformação do transformador de potência;

- configuração de fechamento dos enrolamentos do primário e do secundário do transformador de potência (exemplos: delta, estrela aterrado, estrela não aterrado, etc.);

- diferença entre as relações de transformação dos TCs (também chamada de compensação de TAP);

- configuração de conexão dos TCs (exemplos: delta, estrela e sentido do centro da estrela). 
Nos sistemas de proteção que utilizam relés digitais microprocessados, todas estas compensações e o cálculo do módulo e da fase das correntes Ip e $I s$ são implementadas através de algoritmos matemáticos dos relés [52]-[59]. A Figura 85 demonstra um exemplo de arquitetura utilizada para relés de proteção digital diferencial.

Figura 85 - Exemplo de arquitetura para proteção diferencial digital de transformadores de potência

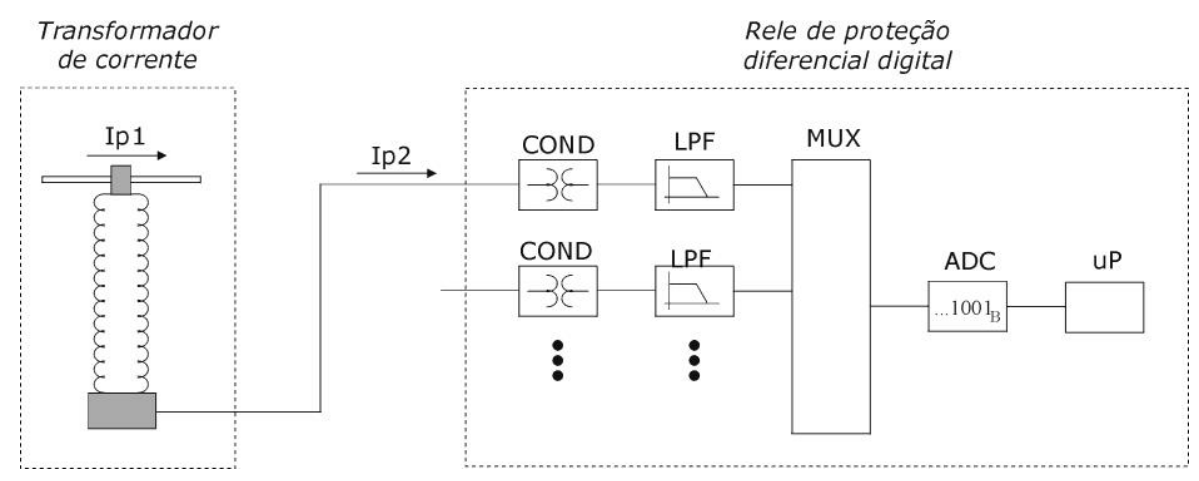

Fonte: o Autor Neste exemplo, o TC convencional reduz a corrente Ip1 e gera uma corrente Ip2 correspondente, que é aplicada no relé de proteção diferencial. O primeiro bloco, denominado COND, é geralmente composto por um transformador indutivo de corrente e tem como objetivos principais condicionar o sinal de corrente Ip2 em um sinal de tensão correspondente e proteger os demais componentes do relé diferencial contra surtos e impulsos oriundos do sistema elétrico de potência, isolando-os de forma galvânica. O segundo bloco, denominado $L P F$, é composto geralmente por circuitos eletrônicos que atuam como filtro passa-baixa com função anti-aliasing, necessário para o correto funcionamento dos filtros digitais. O próximo bloco, denominado $M U X$, é composto por um circuito eletrônico multiplexador, que comuta os vários sinais de corrente medidos para que possam ser digitalizados por um circuito conversor analógico-digital, o bloco $A D C$. Finalmente, os valores digitalizados são enviados para o bloco $u P$, composto por um microprocessador, ou um microcontrolador, capaz de executar todas as lógicas digitais e os algoritmos necessários para o correto funcionamento do relé diferencial.

De posse das amostras dos valores das correntes, o bloco $u P$ realiza, a cada nova amostra, a execução de uma sequência de algoritmos representados pela Figura 86, a seguir. 
Figura 86 - Fluxograma que demonstra a sequência de algoritmos executados pelo bloco uP

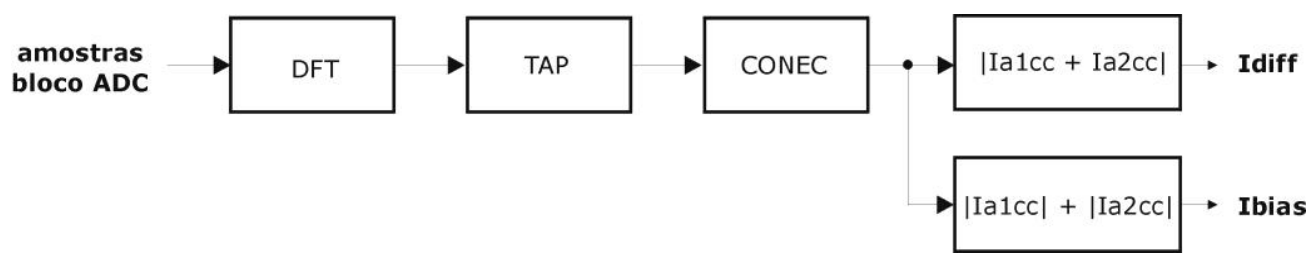

Fonte: o Autor O sistema elétrico de potência da Figura 87 será utilizado como base para descrever o funcionamento destes algoritmos.

Figura 87 - Exemplo de sistema elétrico com transformador trifásico e proteção diferencial

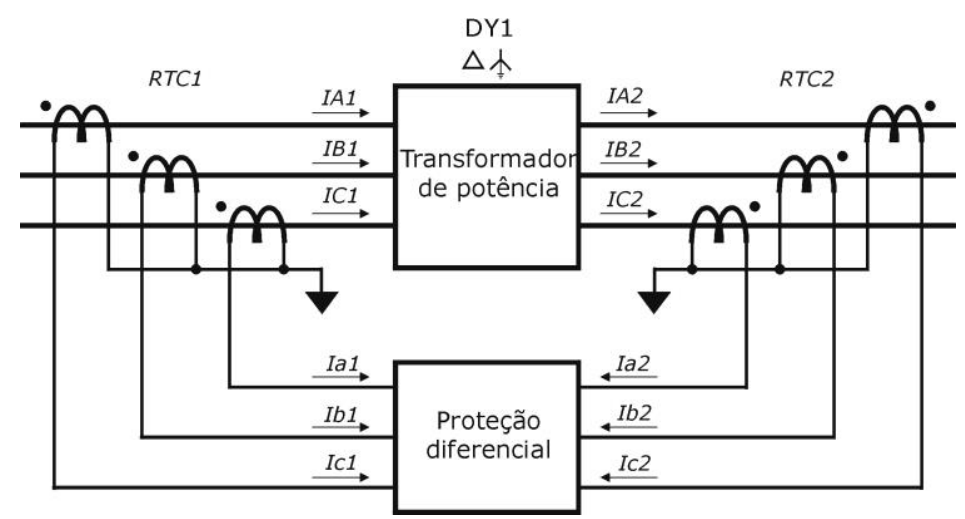

Fonte: o Autor No primeiro bloco, denominado DFT, são calculados os módulos e as fases das correntes de primário $(I a l, I b 1$ e $I c 1)$ e de secundário (Ia2, Ib2 e Ic2) do transformador de potência através de filtros digitais baseados na Transformada Discreta de Fourier.

$$
\begin{gathered}
\mathrm{FSn}(\mathrm{k})=\frac{2}{\mathrm{~N}} \sum_{\mathrm{r}=0}^{\mathrm{N}-1} \mathrm{z}_{(\mathrm{k}-\mathrm{r})} \operatorname{sen}\left(\frac{2 \pi \mathrm{r}}{\mathrm{N}}\right) \\
\mathrm{FCn}(\mathrm{k})=\frac{2}{\mathrm{~N}} \sum_{\mathrm{r}=0}^{\mathrm{N}-1} \mathrm{z}_{(\mathrm{k}-\mathrm{r})} \cos \left(\frac{2 \pi \mathrm{r}}{\mathrm{N}}\right) \\
\mathrm{h}_{\mathrm{n}}=\sqrt{\mathrm{FSn}^{2}+\mathrm{FCn}^{2}} \\
\theta_{\mathrm{n}}=\operatorname{arctg}\left(-\frac{\mathrm{FCn}^{2}}{\mathrm{FSn}^{2}}\right) \\
\text { Ial }=\mathrm{h}_{\mathrm{n}} \theta_{\mathrm{n}}
\end{gathered}
$$

O resultado final é um fasor que representa cada uma das correntes, conforme se observa na Equação (33) (módulo e fase da corrente Ial, na notação polar).

Posteriormente, os módulos dos fasores são corrigidos no bloco TAP com o objetivo de normalizá-los de acordo com a potência do transformador protegido, relação de transformação 
de tensão do transformador de potência e as relações de transformações de cada TC. As Equações (34) e (35) representam os cálculos de compensação aplicados, respectivamente, nas correntes do lado primário e do lado secundário. O termo MVA se refere à potência nominal do transformador de potência (em MVA), os termos KV1 e KV2 se referem, respectivamente, às tensões nominais primária e secundária (em KV), e os termos CTR1 e CTR2 se referem, respectivamente, às relações de transformação dos TCs de primário e de secundário.

$$
\begin{aligned}
& \text { TAP } 1=\frac{\text { MVA } \times 1000}{\sqrt{3} \times \mathrm{KV} 1 \times \mathrm{CTR} 1} \\
& \mathrm{TAP} 2=\frac{\mathrm{MVA} \times 1000}{\sqrt{3} \times \mathrm{KV} 2 \times \mathrm{CTR} 2}
\end{aligned}
$$

A correção é feita dividindo-se cada fasor de corrente calculado pelo bloco DFT pelo seu TAP correspondente, conforme apresentado no exemplo da Equação (36), para a corrente Ialtp (corrente Ial com compensação de TAP).

$$
\text { Ialtp }=\frac{\text { Ia } 1}{\text { TAP1 }}
$$

Em seguida, no bloco CONEC, os fasores já normalizados são multiplicados por matrizes de compensação com o objetivo de corrigir as diferenças de módulo e de fase causadas pelas configurações de fechamento dos enrolamentos do primário e do secundário do transformador de potência. No exemplo da Figura 87, a conexão é DY1, portanto, as matrizes utilizadas para compensar os fasores do lado primário e do lado secundário são apresentadas, respectivamente, nas Equações (37) e (38).

$$
\begin{gathered}
{\left[\begin{array}{l}
\text { Ia1cc } \\
\text { Ia1cc } \\
\text { Ia1cc }
\end{array}\right]=\left[\begin{array}{lll}
1 & 0 & 0 \\
0 & 1 & 0 \\
0 & 0 & 1
\end{array}\right] \times\left[\begin{array}{l}
\text { Ia } 1 \text { tp } \\
\text { Ialtp } \\
\text { Ia1tp }
\end{array}\right]} \\
{\left[\begin{array}{l}
\text { Ia } 2 c c \\
\text { Ia2cc } \\
\text { Ia2cc }
\end{array}\right]=\frac{1}{\sqrt{3}} \times\left[\begin{array}{rrr}
1 & -1 & 0 \\
0 & 1 & -1 \\
-1 & 0 & 1
\end{array}\right] \times\left[\begin{array}{l}
\text { Ia } 2 \text { tp } \\
\text { Ia2tp } \\
\text { Ia2tp }
\end{array}\right]}
\end{gathered}
$$

A última etapa consiste em estabelecer o plano de atuação/restrição da proteção diferencial para cada uma das fases (fases A, B ou C) do transformador de potência, conforme Figura 88. 


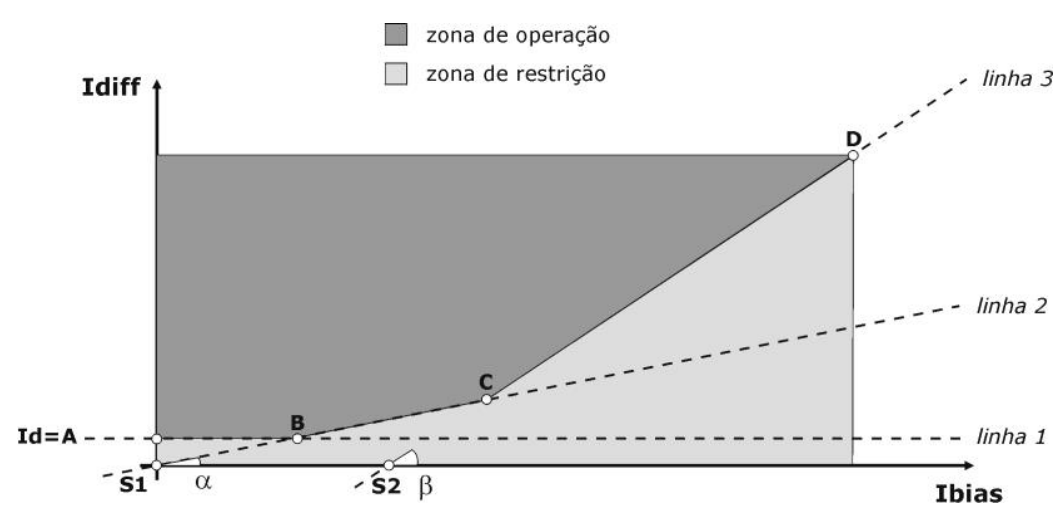

Este plano baseia-se em duas correntes:

- corrente diferencial (Idiff): corresponde ao módulo da soma vetorial dos fasores das correntes primária e secundária da fase a que se refere o plano, conforme ilustra o exemplo da Equação (39) para a fase A.

$$
\text { Idiff }=|\operatorname{Ia} 1 \mathrm{cc}+\mathrm{Ia} 2 \mathrm{cc}|
$$

- corrente de restrição (Ibias): corresponde ao resultado da soma dos módulos dos fasores da corrente primária e secundária da fase a que se refere o plano, conforme se observa no exemplo da Equação (40) para a fase A.

$$
\text { Ibias }=|\operatorname{Ia} 1 \mathrm{cc}|+|\mathrm{Ia} 2 \mathrm{cc}|
$$

Estas duas correntes acabam por definir um ponto de trabalho no plano de operação/restrição. Se o ponto estiver dentro da zona de operação, o relé gerará um comando de trip. Se o ponto estiver dentro da zona de restrição, o comando de trip não será gerado pelo relé.

A zona de restrição e a zona de operação são separadas pelos segmentos $A B, B C$ e $C D$, definidos a partir das linhas 1, 2 e 3. Cada segmento possui um objetivo específico [57] [60], alterando o comportamento da proteção diferencial de acordo com os erros gerados pela dinâmica do sistema protegido.

$\mathrm{O}$ objetivo do segmento $\mathrm{AB}$ é prevenir a operação indevida do relé por fontes de erro constantes, que independam da intensidade da corrente aplicada no sistema, por exemplo: corrente de excitação do transformador. Este segmento é definido sobre a linha 1, que é paralela ao eixo Ibias e cruza o eixo Idiff no ponto de corrente diferencial mínima Id. 
O segmento $\mathrm{BC}$, também denominado slope 1, tem como objetivo prevenir a operação indevida do relé por fontes de erro proporcionais, cujos valores dependem diretamente da intensidade da corrente aplicada no sistema, por exemplo: comutador sob carga do transformador de potência (On Load Tap Changer - OLTC), precisão das medições dos TCs, precisão da medição do relé, compensação de TAP, etc. Este segmento é definido sobre a linha 2, que cruza o eixo Ibias no ponto $\mathrm{S} 1$ e tem inclinação $\alpha$.

O segmento $\mathrm{CD}$, também denominado slope 2, tem, além dos mesmos objetivos do slope 1 , a função de melhorar a performance do relé em condições de corrente extrema, nas quais a saturação do TC pode ocorrer, por exemplo: alta corrente de curto circuito, componente exponencial sobreposta, etc. Este segmento é definido sobre a linha 3, que cruza o eixo Ibias no ponto $\mathrm{S} 2$ e tem inclinação $\beta$.

A Figura 89, a seguir, ilustra um resumo dos conceitos apresentados e os valores usuais encontrados para cada fonte de erro.

Figura 89 - Representação dos diversos erros compensados no plano de atuação/restrição

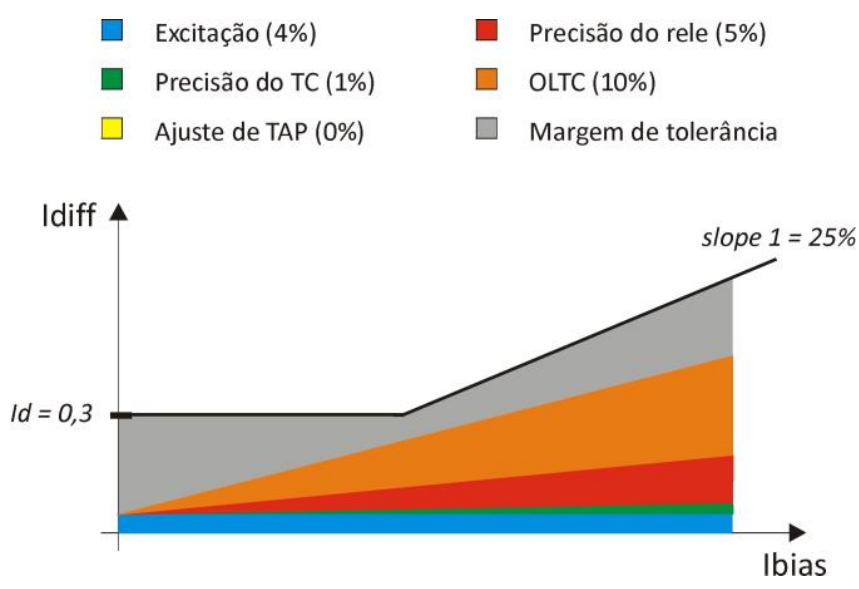

Fonte:adaptado THOMPSON (2011)

A inclinação dos slopes é expressa normalmente em valor percentual, de acordo com a Equação (41).

$$
\text { slope }=\frac{\Delta \text { Idiff }}{\Delta \text { Ibias }} \times 100 \%
$$

sendo AIdiff um trecho qualquer entre dois valores no eixo Idiff e AIbias o seu trecho correspondente projetado no eixo Ibias. Por exemplo, uma inclinação $\alpha$ de $45^{\circ}$ caracteriza um slope 1 de valor $100 \%$.

Com a implementação do barramento de processo digital, a arquitetura convencional da 
proteção diferencial sofreu algumas mudanças. A amostragem e a digitalização dos sinais de corrente passam a ser executados em conversores internos nos TCs, ou através de Merging Units, conforme ilustra a Figura 90, a seguir. Posteriormente, o valor digitalizado é enviado para o barramento de processo em uma SV Message através de uma interface de rede, representada pelo bloco NET.

Figura 90 - Exemplo de arquitetura utilizando barramento de processo digital com Merging Unit
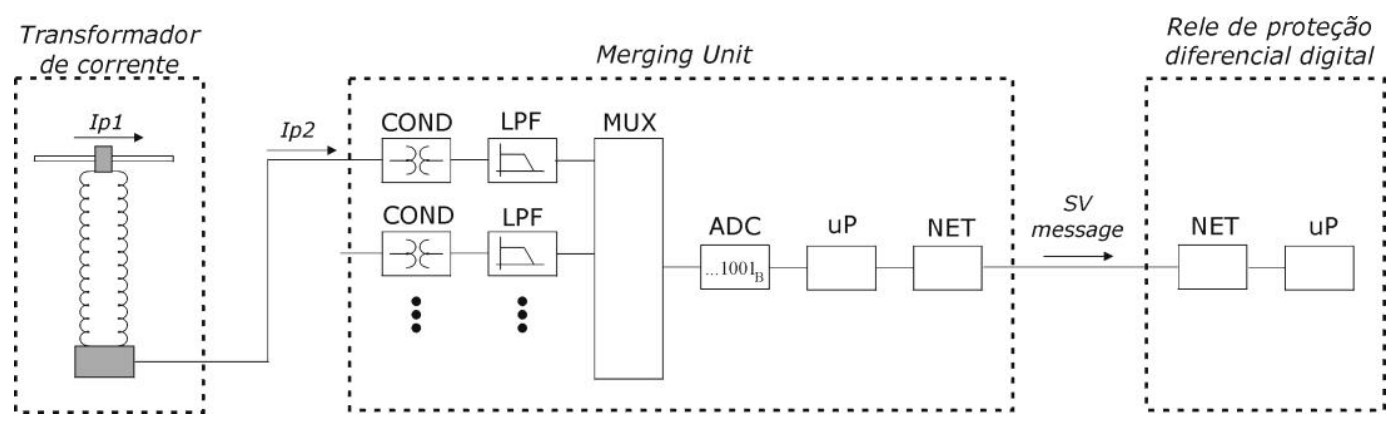

Fonte: o Autor A $S V$ Message é recebida pelo relé diferencial através de sua interface de rede, representada pelo bloco NET, que extrai o valor amostrado e o envia para o bloco $u P$ para execução dos seus algoritmos de proteção e controle. Conforme já mencionado, a Norma IEC 61850-9-2 estabeleceu a taxa de amostragem de 80 amostras/ciclo para fins de proteção. Na prática, esta taxa é alta e desnecessária, pois a maioria dos relés de proteção diferencial presentes no mercado oferece excelente performance nos seus algoritmos de proteção com taxas de amostragens inferiores (por exemplo, 16 ou 24 amostras/ciclo).

Com base nos conceitos apresentados até agora, a Figura 91 ilustra o algoritmo proposto pelo autor para a proteção diferencial de transformadores de potência, que utiliza as amostras enviadas pelo barramento de processo segundo a Norma IEC 61850-9-2.

Figura 91 - Fluxograma do algoritmo de proteção diferencial proposto

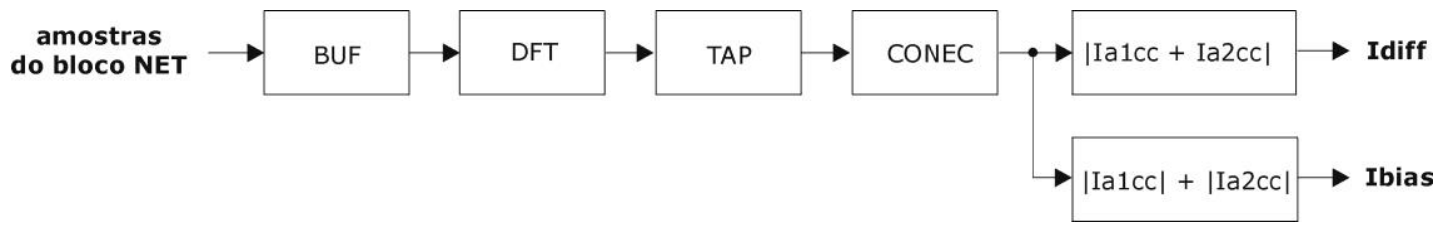

Fonte: o Autor O objetivo do bloco BUF é armazenar em um buffer circular as 80 últimas amostras recebidas pelo bloco NET e enviá-las para o bloco DFT a cada " $n$ " amostras recebidas. Este procedimento tem como função adequar a periodicidade com a qual o bloco DFT e os demais blocos em sequência executam os seus algoritmos nos relés digitais convencionais, com a taxa 
de amostragem de 80 amostras/ciclo utilizada no projeto dos filtros anti-aliasing do bloco $L P F$ da Merging Unit. Portanto, admitindo um exemplo no qual um determinado algoritmo para proteção diferencial seja executado 20 vezes/ciclo, o bloco $B U F$ acumulará as 80 últimas amostras e, a cada $80 / 20=4$ amostras recebidas, ele liberará o bloco DFT para ler as 80 amostras armazenadas e executar o algoritmo de Transformada Discreta de Fourier sobre elas. Os demais blocos seguem os mesmos princípios apresentados na Figura 86.

A validação do algoritmo diferencial proposto foi baseada no sistema de potência da Figura 92, a seguir.

Figura 92 - Sistema proposto para validação do algoritmo de proteção diferencial

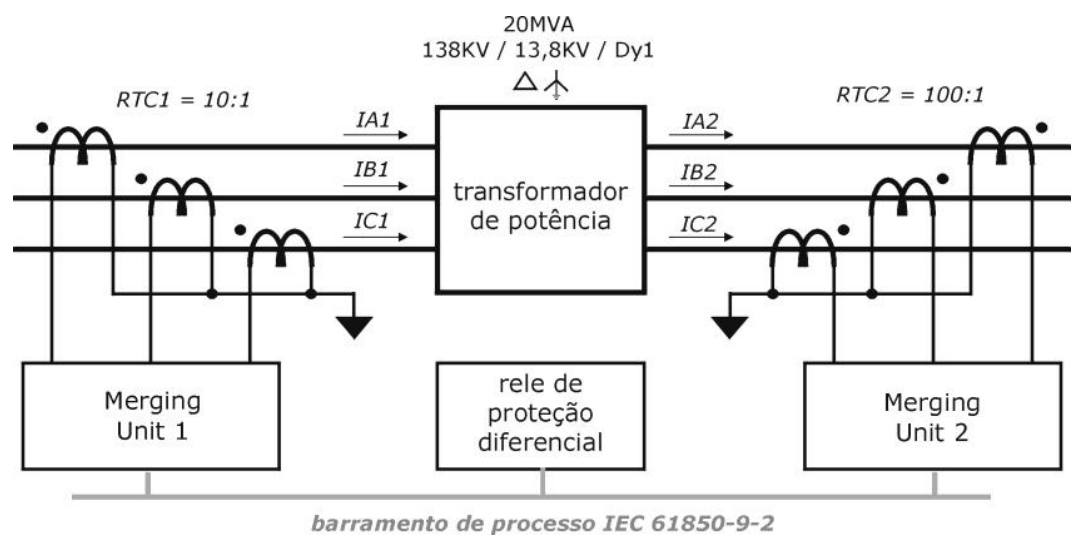

A Figura 93 representa um típico esquema de parametrização do plano de atuação/restrição que foi adotado para as simulações das unidades de proteção diferencial das fases A, B e C.

Figura 93 - Exemplo de esquema típico de parametrização do plano de atuação/restrição

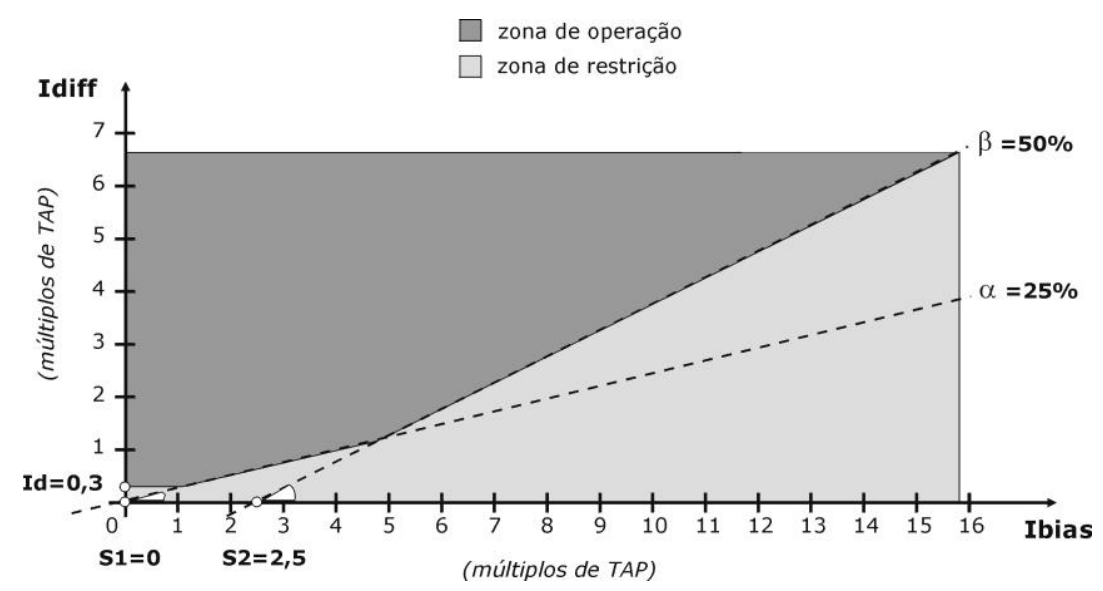

Fonte: o Autor A seguir, serão apresentados alguns dos resultados obtidos a partir da aplicação de vários valores de corrente com o objetivo de simular algumas situações de falha no sistema elétrico. Cada fasor de corrente gerou uma série de valores amostrados baseados na Equação (27). Esta 
série de valores foi aplicada no algoritmo de proteção diferencial proposto na Figura 91. Todas as faltas foram simuladas no lado secundário do transformador a ser protegido e as correntes geradas foram calculadas com base em módulos de teste específicos para transformadores de potência. Os módulos selecionados para as simulações foram o software Advanced Differential da empresa Omicron (utilizado pela mala de teste CMC256) e o software Diferenc da empresa Conprove (utilizado pela mala de teste CE-6006). A taxa de transmissão utilizada foi de 80 amostras/ciclo, armazenamento no bloco BUF das 80 últimas amostras e liberação destas amostras para o bloco DFT a cada 5 amostras recebidas, o que caracteriza uma velocidade de execução do algoritmo diferencial de 16 vezes/ciclo.

\section{Faltas fora da zona de proteção}

Na sequência, a Figura 94 apresenta o sistema testado. Para as simulações foram consideradas correntes de falta iguais a 5 vezes a corrente de carga nominal do transformador.

Figura 94 - Situações de falta testadas fora da zona de proteção: falta trifásica (a), falta dupla fase (b) e falta fase-terra (c)

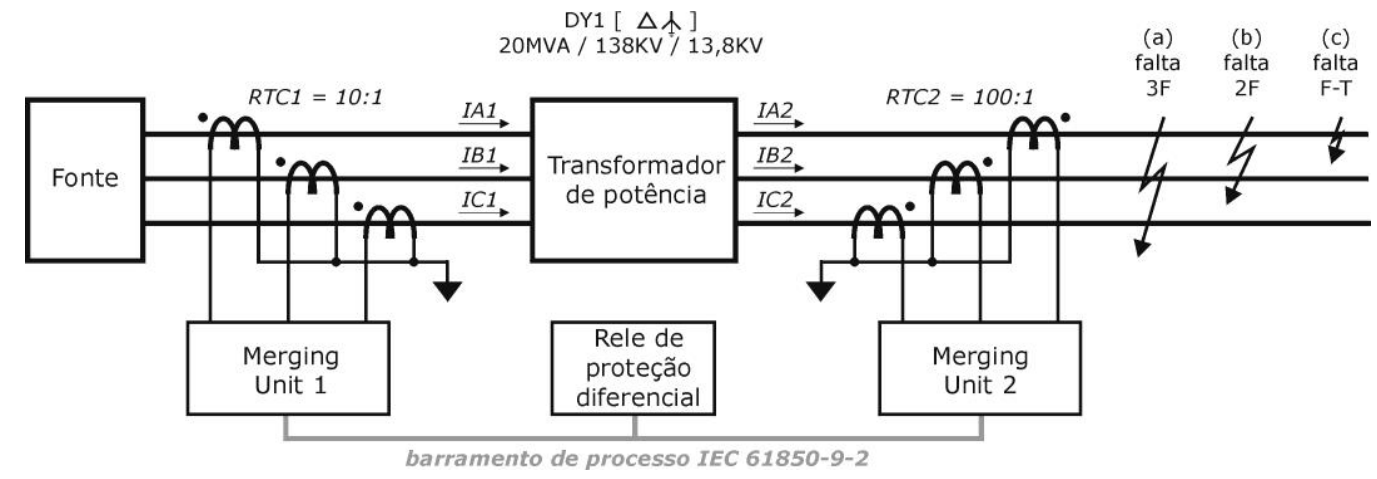

Fonte: o Autor

A Tabela 8 traz os valores das correntes aplicadas em cada fase de cada enrolamento do transformador de potência e das correntes Idiff e Ibias calculadas pelos algoritmos propostos, na unidade de proteção diferencial da fase A, após 1 ciclo do instante de aplicação das correntes de falta trifásica. 
Tabela 8 - Correntes da falta trifásica fora da zona de proteção

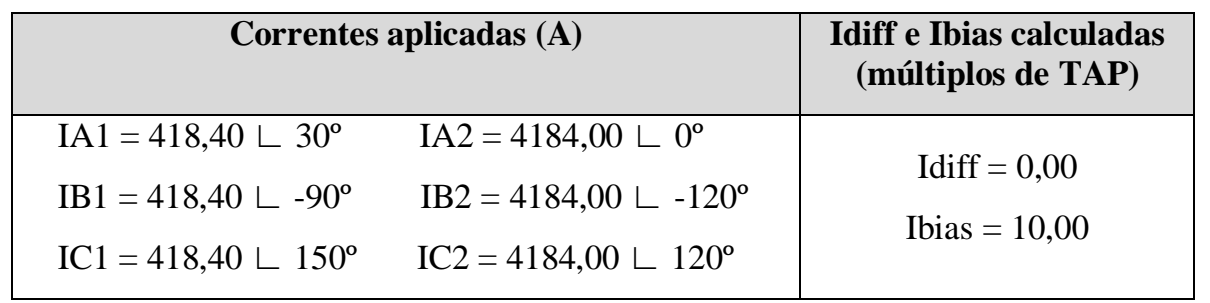

Fonte: o Autor

A Figura 95 apresenta o resultado gráfico da simulação no plano de atuação/restrição, apresentando a evolução do cálculo da falta $($ símbolo +) pelos algoritmos propostos a cada 5 amostras recebidas.

Figura 95 - Evolução da falta trifásica fora da zona de proteção no plano de atuação/restrição

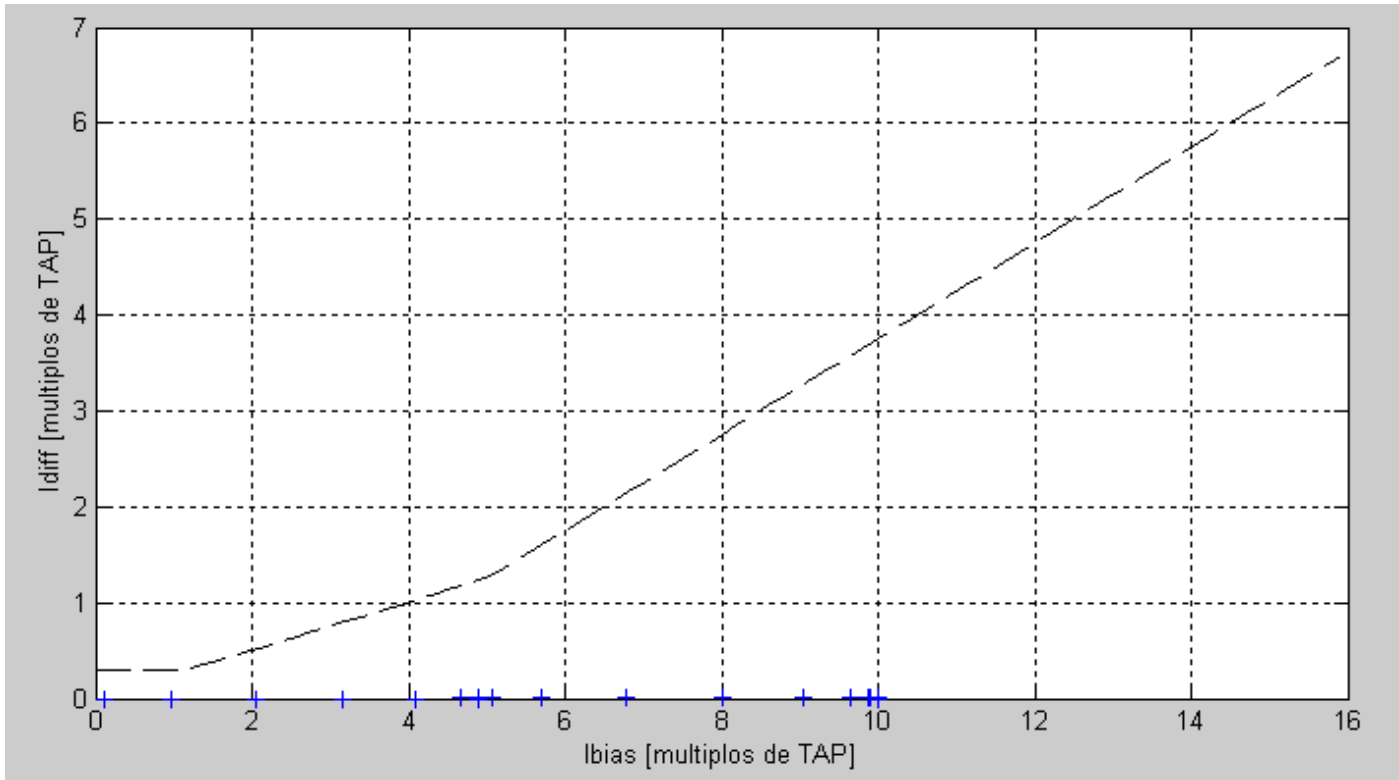

Fonte: o Autor A Tabela 9 apresenta os valores das correntes aplicadas e calculadas na unidade de proteção diferencial da fase A, para a simulação de falta dupla fase (entre as fases A e B).

Tabela 9 - Correntes da falta dupla fase fora da zona de proteção

\begin{tabular}{|ll|c|}
\hline \multicolumn{2}{|c|}{ Correntes aplicadas (A) } & $\begin{array}{c}\text { Idiff e Ibias calculadas } \\
\text { (múltiplos de TAP) }\end{array}$ \\
\hline IA1 $=483,10\left\llcorner 0^{\circ}\right.$ & IA2 $=4184,00\left\llcorner 0^{\circ}\right.$ & Idiff $=0,00$ \\
IB1 $=241,60\left\llcorner 180^{\circ}\right.$ & IB2 $=4184,00\left\llcorner 180^{\circ}\right.$ & Ibias $=11,54$ \\
IC1 $=241,60\left\llcorner 180^{\circ}\right.$ & IC2 $=0,00\left\llcorner 0^{\circ}\right.$ & \\
\hline
\end{tabular}

Fonte: o Autor

A Figura 96 ilustra o resultado gráfico da simulação no plano de atuação/restrição, apresentando a evolução do cálculo da falta $($ símbolo +) pelos algoritmos propostos a cada 5 
amostras recebidas.

Figura 96 - Evolução da falta dupla fase fora da zona de proteção no plano de atuação/restrição

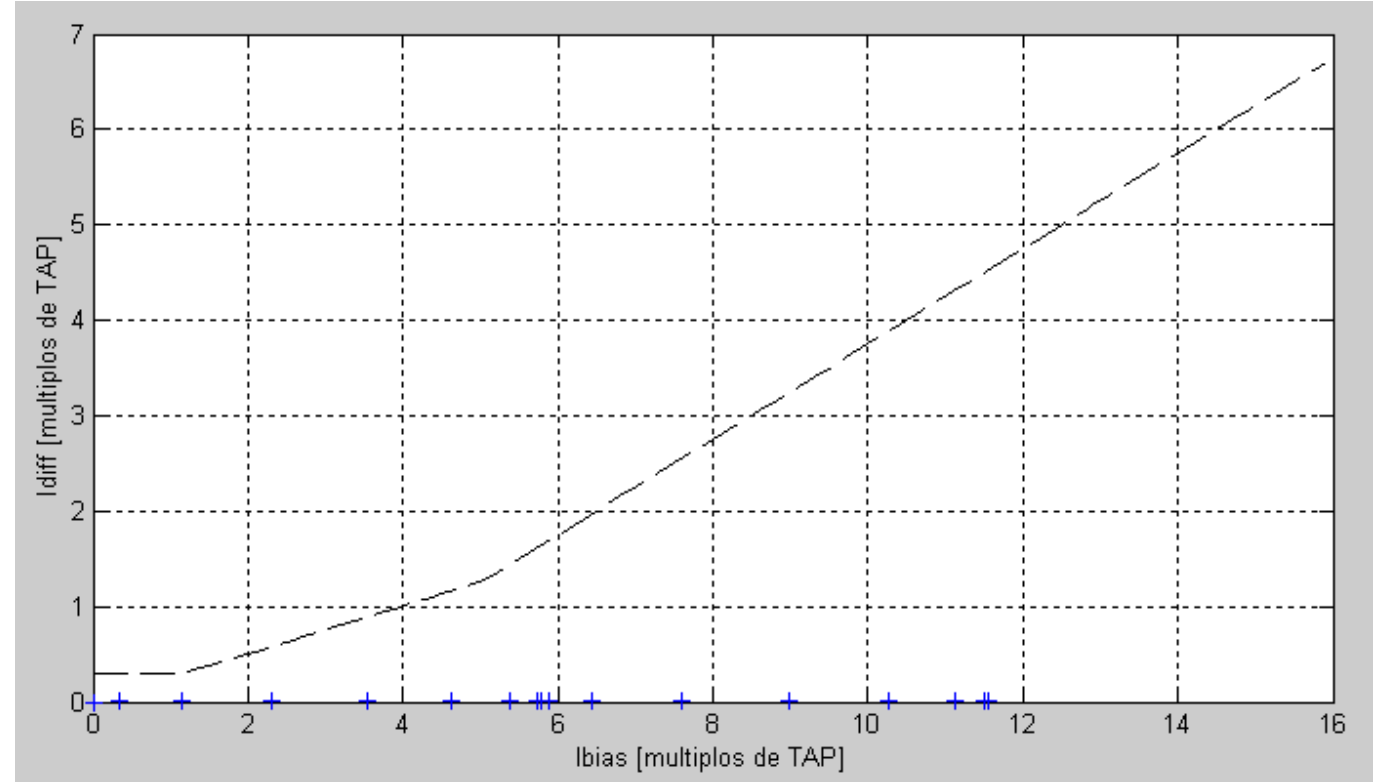

Fonte: o Autor Os valores das correntes aplicadas e calculadas na unidade de proteção diferencial da fase A, para a simulação de falta fase-terra (na fase A), estão representados na Tabela 10.

Tabela 10 - Correntes aplicadas para falta fase-terra fora da zona de proteção

\begin{tabular}{|c|c|c|}
\hline \multicolumn{2}{|c|}{ Correntes aplicadas (A) } & Idiff e Ibias calculadas \\
\hline $\begin{array}{l}\mathrm{IA} 1=241,60\left\llcorner 0^{\circ}\right. \\
\mathrm{IB} 1=0,00\left\llcorner 0^{\circ}\right. \\
\mathrm{IC} 1=241,60\left\llcorner 180^{\circ}\right.\end{array}$ & $\begin{array}{l}\text { IA2 }=4184,00\left\llcorner 0^{\circ}\right. \\
\text { IB2 }=0,00\left\llcorner 0^{\circ}\right. \\
\text { IC2 }=0,00\left\llcorner 0^{\circ}\right.\end{array}$ & $\begin{array}{l}\text { Idiff }=0,00 \\
\text { Ibias }=5,77\end{array}$ \\
\hline
\end{tabular}

Fonte: o Autor

A Figura 97 demonstra o resultado gráfico da simulação no plano de atuação/restrição, apresentando a evolução do cálculo da falta $($ símbolo + ) pelos algoritmos propostos a cada 5 amostras recebidas.

Os resultados mostram que a evolução do cálculo das faltas nas situações testadas com faltas fora da zona de proteção ocorreu de forma retilínea, sem apresentar corrente Idiff, permanecendo dentro da zona de restrição. Portanto, o algoritmo proposto apresentou desempenho satisfatório. 
Figura 97 - Falta fase-terra fora da zona de proteção

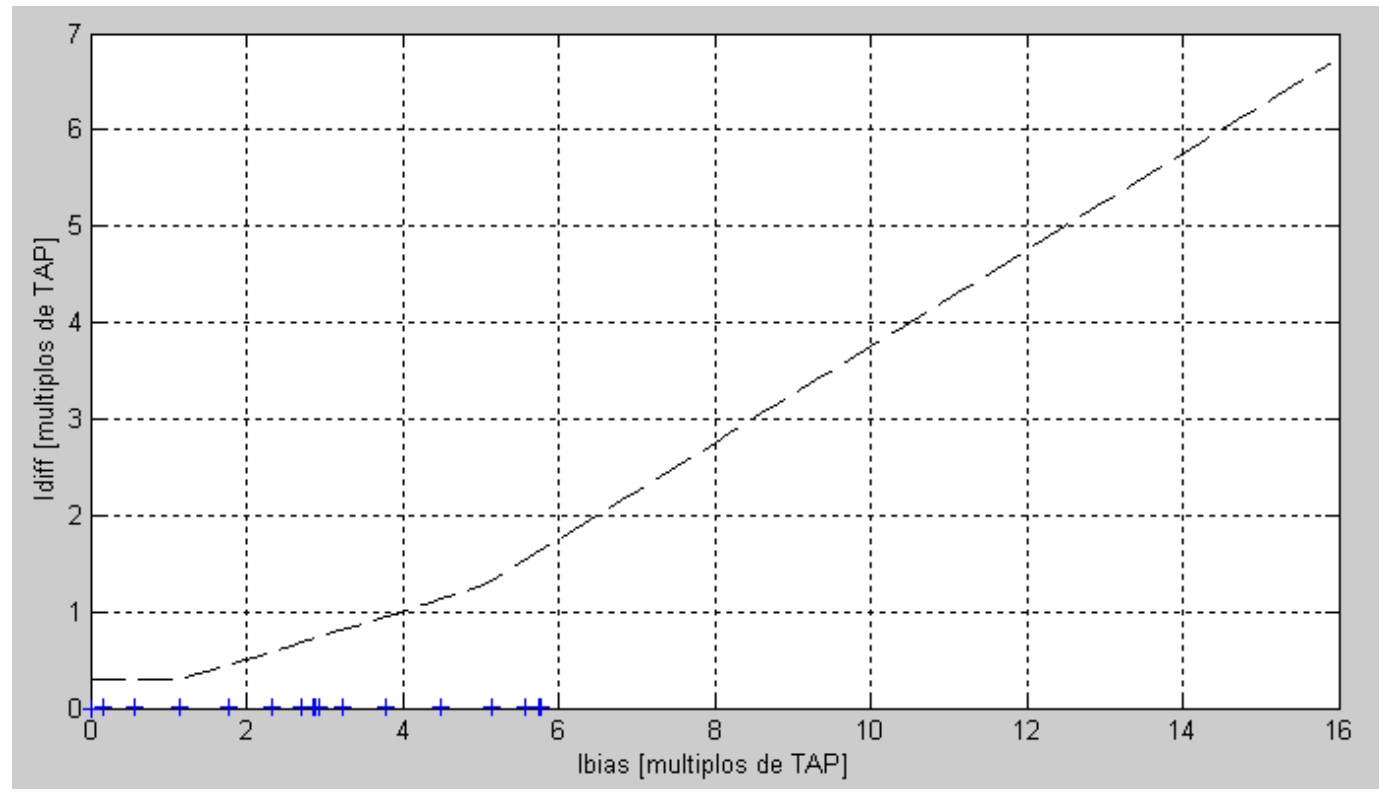

\section{Faltas dentro da zona de proteção}

A Figura 98 apresenta o sistema testado.

Figura 98 - Situações de falta testadas dentro da zona de proteção: falta trifásica (a), falta dupla fase (b) e falta fase-terra $(c)$

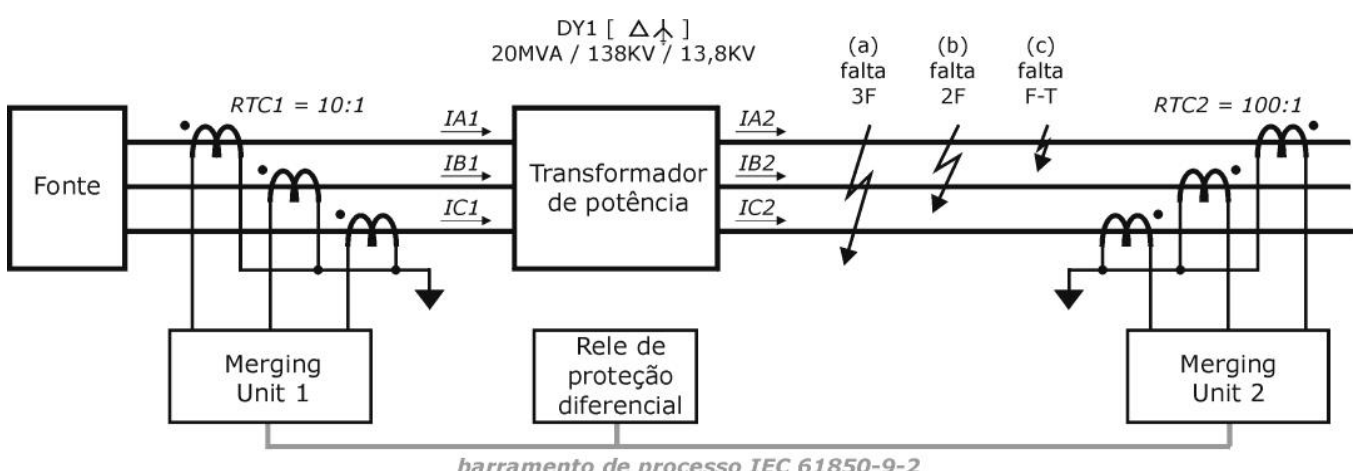

Fonte: o Autor

A Tabela 11 demonstra os valores das correntes aplicadas em cada fase de cada enrolamento do transformador de potência, as correntes Idiff e Ibias estimadas pelos módulos de teste e as correntes Idiff e Ibias calculadas pelos algoritmos propostos, na unidade de proteção diferencial da fase A, após 1 ciclo do instante de aplicação das correntes de falta trifásica. 
Tabela 11 - Correntes aplicadas para falta trifásica dentro da zona de proteção

\begin{tabular}{|c|c|c|c|}
\hline \multicolumn{2}{|c|}{ Correntes aplicadas (A) } & $\begin{array}{c}\text { Idiff e Ibias estimadas } \\
\text { (múltiplos de TAP) }\end{array}$ & $\begin{array}{l}\text { Idiff e Ibias calculadas } \\
\text { (múltiplos de TAP) }\end{array}$ \\
\hline $\begin{array}{l}\mathrm{IA} 1=418,30\left\llcorner 180^{\circ}\right. \\
\mathrm{IB} 1=418,30\left\llcorner 60^{\circ}\right. \\
\mathrm{IC} 1=418,30\left\llcorner-60^{\circ}\right.\end{array}$ & $\begin{array}{l}\text { IA2 }=0,00\left\llcorner 0^{\circ}\right. \\
\text { IB2 }=0,00\left\llcorner 0^{\circ}\right. \\
\text { IC2 }=0,00\left\llcorner 0^{\circ}\right.\end{array}$ & $\begin{array}{l}\text { Idiff }=5,00 \\
\text { Ibias }=5,00\end{array}$ & $\begin{array}{l}\text { Idiff }=5,00 \\
\text { Ibias }=5,00\end{array}$ \\
\hline
\end{tabular}

Fonte: o Autor

A Figura 99 ilustra o resultado gráfico da simulação no plano de atuação/restrição, apresentando a evolução do cálculo da falta $($ símbolo +) pelos algoritmos propostos a cada 5 amostras recebidas.

Figura 99 - Evolução da falta trifásica dentro da zona de proteção no plano de atuação/restrição

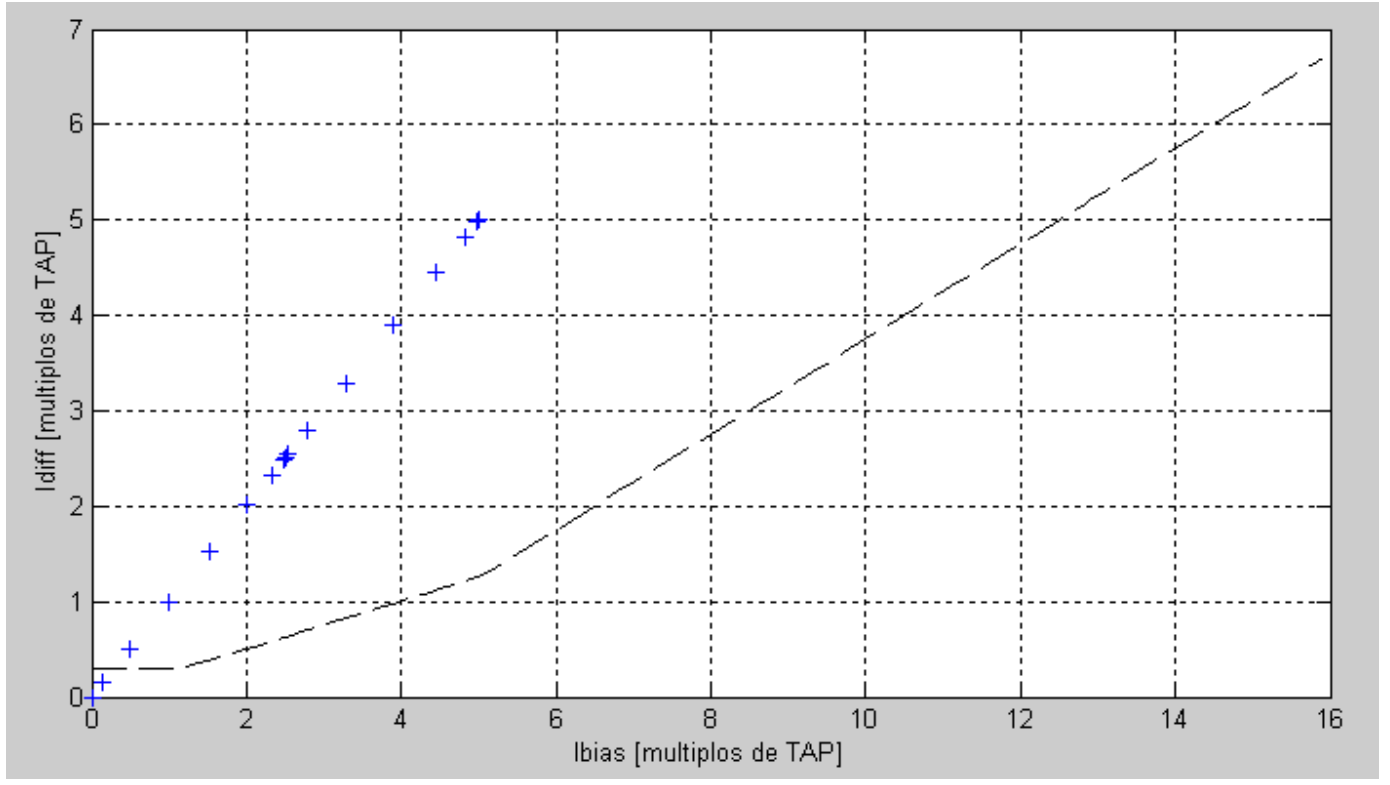

Fonte: o Autor A Tabela 12 mostra os valores das correntes aplicadas e calculadas na unidade de proteção diferencial da fase A, para a simulação de falta dupla fase (entre as fases A e B) dentro da zona de proteção.

Tabela 12 - Correntes aplicadas para falta dupla fase dentro da zona de proteção

\begin{tabular}{|ll|c|c|}
\hline \multicolumn{2}{|c|}{ Correntes aplicadas (A) } & $\begin{array}{c}\text { Idiff e Ibias estimadas } \\
\text { (múltiplos de TAP) }\end{array}$ & $\begin{array}{c}\text { Idiff e Ibias calculadas } \\
\text { (múltiplos de TAP) }\end{array}$ \\
\hline IA1 $=418,30\left\llcorner 180^{\circ}\right.$ & IA2 $=0,00\left\llcorner 0^{\circ}\right.$ & Idiff $=5,00$ & Idiff $=5,00$ \\
IB1 $=418,30\left\llcorner 0^{\circ}\right.$ & IB2 $=0,00\left\llcorner 0^{\circ}\right.$ & Ibias $=5,00$ & Ibias $=5,00$ \\
IC1 $=0,00\left\llcorner 0^{\circ}\right.$ & IC2 $=0,00\left\llcorner 0^{\circ}\right.$ & \\
\hline
\end{tabular}


A Figura 100 apresenta o resultado gráfico da simulação no plano de atuação/restrição, apresentando a evolução do cálculo da falta $($ símbolo + ) pelos algoritmos propostos a cada 5 amostras recebidas.

Figura 100 - Evolução da falta dupla fase dentro da zona de proteção no plano de atuação/restrição

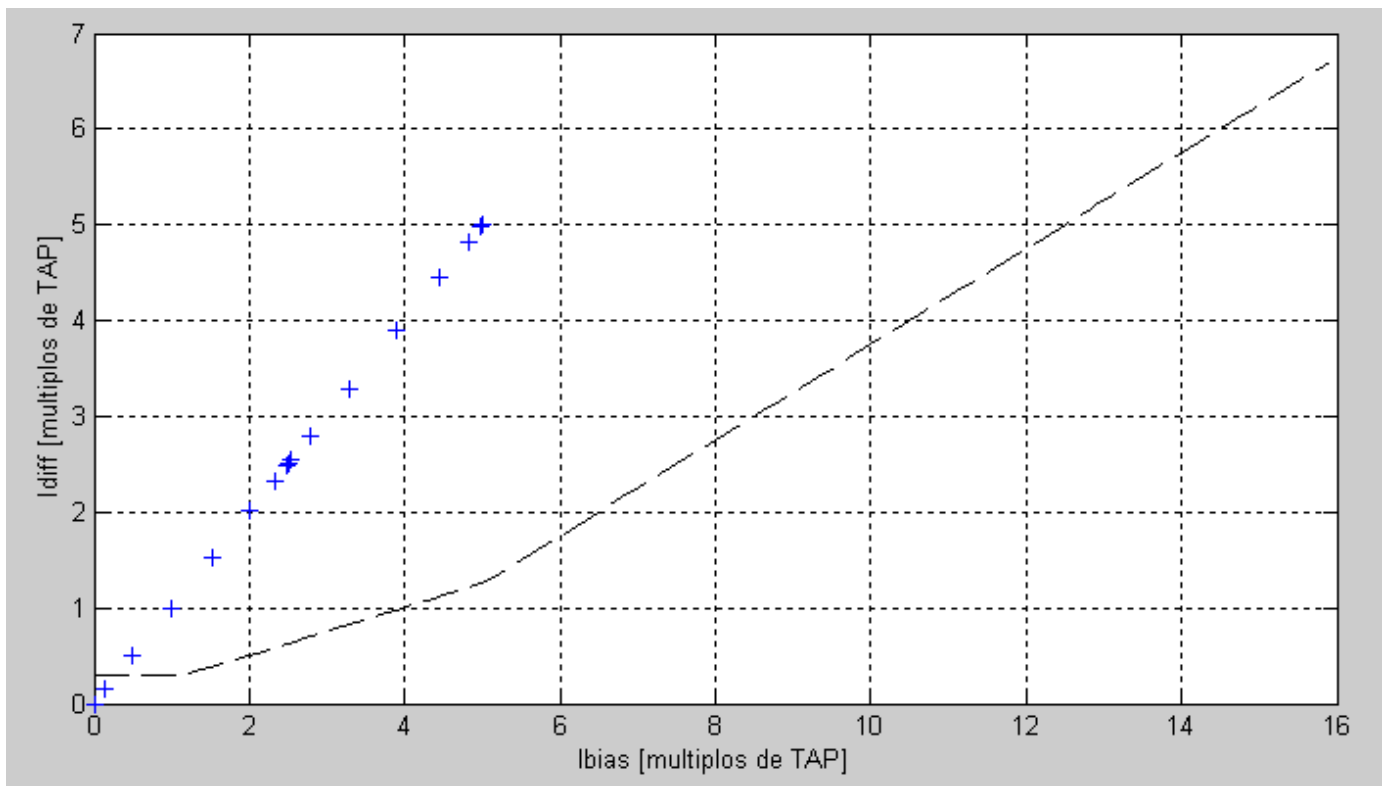

Fonte: o Autor A Tabela 13 demonstra os valores das correntes aplicadas e calculadas na unidade de proteção diferencial da fase A, para a simulação de falta fase-terra (na fase A) dentro da zona de proteção.

Tabela 13 - Correntes aplicadas para falta fase-terra dentro da zona de proteção

\begin{tabular}{|ll|c|c|}
\hline \multicolumn{2}{|c|}{ Correntes aplicadas (A) } & $\begin{array}{c}\text { Idiff e Ibias estimadas } \\
\text { (múltiplos de TAP) }\end{array}$ & $\begin{array}{c}\text { Idiff e Ibias calculadas } \\
\text { (múltiplos de TAP) }\end{array}$ \\
\hline IA1 $=418,30\left\llcorner 180^{\circ}\right.$ & IA2 $=0,00\left\llcorner 0^{\circ}\right.$ & Idiff $=5,00$ & Idiff $=5,00$ \\
IB1 $=209,10\left\llcorner 0^{\circ}\right.$ & IB2 $=0,00\left\llcorner 0^{\circ}\right.$ & Ibias $=5,00$ & Ibias $=5,00$ \\
IC1 $=209,10\left\llcorner 0^{\circ}\right.$ & IC2 $=0,00\left\llcorner 0^{\circ}\right.$ & & Fonte: o Autor \\
\hline
\end{tabular}

A Figura 101 ilustra o resultado gráfico da simulação no plano de atuação/restrição, apresentando a evolução do cálculo da falta $($ símbolo + ) pelos algoritmos propostos a cada 5 amostras recebidas.

Os resultados mostram que a evolução do cálculo das faltas nas situações testadas com faltas dentro da zona de proteção foi quase que retilínea, e apresentaram correntes Idiff e Ibias iguais às correntes estimadas pelos módulos de teste. Portanto, o algoritmo proposto também 
apresentou desempenho satisfatório nestas situações.

Figura 101 - Evolução da falta fase-terra dentro da zona de proteção no plano de atuação/restrição

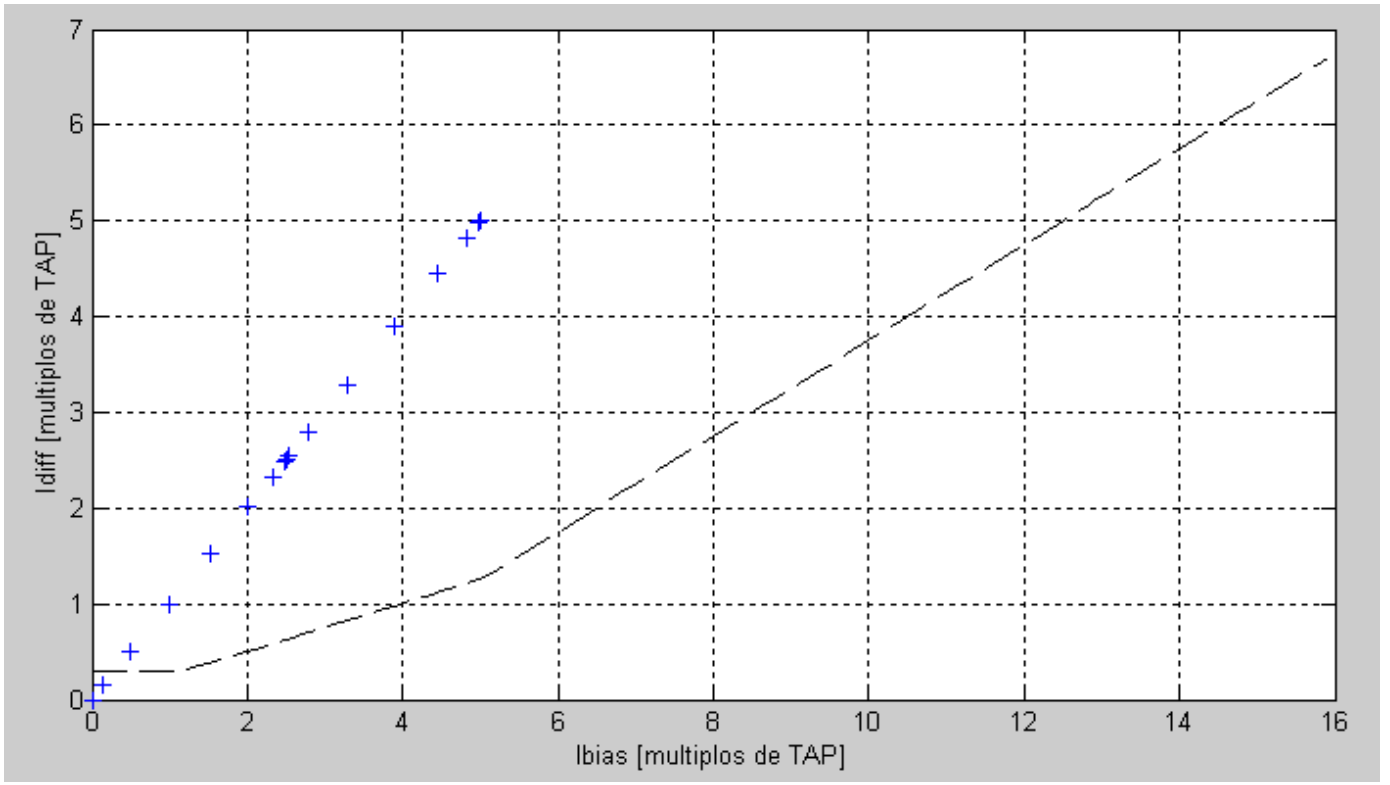

Fonte: o Autor 


\subsection{Comportamento da proteção diferencial considerando a perda de sincronismo de tempo no barramento de processo}

Segundo a Norma IEC 61850, numa situação na qual um IED responsável por enviar $S V$ Messages passe a operar sem seu sinal de sincronismo de tempo, ele deve continuar a enviar as amostras no barramento de processo, utilizando como referência de tempo seu relógio interno. No caso da proteção diferencial de transformadores de potência, isto implica em que os TCs presentes no primário acabam por operar de forma assíncrona com os TCs presentes no secundário. Para estudar alguns dos efeitos que esta perda de sincronismo pode causar na operação do algoritmo diferencial, amostras geradas pela Equação (28) foram aplicadas no algoritmo de proteção diferencial da Figura 91. As simulações foram realizadas com base no sistema da Figura 92 e com a parametrização da unidade diferencial de acordo com a Figura 93.

Num primeiro caso, foram aplicadas correntes no transformador de potência segundo sua carga nominal, considerando frequência da rede elétrica em $60 \mathrm{~Hz}$, drift de $+20 \mathrm{ppm}$ nos TCs de primário e drift de -20ppm nos TCs de secundário. A Tabela 14 mostra os resultados calculados para a unidade diferencial da fase A. A corrente Ibias se manteve constante em 2,000 múltiplos de TAP e a corrente Idiff se elevou gradualmente com o passar do tempo (média de 0,015 múltiplos de TAP por segundo).

Tabela 14 - Resultados da simulação para a frequência de $60 \mathrm{~Hz}$

\begin{tabular}{|c|c|c|c|}
\hline Correntes (A) & Tempo (s) & Idiff (TAP) & Ibias (TAP) \\
\hline \multirow{2}{*}{ IA1 $=83,70\left\llcorner 30^{\circ}\right.$} & 0 & 0,000 & 2,000 \\
\cline { 2 - 4 } IB1 $=83,70\left\llcorner-90^{\circ}\right.$ & 1 & 0,015 & 2,000 \\
\cline { 2 - 4 } IC1 $=83,70\left\llcorner 150^{\circ}\right.$ & 2 & 0,030 & 2,000 \\
\cline { 2 - 4 } IA2 $=837,00\left\llcorner 0^{\circ}\right.$ & 3 & 0,046 & 2,000 \\
\cline { 2 - 4 } IB2 $=837,00\left\llcorner-120^{\circ}\right.$ & 4 & 0,061 & 2,000 \\
\cline { 2 - 4 } IC2 $=837,00\left\llcorner 120^{\circ}\right.$ & 5 & 0,076 & 2,000 \\
\cline { 2 - 4 } & 33,5 & 0,500 & 2,000 \\
\hline
\end{tabular}

Seguindo este comportamento, pode-se assumir que, no plano de atuação/restrição da unidade diferencial, o ponto de trabalho entrará na zona de operação quando cruzar o slope 1 para uma corrente Idiff próxima de 0,500 múltiplos de TAP, o que ocorrerá aproximadamente 33,5 
segundos após o momento em que houver a perda do sinal de sincronismo, conforme ilustra a linha B da Figura 102, a seguir.

Figura 102 - Representação gráfica dos efeitos da perda de sincronismo no plano de atuação/restrição

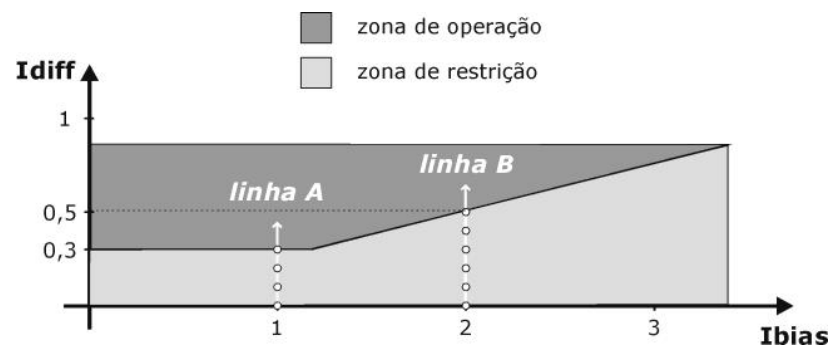

Fonte: o Autor

Num segundo caso, a simulação foi feita em uma situação similar ao primeiro caso, desta vez assumindo que o sistema opera com a frequência de rede elétrica em $50 \mathrm{~Hz}$. A Tabela 15 demonstra os resultados obtidos para a unidade diferencial da fase A.

Tabela 15 - Resultados da simulação para a frequência de $50 \mathrm{~Hz}$

\begin{tabular}{|c|c|c|c|}
\hline Correntes (A) & Tempo (s) & Idiff (TAP) & Ibias (TAP) \\
\hline \multirow{2}{*}{ IA1 $=83,70\left\llcorner 30^{\circ}\right.$} & 0 & 0,000 & 2,000 \\
\cline { 2 - 4 } IB1 $=83,70\left\llcorner-90^{\circ}\right.$ & 1 & 0,013 & 2,000 \\
\cline { 2 - 4 } IC1 $=83,70\left\llcorner 150^{\circ}\right.$ & 2 & 0,025 & 2,000 \\
\cline { 2 - 4 } IA2 $=837,00\left\llcorner 0^{\circ}\right.$ & 3 & 0,038 & 2,000 \\
\cline { 2 - 4 } IB2 $=837,00\left\llcorner-120^{\circ}\right.$ & 4 & 0,051 & 2,000 \\
\cline { 2 - 4 } IC2 $=837,00\left\llcorner 120^{\circ}\right.$ & 5 & 0,063 & 2,000 \\
\cline { 2 - 4 } & 40 & 0,500 & 2,000 \\
\hline
\end{tabular}

Os resultados da simulação mostram que a corrente Ibias permaneceu constante em 2,000 múltiplos de TAP e a corrente Idiff apresentou um pequeno incremento (em torno de 0,013 múltiplos de TAP por segundo). Mantendo esse comportamento, a unidade diferencial entra na zona de operação após a corrente Idiff atingir o slope 1 em 0,500 múltiplos de TAP, o que ocorrerá em torno de 40 segundos após a perda do sincronismo de tempo, conforme ilustrado pela linha B da Figura 102.

Num terceiro caso, a simulação foi feita em uma situação similar ao primeiro caso, assumindo desta vez que o transformador de potência esteja operando na metade de sua potência nominal. A Tabela 16 demonstra os resultados obtidos para a unidade diferencial da fase A. 
Tabela 16 - Resultados da simulação com metade da potência nominal do transformador

\begin{tabular}{|c|c|c|c|}
\hline Correntes (A) & Tempo (s) & Idiff (TAP) & Ibias (TAP) \\
\hline \multirow{2}{*}{ IA1 $=41,85\left\llcorner 30^{\circ}\right.$} & 0 & 0,000 & 1,000 \\
\cline { 2 - 4 } IB1 $=41,85\left\llcorner-90^{\circ}\right.$ & 1 & 0,008 & 1,000 \\
\cline { 2 - 4 } IC1 $=41,85\left\llcorner 150^{\circ}\right.$ & 2 & 0,015 & 1,000 \\
\cline { 2 - 4 } IA2 $=418,50\left\llcorner 0^{\circ}\right.$ & 3 & 0,023 & 1,000 \\
\cline { 2 - 4 } IB2 $=418,50\left\llcorner-120^{\circ}\right.$ & 4 & 0,030 & 1,000 \\
\cline { 2 - 4 } IC2 $=418,50\left\llcorner 120^{\circ}\right.$ & 5 & 0,038 & 1,000 \\
\cline { 2 - 4 } & 40 & 0,300 & 1,000 \\
\hline
\end{tabular}

Os resultados da simulação mostraram que a corrente Idiff manteve seu incremento gradual e constante, agora em torno de 0,008 múltiplos de TAP por segundo. A corrente Ibias permaneceu constante durante todo o tempo, com metade do valor anterior. Mantendo este comportamento, a unidade diferencial entrará na zona de operação quando a corrente diferencial exceder a corrente mínima diferencial de 0,300 múltiplos de TAP, o que ocorrerá em torno de 40 segundos após o instante de perda do sinal de sincronismo de tempo, conforme se observa na linha A da Figura 102.

Portanto, a perda do sinal de sincronismo de tempo interferiu somente na corrente Idiff calculada pela unidade de proteção diferencial, fazendo com que o relé atue após um determinado intervalo de tempo sem o sinal de sincronismo. Neste cenário, a frequência da rede elétrica, a potência de trabalho em que se encontra o transformador de potência e a especificação do ppm dos relógios internos dos IEDs são exemplos de fatores que interferem diretamente na atuação da unidade diferencial.

O uso do barramento de processo segundo a Norma IEC 61850-9-2 adicionou mais um fator de erro àqueles já existentes, causado pela falta de sincronismo de tempo, que precisa ser levado em consideração para o cálculo dos parâmetros que definirão o plano de atuação/restrição. O procedimento que o SAS deve adotar em uma situação de perda do sinal de sincronismo de tempo não é completamente definido pela Norma IEC 61850, deixando a cargo dos desenvolvedores de IEDs e dos integradores a decisão de quais providências serão efetivamente tomadas.

Uma análise mais detalhada dos resultados apresentados pelas simulações mostra que, quando a corrente de carga foi reduzida pela metade, durante o intervalo de tempo sem sincronis mo, o avanço do ponto de trabalho no plano de atuação/restrição também foi reduzido pela metade 
(de 0,015 múltiplos de TAP por segundo para 0,008 múltiplos de TAP por segundo), evoluindo de forma linear, demonstrando que o erro causado pela falta de sincronismo pode ser aproximado durante os primeiros segundos de falta de sincronismo de tempo como uma relação diretamente proporcional à corrente aplicada no transformador de potência.

De fato, analisando de forma literal a Equação (39), o valor da corrente Idiff é calculado em razão do módulo da soma vetorial entre a corrente de primário e a corrente de secundário do transformador, onde $\Theta$ é o erro em graus gerado pelo desvio em ppm do oscilador interno do IED. Devido às polaridades dos TCs de primário e secundário estarem apontados em direção oposta ao transformador de potência isto altera a soma vetorial das correntes para uma subtração vetorial, ou seja:

$$
\begin{gathered}
\mid \mathrm{I}\left\lfloor 0^{\circ}-\mathrm{I}\lfloor\theta \mid=\text { Idiff }\right. \\
\mid 1\left\lfloor 0^{\circ}-1\left\lfloor\theta \mid=\frac{\text { Idiff }}{\mathrm{I}}\right.\right. \\
|1-(\cos \theta+\mathrm{j} \operatorname{sen} \theta)|=\frac{\text { Idiff }}{\mathrm{I}} \\
\sqrt{(1-\cos \theta)^{2}+\operatorname{sen}^{2} \theta}=\frac{\text { Idiff }}{\mathrm{I}} \\
(1-\cos \theta)^{2}+\operatorname{sen}^{2} \theta=\frac{\text { Idiff }^{2}}{\mathrm{I}^{2}} \\
1-2 \cos \theta+\cos ^{2} \theta+\operatorname{sen}^{2} \theta=\frac{\text { Idiff }^{2}}{\mathrm{I}^{2}} \\
1-2 \cos \theta+1=\frac{\text { Idiff }^{2}}{\mathrm{I}^{2}} \\
\text { Idiff }=\mathrm{I} \sqrt{2-2 \cos \theta} \quad \operatorname{sendo:} \theta=\frac{\mathrm{ppm}}{1000000} 2 \pi \mathrm{ft}
\end{gathered}
$$

A Figura 103 representa os resultados obtidos através da Equação (42) para diversos valores de desvio em ppm. Portanto, embora a evolução de Idiff apresente um comportamento hiperbólico, os resultados reforçam a hipótese de que ele pode ser aproximado sem grandes erros para uma evolução linear durante os primeiros segundos após a perda do sincronismo de tempo. 


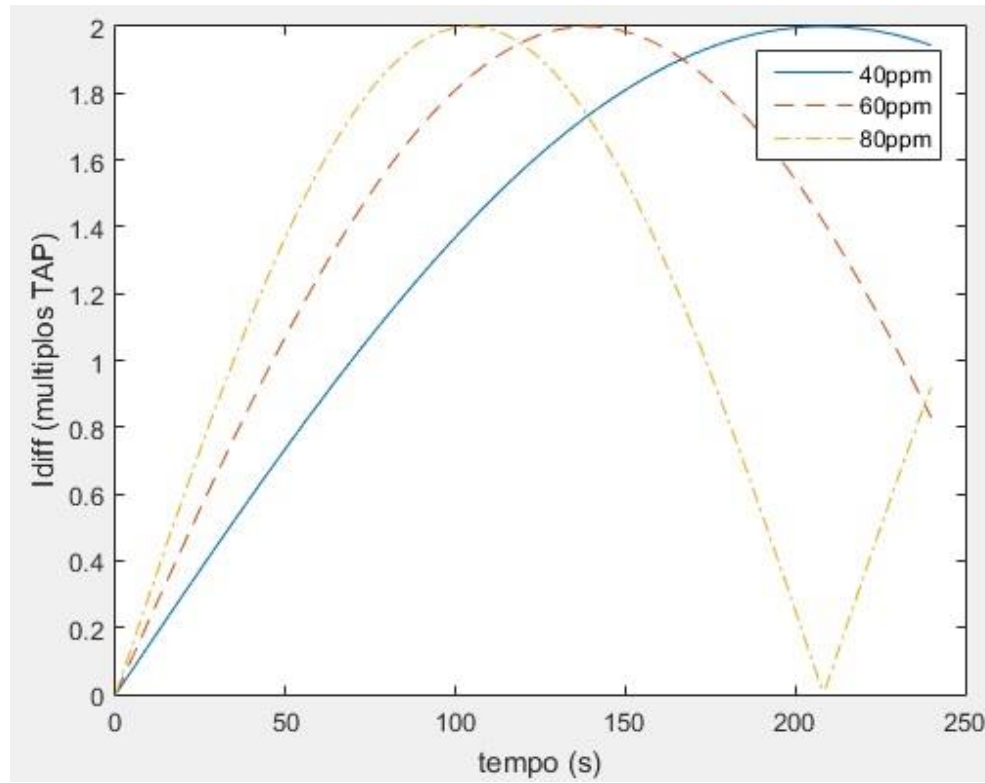

Fonte: o Autor Uma possível ação frente a este problema seria fazer com que o IED aguardasse por um determinado tempo pelo retorno do sinal de sincronismo [61]. Se este tempo for excedido, o IED continua enviando as amostras no barramento de processo, sinalizando em sua $S V$ Message que está operando sem sinal de sincronismo. Para esta situação, o autor sugere que o relé de proteção possa implementar um comportamento adaptativo de sua lógica de proteção, adequando-se a este novo cenário. Um exemplo seria bloquear suas unidades diferenciais (que dependem da informação de fase das correntes) e ativar proteções de retaguarda baseadas em unidades de sobrecorrente (que não dependem da informação de fase das correntes). Outra opção seria readequar o processo de sincronismo de tempo, por exemplo, tornando o relé diferencial em uma espécie de "grandmaster clock" dos TCs instalados no primário e no secundário do transformador de potência. Desta forma, os TCs estariam sincronizados entre si de forma relativa (e não mais de forma absoluta em relação a uma base de tempo TAI), não correndo o risco de enviarem amostras dessincronizadas entre eles para o relé diferencial.

A Norma IEC 61869-9, que se encontra em fase final de elaboração, estabelece um limite de \pm 100 ppm para os TIs com interface de acordo com a Norma IEC 61850-9-2. Conforme já mencionado na seção 3.3, um IED que não recebe sinal de sincronismo deve operar em holdover mode por, no mínimo, 5 segundos e, em seguida, entrar em free-runing mode.

Com base nas observações acima, realizou-se uma nova simulação com o objetivo de estimar um ajuste do plano de atuação/restrição que permita que a proteção do transformador de potência opere de forma adaptativa, sem atuações indevidas na ausência do sinal de 
sincronismo de tempo. Foram consideradas as mesmas condições do primeiro caso, admitindo, desta vez, as seguintes hipóteses:

- drift de +100ppm nos TCs de primário e de -100ppm nos TCs de secundário;

- proteção diferencial capaz de se adaptar, de forma que os TCs passem a ser sincronizados no tempo pelo relé de proteção diferencial na ausência do sinal de sincronismo;

- intervalo de tempo em que a proteção diferencial deve ser capaz de funcionar, sem atuar por perda de sinal de sincronismo, igual a 5 segundos (tempo em holdover mode);

- após detectar a falta de sincronismo nas SV Messages, o relé pode adaptar seu esquema de proteção, bloqueando temporariamente sua unidade diferencial e habilitando as proteções de retaguarda (compostas por unidades de sobrecorrente) enquanto realiza o sincronismo de tempo relativo entre ele e os TCs;

- com os TCs sincronizados, a unidade diferencial é desbloqueada.

Os primeiros resultados desta simulação são mostrados na Tabela 17. Analisando os valores obtidos, conclui-se que seria praticamente inviável a adoção das hipóteses consideradas, uma vez que, após 5 segundos, o valor de Idiff obtido seria de 0,375 múltiplos de TAP, com um Ibias de 2,000 múltiplos de TAP. Para compensar apenas este deslocamento do ponto de trabalho, seria necessário um slope de aproximadamente $(0,375 / 2,000) \times 100 \%=19 \%$, o que ocasionaria um incremento do slope 1 para $25 \%+19 \%=44 \%$. Este valor tornaria o plano de atuação/restrição demasiadamente insensível a faltas no sistema elétrico. 
Tabela 17 - Resultado da simulação considerando drift de $\pm 100 \mathrm{ppm}$

\begin{tabular}{|c|c|c|c|}
\hline Correntes $(\mathbf{A})$ & Tempo $(\mathbf{s})$ & Idiff $($ TAP) & Ibias (TAP) \\
\hline \multirow{2}{*}{ IA $1=83,70\left\llcorner 30^{\circ}\right.$} & 0 & 0,000 & 2,000 \\
\cline { 2 - 4 } IB1 $=83,70\left\llcorner-90^{\circ}\right.$ & 1 & 0,076 & 2,000 \\
\cline { 2 - 4 } IC1 $=83,70\left\llcorner 150^{\circ}\right.$ & 2 & 0,151 & 2,000 \\
\cline { 2 - 4 } IA2 $=837,00\left\llcorner 0^{\circ}\right.$ & 3 & 0,226 & 2,000 \\
\cline { 2 - 4 } IB2 $=837,00\left\llcorner-120^{\circ}\right.$ & 4 & 0,301 & 2,000 \\
\cline { 2 - 4 } IC2 $=837,00\left\llcorner 120^{\circ}\right.$ & 5 & 0,375 & 2,000 \\
\cline { 2 - 4 } & 6 & 0,449 & 2,000 \\
\hline
\end{tabular}

Uma sugestão, proposta pelo autor, para evitar a necessidade do acréscimo excessivo do slope 1 seria a revisão na tolerância de drift especificado pela Norma IEC 61869-9, desde que a precisão da frequência do relógio interno dos TCs permita tal alteração.

Os cristais ressonantes e os osciladores a cristal, que compõem a base da maioria dos relógios internos utilizados pelos IEDs, são componentes cujo drift de sua frequência de oscilação é definido, fundamentalmente, por três parâmetros [62]-[65]:

- tolerância de frequência (frequency tolerance): faixa de desvio permitida em relação à frequência nominal, em condições nominais de operação (definida em ppm);

- estabilidade de frequência (frequency stability): faixa de desvio permitida em relação à frequência nominal devido a fatores como variação da temperatura e variação de tensão de alimentação (definida em ppm);

- envelhecimento (aging): desvio estimado em relação à frequência nominal causado por fatores responsáveis por alterar a frequência de oscilação do cristal com o passar do tempo, como transferência de massa e stress térmico (definido em ppm/ano).

Esses efeitos devem ser somados para a obtenção do drift total dos componentes. O autor realizou uma pesquisa buscando identificar, entre os componentes disponíveis no mercado, aqueles que apresentam os melhores desempenhos. As melhores performances foram encontradas em osciladores a cristal. O oscilador FOX251 da empresa FOX [63], por exemplo, oferece uma tolerância de frequência de $\pm 1,5 \mathrm{ppm}$, estabilidade de frequência de $\pm 2,9 \mathrm{ppm}$ e um envelhecimento de $\pm 1 \mathrm{ppm} / \mathrm{ano}$. Admitindo uma vida útil de 20 anos para um determinado IED, o drift total de seu oscilador seria de aproximadamente $1,5+2,9+(20 \times 1)$ 
$= \pm 25 \mathrm{ppm}$.

Para avaliar as consequências de redução do drift especificado para valores próximos ao deste componente, foi refeita a simulação anterior, admitindo um drift de $\pm 30 \mathrm{ppm}$. A tolerância adicional de $\pm 5 \mathrm{ppm}$ foi somada a título de margem de folga para possibilitar a utilização de componentes com performance inferior ao melhor encontrado. Os resultados obtidos nesta simulação estão demonstrados na Tabela 18, a seguir.

Tabela 18 - Resultados da simulação considerando drift de $\pm 30 p p m$

\begin{tabular}{|c|c|c|c|}
\hline Correntes (A) & Tempo (s) & Idiff (TAP) & Ibias (TAP) \\
\hline \multirow{2}{*}{ IA1 $=83,70\left\llcorner 30^{\circ}\right.$} & 0 & 0,000 & 2,000 \\
\cline { 2 - 4 } IB1 $=83,70\left\llcorner-90^{\circ}\right.$ & 1 & 0,022 & 2,000 \\
\cline { 2 - 4 } IC1 $=83,70\left\llcorner 150^{\circ}\right.$ & 2 & 0,045 & 2,000 \\
\cline { 2 - 4 } IA2 $=837,00\left\llcorner 0^{\circ}\right.$ & 3 & 0,068 & 2,000 \\
\cline { 2 - 4 } IB2 $=837,00\left\llcorner-120^{\circ}\right.$ & 4 & 0,090 & 2,000 \\
\cline { 2 - 4 } IC2 $=837,00\left\llcorner 120^{\circ}\right.$ & 5 & 0,113 & 2,000 \\
\cline { 2 - 4 } & 6 & 0,135 & 2,000 \\
\hline
\end{tabular}

Decorridos 5 segundos, o valor de Idiff obtido foi de 0,113 múltiplos de TAP, com um Ibias de 2,000 múltiplos de TAP. Para compensar somente este deslocamento do ponto de trabalho, seria necessário um slope de aproximadamente $(0,113 / 2,000) \times 100 \%=6 \%$, o que ocasionaria um incremento do slope 1 para $25 \%+6 \%=31 \%$. Este novo valor não reduziria de forma tão excessiva a sensibilidade do plano de atuação/restrição da unidade diferencial, disponibilizando tempo suficiente para a atuação da proteção adaptativa do transformador numa situação de perda do sinal de sincronismo de tempo. A Figura 104 ilustra o efeito final esperado. 
Figura 104 - Compensação da perda de sincronismo de tempo através do slope 1
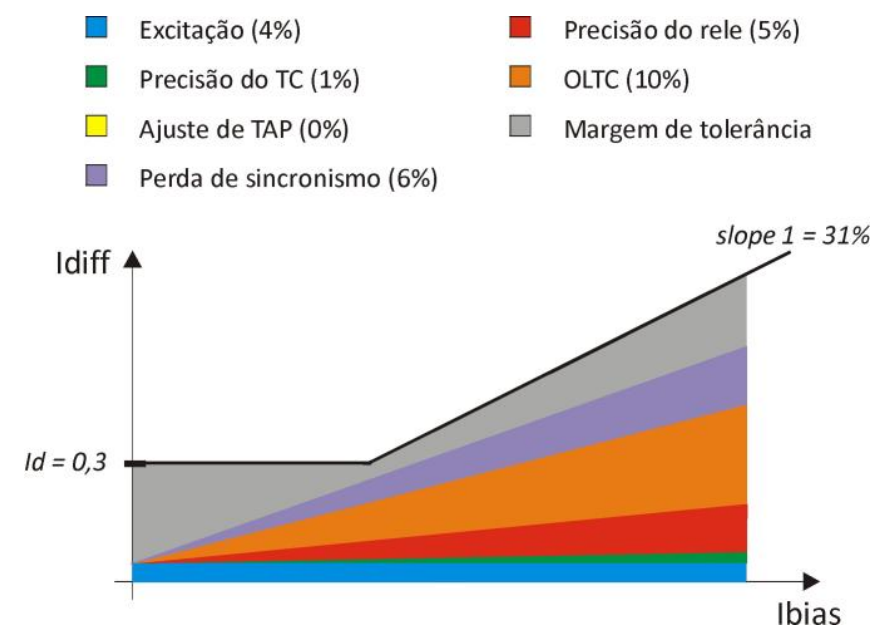

Fonte: o Autor

Por fim, nos TCs que utilizam tecnologia não convencional em seus projetos (ex: Efeito Faraday ou Bobina de Rogowski), não ocorre o fenômeno da saturação, o que, dependendo da aplicação, pode tornar desnecessário o uso do slope 2 e simplificar o plano de atuação/restrição da unidade diferencial. 


\section{Implementação da SV Message}

Nesta etapa do trabalho, foi realizado um estudo mais específico a respeito da estrutura que compõe as SV Messages que circulam no barramento de processo segundo a Norma IEC 61850-9 (conforme mostra o diagrama unifilar da Figura 13) com o objetivo de gerar mensagens, aprofundar o conhecimento dos conceitos apresentados e testar algumas ferramentas de mercado disponíveis para gerar e avaliar este tipo de mensagem. Para isto, definiu-se a seguinte estrutura, representada pela Figura 105.

Figura 105 - Estrutura utilizada para geração e avaliação de SV Messages

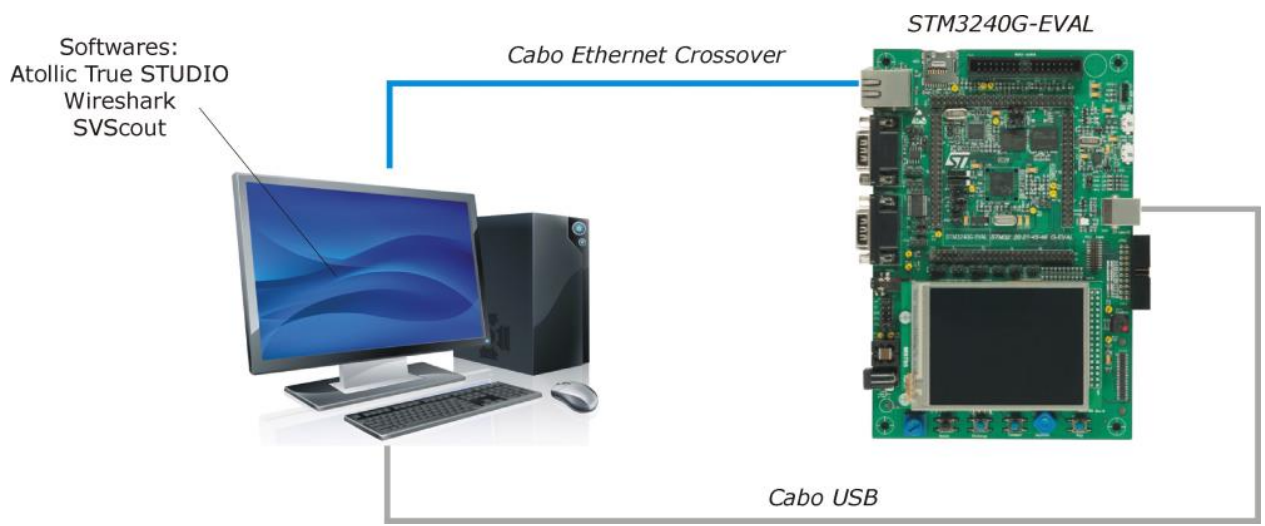

Fonte: o Autor

Nesta estrutura, foram utilizados:

- computador;

- kit de desenvolvimento STM3240G-EVAL, da empresa ST Microelectronics, para a geração das SV Messages;

- software Atollic TrueSTUDIO for ARM Pro, versão 5.3.0, da empresa Atollic, para a geração do firmware do kit de desenvolvimento;

- firmware LwIP, desenvolvido pelo Professor Dr. Adam Dunkels, do Swedish Institute of Computer Science, e modificado pela ST Microelectronics e pelo autor, para o envio das $S V$ Messages através da interface MAC do microcontrolador;

- software SVScout, versão 1.10.197, da empresa Omicron, para validação das SV Messages geradas;

- software WireShark, versão 1.12.6, para análise e validação das SV Messages geradas. 
Primeiramente, com base na Norma IEC 61850-9-2 [21] e nos trabalhos [66] [67] [68], definiu-se uma estrutura básica de um frame Ethernet utilizada para o envio de SV Messages. Em seguida, estas mensagens foram geradas e analisadas com algumas ferramentas disponíveis no mercado. O autor ainda acrescentou em sua análise os campos opcionais previstos pelas normas, os protocolos responsáveis por implementar a redundância de rede e os procedimentos para implementação de segurança cibernética, com o intuito de avançar e contribuir com os resultados apresentados pelos trabalhos citados. Os resultados obtidos são apresentados nos itens a seguir. 


\subsection{Implementação do frame básico da $S V$ Message}

Com base em [21] e nos trabalhos [66] [67] [68], definiu-se uma estrutura básica de um frame Ethernet a ser utilizado na elaboração de SV Messages, representada pela Figura 106.

Figura 106 - Estrutura básica, de um frame Ethernet, utilizada na construção de SV Messages

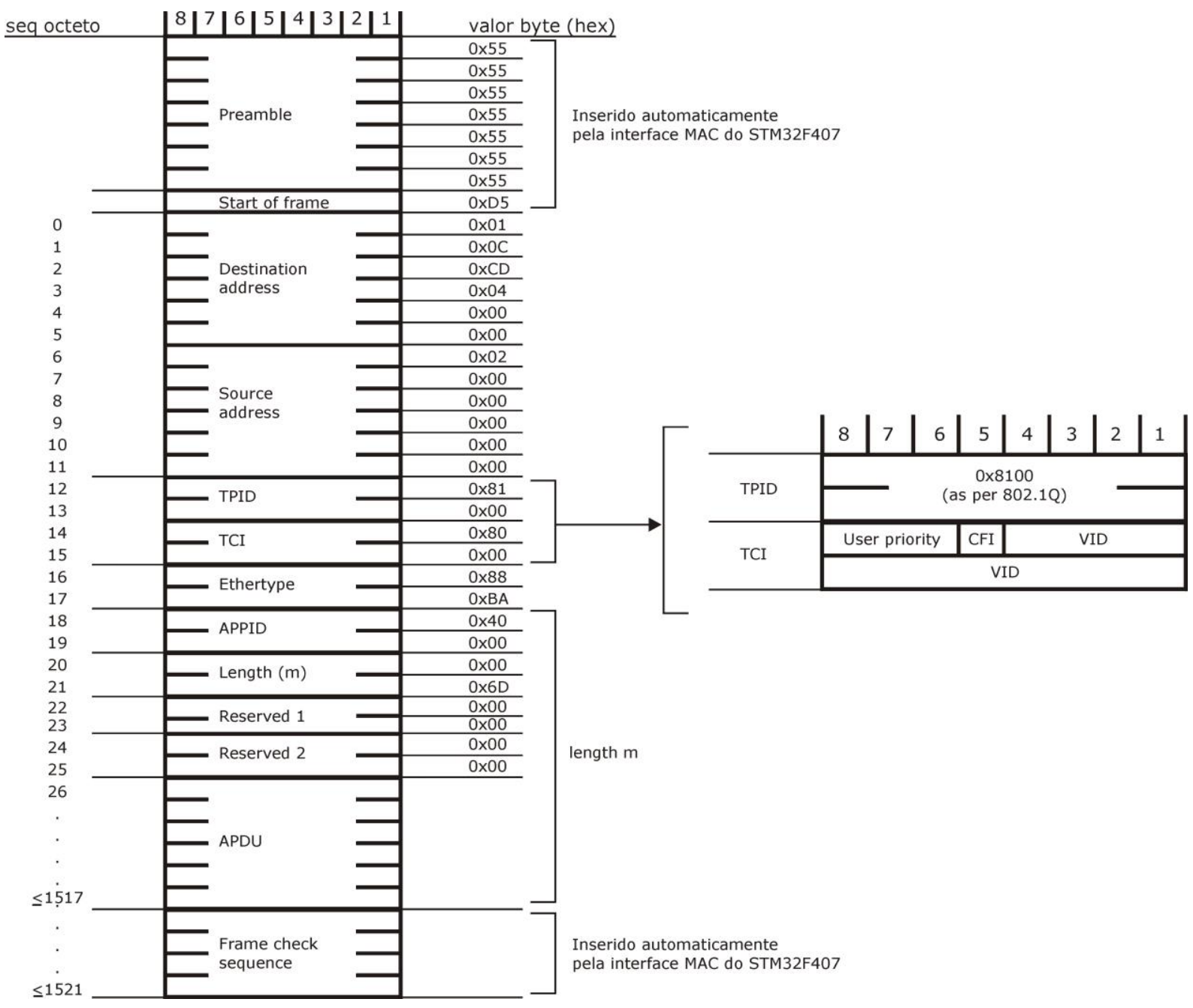

Fonte: o Autor

A seguir, é feita uma descrição resumida de cada campo:

- Campo: Preamble

Descrição: Utilizado para propósitos de sincronismo do circuito da interface MAC. Definido pela Norma IEEE 802.3 como sendo sete bytes de valor 0x55. Inserido automaticamente pela interface MAC.

Valor: 0x55-0x55-0x55-0x55-0x55-0x55-0x55 
- Campo: Start of frame

Descrição: Indica o início do frame. Definido pela Norma IEEE 802.3 como sendo um byte de valor 0xD5. Inserido automaticamente pela interface MAC.

Valor: 0xD5

- Campo: Destination address

Descrição: Endereço MAC de destino. A Norma IEC 61850-9-2 recomenda as seguintes faixas de endereços MAC a serem utilizadas pelos serviços de alta performance, conforme Tabela 19, a seguir.

Tabela 19 - Faixas de endereços MAC recomendadas pela Norma IEC 61850-9-2

\begin{tabular}{|l|l|l|}
\hline \multirow{2}{*}{\multicolumn{1}{|c|}{ Service }} & \multicolumn{2}{c|}{ Recommended address range assignments } \\
\cline { 2 - 3 } & \multicolumn{1}{|c|}{$\begin{array}{c}\text { Starting address } \\
\text { (hexadecimal) }\end{array}$} & $\begin{array}{c}\text { Ending address } \\
\text { (hexadecimal) }\end{array}$ \\
\hline GOOSE & $01-0 C-C D-01-00-00$ & $01-0 C-C D-01-01-F F$ \\
\hline GSSE & $01-0 C-C D-02-00-00$ & $01-0 C-C D-02-01-F F$ \\
\hline Multicast sampled values & $01-0 C-C D-04-00-00$ & $01-0 C-C D-04-01-F F$ \\
\hline
\end{tabular}

Fonte: Norma IEC 61850 O valor escolhido foi o primeiro permitido na faixa de valores especificada para os Multicast sample values.

Valor: 0x01-0x0C-0xCD - 0x04-0x00-0x00

- Campo: Source address

Descrição: Endereço MAC de origem. Valor controlado e fornecido pelo IEEE, pois deve ser único para cada controlador de rede. Pelo fato de serem geradas SV Messages em caráter de teste, tomou-se a liberdade de escolher arbitrariamente um endereço MAC fora das faixas definidas pela Tabela 19 .

Valor: 0x02-0x00-0x00-0x00-0x00-0x00

- Campo: TPID

Descrição: Tag identificadora de protocolo. Definido por [21] como sendo 0x8100.

Valor: 0x81 - 0x00 
- Campo: TCI

Descrição: Tag de controle de informação. Composta pelos seguintes campos:

User priority: define a prioridade do frame. Definido por [21] como valor padrão 4.

CFI: indicador de formato canônico. Definido por [21] como valor 0 (zero).

VID: suporte para VLAN. Definido por [21] como valor padrão 0 (zero).

Valor: 0x80-0x00

- Campo: Ethertype

Descrição: Controlado pelo IEEE, identifica o protocolo diretamente transportado pelo frame Ethernet. Definido por [21] como sendo 0x88BA.

Valor: 0x88-0xBA

- Campo: APPID

Descrição: Identificador de aplicação. Definido por [21] como valor padrão 0x4000.

Valor: $0 \times 40-0 \times 00$

- Campo: Length

Descrição: Quantidade de octetos no intervalo $m$, conforme ilustra a Figura 106. Para o frame básico elaborado seu valor é de 109 octetos.

Valor: 0x00-0x6D

- Campo: Reserved1

Descrição: Reservado para futuras aplicações. Definido por [21] como valor 0x0000.

Valor: 0x00-0x00

- Campo: Reserved2

Descrição: Reservado para futuras aplicações. Definido por [21] como valor 0x0000. 
Valor: 0x00-0x00

- Campo: Frame check sequence

Descrição: Sequencia de checagem de integridade do frame. Valor de 4 bytes calculado e inserido automaticamente pela interface MAC.

Valor: calculado pela interface MAC

O campo APDU contém a seguinte estrutura, representada pela Figura 107, codificada em ASN.1. Os campos indicados como opcionais não são inseridos no frame básico da $S V$ Message definido pela Norma IEC 61850-9-2.

Figura 107 - Descrição do campo APDU transmitido no frame básico da SV Message

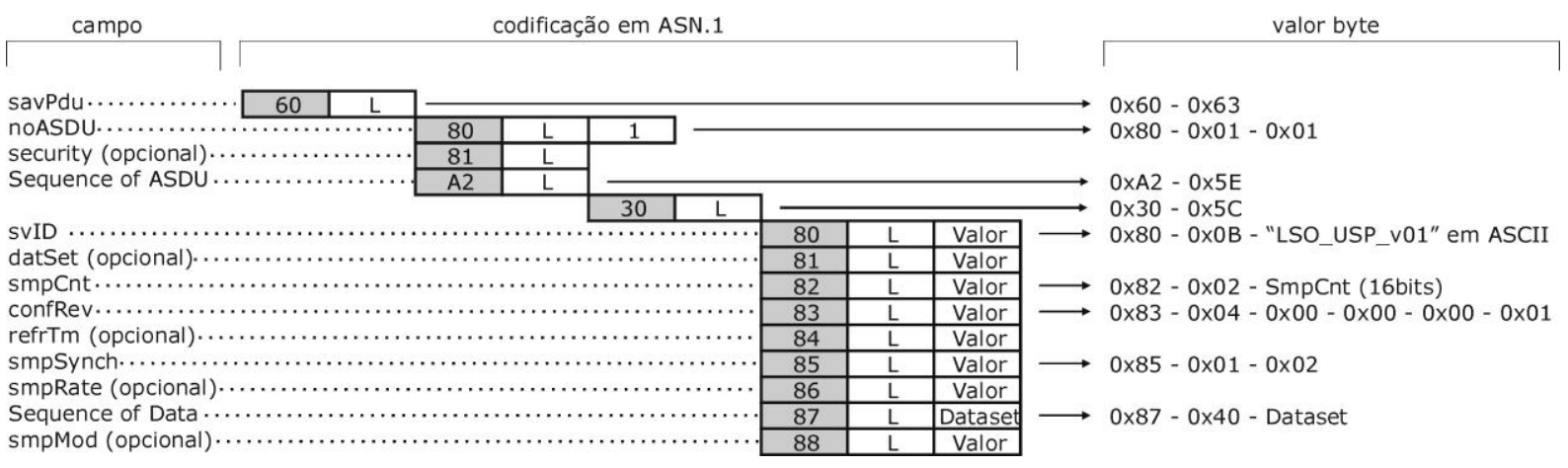

- Campo: savPdu

Fonte: o Autor

Descrição: Indica o início do APDU

Valor: 0x60 - 0x63

- Campo: noASDU

Descrição: Indica a quantidade de ASDUs transmitidas pelo APDU. Possui tamanho de 1 byte. No exemplo da Figura 107, está representada uma SV Message para finalidade de proteção (taxa de amostragem de 80 amostras/ciclo com taxa de transmissão de $80 \mathrm{SV}$ Messages/ciclo, onde cada mensagem contém 1 ASDU), portanto seu valor é 1 (um).

Valor: 0x80-0x01-0x01

- Campo: Sequence of ASDU 
Descrição: Indica o início do ASDU

Valor: 0xA2 - 0x5E-0x30-0x5C

- Campo: svID

Descrição: Contém uma string que identifica a SV Message. A Norma IEC61869-9 recomenda que não possua tamanho elevado. Por exemplo, dispositivos legados disponibilizam em torno de 10 a 34 caracteres para este campo. No exemplo da Figura 107, utilizou-se a string "LSO_USP_v01", que, convertida para caracteres ASCII, gera a sequência (0x4C - 0x53 - 0x4F - 0x5F - 0x55 - 0x53 - 0x50 - 0x5F - 0x76 - 0x30 - 0x31), que é inserida logo após o campo length.

Valor: 0x80 - 0x0B - 0x4C - 0x53 - 0x4F-0x5F-0x55 - 0x53 - 0x50-0x5F-0x76-0x30 $-0 \times 31$

- Campo: smpCnt

Descrição: contém o valor do contador smpCnt, com tamanho de 2 bytes, utilizado para identificar a amostra de forma relativa no tempo. Por exemplo, se o valor do smpCnt da amostra a ser transmitida for 15 , o valor inserido logo após o campo length será de 0x000F.

Valor: 0x82-0x02-0x00-0x0F (exemplo acima)

- Campo: confRev

Descrição: de acordo com a Norma IEC 61850-7-2, é um campo de indicação de revisão que tem como objetivo controlar possíveis mudanças realizadas na configuração do campo Dataset, presente no campo Sequence of Data. O valor 0 (zero) é reservado; portanto, deve iniciar com valor 1 (um). Possui tamanho de 4 bytes.

Valor: 0x83-0x04-0x00-0x00-0x00-0x01

- Campo: smpSynch

Descrição: Indica o sincronismo da SV Message. Possui tamanho de 1 byte. De acordo com a Norma IEC 61850-9-2, ele pode ser:

$$
0 \text { = não sincronizado }
$$


$1=$ sincronizado por um local area clock não especificado

$2=$ sincronizado por um global area clock

5 a $254=$ sincronizado por um local area clock especificado

3,4 e $255=$ reservado

Admitindo, hipoteticamente, que a $S V$ Message gerada se encontre sincronizada através do Protocolo PTP, o valor deste campo será igual a 2.

Valor: 0x85-0x01-0x02

- Campo: Sequence of Data

Descrição: contém o Dataset com os valores das amostras. Possui tamanho de 64 bytes.

Valor: definido de acordo com a estrutura da Figura 21.

Para a simulação foram geradas, através do firmware do microcontrolador, amostras dos sinais de corrente a uma taxa de amostragem de 80 amostras/ciclo, admitindo um sistema trifásico equilibrado com correntes de valor de pico igual a 1A. As SV Messages foram geradas e transmitidas a uma taxa de 80 SV Messages/ciclo. Estes frames foram capturados pelo software Wireshark para análise e validação. Os resultados obtidos estão ilustrados na Figura 108, a seguir. Pode-se observar na análise estrutural da SV Message que todos os campos transmitidos foram aceitos e que, aparentemente, nenhum problema foi encontrado. 
Figura 108 - Tela do software Wireshark contendo a SV Message analisada

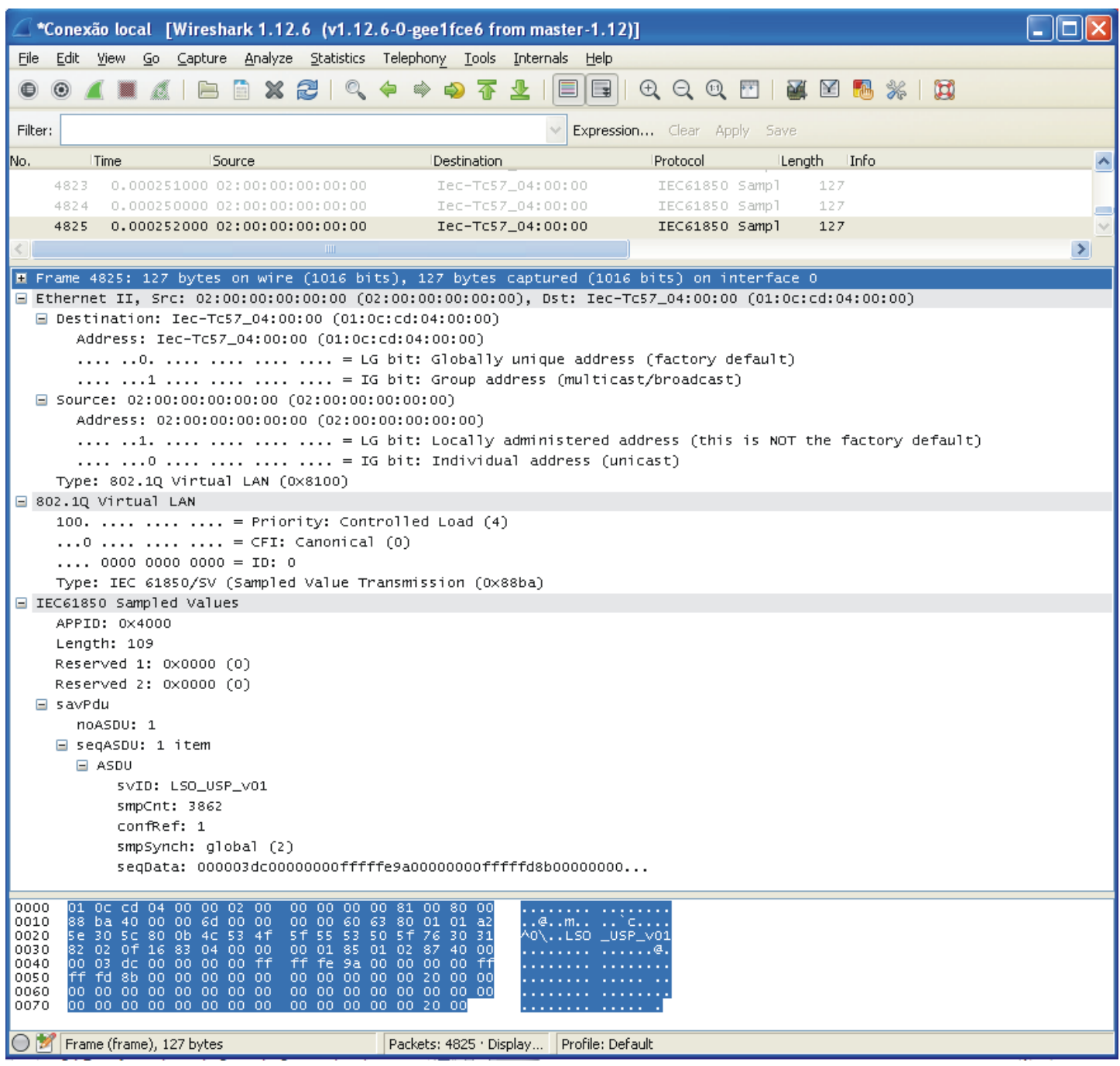

Fonte: o Autor

O passo seguinte foi analisar e validar as SV Messages geradas através do software SVScout.

Através do menu Configuration (Figura 109), clicando no botão Find stream, configura-se o software para capturar todas as SV Messages disponíveis no barramento de processo. 


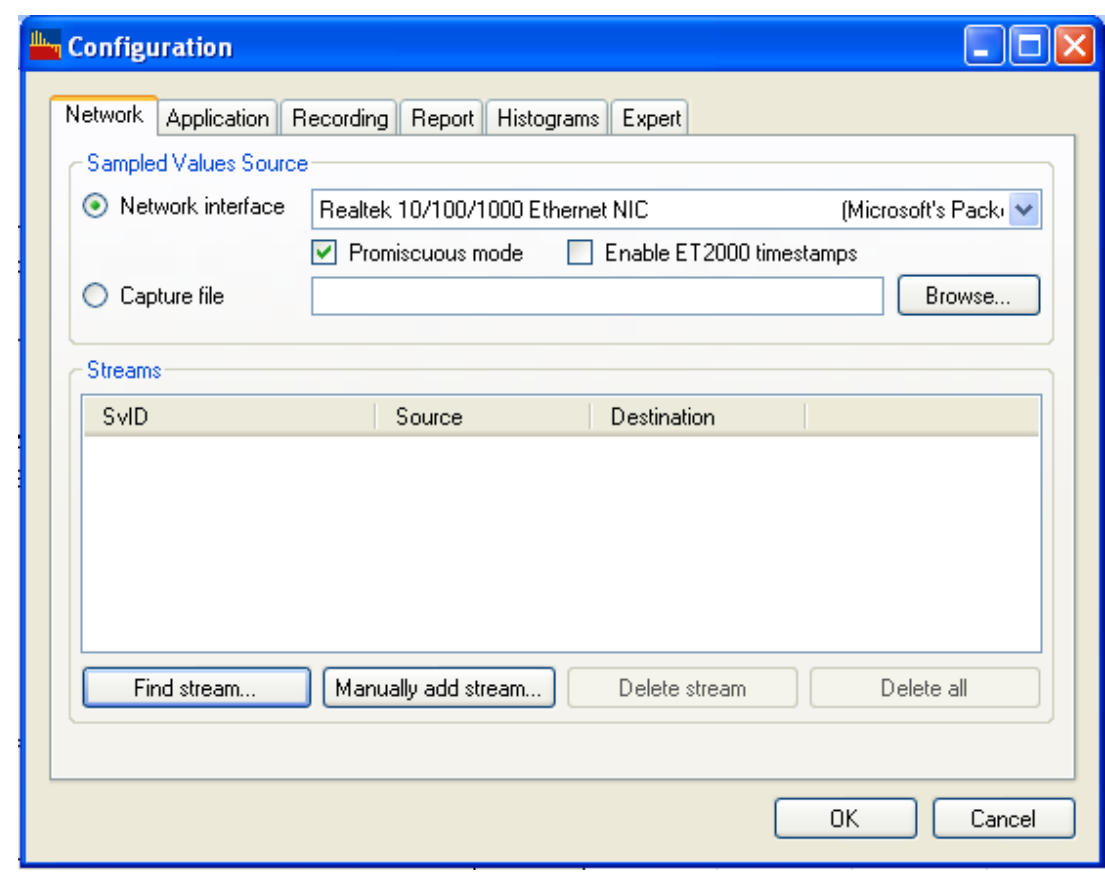

Fonte: o Autor A Figura 110 demonstra que a SV Message gerada, identificada pelo svID "LSO_USP_v01", foi capturada com sucesso.

Figura 110 - SV Messages disponíveis no barramento de processo capturadas pelo software SVScout

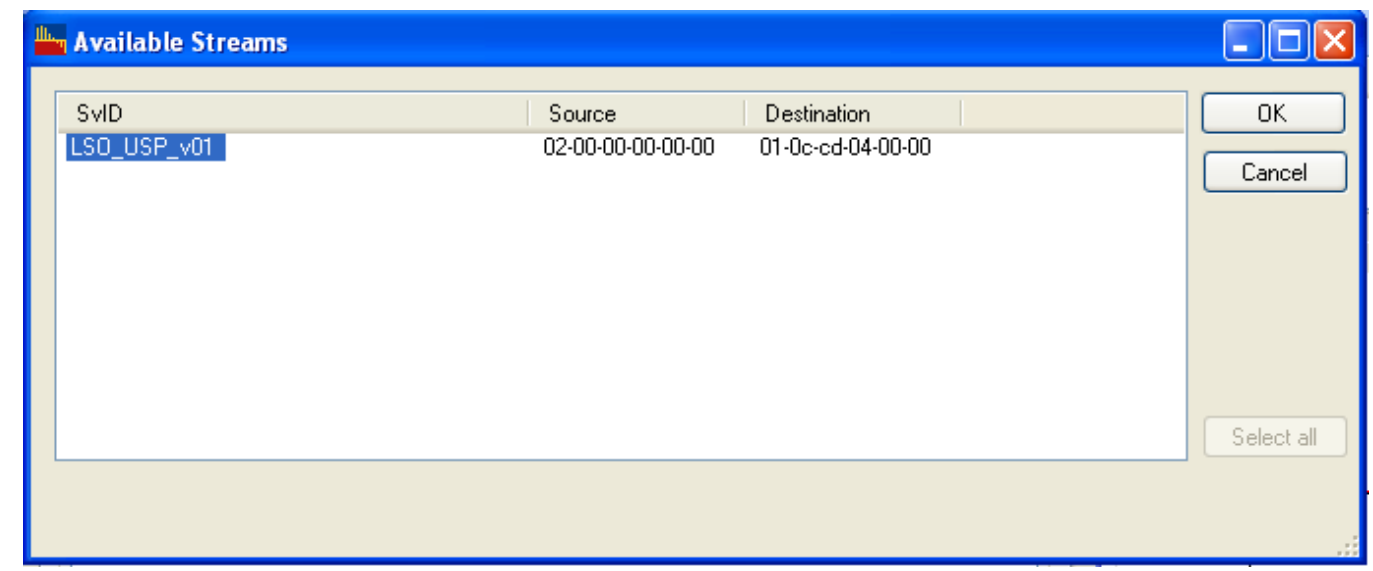

Fonte: o Autor A Figura 111 apresenta as formas de onda geradas pelo software SVScout como resultado das SV Messages capturadas. Aparentemente, nenhum erro foi encontrado, destacando que a amplitude do sinal (1 A de pico) e a taxa de amostragem (80 amostras/ciclo com contador smpCnt variando de 0 a 79 dentro de um período das fases das correntes) apresentaram resultados de acordo com o esperado. 


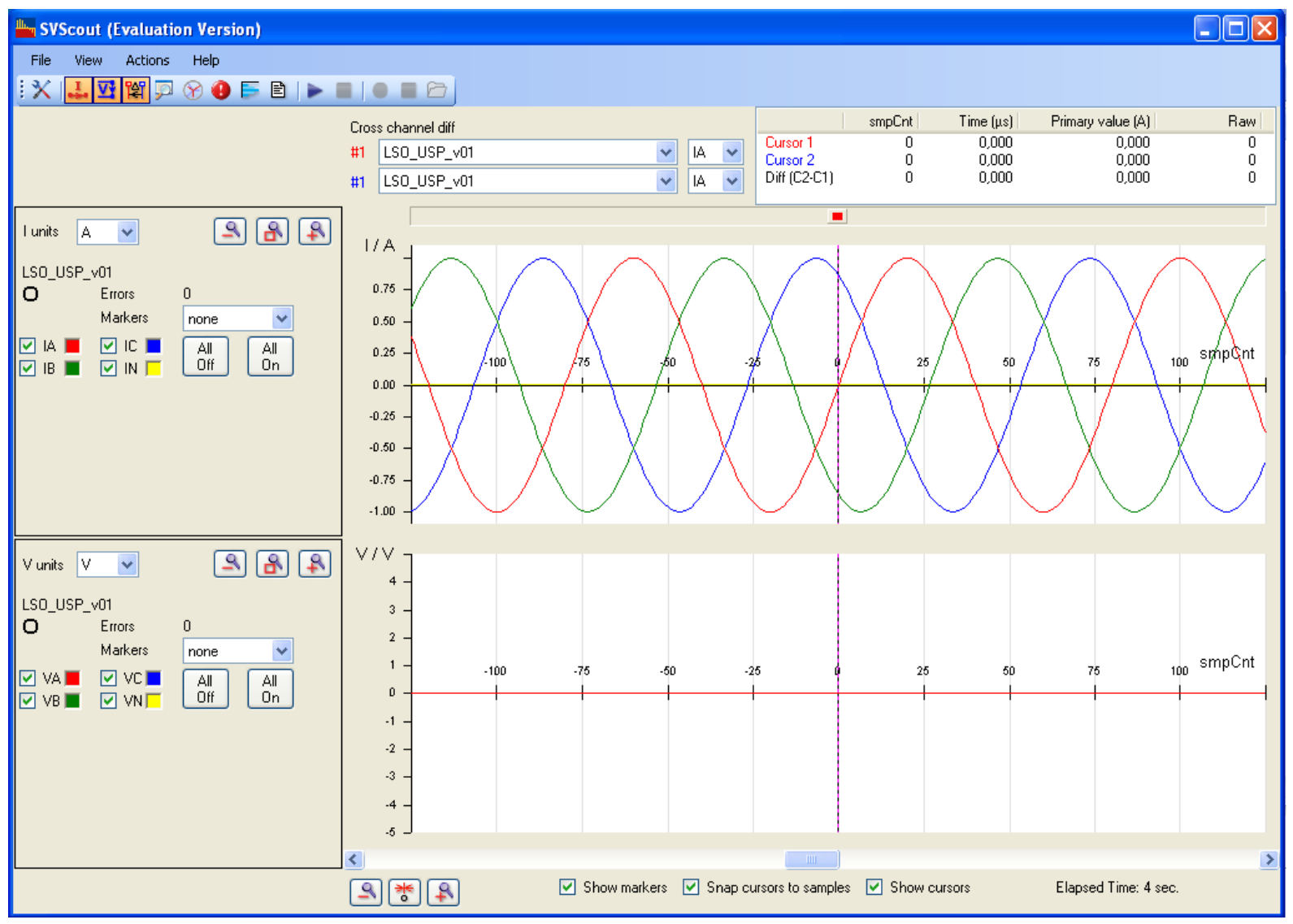

Com o objetivo de avançar a partir dos resultados apresentados, foram inseridos, um a um, os campos opcionais (security, datSet, RefrTm, smpRate e smpMode). Verificou-se também a aceitação destes novos frames pelo software Wireshark e pelo software SVScout.

A seguir estão descritos, de forma resumida, cada um destes campos e os valores utilizados para os testes.

- Campo: security

Descrição: utilizado em conjunto com outros campos para implementar procedimentos de segurança cibernética nas SV Messages. Para esta etapa de testes, ele foi suprimido. Será abordado com mais detalhes na seção 6.3 .

Valor: não transmitido

- Campo: datSet

Descrição: de acordo com [15], este campo é composto por uma string com a finalidade de 
identificar o DataSet utilizado na estrutura de datasets do IED. No preenchimento deste campo, surgiram algumas dúvidas de interpretação com relação às informações mencionadas. Numa primeira análise, devido ao fato de este campo ser do tipo string, esperava-se a inserção da sequência ASCII correspondente ao nome que identifica o DataSet que contém os valores das amostras (por exemplo, PhsMeas1). Inserida esta sequência, o software Wireshark passou a acusar erro na estrutura de dados da SV Message capturada. O autor, então, realizou algumas simulações e, ao reduzir tamanho do campo para 1 caracter, ou 2 caracteres, este passou a ser reconhecido corretamente. Uma possível razão para este comportamento pode ser a de que os DataSets de um determinado IED, embora identificados por nomes, internamente possuem um índice numérico utilizado como referência para identificá-lo, e este número seja o valor transmitido no campo datSet. Portanto, para o teste, foi definido o valor ASCII correspondente ao número 1 (um).

Valor: 0x81-0x01-0x31

- Campo: RefrTm

Descrição: de acordo com [21], este campo informa o instante de atualização do buffer das SV Messages. Seu formato é do tipo TimeStamp (contador baseado no padrão UTC - 64 bits de tamanho, com incremento a cada microssegundo) e possui 8 bytes de tamanho. Para os testes, utilizou-se um valor hipotético igual a zero.

Valor: 0x84-0x08-0x00-0x00-0x00-0x00-0x00-0x00-0x00-0x00

- Campo: smpRate

Descrição: segundo [21], este campo representa a quantidade de amostras de acordo com a configuração estabelecida no campo smpMode. Possui 2 bytes de tamanho. Como o valor configurado para os testes foi smpMode $=0$ (amostras/período nominal), o valor inserido no campo smpRate é de 80 amostras por ciclo.

Valor: 0x86-0x02-0x00-0x50

- Campo: smpMode

Descrição: de acordo com [21], este campo informa o modo de amostragem a ser utilizado como base pelo campo smpRate. Possui 2 bytes de tamanho. Seu valor pode ser: 
0: amostras por período nominal da rede elétrica (valor padrão para este campo)

1: amostras por segundo

2: segundos por amostra

O valor configurado para os testes foi 0 (zero).

Valor: 0x88-0x02-0x00-0x00

A Figura 112 ilustra os resultados obtidos pelo software Wireshark ao capturar as $S V$ Messages geradas, com a inclusão dos campos opcionais, sem erros reportados na análise do frame.

Figura 112 - Tela do software Wireshark contendo a análise dos campos opcionais

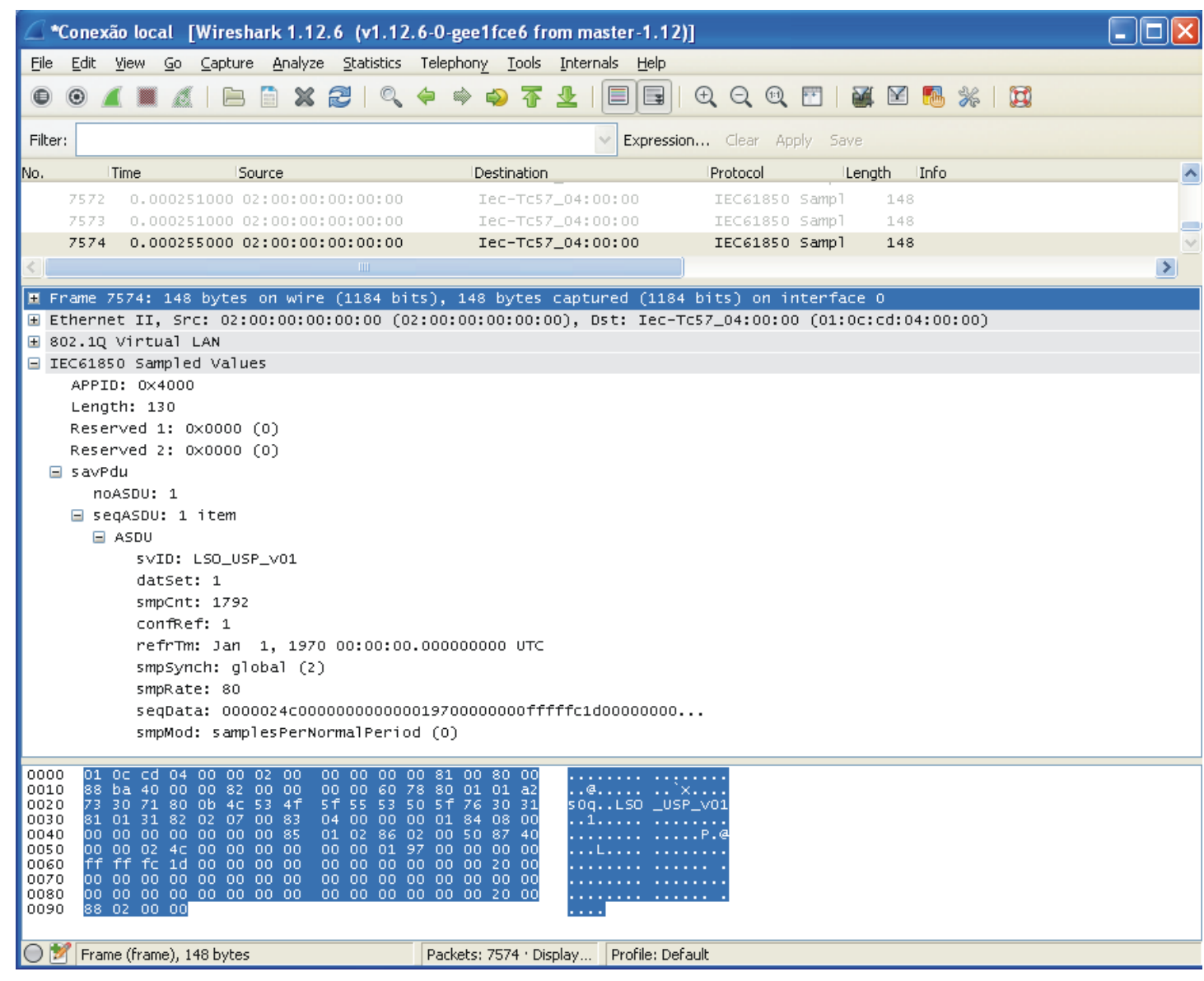

Fonte: o Autor

O acréscimo dos campos opcionais não foi aceito, aparentemente, pelo software SVScout, impossibilitando que as $S V$ Messages fossem utilizadas de forma correta.

Também foram realizados testes com o intuito de elaborar SV Messages que atendessem o 
formato especificado para finalidade de medição (taxa de amostragem de 256 amostras/ciclo, 8 APDUs em cada SV Message e taxa de envio de mensagens de 32 SV Messages/ciclo). Os resultados obtidos são apresentados na Figura 113. Nenhuma mensagem de erro foi reportada pelo software em sua análise. Os testes realizados através do software SVScout não foram possíveis, pois o mesmo foi desenvolvido somente para análise de SV Messages para finalidade de proteção. 
Figura 113 - Tela do software Wireshark contendo a análise da SV Message com formato especificado para finalidade de medição

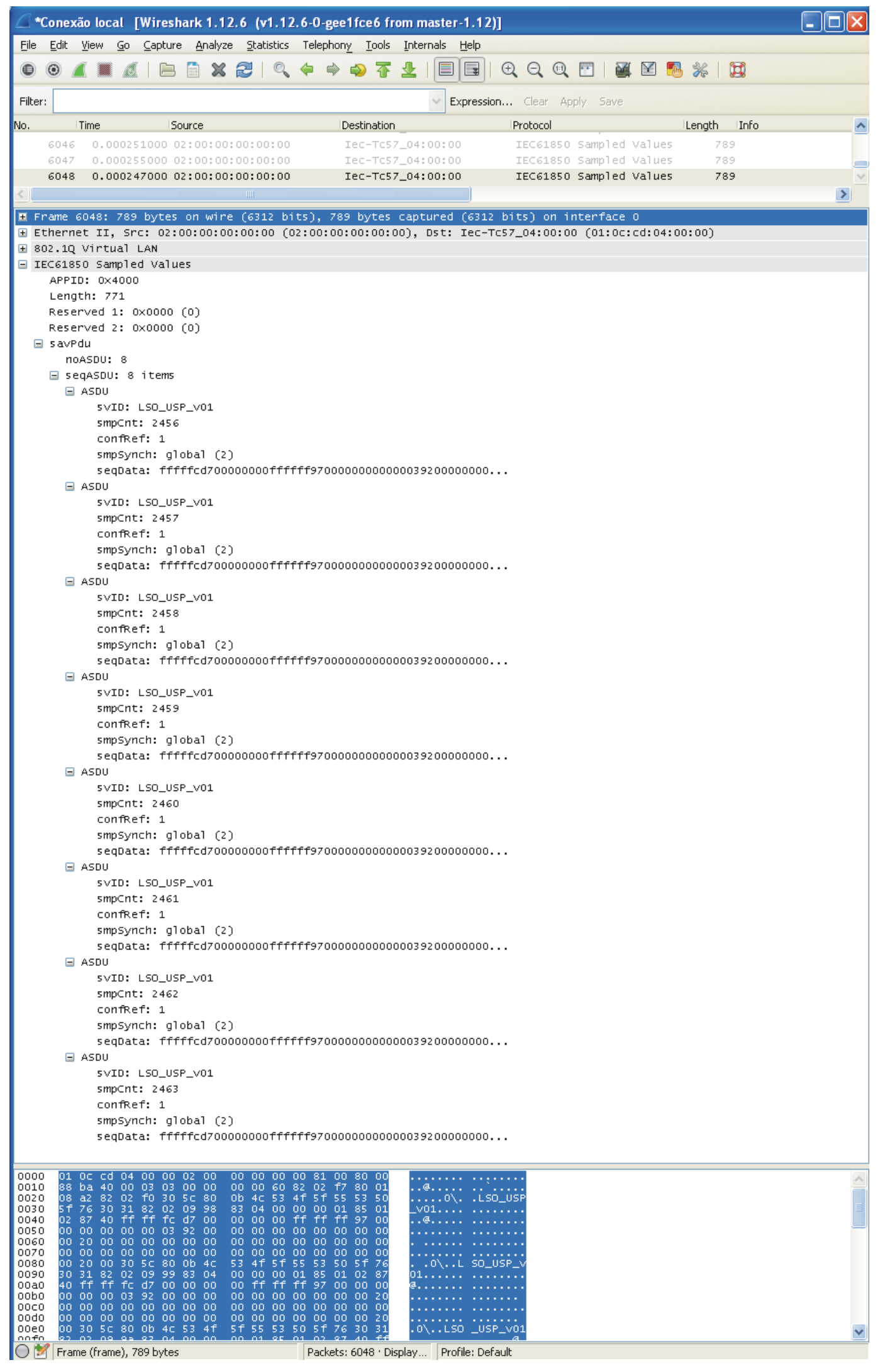


Observou-se que alguns dos resultados apresentados em [66] [68] mostraram uma análise mais detalhada de alguns dos campos que compõem o frame básico, se comparado com os resultados apresentados na Figura 108. Levantou-se uma suspeita de que esta mudança de comportamento tenha sido causada pelo fato de que no trabalho [68] foi utilizada, aparentemente, a versão 1.8.0 do software Wireshark. Para averiguar tal hipótese, foram realizados alguns testes de captura de frames básicos de SV Messages utilizando a versão 1.6.7 do software Wireshark, que estava à disposição do autor.

Curiosamente, o campo Dataset, que contém as informações das amostras de tensão/corrente, passou a ser analisado com mais detalhes, sendo identificado pelo software como campo PhsMeas1 e contendo a discriminação de todos os bytes que o compõe, conforme ilustra a Figura 114. A versão mais atual do software (versão 1.12.6) apresenta o campo Dataset como sendo o campo seqData, sem discriminar com maiores detalhes os bytes que o compõem. Infelizmente, ao acrescentar os campos opcionais, a versão 1.6.7 do software passou a apresentar mensagens de erro de construção do frame da SV Message. 
Figura 114 - Tela do software Wireshark versão 1.6.7 apresentando a análise detalhada do cabeçalho ASDU

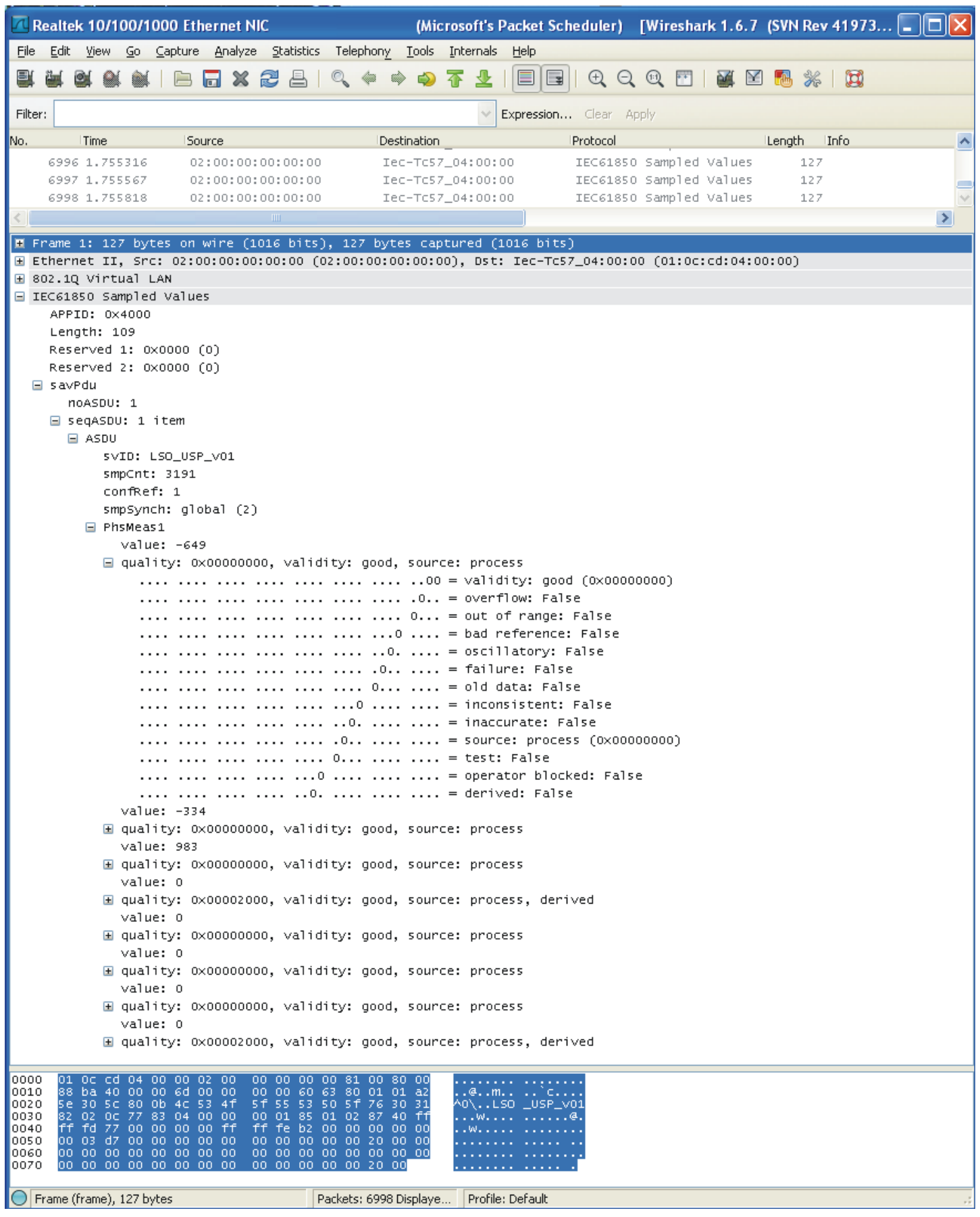

Fonte: o Autor Por fim, realizou-se uma análise para estimar o tempo necessário para a construção e a transmissão de um frame básico da SV Message. O formato escolhido para os testes foi o de finalidade de proteção, seguindo o diagrama da Figura 106, devido ao intervalo de tempo entre as transmissões de $S V$ Message ser mais crítico, se comparado ao formato para finalidade de medição. O firmware foi elaborado de forma que um dos timers internos do microcontrolador gerasse interrupções com periodicidade igual a taxa de amostragem de 80 amostras/ciclo para uma frequência de rede elétrica de $50 \mathrm{~Hz}$, ou seja, uma interrupção a cada 
$250 \mu$ s, sendo que, a cada interrupção, uma SV Message era enviada no barramento. No início de cada interrupção, foi feito um toggle de um dos ports, que se encontrava conectado ao canal 1 do osciloscópio. Na Interrupt Service Routine do timer, foi feita a composição da $S V$ Message e seu posterior encaminhamento para a interface MAC através de DMA específico para este fim. O canal 2 do osciloscópio foi conectado, num primeiro momento, nos sinais diferenciais TX+ e TX- do barramento Ethernet, presentes no conector RJ45. Os resultados obtidos mostraram que o reconhecimento do ponto de início de frame, dentro do sinal diferencial, é extremamente complexo devido à codificação Manchester utilizada pelo padrão IEEE 802.3, o que torna necessária a utilização de ferramentas específicas para sua análise, como os módulos SR-ENET e DPO4ENET da empresa Tektronix [69].

Portanto, para que fosse possível mensurar este tempo de forma satisfatória, optou-se por conectar o canal 2 do osciloscópio no terminal TX_EN da interface MII. Este terminal vai para nível lógico 1 quando existem dados no barramento MII para serem transmitidos através do barramento de rede Ethernet. Analisando o datasheet do circuito integrado PHY utilizado [70], pode-se deduzir que o atraso entre a borda de subida do sinal presente no terminal TX_EN e o sinal diferencial presente nos terminais TX+ e TX- é desprezível (em torno de 80 ns, no modo de transmissão $100 \mathrm{Mb} / \mathrm{s}$ ). Considerando estas simplificações, o tempo medido para a construção e a transmissão da $S V$ Message foi de, aproximadamente, 17,50 $\mu \mathrm{s}$, conforme ilustrado na Figura 115, o que deve ser suficiente para que a plataforma proposta de TP óptico com interface IEC 61850-9-2 atenda aos requisitos exigidos.

Também foi possível estimar o tempo necessário para transmitir todos os bytes do frame no barramento de processo. De acordo com a Figura 108, o software Wireshark contabilizou 127 bytes na composição do frame. Nesta contagem não estão incluídos os 7 bytes de preâmbulo, 1 byte de start of frame, e 4 bytes de frame check sequence, que totalizam, no final, $127+7+$ $1+4=139$ bytes. Admitindo $100 \mathrm{Mb} / \mathrm{s}$ de velocidade, o tempo teórico para transmissão seria de $11,12 \mu \mathrm{s}$. O tempo medido foi de, aproximadamente, 11,25 $\mu \mathrm{s}$. 
Figura 115 - Tela do osciloscópio com os sinais medidos para estimativa do tempo de construção e transmissão da SV Message
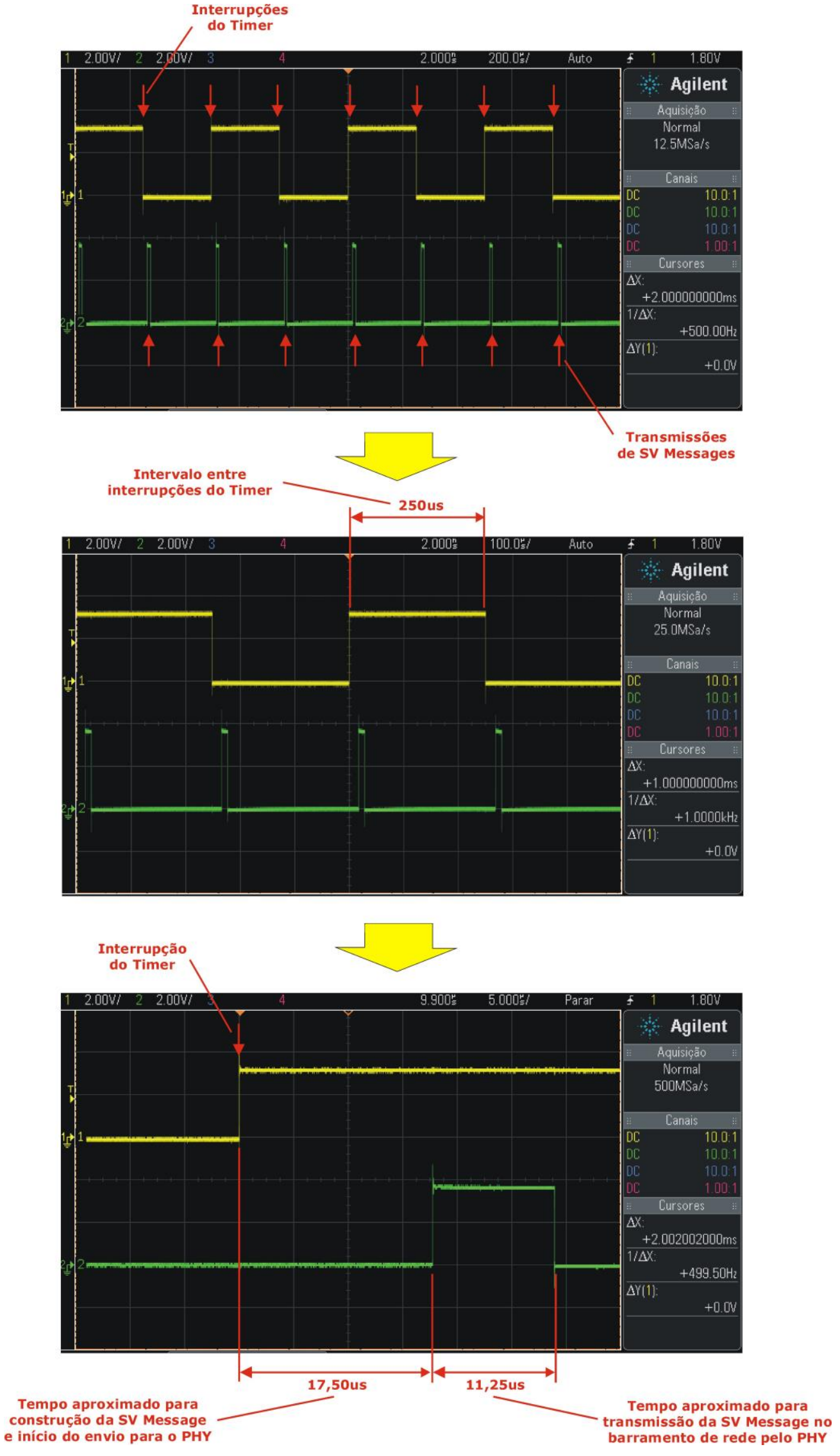

Fonte: o Autor 


\subsection{Implementação da $S V$ Message em conjunto com os Protocolos PRP/HSR para redundância de rede}

Esta etapa do trabalho tem como objetivo acrescentar ao frame básico da $S V$ Message os Protocolos PRP/HSR e analisar os frames gerados através do software Wireshark e do software SVScout.

Primeiramente, de acordo com [13] [21], definiu-se o seguinte frame Ethernet, representado pela Figura 116, para a elaboração de SV Messages, aplicando-se a redundância em dupla estrela proposta pelo Protocolo PRP.

Figura 116 - Frame Ethernet contendo o cabeçalho do Protocolo PRP

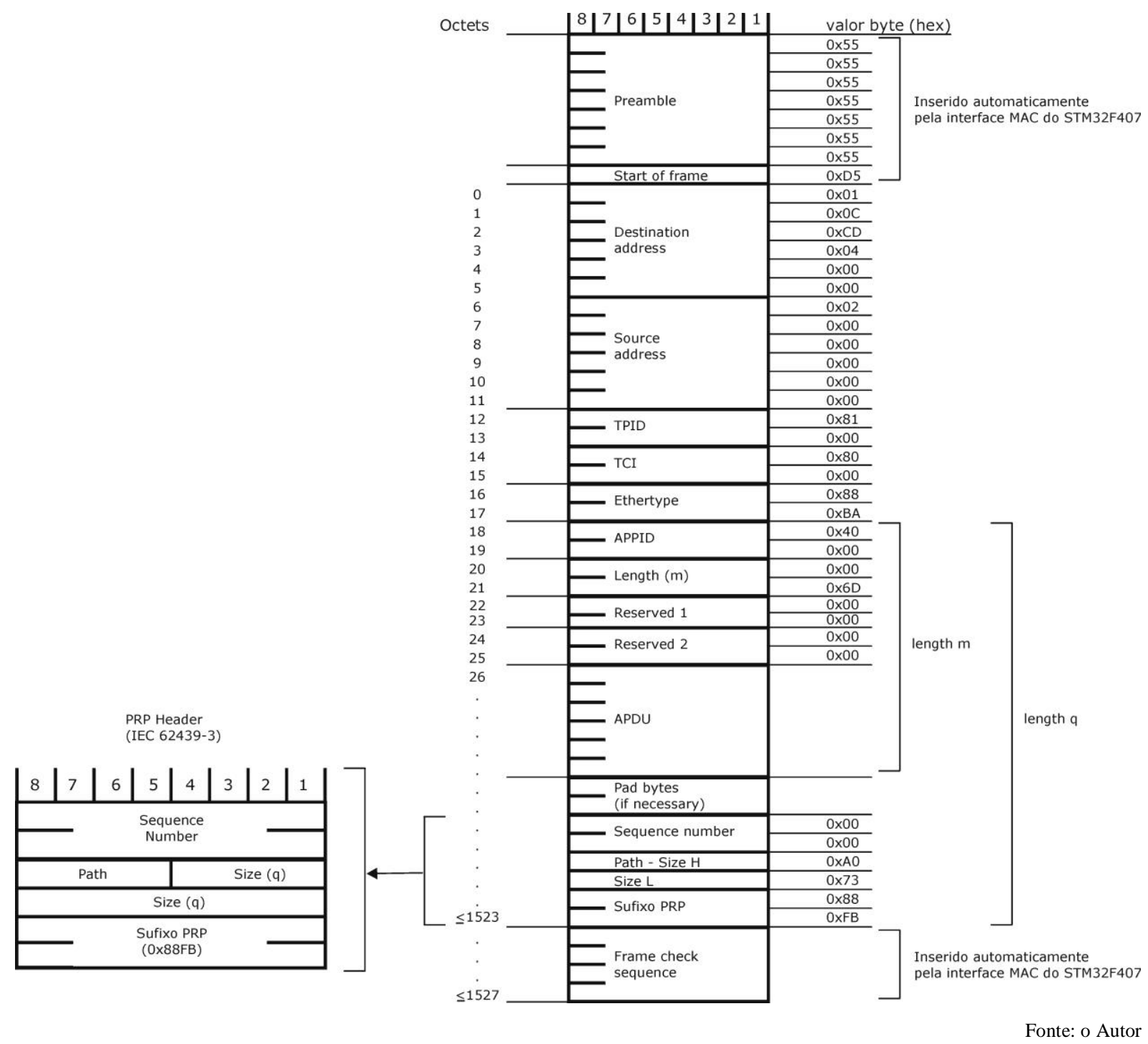


O Protocolo PRP exige o acréscimo de um cabeçalho após o campo APDU. A seguir estão descritos, de forma resumida, cada um dos campos que compõem este cabeçalho e os valores utilizados para os testes.

- Campo: Sequence number

Descrição: este campo, em conjunto com o campo Source address, tem como objetivo identificar a chegada de frames duplicados e permitir o seu correto descarte. É constituído por um contador que é incrementado a cada frame enviado no barramento de processo. Possui 2 bytes de tamanho.

Valor: 0x00 - 0x00 (para o primeiro frame enviado)

- Campo: Path

Descrição: identifica a qual rede o frame pertence. Possui 4 bits de tamanho. Seu valor será:

$1010_{\mathrm{B}}=$ frame pertence a LAN_A

$1011_{\mathrm{B}}=$ frame pertence a LAN_B

Valor: $1010_{\mathrm{B}}$

- Campo: Size

Descrição: contabiliza a quantidade de octetos enviados. Possui 12 bits de tamanho. O intervalo de octetos considerado esta identificado pela sigla length $q$.

Valor: 0x073

- Campo: Sufixo PRP

Descrição: identifica o cabeçalho como sendo do Protocolo PRP. Possui 2 bytes de tamanho. Seu valor é constante e igual a 0x88FB.

Valor: 0x88-0xFB

A Figura 117, a seguir, mostra a tela do software Wireshark contendo a SV Message gerada, com o cabeçalho do Protocolo PRP inserido. Embora na análise detalhada do frame o software 
tenha apresentado um aviso de erro (mensagem Internal error, zero-byte $S V P D U$ ), o cabeçalho foi aceito. Os testes também foram realizados no software SVScout e o frame foi reconhecido sem apresentar problemas.

Figura 117 - Tela do software Wireshark contendo a SV Message com Protocolo PRP

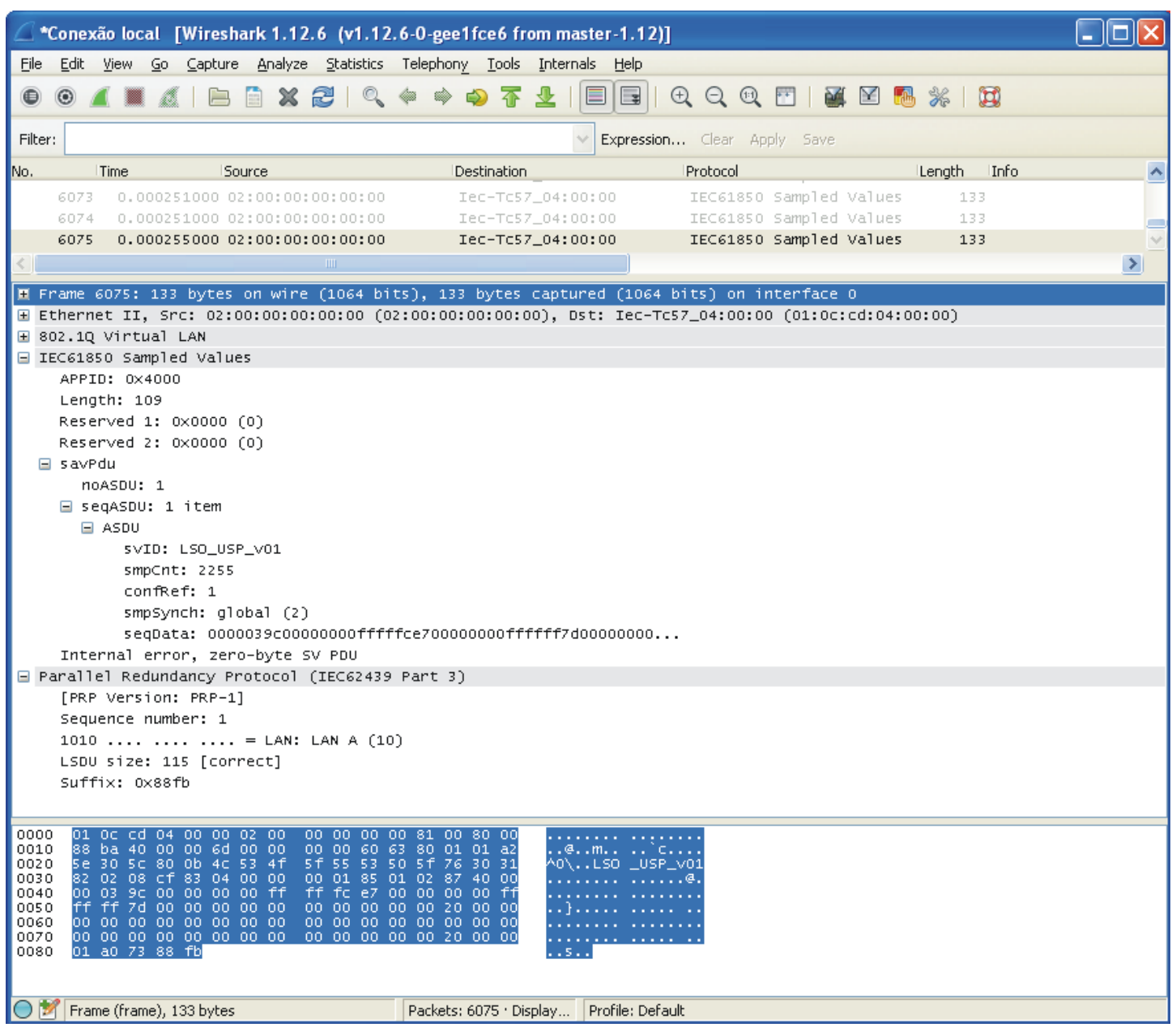

Fonte: o Autor Posteriormente, de acordo com [13] [21], definiu-se o seguinte frame Ethernet, representado pela Figura 118, para a elaboração de SV Messages, aplicando-se a redundância em anel proposta pelo Protocolo HSR. 
Figura 118 - Frame Ethernet contendo o cabeçalho do Protocolo HSR

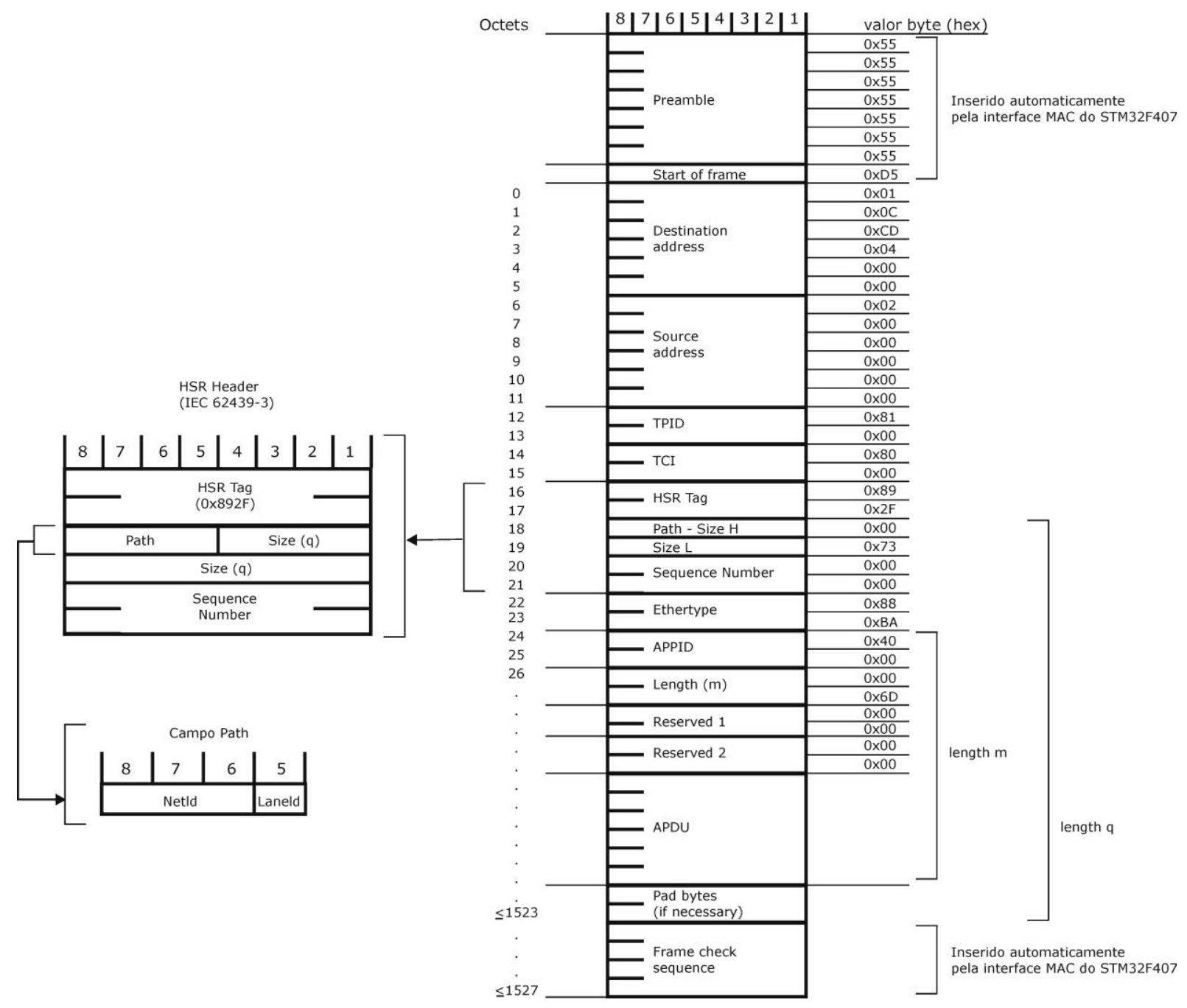

Fonte: o Autor O Protocolo HSR exige o acréscimo de um cabeçalho após o campo TCI. A seguir são descritos, de forma resumida, cada um dos campos que compõem este cabeçalho e os valores utilizados para os testes.

- Campo: HSR Tag

Descrição: identifica o cabeçalho como sendo do Protocolo HSR. Possui 2 bytes de tamanho. Seu valor é constante e igual a 0x892F.

Valor: 0x89-0x2F

- Campo: Path

Descrição: identifica a qual rede o frame pertence. Possui 4 bits de tamanho. Seu valor é composto pelos seguintes campos: 
NetId: Possui tamanho de 3 bits. Seu valor é $000_{\text {в }}$ para frames do Protocolo HSR

LaneId: Identifica por qual port o frame foi recebido. Possui 1 bit de tamanho. Seu valor é:

$0=$ frame recebido pelo Port $A$

1 = frame recebido pelo Port $B$

Para os testes, considerou-se que o frame foi recebido pelo Port A.

Valor: $0000_{\mathrm{B}}$

- Campo: Size

Descrição: contabiliza a quantidade de octetos enviados. Possui 12 bits de tamanho. O intervalo de octetos considerado esta identificado pela sigla length $q$.

Valor: 0x073

- Campo: Sequence number

Descrição: este campo, em conjunto com o campo Source address, tem como objetivo identificar a chegada de frames duplicados e permitir o seu correto descarte. É constituído por um contador que é incrementado a cada frame enviado no barramento de processo. Possui 2 bytes de tamanho.

Valor: 0x00 - 0x00 (para o primeiro frame enviado)

A Figura 119, a seguir, apresenta a tela do software Wireshark contendo a SV Message gerada, com o cabeçalho do Protocolo HSR inserido. A análise detalhada do frame mostra que o mesmo foi aceito sem avisos de erro. Os testes também foram realizados no software SVScout e o frame, infelizmente, não foi reconhecido corretamente. 
Figura 119 - Tela do software Wireshark contendo a SV Message com Protocolo HSR

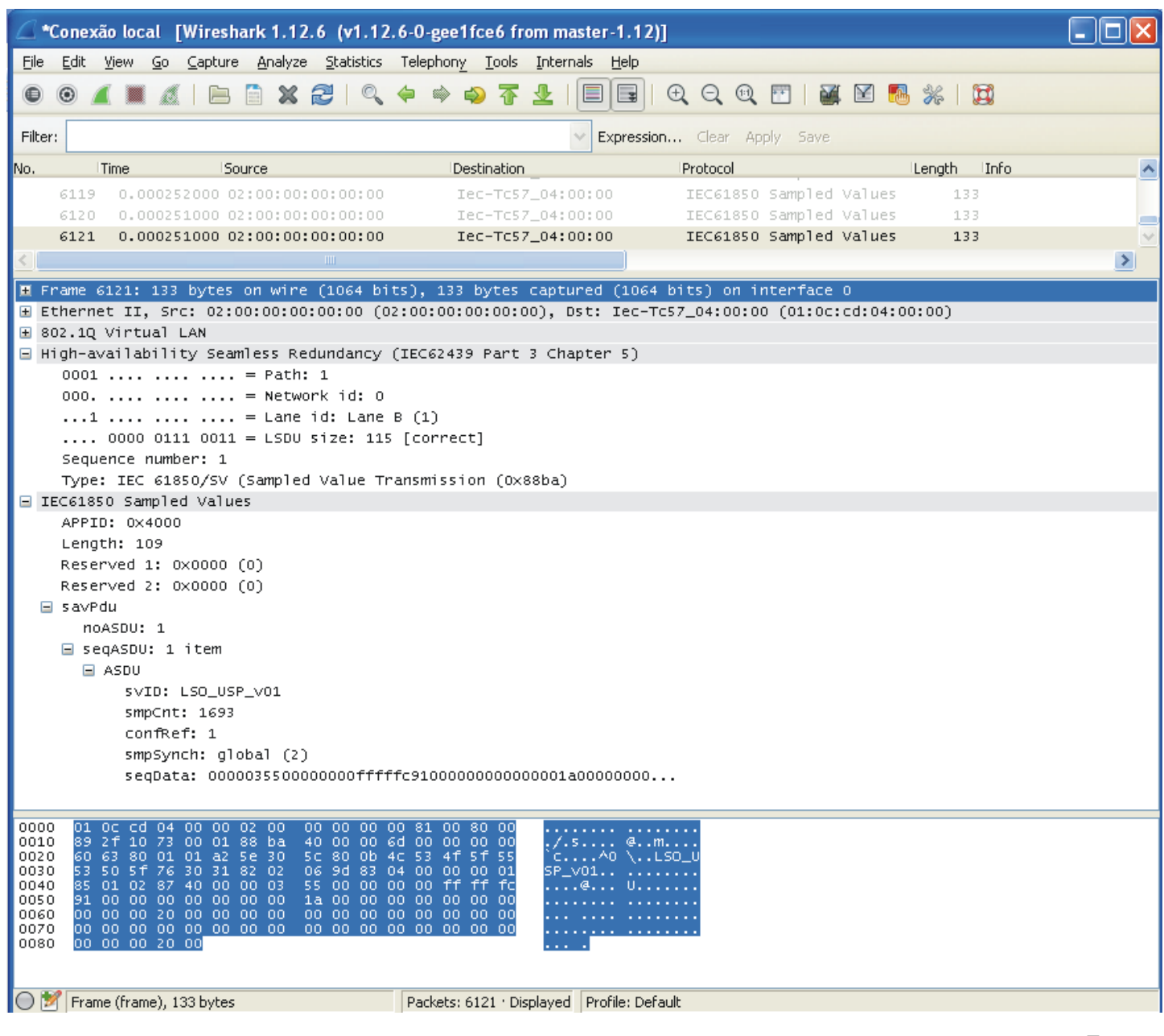

Fonte: o Autor 


\subsection{Implementação da $S V$ Message em conjunto com a Norma IEC 62351-6 para segurança cibernética}

Esta última etapa tem como objetivo acrescentar ao frame básico da SV Message os procedimentos exigidos para implementação de segurança cibernética e analisar os frames gerados através do software Wireshark e do software SVScout. De acordo com [17] [21], pode-se definir o seguinte frame Ethernet, denominado Extended PDU, representado pela Figura 120, para a elaboração de SV Messages.

Figura 120 - Frame Ethernet contendo os cabeçalhos para segurança cibernética (Extended PDU)

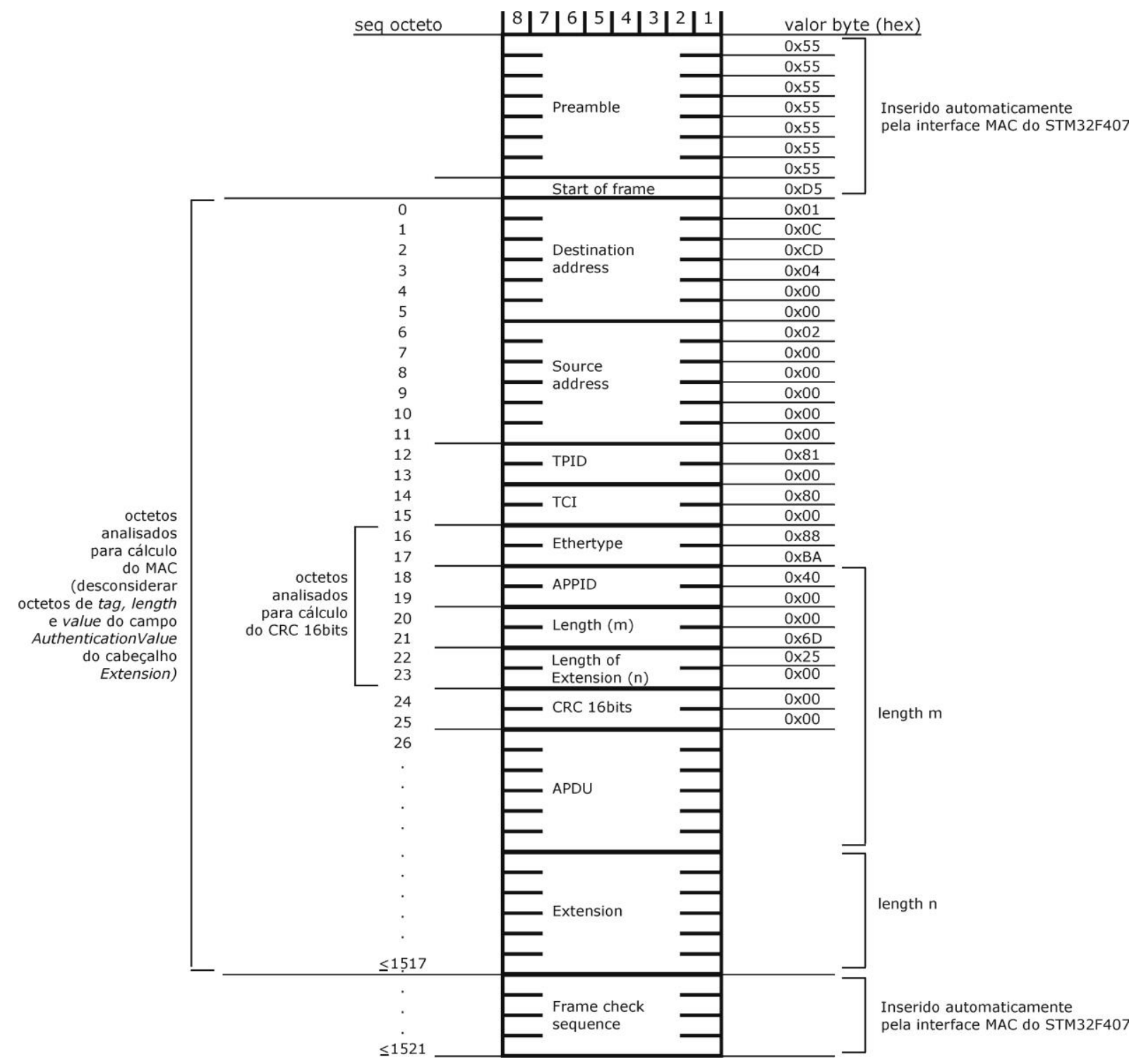


Basicamente, os procedimentos de segurança cibernética exigem alterações nos campos Reserved1 e Reserved2 (definidos no frame da Figura 106), no campo security do cabeçalho APDU (definido na estrutura APDU da Figura 107), e no acréscimo de um cabeçalho, denominado Extension, após o cabeçalho APDU. A seguir estão descritos, de forma resumida, cada um dos campos alterados e os valores utilizados para os testes.

- Campo: Length of Extension (n) (antigo Reserved1)

Descrição: de acordo com [17], informa o comprimento do campo Extended. Possui 2 bytes de tamanho. É composto da seguinte forma:

Primeiro byte: Quantidade de octetos do campo Extended. No exemplo utilizado nos testes, o comprimento do campo é de 37 bytes.

Segundo byte: Reservado para uso futuro. Para os testes, foi considerado como sendo 0x00.

Valor: 0x25-0x00

- Campo: CRC 16bits (antigo Reserved2)

Descrição: segundo [17], contém um CRC calculado de acordo com a Norma IEC 13239, em função dos octetos indicados na Figura 120. Possui 2 bytes de tamanho. Para os testes, considerou-se um valor hipotético igual a 0x0000.

Valor: 0x00-0x00

- Campo: security (do cabeçalho APDU)

Descrição: de acordo com [17], contém o timestamp aproximado, no formato UTC, do instante no qual a amostra foi realizada. Tem como objetivo prevenir ataques cibernéticos do tipo Interceptação (Replay Attack e Tampering of Data). Caso sejam recebidas SV Messages com atraso superior a 2 minutos, as mesmas deverão ser descartadas. Possui 8 bytes de tamanho. Para os testes, utilizou-se um valor hipotético igual a zero.

Valor: 0x81 - 0x08-0x00-0x00-0x00-0x00-0x00-0x00-0x00-0x00

O cabeçalho Extension é composto pela seguinte estrutura, codificada em ASN.1: 


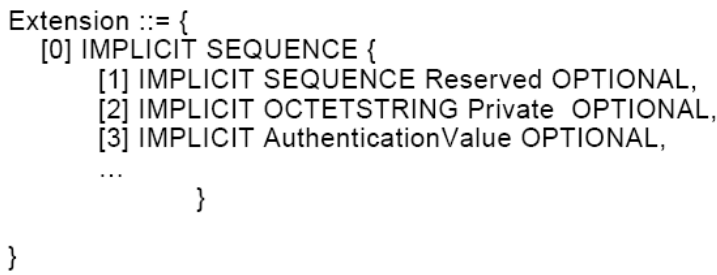

A definição destes campos ainda não está muito clara, o que gerou dúvidas com relação à sequência de octetos que descreve esta estrutura. A seguir, é apresentado um resumo de cada um dos campos e, na Figura 121, a construção do cabeçalho Extension proposta pelo autor, a partir de sua interpretação a respeito das informações encontradas em [7] [17] [21].

Figura 121 - Descrição do campo Extension utilizado para os testes

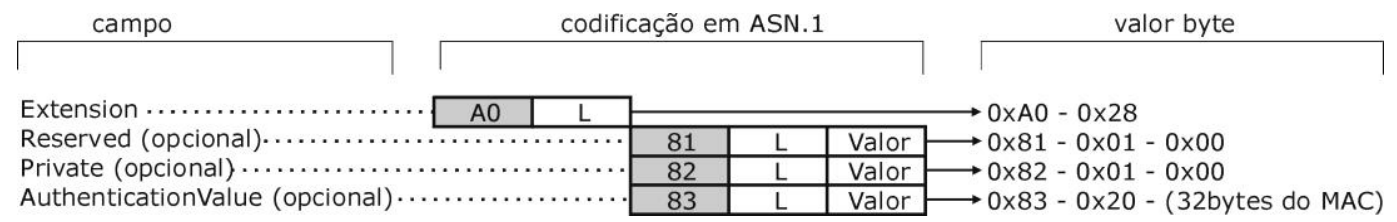

Fonte: o Autor

- Campo: Reserved

Descrição: Reservado para uso futuro. Para os testes, utilizou-se o valor 0 (zero).

Valor: 0x81-0x01-0x00

- Campo: Private

Descrição: Reservado para transmitir informações privadas. A definição de sua semântica está fora dos âmbitos da Norma IEC 62351-6 e deve ser previamente acordada entre os IEDs que trocarão informações entre si através de mensagens no barramento de processo. Para os testes, utilizou-se o valor 0 (zero).

Valor: 0x82-0x01-0x00

- Campo: Authentication Value

Descrição: Contém o Message Authentication Code (MAC) gerado pelo algoritmo HMAC utilizando o algoritmo hash criptográfico do tipo SHA256 sobre todos os octetos, com exceção daqueles que compõem o próprio campo Authentication Value, conforme demonstrado na Figura 120. Este tipo de codificação gera MACs com tamanho de 32 bytes [71], portanto, seu tamanho é de 32 bytes. Para os testes, utilizou-se uma sequência 
numérica arbitrária de 1 a 32.

Valor: 0x83 - 0x20 - 0x01 - 0x02 - 0x03 - 0x04 - 0x05 - 0x06-0x07 - 0x08 - 0x09-

0x0A - 0x0B - 0x0C - 0x0D - 0x0E - 0x0F-0x10-0x11-0x12-0x13-0x14-0x15-

$0 \times 16-0 \times 17-0 \times 18-0 \times 19-0 \times 1 \mathrm{~A}-0 \times 1 \mathrm{~B}-0 \times 1 \mathrm{C}-0 \times 1 \mathrm{D}-0 \times 1 \mathrm{E}-0 \times 1 \mathrm{~F}-0 \times 20$

Os testes com o software Wireshark mostraram que somente o campo security não foi aceito, gerando um aviso de erro na construção do frame. Os demais campos e cabeçalhos foram aceitos, mas não interpretados, conforme ilustra a Figura 122. O mesmo comportamento também foi observado no software SVScout.

A análise desses resultados mostrou que ambos os softwares ainda não estão preparados para tratamento destes campos e cabeçalhos adicionais, mas que a transmissão do Extended APDU não implicou na rejeição do frame, o que confirma a sua interoperabilidade com o formato do frame não seguro.

Figura 122 - Tela do software Wireshark apresentando a SV Message capturada contendo os campos e os cabeçalhos para segurança cibernética

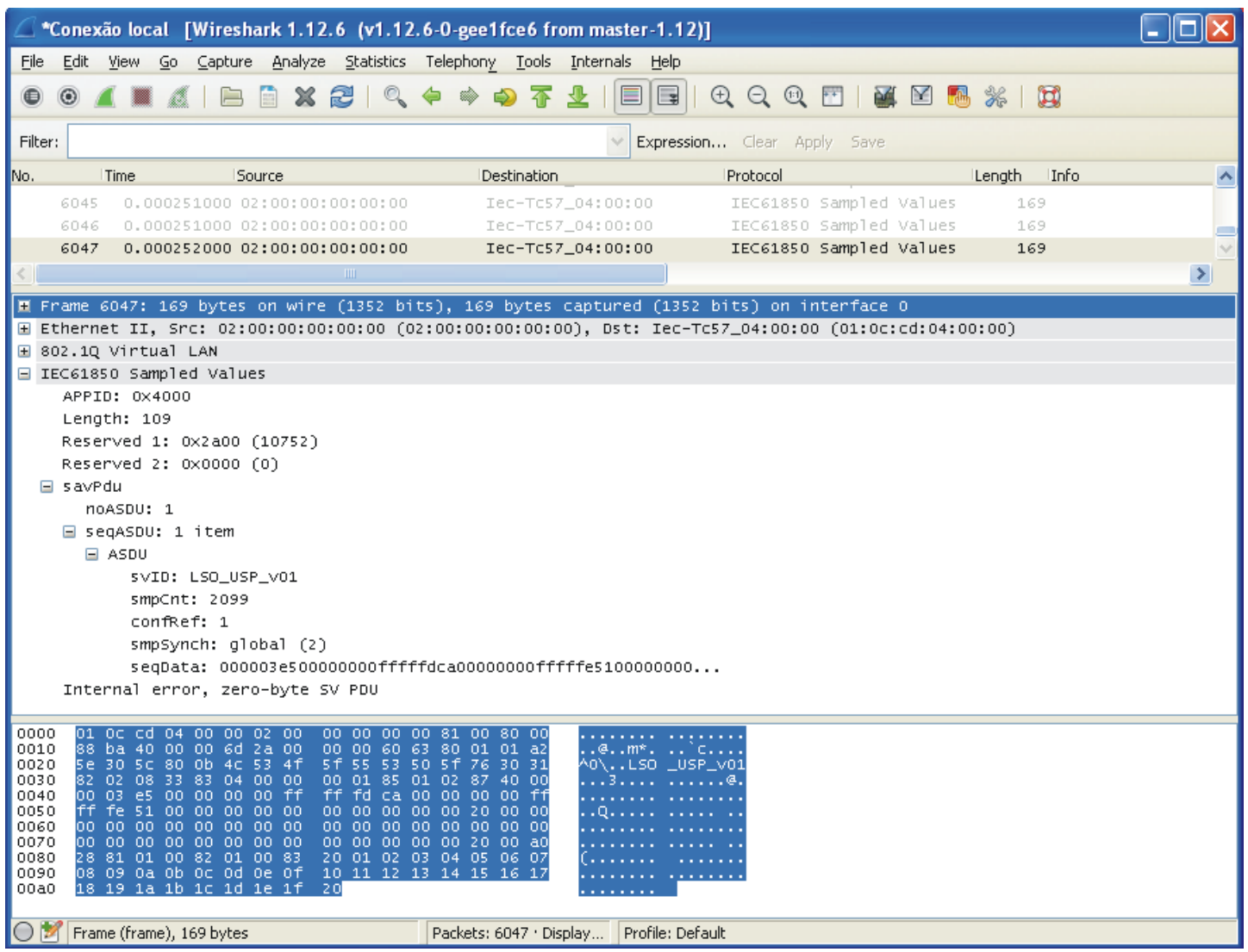

Fonte: o Autor 


\section{Simulação de barramento de processo IEC 61850-9-2 utilizando Matlab/Simulink}

Neste novo cenário que está se formando, onde a Norma IEC 61850 esta cada vez mais presente como padrão a ser adotado nos projetos de SAS, tanto no barramento de subestação, quanto no barramento de processo, existe a necessidade de se realizar estudos através de simulações de modo a auxiliar no desenvolvimento de novos projetos, tanto pelo aspecto de redução de tempo de desenvolvimento quanto para a redução de custos, sobretudo simulações que consigam abranger o funcionamento conjunto dos elementos que compõem o sistema de potência (transformadores de força, transformadores para instrumentos, disjuntores, etc.) com os elementos que compõem o barramento de rede (switches). Existem inúmeros fatores a serem levados em consideração e diversas formas de se realizar estas simulações. Nesta parte do trabalho são apresentados inicialmente alguns dos principais conceitos envolvidos na simulação de sistemas de potência em conjunto com o barramento de rede de dados. Com base nestes conceitos e usando como referência o diagrama unifilar da Figura 13, é proposto um modelo para a simulação do barramento de processo IEC 61850-9-2 envolvendo os dispositivos que compõem o sistema de potência em conjunto com os dispositivos que compõem o barramento de processo, a partir de modelos construídos com a ferramenta Matlab/Simulink. Resultados de algumas situações simuladas utilizando este modelo proposto são apresentados no final deste capítulo.

\subsection{Conceitos gerais envolvendo a simulação de sistemas de potência em conjunto com barramento de processo IEC 61850-9-2}

A simulação de sistemas de potência em conjunto com o barramento de processo envolve uma série de conceitos que acabam por definir a estratégia adotada na simulação realizada [74]. Existem, basicamente, duas formas de se realizar esta simulação:

- co-simulation: simulação do sistema de potência e do barramento de rede em ambientes separados; 
- comprehensive simulation, ou integrated simulation: simulação do sistema de potência e do barramento de rede num mesmo ambiente.

Quando se trata de simulação de sistemas existem diferentes abordagens que podem ser adotadas como métodos para a obtenção dos resultados. Algumas destas abordagens são:

- continuous time simulation: nesta metodologia a ferramenta de simulação executa os cálculos para estimar os valores das grandezas do sistema simulado segundo uma determinada periodicidade estabelecida (ex: em um circuito elétrico, calcular o valor da corrente que circula sobre um determinado resistor a cada $1 \mu \mathrm{s})$;

- discrete event simulation: nesta metodologia a ferramenta de simulação executa os cálculos somente quando determinados eventos característicos do sistema a ser simulado ocorrerem (ex: cálculo do tempo de transmissão de uma mensagem em uma rede de dados a cada passagem desta mensagem nos switches desta rede).

A maneira como cada ferramenta é composta varia bastante, podendo ser somente software, somente hardware ou uma junção dos dois. A utilização conjunta de ferramentas de software (para simular algumas partes do sistema) e de hardware (para simular outras partes do sistema) é denominada hardware-in-the-loop simulation (HIL).

Com relação à execução dos cálculos da simulação e à apresentação dos resultados, estes podem ser realizados de duas formas:

- real time: onde os resultados da simulação são apresentados para o usuário exatamente no instante em que ocorreriam no sistema real modelado (ex: Real Time Digital Power System Simulators - RTDS);

- off-line: onde os resultados são apresentados conforme os cálculos são processados, não necessariamente no instante em que ocorreriam no sistema real modelado (ex: softwares para simulação de microcontroladores).

Por fim, especificamente com relação à simulação da rede de dados, existem diversas opções de modelamento, de acordo com o nível de detalhamento com o qual se deseja realizar a simulação:

- no communication model: nesta modalidade a rede é modelada como sendo ideal, sem levar 
em consideração, por exemplo, atrasos e limite de largura de banda;

- black box communication model: nesta modalidade os dispositivos da rede são modelados utilizando modelos abstratos para simular, por exemplo, atrasos na transmissão de mensagens;

- detailed communication model: nesta modalidade os dispositivos são modelados visando simular com maior detalhamento possível determinados aspectos da rede, por exemplo, o tratamento dos bytes que compõem uma mensagem por softwares que executam a lógica dos protocolos de comunicação presentes nas camadas de rede do modelo ISO/OSI.

\subsection{Proposta de sistema de potência com barramento de processo IEC 61850-9-2 para simulação}

A proposta do sistema de potência com barramento de processo a ser simulado tem como base o diagrama unifilar apresentado na Figura 13, as sugestões de projeto apresentados em [75] [76] e na Subestação de Altamira da empresa Eletronorte [77]. Seu diagrama é apresentado na Figura 123. 
Figura 123 - Diagrama do sistema de potência com barramento de processo IEC 61850-9-2
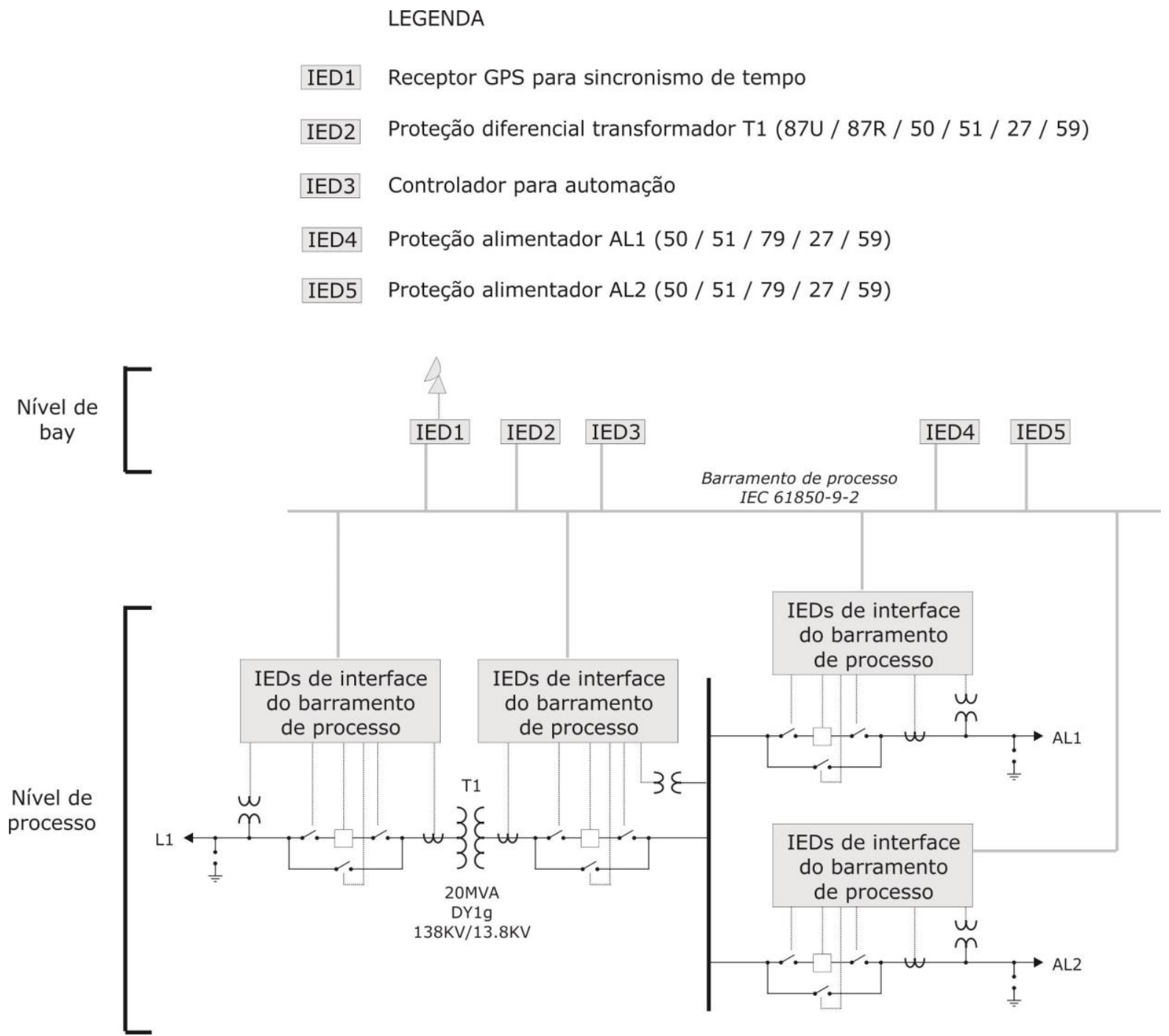

Fonte: o Autor A forma pela qual o barramento de rede será efetivamente implementado depende da arquitetura de redundância de rede utilizada (Protocolo PRP ou Protocolo HSR) e dos IEDs escolhidos. Para este trabalho os modelos de IEDs a serem simulados foram definidos com base em equipamentos de mercado de alguns dos principais fabricantes do setor, apresentados a seguir. 
7.2.1 IEDs de interface do barramento de processo

Neste bloco são apresentados os IEDs que digitalizam os sinais analógicos dos dispositivos presentes no sistema de potência. Eles podem ser de dois tipos [15]:

- Merging Unit (MU): É um componente que faz parte do dispositivo presente no sistema de potência responsável por gerar as portas de comunicação para o barramento de processo. $\mathrm{O}$ bloco CPU da plataforma de TP óptico digital com interface IEC 61850-9-2 apresentado no Capítulo 4 é um exemplo de implementação de uma Merging Unit.

- Stand Alone Merging Unit (SAMU): É um dispositivo físicamente separado, responsável por receber os sinais analógicos dos dispositivos presentes no sistema de potência, digitaliza-los e envia-los para o barramento de processo através de sua porta de comunicação. Na Tabela 20 é apresentado um resumo de alguns modelos de SAMUs disponíveis no mercado.

Tabela 20 - Resumo das características de SAMUs disponíveis no mercado

\begin{tabular}{|c|c|c|c|c|c|}
\hline Fabricante & Modelo & $\begin{array}{c}\text { Qtde. de } \\
\text { entradas } \\
\text { digitais }\end{array}$ & $\begin{array}{c}\text { Qtde. de saídas } \\
\text { digitais }\end{array}$ & $\begin{array}{c}\text { Qtde. de } \\
\text { entradas } \\
\text { analógicas de } \\
\text { tensão }\end{array}$ & $\begin{array}{c}\text { Qtde. de } \\
\text { entradas } \\
\text { analógicas de } \\
\text { corrente }\end{array}$ \\
\hline Siemens [78] & 7SC805 & 12 & 8 & 4 & 4 \\
\hline ABB [79] & SAM600 & - & - & 3 & 4 \\
\hline GE/Alstom [80] & MU320 & 6 & 8 & 8 & 8 \\
\hline
\end{tabular}

\subsubsection{IEDs presentes no nível de bay}

Na Tabela 21 são apresentados alguns exemplos de IEDs possíveis de serem utilizados no nível de bay no diagrama apresentado na Figura 123. 
Tabela 21 - Exemplos de IEDs utilizados no nível de bay disponíveis no mercado

\begin{tabular}{|c|c|c|c|c|c|}
\hline Fabricante & IED1 & IED2 & IED3 & IED4 & IED5 \\
\hline Siemens [78] & RSG2288 & 7UT82 & 6 CD85 & 7SJ85 & 7SJ85 \\
\hline ABB [79] & - & REL670 & REC650 & REQ650 & REQ650 \\
\hline GE/Alstom [80] & RT430 & P642 & - & P841 & P841 \\
\hline
\end{tabular}

\subsubsection{Switches presentes no barramento de processo}

Fisicamente, o barramento de processo é composto por pares de fibras ópticas e switches. A Tabela 22 apresenta um resumo das principais características de alguns switches disponíveis no mercado.

Tabela 22 - Resumo das características de switches disponíveis no mercado

\begin{tabular}{|c|c|c|c|c|c|}
\hline Fabricante & Modelo & Qtde. de portas & Latency $(\boldsymbol{\mu s})$ & VLAN priority & $\begin{array}{c}\text { Taxas de } \\
\text { transmissão } \\
\text { (Mbps) }\end{array}$ \\
\hline Siemens [78] & RSG2288 & 18 & $7 \mu \mathrm{s}$ & $\operatorname{sim}$ & $10 / 100 / 1000$ \\
\hline SEL [81] & SEL2730M & 20 & $7 \mu \mathrm{s}$ & $\mathrm{sim}$ & $10 / 100 / 1000$ \\
\hline GE/Alstom [80] & ML3000 & 36 & $6 \mu \mathrm{s}$ & $\mathrm{sim}$ & $10 / 100 / 1000$ \\
\hline
\end{tabular}

\subsection{Modelo proposto para a simulação do sistema de potência em conjunto com o barramento de processo IEC 61850-9-2}

O modelo de simulação proposto neste trabalho tem como objetivo, através do software Matlab/Simulink, realizar uma simulação do tipo comprehensive simulation do sistema de potência em conjunto com os dispositivos que compõem o barramento de processo IEC 61850-9-2. Pesquisas realizadas pelo autor apontaram que este tipo de simulação é preferível por ser potencialmente mais rápido, mais versátil e mais prático do que o tipo co-simulation, além de ter sido ainda pouco explorado, o que despertou e motivou o interesse em desenvolver um modelo capaz de realizar esta simulação. Neste trabalho foram selecionadas duas ferramentas do ambiente Simulink: SimPowerSystem (desenvolvida pela empresa Hydro-Québec) [82] para simulação do sistema de potência e SimEvents (desenvolvida pela MathWorks) [83] para a simulação dos dispositivos que compõem o barramento de processo. 
A ferramenta SimPowerSystem foi configurada para trabalhar na modalidade continuous time simulation, utilizando o bloco powergui com configuração do parâmetro simulation type: discrete, e do parâmetro sample time: 1 e-6.

A ferramenta SimEvents trabalha intrinsicamente na modalidade discrete event simulation, modelando os dispositivos da rede na configuração black box communication model.

Ambas as ferramentas trabalham de forma off-line.

A Figura 124 ilustra o modelo proposto para simulação. Em relação ao modelo inicial apresentado na Figura 123 foram adotadas as seguintes premissas:

- uso de SAMUs como IEDs de interface para o barramento de processo;

- redundância do barramento de rede utilizando a arquitetura do Protocolo PRP;

- inclusão de IEDs para desempenho de funções mínimas de automação e proteção;

- adição de seccionadoras utilizadas para manobras da subestação;

- inclusão de TIs para envio de sinais de corrente/tensão para as lógicas de medição e proteção. 
Figura 124 - Modelo proposto para a simulação do sistema de potência em conjunto com o barramento de processo

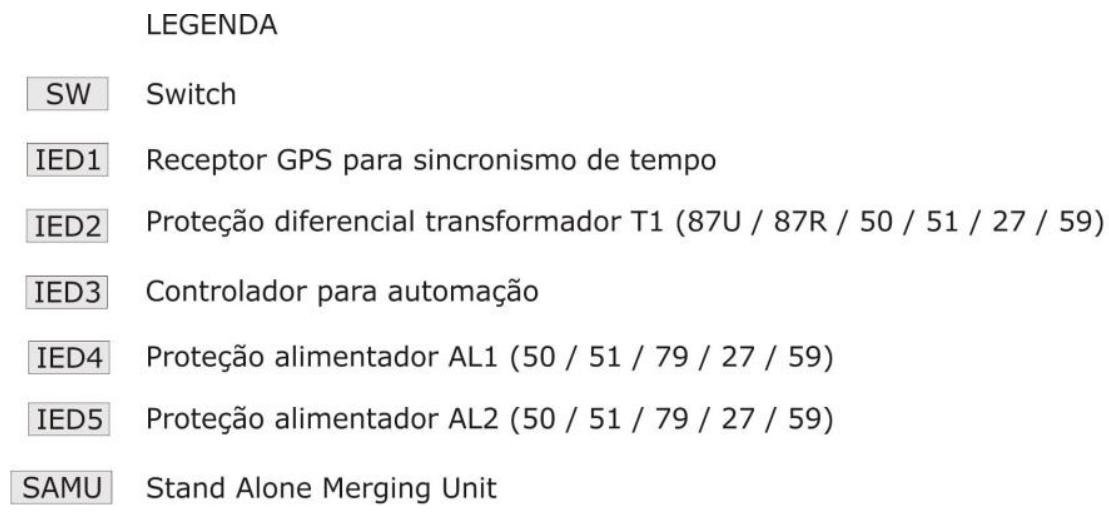

\section{Sala de comando}

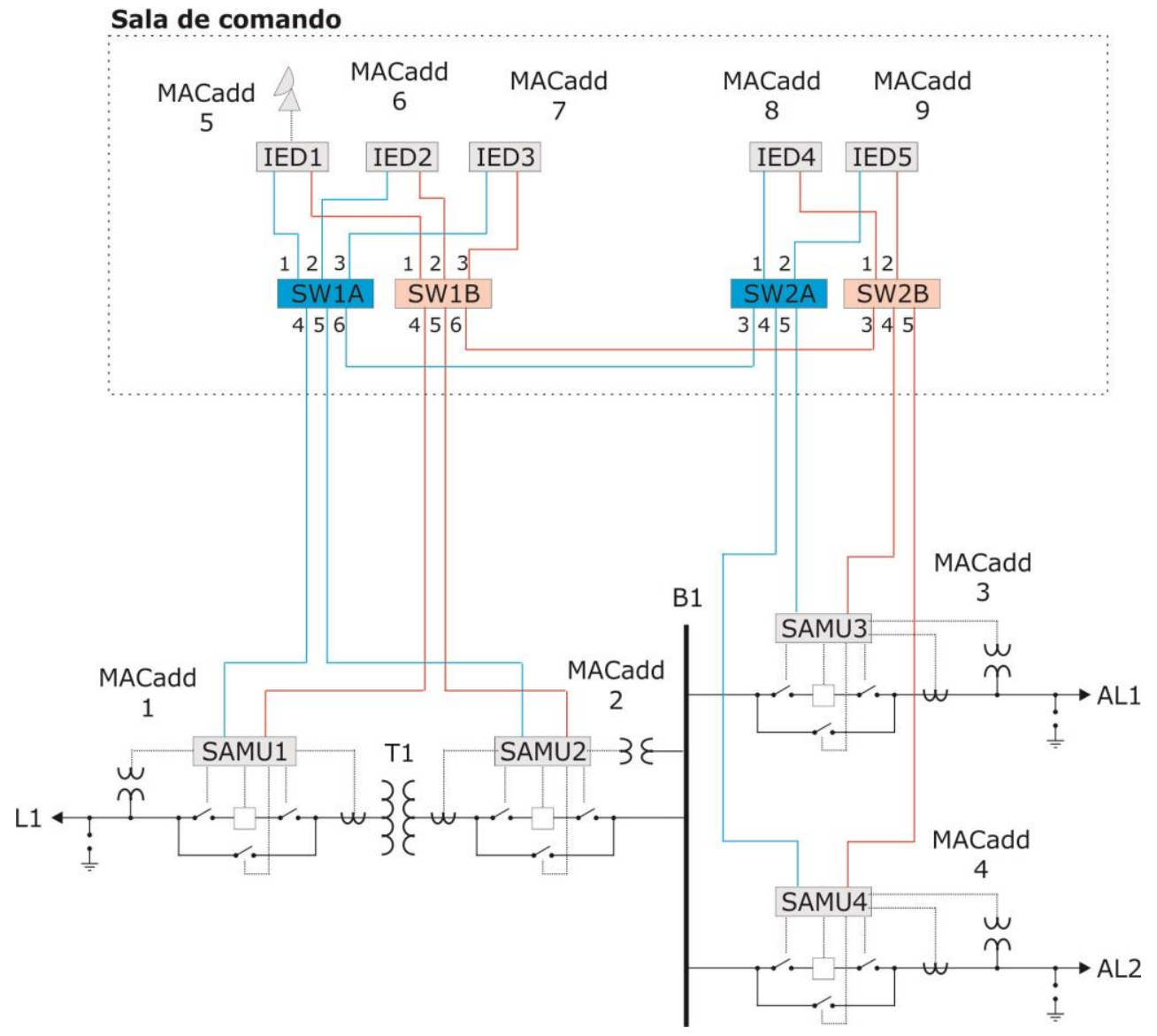

Fonte: o Autor 
7.3.1 Diagrama unifilar do sistema de potência proposto

A Figura 125 representa o trecho do diagrama unifilar entre a linha $L 1$ e o transformador $T 1$ e as conexões dos equipamentos do sistema de potência à SAMU1.

Figura 125 - Trecho do modelo desde a linha L1 até o transformador T1

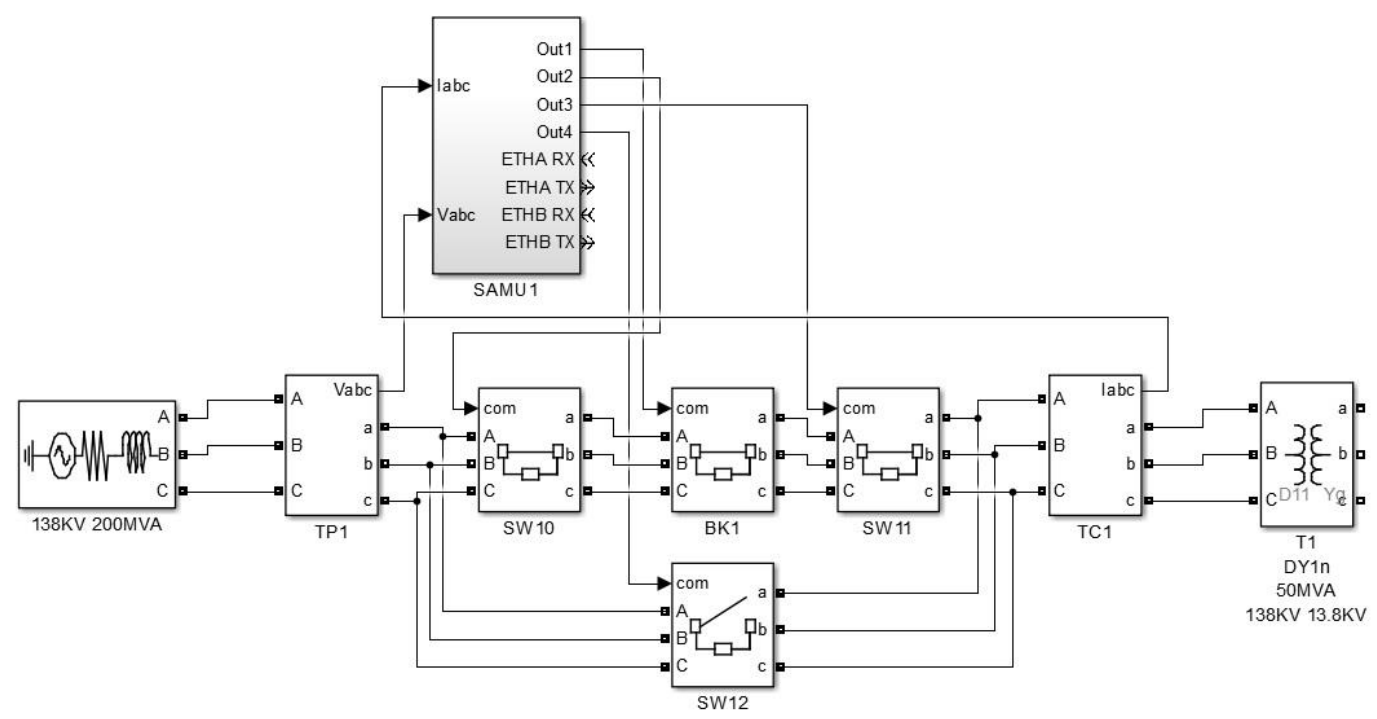

Fonte: o Autor

A Figura 126 representa o trecho do diagrama unifilar entre o transformador $T 1$ e o barramento $B 1$ e as conexões dos equipamentos do sistema de potência à SAMU2.

Figura 126 - Trecho do modelo entre o transformador T1 e o barramento B1

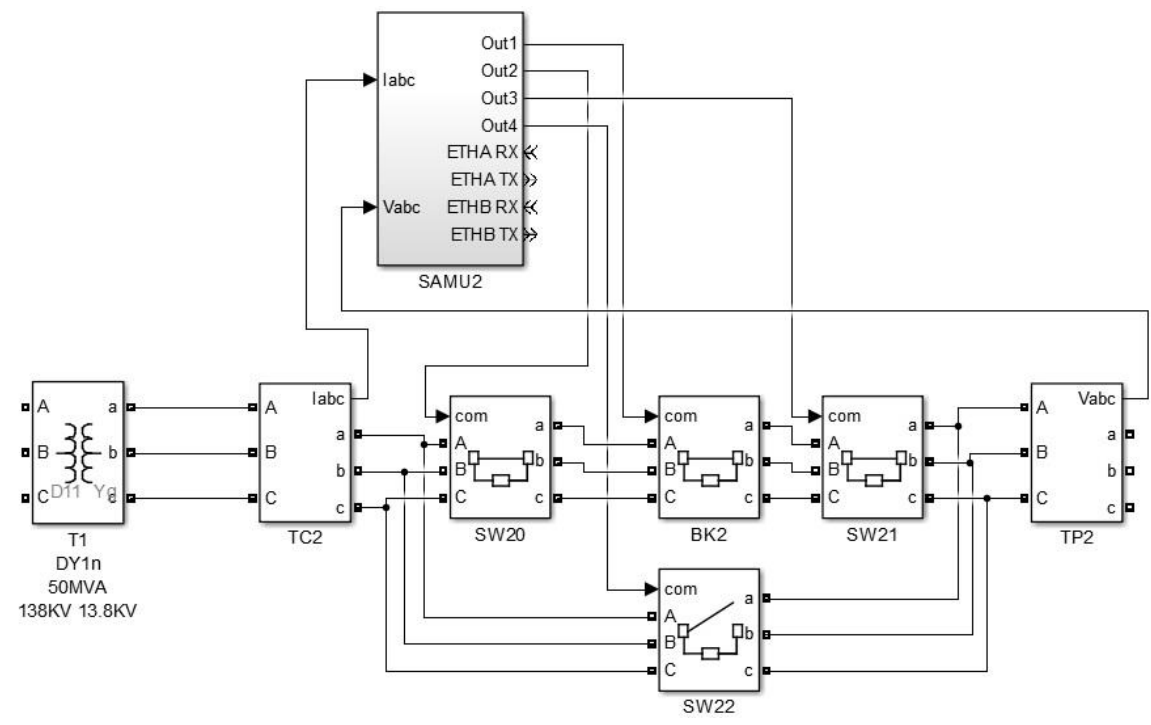

Fonte: o Autor 
A Figura 127 representa o trecho do diagrama unifilar entre o barramento $B 1$ e o alimentador $A L 1$ e as conexões dos equipamentos do sistema de potência à SAMU3.

Figura 127 - Trecho do modelo entre o barramento B1 e o alimentador AL1

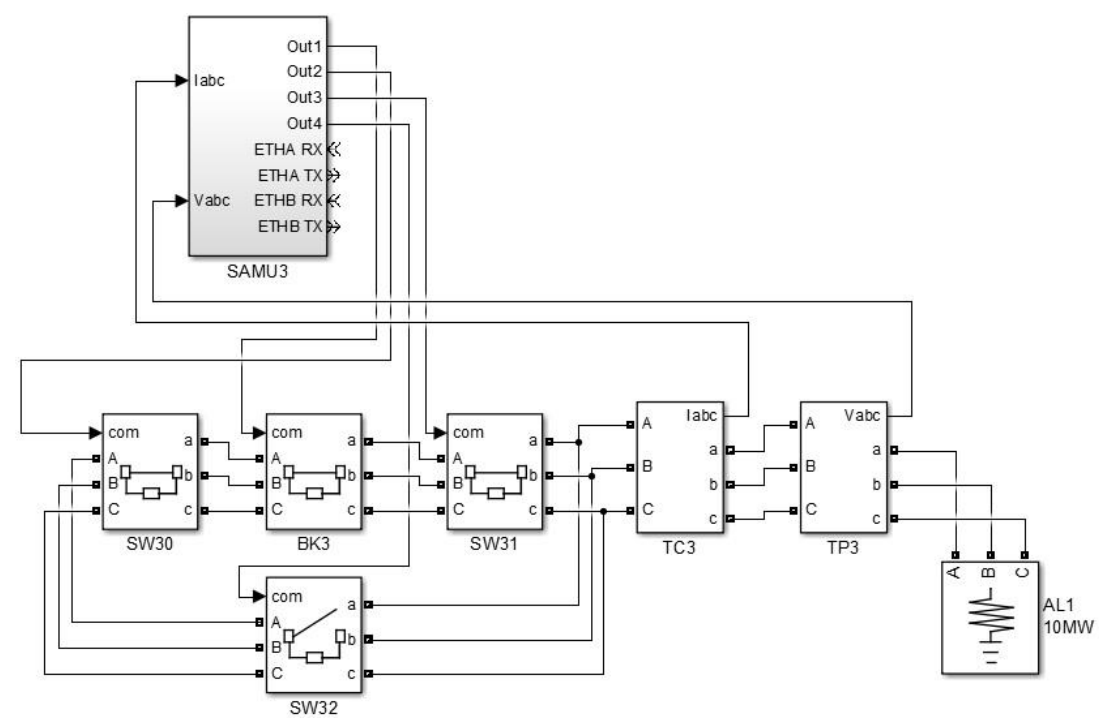

Fonte: o Autor A Figura 128 representa o trecho do diagrama unifilar entre o barramento $B 1$ e o alimentador $A L 2$ e as conexões dos equipamentos do sistema de potência à SAMU4.

Figura 128 - Trecho do modelo entre o barramento B1 e o alimentador AL2

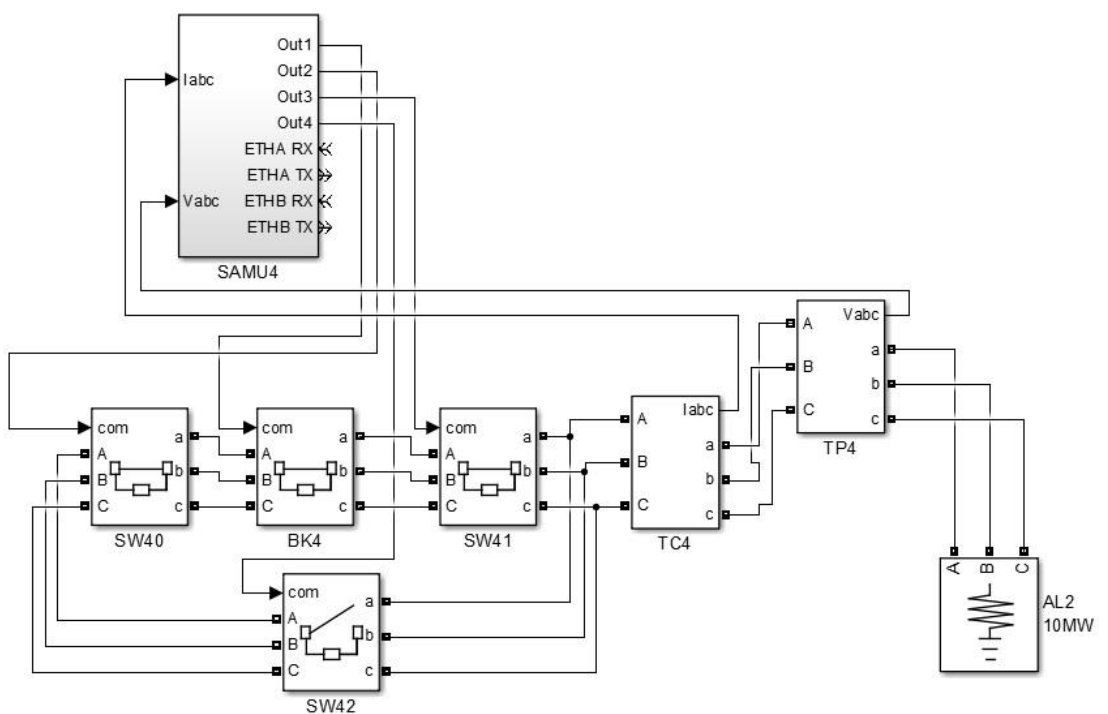

Fonte: o Autor 
A Figura 129 representa as conexões da rede de comunicação de dados entre os dispositivos IED1, IED2, IED3, SWIA e SWIB.

Figura 129 - Trecho do modelo englobando IED1, IED2, IED3, SWIA e SWIB

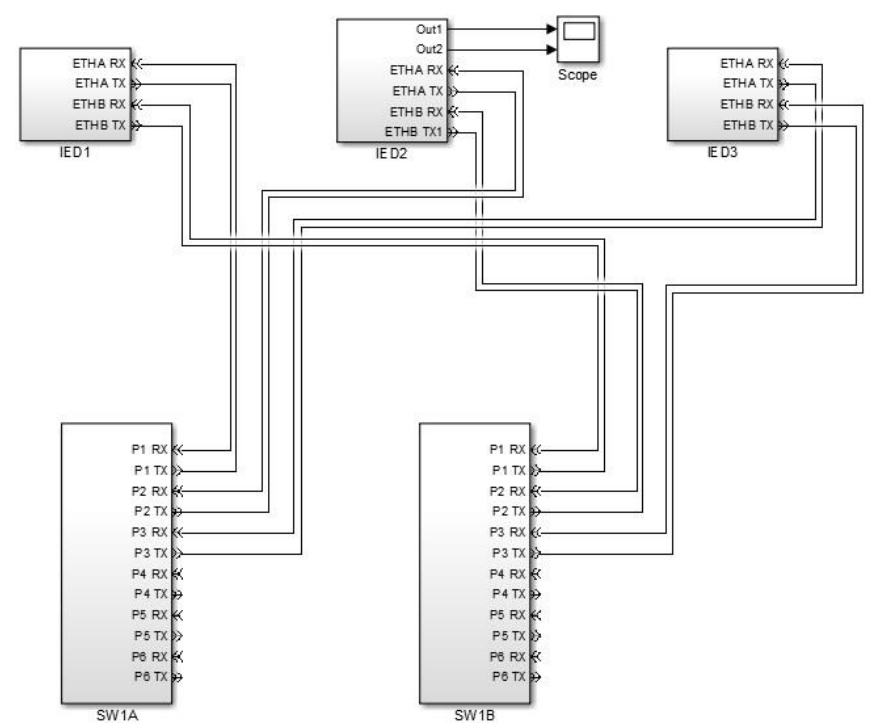

Fonte: o Autor

A Figura 130 representa as conexões da rede de comunicação de dados entre os dispositivos IED4, IED5, SW2A e SW2B.

Figura 130 - Trecho do modelo englobando IED4, IED5, SW2A e SW2B

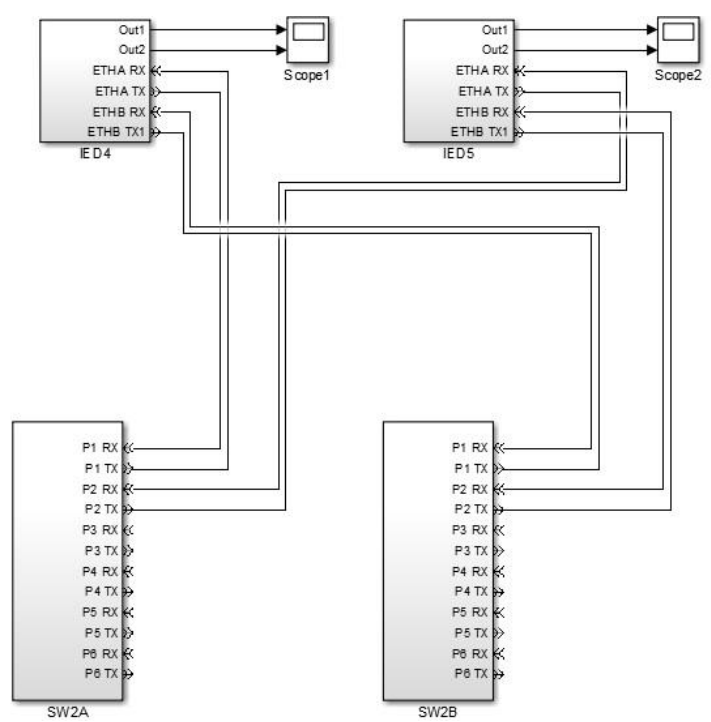

Fonte: o Autor 


\subsubsection{Diagrama do SAMU proposto}

A Figura 131 representa diagrama dos blocos utilizado no modelo do SAMU. Para a simulação adotou-se a taxa de 80 amostras/ciclo (finalidade de proteção) e frequência da rede elétrica de 60Hz. O bloco Time-Based Entity Generator é responsável por gerar a cada $208,33 \mu$ s as entities que representam as SV Messages a serem transmitidas no barramento de processo. O bloco Set Attribute é responsável por inserir nas mensagens os atributes, que irão representar os valores de alguns campos transmitidos dentro das SV Messages e algumas características destas SV Messages. Os valores inseridos são o endereço MAC (MACadd), a prioridade (priority), a quantidade de bytes da mensagem (nbytes), os valores trifásicos instantâneos das correntes $(I a b c)$ e das tensões $(V a b c)$. A constante Delay time representa a característica Delay Time do SAMU. Ela será utilizada para simular o tempo de transmissão da SV Message através das portas ETHA TX e ETHB TX. Na porta ETHA TX a função executada pelo bloco TX time ETHA utiliza o valor nbytes lido pelo bloco Get Attributel, multiplica pelo valor $80 \mathrm{~ns}$, e altera o atraso do bloco Single Server3 através da porta $t$. De modo análogo o mesmo procedimento é realizado na porta ETHB TX. A simulação da transmissão das mensagens pelo Protocolo PRP é feita através do bloco Replicate, que duplica a SV Message recebida (mantendo o mesmo endereço MAC em ambas as mensagens) e os blocos Set Attribute1 e Set Attribute2, que inserem a identificação da rede a qual pertencem cada SV Message. 
Figura 131 - Diagrama contendo os blocos que compõem o SAMU proposto
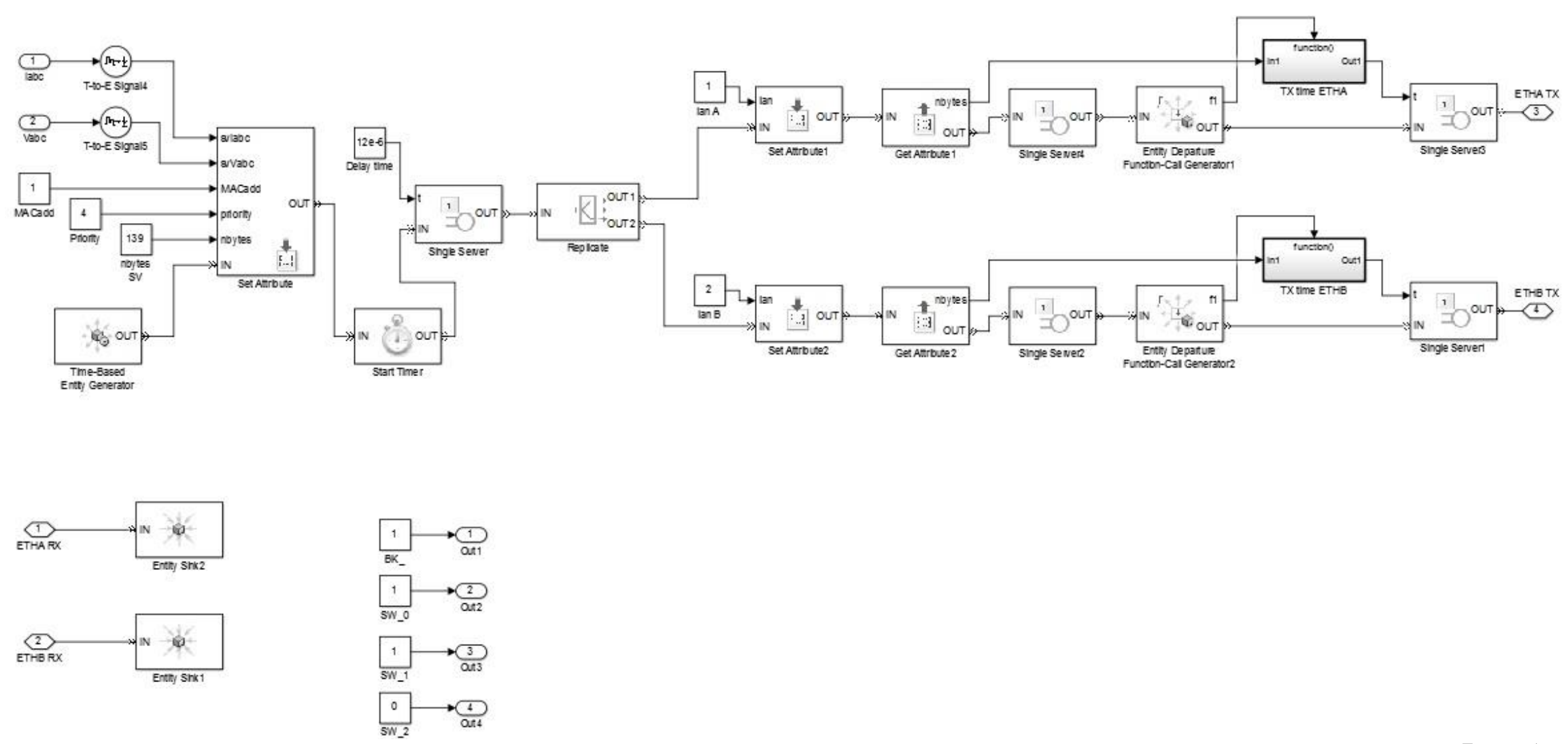


\subsubsection{Diagrama do switch proposto}

A Figura 132 mostra especificamente o bloco que representa o switch utilizado no modelo proposto e a Figura 133 o diagrama geral dos blocos utilizados para construí-lo. A sua dinâmica de simulação funciona da seguinte forma:

Figura 132 - Black-box que representa o switch proposto

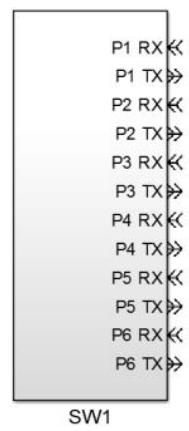

Fonte: o Autor

Figura 133 - Diagrama geral dos blocos utilizados para o modelo de switch proposto

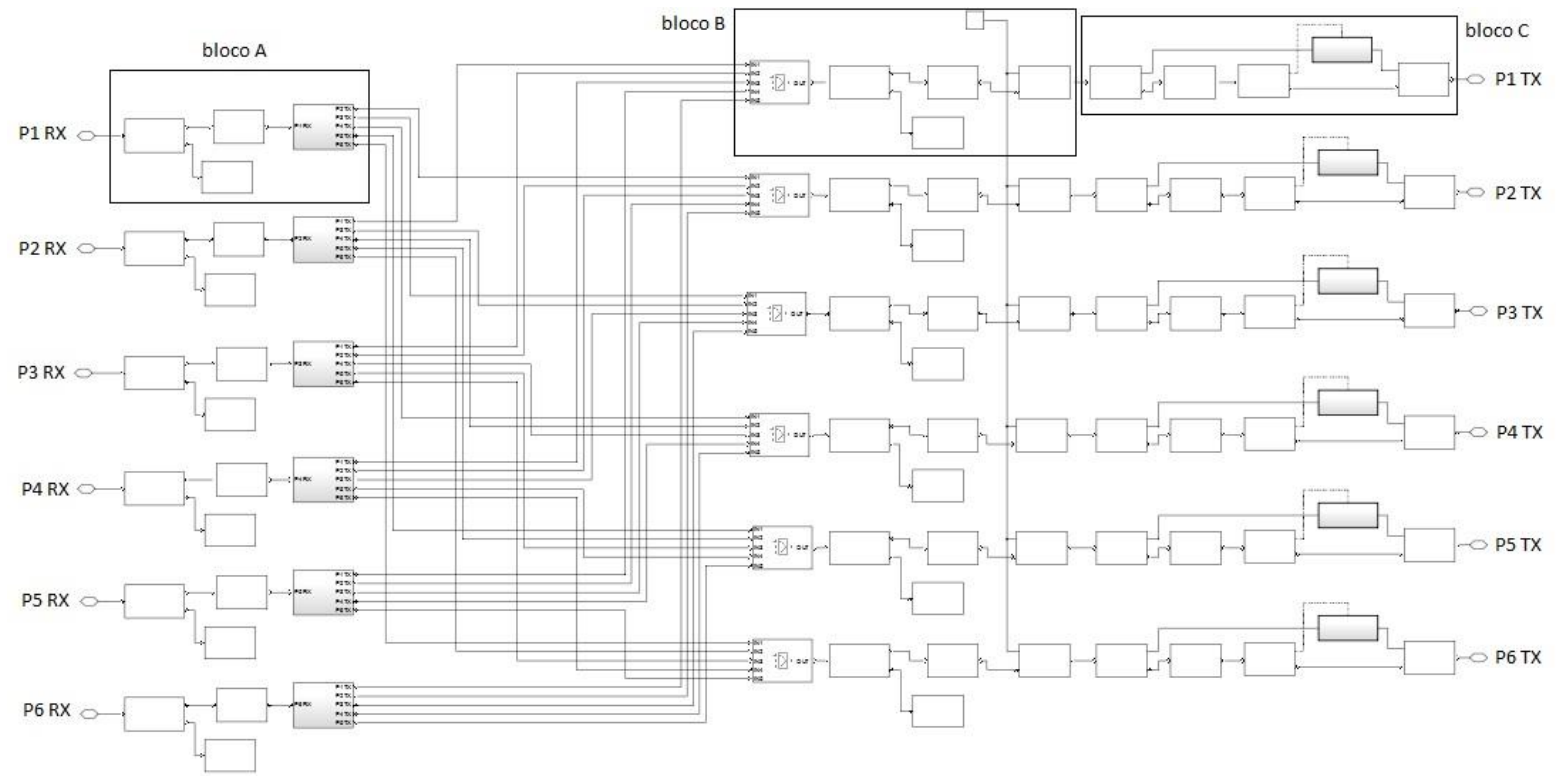

Fonte: o Autor

A Figura 134 ilustra os blocos que compõem o bloco $A$ da Figura 133. Quando uma mensagem chega, por exemplo, através da porta $P I R X$ ela é armazenada no bloco FIFO Quеие, configurado com o parâmetro capacity: 1. Ele representa a área de memória responsável por armazenar a mensagem que acabou de ser recebida. Caso ela não seja tratada antes da chegada de uma nova mensagem, esta nova mensagem será encaminhada pelo bloco 
Output Switch para o bloco Entity Sink, que a descartará.

Figura 134 - Diagrama contendo os blocos que compõem a entrada do switch proposto

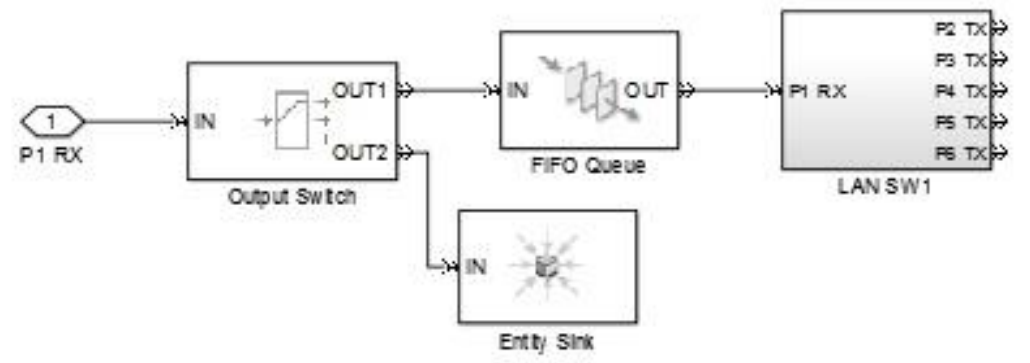

Fonte: o Autor A Figura 135 ilustra os blocos que compõem o bloco $L A N S W 1$. Seu objetivo é simular a VLAN e o direcionamento das mensagens para as portas de saída. Assim que a mensagem chegar pelo ponto $P 1 R X$ ela é replicada igualmente nas saídas do bloco Replicate. Cada bloco Output Switch tomará a decisão de passar a mensagem adiante, ou não, dependendo do valor aplicado na porta $p$. O bloco Get Attribute lê o valor do atribute MACadd contido na mensagem e o envia para o bloco VLAN table Port, que contém um bloco 1-D Lookup Table configurado pelo usuário para devolver o valor 1 na saída Out1 quando o MACadd contiver um endereço de uma mensagem que se deseja transmitir, ou o valor 2 quando o MACadd contiver um endereço de uma mensagem que não se deseja transmitir. 


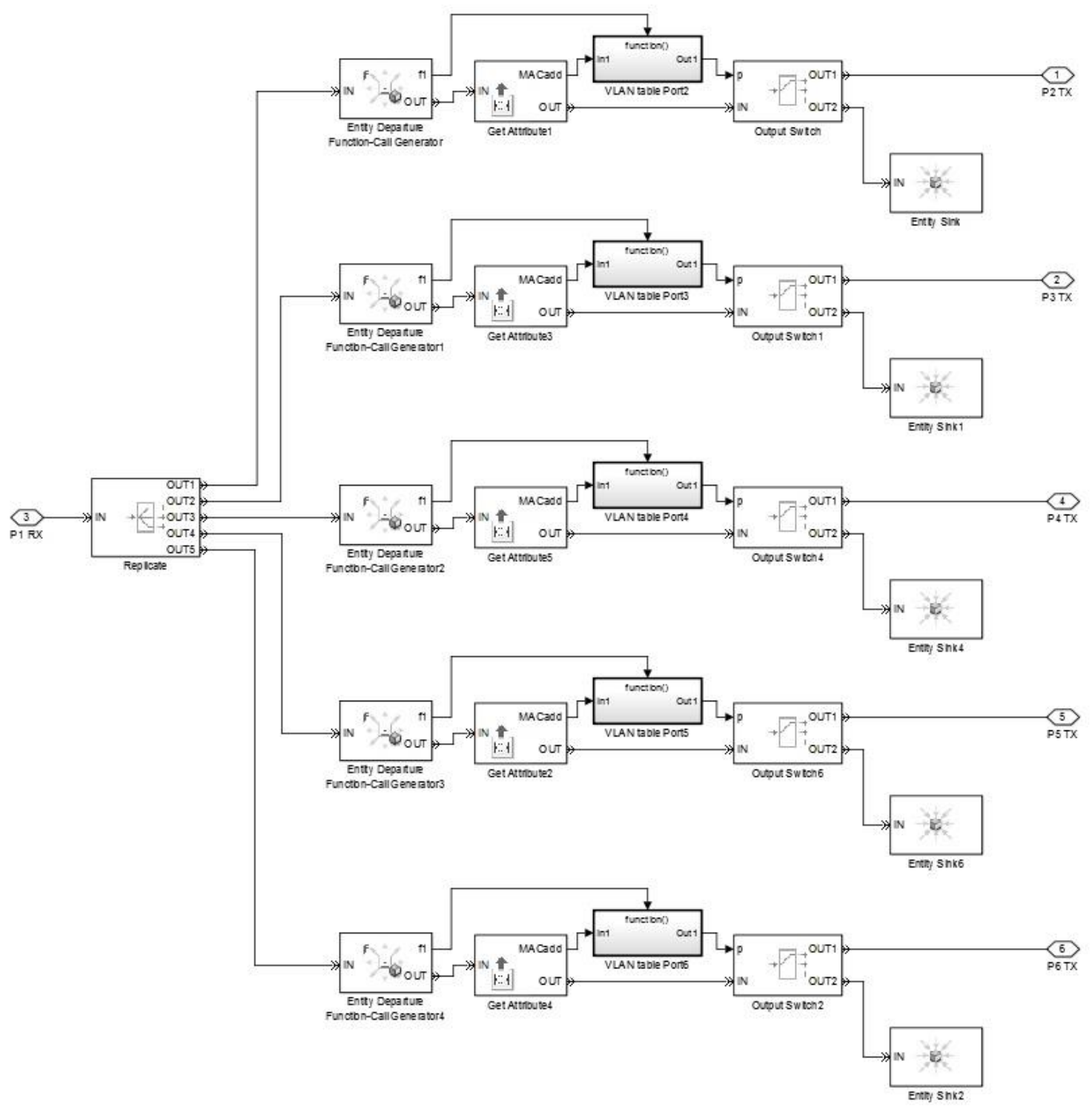

Fonte: o Autor

Cada uma das saídas do switch é composta pelo bloco $B$ e pelo bloco $C$ da Figura 133 ilustrados, respectivamente, pela Figura 136 e pela Figura 137. A saída $P 2 T X$ do bloco $L A N$ SW1 é conectada na entrada IN1 do bloco Path Combiner da porta P2 TX, a saída P3 TX do bloco LAN SW1 é conectada na entrada IN1 do bloco Path Combiner da porta P3 TX, e assim sucessivamente.

O objetivo dos blocos da Figura 136 é simular a dinâmica de queue de um switch, levando em consideração a análise de prioridade de cada mensagem, o limite na quantidade de mensagens possíveis de serem armazenadas no queue e o latency de um switch. Com base nos switches de mercado levantados na Tabela 22 foi admitido neste modelo um tempo de latency de $7 \mu \mathrm{s}$. Supondo que uma primeira mensagem chegue pelo bloco Path Combiner, ela será 
encaminhada pelo bloco Output Switch para o bloco Priority Queue que, como está vazio, imediatamente encaminhará a mensagem para o bloco latency LAN SW1. Caso cheguem novas mensagens pelo bloco Path Combiner durante os primeiros $7 \mu \mathrm{s}$ elas serão encaminhadas pelo bloco Output Switch para o bloco Priority Queue, que as armazenará e as organizará em função do valor do attribute priority (parâmetro Sorting attribute name: priority). Caso a quantidade de mensagens acumuladas ultrapasse 25 (parâmetro Capacity: 25 do bloco Priority Quеue) as mensagens passarão a ser encaminhadas pelo bloco Output Switch para o bloco Entity Sink, onde serão descartadas.

Figura 136 - Blocos responsáveis por implementar a dinâmica de queue do switch

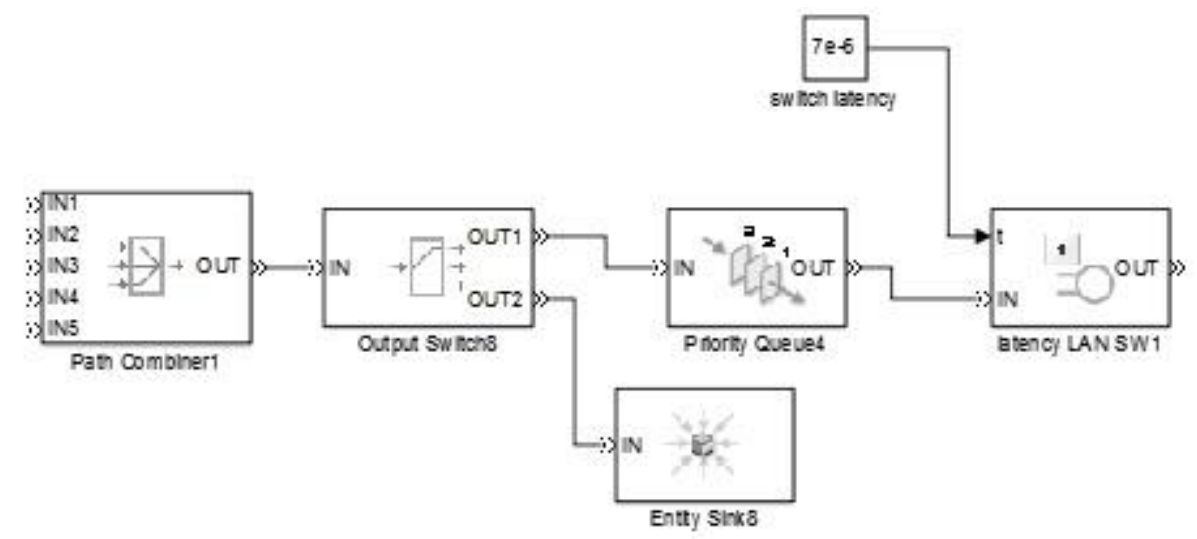

Fonte: o Autor Após o tempo de latency ser processado pelo bloco latency LAN SW1 as mensagens são enviadas para o bloco Get Attribute da Figura 137, que desempenha a função de simular o tempo de transmissão das mensagens de acordo com a sua quantidade de bytes (semelhante à lógica implementada no diagrama da Figura 131).

Figura 137 - Blocos responsáveis por implementar o tempo de transmissão das mensagens

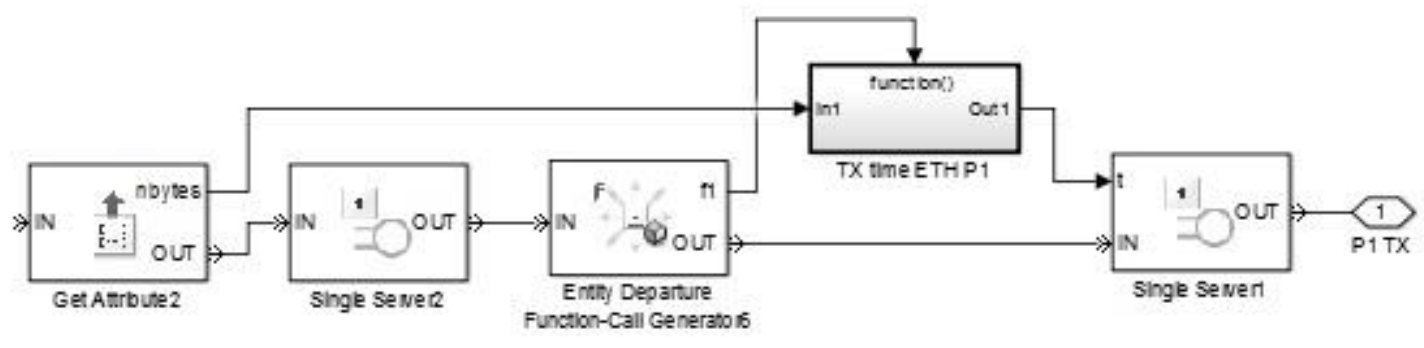

Fonte: o Autor 


\subsubsection{Diagrama do IED1 proposto}

A Figura 138 ilustra os blocos que compõem o modelo de IEDl proposto. A dinâmica de geração de mensagens é semelhante ao do bloco SAMU, ilustrado pela Figura 131. Para as simulações realizadas o bloco Time-Based Entity Generator foi programado com Period: 1s, simulando uma periodicidade de envio de mensagens menor, característico de mensagens de menor prioridade.

O mesmo esquema foi utilizado para modelar o IED3. 

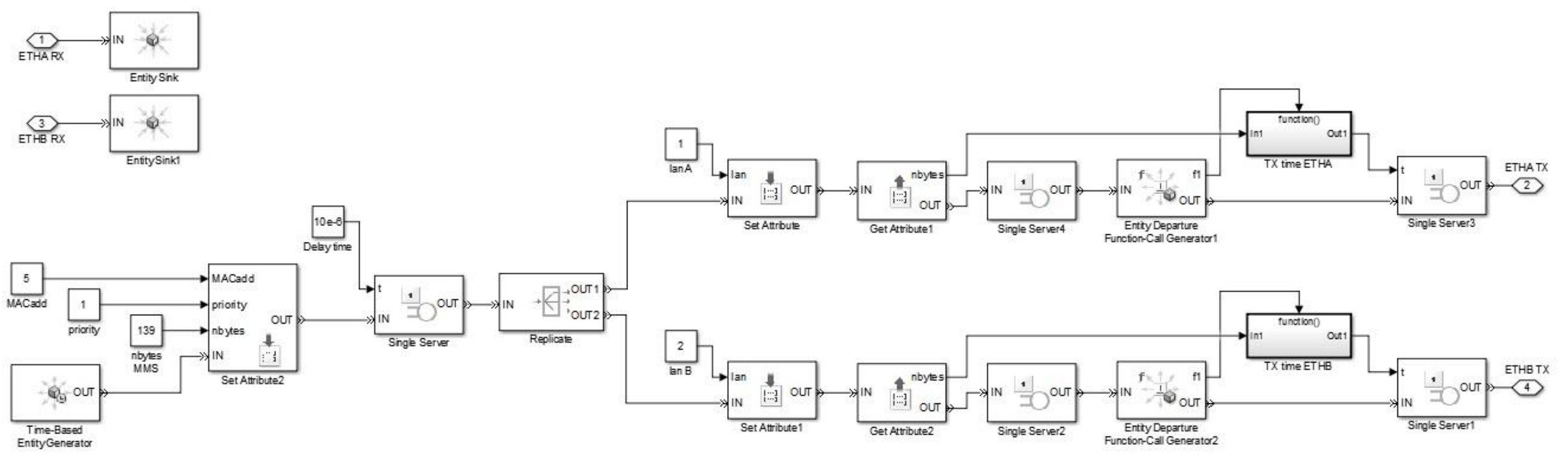

Fonte: o Autor 


\subsubsection{Diagrama do IED2 proposto}

A Figura 138 ilustra os blocos que compõem o modelo de IED2 proposto.

A dinâmica de geração de mensagens também é semelhante ao do bloco SAMU, ilustrado pela Figura 131.

A recepção das mensagens foi implementada de forma a identificar e separar as mensagens recebidas, de acordo com o valor do MACadd. O bloco VLAN table possui internamente um bloco 1-D Lockup Table que recebe o valor do MACadd lido pelo bloco Get Atribute2 e devolve um valor correspondente para selecionar a saída do bloco Output Switch1. Para o modelo proposto a saída OUT1 está programada para receber mensagens com MACadd igual a 1 (SAMU1), a saída OUT2 para receber mensagens com MACadd igual a 2 (SAMU2) e a saída OUT3 para receber mensagens com os demais valores de MACadd.

O mesmo esquema foi utilizado para modelar o IED4 e o IED5. 

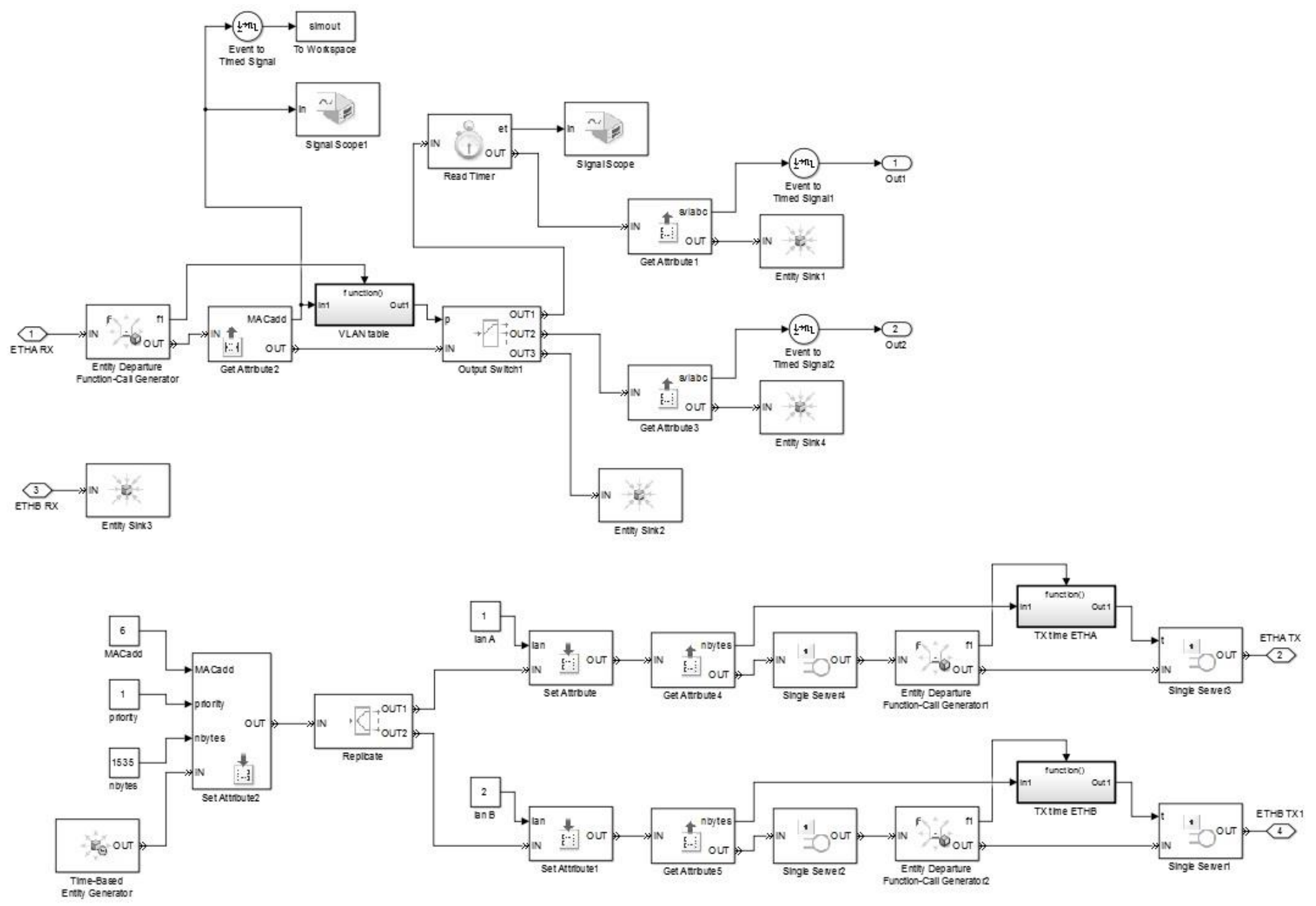


\subsection{Simulações realizadas no modelo proposto}

\subsubsection{Transmissão dos valores amostrados}

O objetivo desta simulação foi verificar se o modelo proposto realiza uma simulação do tipo comprehensive simulation do sistema de potência em conjunto com os dispositivos que compõem o barramento de processo IEC 61850-9-2. A situação simulada foi a transmissão das correntes amostradas pela SAMU1 e pela SAMU2 para o IED2. As seguintes configurações foram adotadas:

- SAMU1: Priority igual a 4, nbytes $S V$ igual a 139 e Delay time igual a $12 \mu$ s;

- SAMU2: Priority igual a 4, nbytes $S V$ igual a 139 e Delay time igual a $12 \mu$ s;

- SWIA e SWIB: configurações das VLAN table Port de forma a encaminhar as mensagens recebidas na porta $\mathrm{P} 4(S A M U 1)$ para a porta $P 2$ (IED2) e as mensagens recebidas na porta P5 (SAMU2) para a porta $P 2(I E D 2)$ e switch latency igual a $7 \mu \mathrm{s}$.

Os parâmetros MACadd de todos os dispositivos foram configurados segundo o diagrama da Figura 124 e o intervalo de simulação adotado foi de $70 \mathrm{~ms}$. A Figura 140 mostra os sinais obtidos por um bloco Scope, onde o canal 1 foi conectado na entrada de corrente Iabc do SAMU1 e o canal 2 foi conectado na entrada de corrente Iabc do SAMU2. A Figura 141 mostra os sinais obtidos através de um bloco Scope, onde o canal 1 foi conectado na saída Out1 do IED2 (que contém as amostras recebidas do SAMU1) e o canal 2 foi conectado na saída Out2 do IED2 (que contém as amostras recebidas do SAMU2). As amostras de corrente recebidas pelo IED2 corresponderam as correntes medidas pelo SAMU1 e pelo SAMU2.

Figura 142 mostra os sinais obtidos pelo Scope conectado no IED2 alterando as configurações do SWIA e $S W 1 B$ de forma a encaminhar para a porta P2 (IED2) somente as mensagens recebidas pela porta $P 4$ (SAMU1). O sinal do canal 2 permaneceu em zero, o que comprova o não encaminhamento das mensagens enviadas pelo SAMU2 e a capacidade de direcionamento de mensagens pelo modelo de switch proposto. 
Figura 140 - Resultados obtidos pelo Scope conectado nas entradas de corrente do SAMU1 e do SAMU2

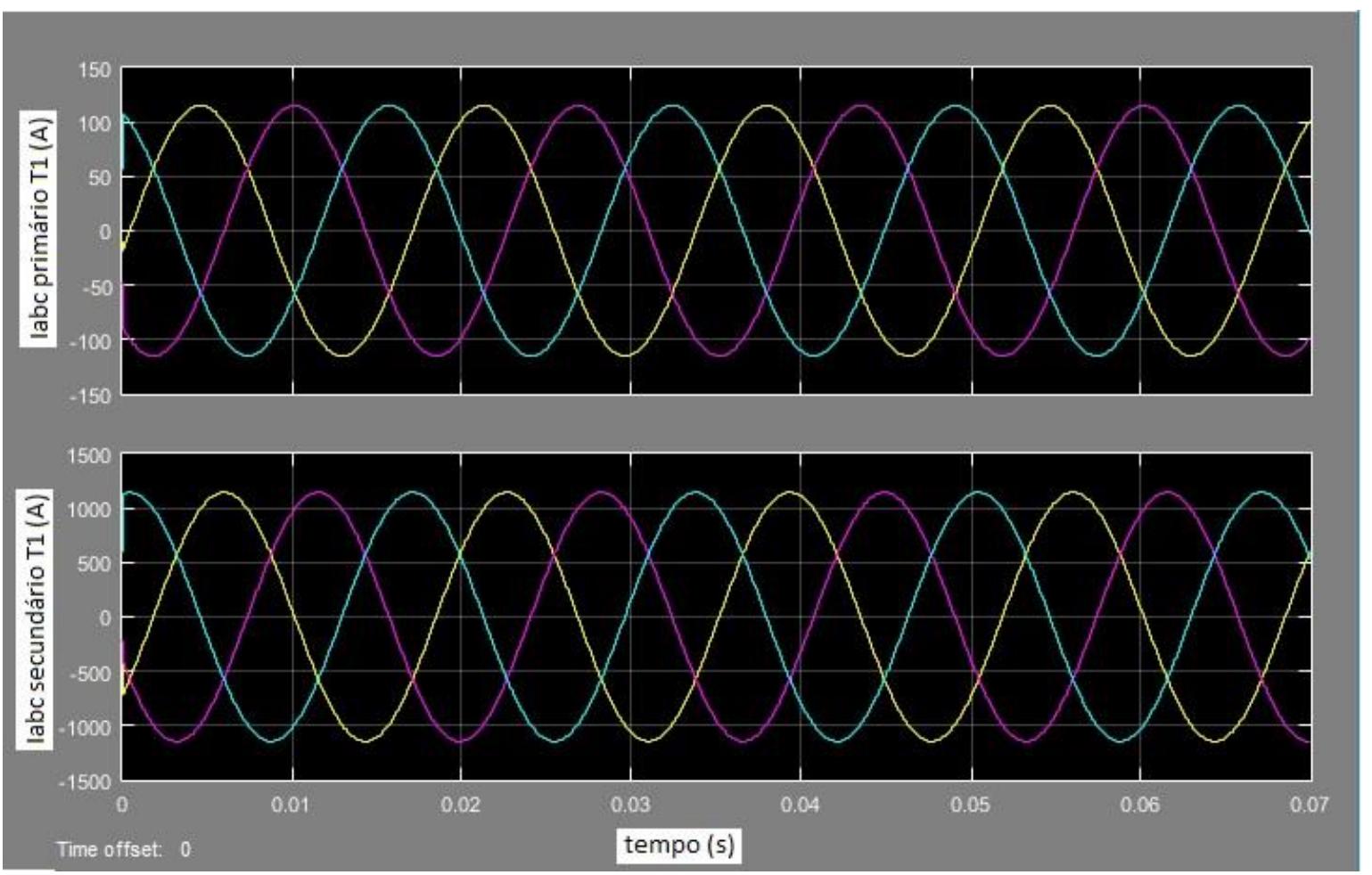

Fonte: o Autor

Figura 141 - Resultados obtidos pelo Scope conectado nas saídas Out1 e Out2 do IED2

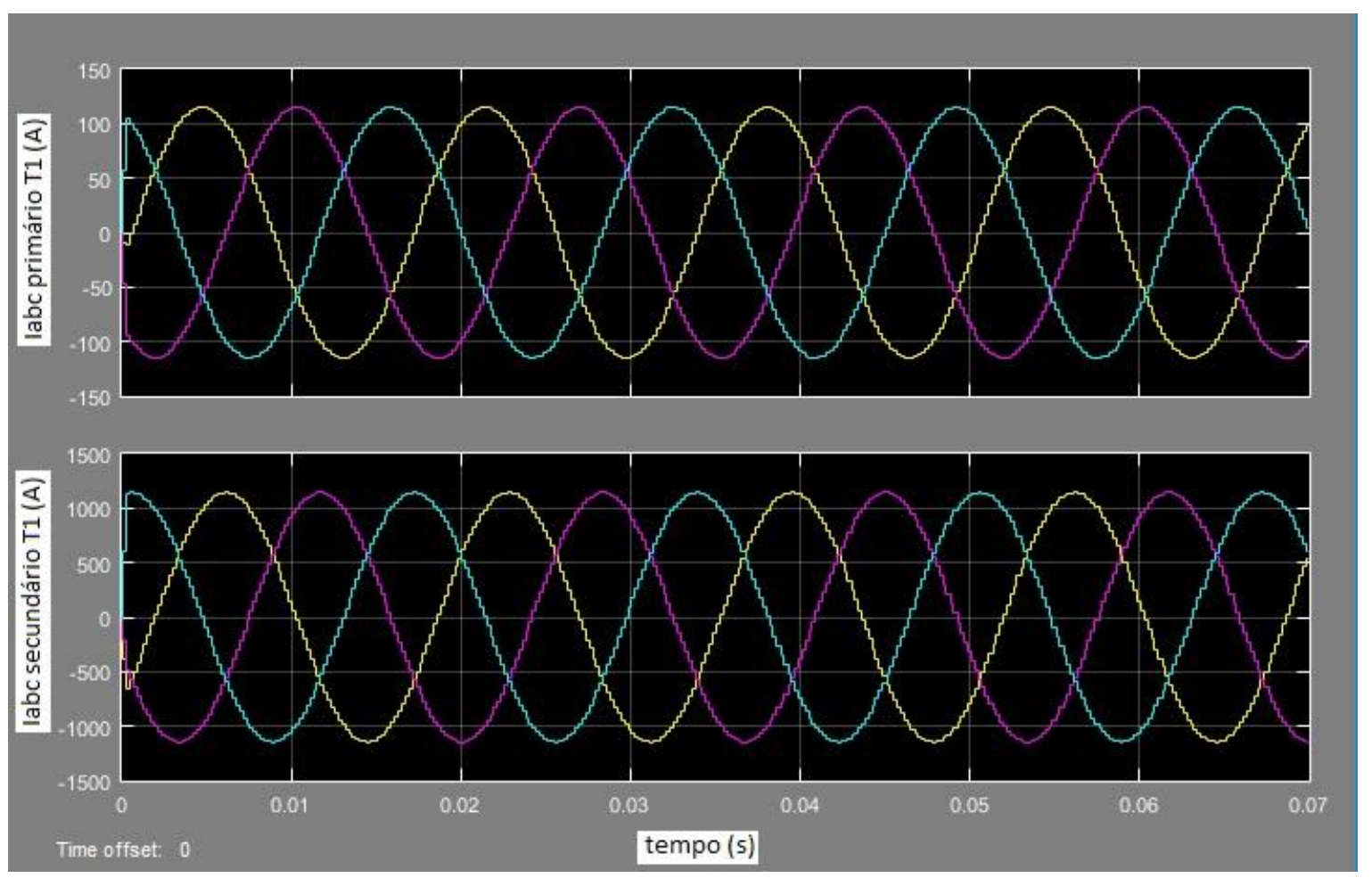

Fonte: o Autor 


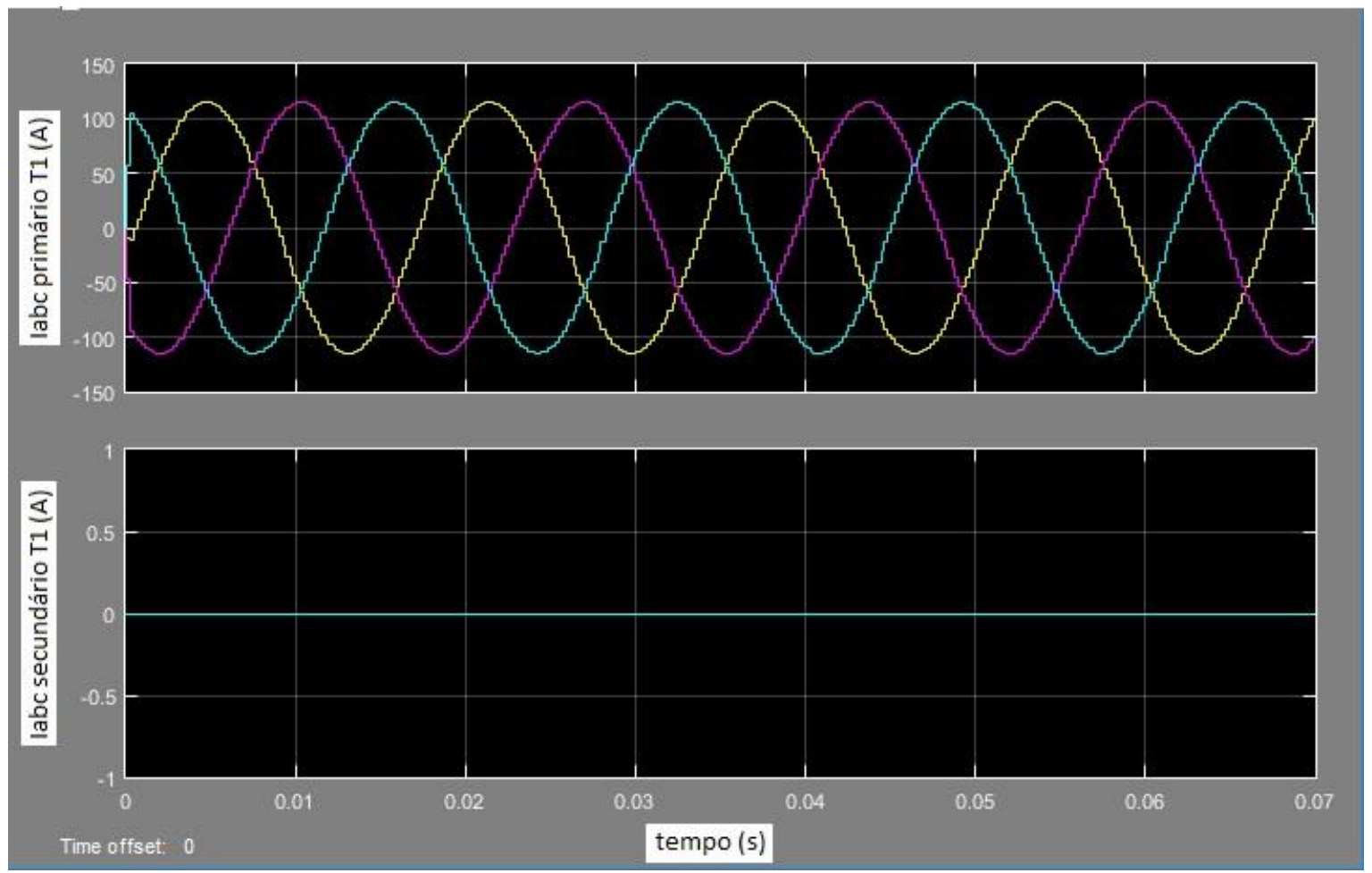

Fonte: o Autor

\subsubsection{Avaliação do tempo de transmissão das SV Messages}

O objetivo desta simulação foi verificar se o modelo proposto realiza a simulação do tempo de transmissão das SV Messages pelo barramento de processo. A situação simulada foi medir as correntes do primário do transformador $T 1$ através do SAMU1, que enviará as amostras através de $S V$ Messages que serão encaminhadas através do SWIA para o IED2. As seguintes configurações foram adotadas:

- SAMU1: Priority igual a 4, nbytes $S V$ igual a 139 e Delay time igual a $20 \mu$ s;

- SW1A: configurações das VLAN table Port de forma a encaminhar as mensagens recebidas na porta $\mathrm{P} 4(S A M U 1)$ para a porta $P 2$ (IED2) e switch latency igual a $7 \mu$ s.

Os parâmetros MACadd de todos os dispositivos foram configurados segundo o diagrama da Figura 124 e o intervalo de simulação adotado foi de $1 \mathrm{~ms}$. Para a avaliação do tempo de transmissão das mensagens a ferramenta SimEvents disponibiliza os blocos Start Timer e Read Timer. O bloco Start Timer foi inserido no bloco SAMU1, conforme ilustra a Figura 131, 
e o bloco Read Timer foi inserido no bloco IED2, conforme ilustra a Figura 139, de forma a medir o tempo de transmissão das SV Messages, levando em consideração o Delay Time do SAMU1, o latency do SWIA e o tempo para transmissão das SV Messages entre cada dispositivo de acordo com a quantidade de bytes.

No instante zero o SAMU1 realiza a amostragem das correntes trifásicas no primário do transformador T1, e começa a enviar a SV Message após seu Delay Time de 20 $\mu$ s. O tempo de transmissão desta SV Message do SAMU1 até o SWIA é calculado em razão da quantidade de bytes transmitida e da taxa de transmissão. Nesta simulação foram considerados o frame básico da SV Message (com base nas análises realizadas do Capítulo 6) com 139 bytes e a taxa de transmissão de 100Mbps, o que totaliza um tempo de transmissão igual a 11,12 $\mu$ s. Assim que esta $S V$ Message for recebida pelo SWIA ela será encaminhada para o IED2 após o latency de $7 \mu \mathrm{s}$. A transmissão da SV Message do SWIA até o IED2 também será de 11,12 $\mu \mathrm{s}$. Portanto, o tempo total estimado para a transmissão da SV Message será $20 \mu \mathrm{s}+11,12 \mu \mathrm{s}+7 \mu \mathrm{s}$ $+11,12 \mu \mathrm{s}=49,24 \mu \mathrm{s}$.

A Figura 143 traz os resultados obtidos pelo bloco Scope conectado ao bloco Read Timer presente no IED2, que corresponderam com o tempo total estimado calculado.

Figura 143 - Resultados obtidos pelo Scope conectado ao bloco Read Timer do IED2

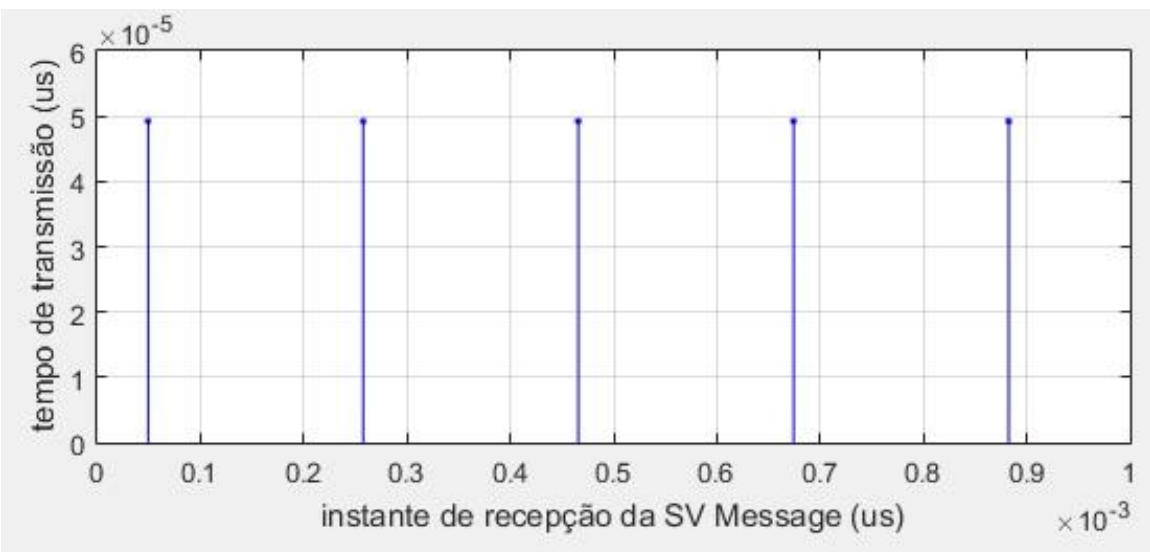

Fonte: o Autor

\subsubsection{Processamento de prioridade das mensagens pelos switches}

O objetivo desta simulação foi verificar se o modelo proposto realiza o processamento de prioridade das mensagens recebidas pelo switches. A situação simulada foi medir a corrente 
primária do transformador $T 1$ através do $S A M U 1$ e a corrente secundária do transformador $T 1$ através do SAMU2. Ambos enviam suas amostras através de $S V$ Messages de alta prioridade para o SWIA. Simultaneamente o IEDI também envia mensagens com prioridade mais baixa para o SWIA. Todas estas mensagens serão encaminhadas pelo SWIA para o IED2. As seguintes configurações foram adotadas:

- SAMU1: Priority igual a 4, nbytes $S V$ igual a 139 e Delay time igual a $20 \mu$ s;

- SAMU2: Priority igual a 4, nbytes $S V$ igual a 139 e Delay time igual a $24 \mu$ s;

- IED1: Priority igual a 1, nbytes $M M S$ igual a 139 , Delay time igual a $22 \mu$ s e o parâmetro Period do bloco Time-Based Entity Generator igual a 1s;

- SW1A: configurações das VLAN table Port de forma a encaminhar as mensagens recebidas na porta $P 4(S A M U 1)$ para a porta $P 2$ (IED2), na porta $P 5$ (SAMU2) para a porta $P 2$ (IED2) e na porta $P 1$ (IED1) para a porta $P 2$ (IED2), e switch latency igual a $7 \mu \mathrm{s}$.

Os parâmetros MACadd de todos os dispositivos foram configurados segundo o diagrama da Figura 124 e o intervalo de simulação adotado foi de $1 \mathrm{~ms}$.

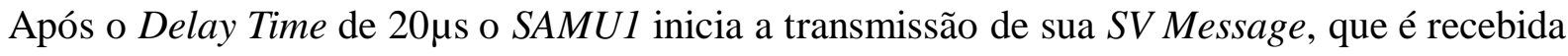
completamente pela porta $P 4$ do $S W 1 A$ após o tempo de transmissão $11,12 \mu$ s. Devido a esta mensagem ser a primeira a ser recebida pelo $S W 1 A$ ela será encaminhada diretamente para a transmissão, sem passar pelo processo de queue. Após o latency de $7 \mu$ s (que se inicia no instante $20 \mu \mathrm{s}+11,12 \mu \mathrm{s}=31,12 \mu \mathrm{s})$ o $S W 1 A$ inicia a transmissão da $S V$ Message pela porta $P 2$. Portanto, se alguma nova mensagem chegar no $S W 1 A$ e precisar ser transmitida pela porta $P 2$ entre os instantes de tempo $31,12 \mu$ s e $38,12 \mu$ s ela será acumulada no processo de queue.

Após o Delay Time de $22 \mu$ s o IED1 inicia a transmissão de sua mensagem, que é recebida completamente pela porta $P 1$ do $S W 1 A$ após o tempo de transmissão $11,12 \mu$ s, portanto, no instante $22 \mu \mathrm{s}+11,12 \mu \mathrm{s}=33,12 \mu \mathrm{s}$. Devido ao SWIA encontrar-se neste instante no latency da SV Message do SAMU1, a mensagem entrará no processo de queue que, como está vazio, será preenchido na sua primeira posição com a mensagem do IEDI.

Após o Delay Time de $24 \mu$ s o SAMU2 inicia a transmissão de sua SV Message, que é recebida completamente pela porta $P 5$ do $S W 1 A$ após o tempo de transmissão $11,12 \mu \mathrm{s}$, portanto, no instante $24 \mu \mathrm{s}+11,12 \mu \mathrm{s}=35,12 \mu \mathrm{s}$. Neste instante o SWIA encontra-se no latency da $S V$ Message do SAMU1 e com a mensagem do IEDl na primeira posição do processo de queue. Como a mensagem do SAMU2 possui prioridade superior ao da mensagem do IED1, a 
mensagem do IEDI será deslocada para a segunda posição no processo de queue e a $S V$ Message do SAMU2 será inserida na primeira posição do processo de queue.

Após o instante de tempo $38,12 \mu$ s a $S V$ Message do SAMU1 será transmitida pela porta $P 2$ e será recebida completamente pelo IED2 após o tempo de transmissão $11,12 \mu$ s, portanto no instante $38,12 \mu \mathrm{s}+11,12 \mu \mathrm{s}=49,24 \mu \mathrm{s}$.

Após o término do latency da SV Message do SAMU1, o SWIA retira do processo de queue a mensagem que está na primeira posição ( $S V$ Message do SAMU2) deslocando as demais mensagens uma posição à frente, e após o latency de $7 \mu$ s inicia a transmissão desta mensagem, ou seja, no instante $38,12 \mu \mathrm{s}+7 \mu \mathrm{s}=45,12 \mu \mathrm{s}$. Neste instante a $S V$ Message do SAMU1 ainda está sendo transmitida, portanto, somente quando ela for recebida completamente pelo IED2 é que começara a ser transmitida efetivamente a SV Message do SAMU2 pela porta $P 2$. Portanto, a SV Message do SAMU2 será recebida completamente pelo IED2 no instante $49,24 \mu \mathrm{s}+11,12 \mu \mathrm{s}=60,36 \mu \mathrm{s}$.

Após o término do latency a mensagem do IEDI começará a ser transmitida somente quando as SV Messages do SAMU1 e do SAMU2 forem efetivamente recebidas pelo IED2. Portanto, a mensagem do IED1 será recebida completamente pelo IED2 no instante $60,36 \mu \mathrm{s}+11,12 \mu \mathrm{s}=$ $71,48 \mu \mathrm{s}$.

A Figura 144 ilustra os resultados obtidos pelo Scope conectado na saída MACadd do bloco Get Attribute2 do IED2, cujos valores corresponderam com os resultados estimados calculados.

Figura 144 - Resultados obtidos pelo Scope conectado na saída MACCadd do bloco Get Attribute2

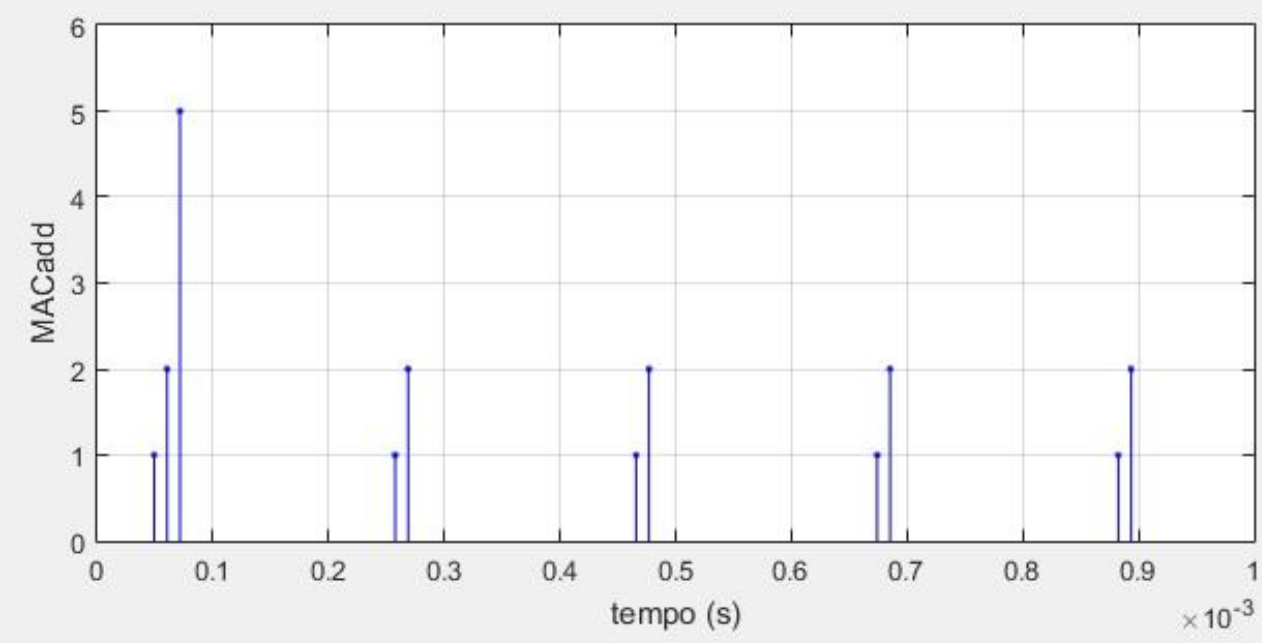


7.4.4 Atraso nas mensagens de maior prioridade devido às mensagens de baixa prioridade

O objetivo desta simulação foi verificar se o modelo proposto simula o atraso que pode ocorrer na transmissão de mensagens de alta prioridade em conjunto com a transmissão de mensagens de baixa prioridade. A situação simulada foi medir a corrente primária do transformador $T 1$ através do SAMU1 que envia suas amostras através de SV Messages de alta prioridade para o SWIA. Simultaneamente o IEDI também envia mensagens com prioridade mais baixa para o $S W 1 A$. Todas estas mensagens serão encaminhadas pelo SWIA para o IED2. As seguintes configurações foram adotadas:

- SAMU1: Priority igual a 4, nbytes $S V$ igual a 139 e Delay time igual a $12 \mu$ s;

- IED1: Priority igual a 1, nbytes MMS igual a 139, Delay time igual a $10 \mu$ s e o parâmetro Period do bloco Time-Based Entity Generator igual a 1s;

- SWIA: configurações das VLAN table Port de forma a encaminhar as mensagens recebidas na porta $P 4$ (SAMU1) para a porta $P 2$ (IED2) e na porta $P 1$ (IED1) para a porta P2 (IED2), e switch latency igual a $7 \mu \mathrm{s}$.

Admitindo uma situação hipotética onde houvesse somente as SV Messages do SAMU1 a serem encaminhadas pelo SWIA a primeira mensagem seria recebida completamente pelo IED2 após o Delay time do SAMU1 de $12 \mu \mathrm{s}$, o tempo de transmissão entre o SAMU1 e o $S W 1 A$ de $11,12 \mu \mathrm{s}$, o latency do $S W 1 A$ de $7 \mu$ s e o tempo de transmissão entre o $S W 1 A$ e o IED2 de $11,12 \mu \mathrm{s}$, portanto, no instante $12 \mu \mathrm{s}+11,12 \mu+7 \mu \mathrm{s}+11,12 \mu \mathrm{s}=41,24 \mu \mathrm{s}$.

Na situação simulada o IEDl esta programado para transmitir mensagens em conjunto com o SAMU1. Embora as mensagens geradas pelo IEDI sejam de prioridade mais baixa, se comparadas com as mensagens geradas por $S A M U 1$, dependendo do momento no qual elas chegam no switch o tempo de transmissão das SV Messages do SAMU1 pode ser alterado.

A primeira mensagem gerada pelo IEDI é completamente recebida pelo $S W 1 A$ após o Delay time do IEDI de $10 \mu$ s e o tempo de transmissão entre o IEDI e o $S W 1 A$ de $11,12 \mu$ s, ou seja, no instante $10 \mu \mathrm{s}+11,12 \mu \mathrm{s}=21,12 \mu$ s ela é processada pelo queue do $S W 1 A$ e encaminhada para a transmissão na porta $P 2$ após o latency de $7 \mu$ s. Durante o intervalo de tempo entre $21,12 \mu \mathrm{s}$ a $28,12 \mu \mathrm{s}$, se alguma nova mensagem chegar para ser transmitida pela porta P2 (independente da prioridade) ela será inserida no processo de queue.

A primeira mensagem gerada pelo SAMU1 é completamente recebida pelo $S W 1 A$ após o 
Delay time do IEDI de $12 \mu$ s e o tempo de transmissão entre o $S A M U 1$ e o $S W 1 A$ de $11,12 \mu$ s, ou seja, no instante $12 \mu \mathrm{s}+11,12 \mu \mathrm{s}=23,12 \mu \mathrm{s}$, que se encontra dentro do intervalo de tempo do latency da mensagem do IED1. Portanto, mesmo tendo alta prioridade ela terá de aguardar o término da transmissão da mensagem do IEDl, que será após o final do latency no instante $28,12 \mu$ s mais o tempo de transmissão entre o $S W 1 A$ e o $I E D 2$ de $11,12 \mu \mathrm{s}$, ou seja, no instante $28,12 \mu \mathrm{s}+11,12 \mu \mathrm{s}=39,24 \mu \mathrm{s}$.

Finalmente, a $S V$ Message do $S A M U 1$ será transmitida pela porta $P 2$ e será completamente recebida pelo IED2 após o tempo de transmissão de $11,12 \mu \mathrm{s}$, ou seja, $39,24 \mu \mathrm{s}+11,12 \mu \mathrm{s}=$ $50,36 \mu$ s, ao invés do instante $41,24 \mu$ s (calculado anteriormente numa situação onde somente o SAMU1 envia mensagens no barramento).

A Figura 145 ilustra os resultados obtidos pelo Scope conectado na saída MACadd do bloco Get Attribute2, cujos valores corresponderam com os resultados estimados calculados.

A transmissão de mensagens de baixa prioridade, como as Mensagens MMS, compartilhando um mesmo barramento de rede com mensagens de alta prioridade, como as SV Messages, interfere no tempo de transmissão destas últimas, sobretudo no barramento de processo onde a sua quantidade é elevada. Portanto, a utilização de uma política de análise de prioridade não é suficiente para garantir o seu tempo de transmissão. Uma possível solução para contornar este problema seria limitar a quantidade de bytes das mensagens de baixa prioridade para um valor mais próximo a quantidade de bytes das mensagens de alta prioridade, por exemplo.

Figura 145 - Resultados obtidos pelo Scope conectado na saída MACCadd do bloco Get Attribute2

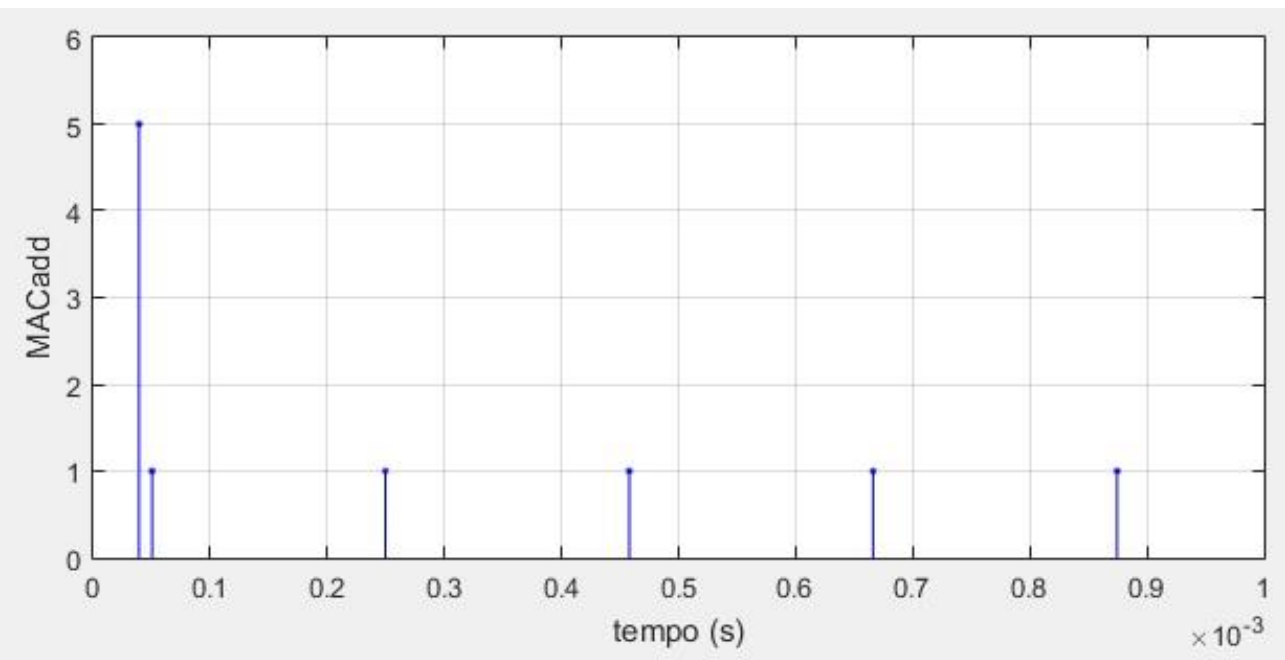

Fonte: o Autor 


\section{Conclusões e Comentários}

A utilização da Norma IEC 61850 vem crescendo ano após ano, consolidando-se definitivamente como padrão a ser seguido nos projetos de SAS. O comprometimento por parte dos fabricantes e dos pesquisadores com o cumprimento de seus três principais fundamentos (interoperabilidade, versatilidade e capacidade de incorporação de novas tecnologias) é o principal motivo de seu sucesso. A possibilidade de agregar seus benefícios com as vantagens oferecidas pelos TIs ópticos são as razões centrais que motivaram a pesquisa e o desenvolvimento deste trabalho, que foi elaborado com o objetivo de contribuir na compreensão, na pesquisa e no desenvolvimento dos diversos aspectos que envolvem a implementação de um barramento de processo de acordo com a Norma IEC 61850-9.

Os primeiros resultados mostraram que o barramento de processo, definido pela Norma IEC 61850-9, se encontra em constante evolução, envolve o conhecimento multidisciplinar de várias áreas e exige a compreensão de várias outras normas. Desde o seu lançamento, em meados de 2002, não havia definições concretas sobre vários atributos. Estes foram estabelecidos gradativamente com o tempo, muitas vezes incorporando tecnologias que foram pesquisadas e desenvolvidas após o seu lançamento.

A classificação de todos os aspectos envolvidos, organizados no formato de cinco grandes tópicos propostos pelo autor, auxiliou no esclarecimento e na definição dos principais requisitos desta norma. Abaixo, segue um resumo das principais conclusões obtidas:

- variações da Norma IEC 61850-9: consolidação do frame proposto pela Norma IEC 618509-2 como padrão a ser adotado no SAS, e descontinuação do frame proposto pela Norma IEC 61850-9-1;

- confiabilidade do barramento de processo: Protocolos PRP e HSR, definidos pela Norma IEC 62439-3, serão utilizados como padrão para a redundância do barramento de processo, oferecendo zero recovering time. A recomposição de eventuais amostras perdidas não é escopo da Norma IEC 61850;

- sincronismo de tempo através do barramento de rede: Protocolo PRP, definido pela Norma IEEE 1588v2, será utilizado como padrão para sincronismo de tempo entre IEDs. Os padrões 1pps e IRIG-B ainda devem ser disponibilizados para dispositivos legados, mas devem ser 
descontinuados no futuro;

- análise da qualidade de medição disponibilizada no barramento de processo: a Norma IEC 61869-9, em fase final de elaboração, avançará na definição de requisitos importantes relacionados aos TIs eletrônicos (classe de dispositivos que engloba os TPs e TCs ópticos), com especial destaque para as definições de requisitos de rede não definidos na Norma IEC 61850-9-2, de requisitos de resposta harmônica e de requisitos para avaliação de erros de módulo e de fase para valores de corrente/tensão transmitidos de forma discreta. Algumas destas definições foram simuladas matematicamente pelo autor, e os resultados obtidos sugerem uma possível revisão de algumas definições estabelecidas no draft desta norma.

- segurança cibernética: a Norma IEC 62351-6 estabeleceu os primeiros requisitos para a implementação de recursos de segurança cibernética no barramento de processo. Sua consolidação ainda carece de mais pesquisa e desenvolvimento, sobretudo relacionadas ao cumprimento dos requisitos de tempo real, à definição de alguns parâmetros internos do IED e ao gerenciamento de certificados.

A plataforma proposta para TP óptico com interface IEC 61850-9-2 mostrou-se promissora, com os primeiros protótipos e as simulações matemáticas realizadas apresentando resultados favoráveis à sua implementação.

O uso do barramento de processo de acordo com a Norma 61850-9-2 estabelece um novo cenário para o SAS, onde profissionais envolvidos com o seu desenvolvimento e a sua aplicação devem estar atentos aos requisitos exigidos e às implicações decorrentes de sua implementação, como a alteração nas interfaces dos IEDs e as mudanças no comportamento das funções de proteção. Algumas delas foram exploradas neste trabalho.

A tolerância permitida para drift dos relógios internos de IEDs que compõem um sistema para proteção diferencial de transformadores de potência foi simulada, apontando uma possível necessidade de revisão de alguns requisitos definidos pela norma. Uma readequação de conceitos normalmente analisados para a definição de parâmetros da unidade de proteção diferencial também foi explorada. Sugestões foram propostas e simuladas, apresentando bons resultados.

Testes realizados na elaboração das SV Messages com ferramentas disponíveis no mercado mostraram que seu formato básico está razoavelmente bem consolidado. A implementação, 
em conjunto com outros serviços (como redundância de rede e segurança cibernética), ainda precisa evoluir.

O modelo proposto para a simulação conjunta do sistema de potência e do barramento de comunicação de dados utilizando o software Matlab/Simulink mostrou-se bastante promissora e realista. Os resultados apresentados comprovaram diversas situações que podem acontecer em campo, mostrando que o modelo proposto tem enorme potencial para ser utilizado na simulação das mais diversas configurações de SAS.

Por fim, são sugeridos os seguintes assuntos, que podem ser explorados em futuros trabalhos:

- proteção diferencial de barra com elevada quantidade de bays: uma grande quantidade de bays de uma subestação implica em uma elevada quantidade de TIs transmitindo SV Messages simultaneamente em um único barramento conectado à entrada de rede de um relé de proteção diferencial de barra, o que pode esgotar seu bandwidth.

- metodologias e ferramentas para avaliação de QoS do barramento de processo: a avaliação dinâmica do QoS da rede, aliadas ao seu caráter não determinístico e de tempo real, constitui um grande desafio no desenvolvimento de metodologias e de ferramentas para sua análise.

- recomposição de amostras perdidas: atualmente, não é escopo da Norma IEC 61850 estabelecer metodologias para a recomposição de eventuais amostras perdidas durante a transmissão de SV Messages, sendo de responsabilidade dos desenvolvedores de IEDs a implantação de lógicas específicas para este fim.

- análise de ondas viajantes: a medição de ondas viajantes, normalmente utilizada para a localização de falhas em linhas de transmissão, exige altas taxas de amostragem dos sinais de tensão que excedem as taxas praticadas pelas $S V$ Messages com finalidade de medição, o que inviabiliza seu uso para tal finalidade.

- segurança cibernética: importantes requisitos ainda não foram definidos, tais como a dinâmica de distribuição de chaves, o gerenciamento de certificados e o tempo de execução do algoritmo HMAC-SHA256, e merecem um estudo específico.

- sistema para teste de conformidade de TIs com interface IEC 61850-9-2: algumas plataformas foram propostas, mas estas ainda não são capazes de avaliar todos os requisitos exigidos de um TI com interface IEC 61850-9-2. 
- melhorias no modelo proposto, incluindo por exemplo o tratamento do Protocolo PRP no recebimento das mensagens e a implementação das mensagens GOOSE para o acionamento e leitura do estado das seccionadoras e disjuntores do sistema de potência. 


\section{Referências Bibliograficas}

[1] Instrument Transformers Application Guide, ABB, 2009.

[2] IEC 61850 Standard, International Electrotechnical Commission, 2002.

[3] IGARASHI, G.; SANTOS, J. C., Challenges to the Implementation of a Real-Time Process Bus According to IEC 61850-9, 5th IEEE PES Conference on Innovative Smart Grid Technologies Europe, 2014.

[4] INGRAM, D. M. E., Assessment of Precision Timing and Real-Time Data Networks for Digital Substation Automation, School of Electrical Engineering and Computer Science Queensland University of Technology, Tese de Doutorado, 2013.

[5] IEC 60044 Standard, International Electrotechnical Commission, 2003.

[6] X.690: ASN.1 encoding rules: Specification of Basic Encoding Rules (BER), Canonical Encoding Rules (CER) and Distinguished Encoding Rules (DER), International Telecomunication Union, 2002.

[7] http://www.nettedautomation.com/standardization/ISO/TC184/SC5/WG2/mms_intro/ intro6.html, website acessado em 01/julho/2015.

[8] Implementation Guideline For Digital Interface To Instrument Transformers Using IEC 61850-9-2, UCA International Users Group, 2004.

[9] Power Engineering Guide Ed7.1, Siemens, 2014.

[10] IEEE Std 802.1D - IEEE Standard for Local and metropolitan area networks, IEEE, 2004.

[11] Special Report IEC 61850, ABB, 2010.

[12] IEC/TR 61850-90-4: Communication networks and systems for power utility automation

- Part 90-4: Network engineering guidelines, Ed1.0, International Electrotechnical Commission (IEC), 2013.

[13] IEC 62439 Standard, 2012.

[14] IEEE 1588 v2 Standard, 2012.

[15] IEC 61869-9 draft, International Electrotechnical Commission, 2013.

[16] OLIVEIRA, C. E. F;; ABBOUD, R., Desafios da Segurança Cibernética nas Subestações 
de Energia Elétrica, XV ERIAC, 2013.

[17] IEC 62351-6 Standard, International Electrotechnical Commission, 2007.

[18] RM0090 - Reference Manual - STM32F405xx/07xx, STM32F415xx/17xx, STM32F42xxx and STM32F43xxx advanced ARM-based 32-bit MCUs, ST Microelectronics, 2013.

[19] WU, J.; PELOQUIN, R, Synchronizing Device Clocks Using IEEE 1588 and Blackfin Embedded Processors, Analog Devices, 2009.

[20] McGHEE, J.; GORAJ, M., Smart High Voltage Substation Based On IEC 61850 Process Bus And IEEE 1588 Time Synchronization, First IEEE International Conference on Smart Grid Communications, 2010.

[21] IEC 61850-9-2 Standard Ed 2.0, International Electrotechnical Commission (IEC), 2011.

[22] Instrument Transformer Accuracy Manual, Northern Design Electronics, 2007.

[23] Industrial Ethernet PHY Reference Guide, Texas Instruments, 2012.

[24] IEEE Std C37.238: IEEE Standard Profile for Use of IEEE 1588 Precision Time Protocol in Power System Applications, Institute of Electrical and Electronics Engineers (IEEE), 2011.

[25] ANTONOVA, G. S. et al, Standard Profile for Use of IEEE Std 1588-2008 Precision Time Protocol (PTP) in Power System Applications, IEEE PES PSRC Working Group H7/Sub C7 Members and Guests, 2012.

[26] DJOKIC, B.; SO, E., Calibration System for Electronic Instrument Transformers With Digital Output, IEEE Transactions on Instrumentation and Measurement, 2005;

[27] YAMADA, T., et al, ECT Evaluation by an Error Measurement System According to IEC 60044-8 and IEC 61850-9-2, IEEE Transactions on Power Delivery, 2012;

[28] THRYBOM, L.; PRYTZ, G., QoS in Switched Industrial Ethernet, IEEE Conference on Emerging Technologies \& Factory Automation, 2009.

[29] IEEE Std. 802.1Q, Media Access Control (MAC) Bridges and Virtual Bridge Local Area Networks, Institute of Electrical and Electronics Engineers (IEEE), 2011.

[30] INGRAM, D.M.E.; SCHAUB, P., CAMPBELL, D.A., Multicast Traffic Filtering for Sampled Value Process Bus Networks, IECON 2011 - 37th Annual Conference on IEEE Industrial Electronics Society, IEEE, 2011. 
[31] GURBIEL, M., et al, Merging Unit Accuracy Testing, Power \& Energy Society General Meeting, IEEE PES`09, 2009.

[32] FERRARI, P., et al, Mixing Real Time Ethernet Traffic on the IEC 61850 Process Bus, 9th IEEE International Workshop on Factory Communication Systems (WFCS), 2012.

[33] TANAKA, Y., et al, Development of Process Bus for Busbar Protection and Voltage Selection Scheme, 11th International Conference on Developments in Power Systems Protection (DPSP 2012), 2012.

[34] WANG, B., et al, Performance of process bus communication of transient traveling waves data in smart substation, China International Conference on Electricity Distribution (CICED), 2010.

[35] YONG-HUI, Y.; LEI-TAO, W.; YONG-JIAN, T., Research of Network Transmission of Process Bus based upon IEC 61850, The International Conference on Advanced Power System Automation and Protection, 2011.

[36] FULORIA, S.; ANDERSON, R., Towards a security architecture for substations, 2nd IEEE PES International Conference and Exhibition on Innovative Smart Grid Technologies (ISGT Europe), 2011.

[37] HOYOS, J.; DEHUS, M.; BROWN, T. X., Exploiting the GOOSE protocol: A practical attack on cyber-infrastructure, IEEE Globecom Workshops (GC Wkshps), 2012.

[38] HANH, A., et al, Cyber-Physical Security Testbeds: Architecture, Application, and Evaluation for Smart Grid, IEEE Transactions on Smart Grid, vol. 4, no. 2, 2013.

[39] HONG, J., Cyber Security of Substation Automation Systems, School of Electrical Engineering and Computer Science - Washington State University, Tese de Doutorado, 2014.

[40] HOHLBAUM, F.; BRAENDLE, M.; AlvareZ, F., Cyber Security: Practical considerations for implementing IEC 62351, PAC World Conference, 2010.

[41] HOHLBAUM, F.; SCHWYTER, P.; ALVAREZ, F., Cyber Security requirements and related standards for Substation Automation Systems, Cigré Colloquium, 2011.

[42] XIAO, Y., Security and Privacy in Smart Grids, CRC Press, 2013.

[43] FIAT, R., Security in IEC 62351 for GOOSE and MMS, TÜV SÜD AG, 2013.

[44] ALMEIDA, J. C. J.; SANTOS, J. C., Demodulação Coerente do Sinal de Saída de Transformador de Potencial Óptico, IEEE Latin America Transactions, Vol. 3, No. 5, pp. 423- 
$428,2005$.

[45] SANTOS, J. C., Contribuições para o desenvolvimento de transformadores de potencial a fibras ópticas (TPs ópticos) aplicáveis em sistemas elétricos de potência, Tese de Livre Docência, EPUSP, 2009.

[46] lwIP TCP/IP stack demonstration for STM32F107xx connectivity line microcontrollers, Application Note AN3102, ST Microelectronics, 2009.

[47] IEEE 1588 precision time protocol demonstration for STM32F107 connectivity line microcontroller, Application Note AN3411, ST Microelectronics, 2011.

[48] International vocabulary of metrology - Basic and general concepts and associated terms, Joint Committee for Guides in Metrology, 2008.

[49] Implementing an IEEE 1588 V2 Node on the Kinetis K60 Using the Freescale MQX IEEE 1588 Communication Library, Application Note AN4332, Freescale Semiconductor, 2011.

[50] Industrial Ethernet PHY, Reference Guide, Texas Instruments, 2012.

[51] IEEE Guide for Protective Relay Application to Power Transformers, IEEE Std C37.91, 2000.

[52] HERMANATO, I., A stand-alone digital protective relay for power transformers, IEEE Transactions on Power Delivery, Vol. 6, No 1, January 1991.

[53] PHADKE, A.G.; THORP, J. S., Computer Relaying for Power Systems - Second Edition, RSP Limited, 2009.

[54] SEL-387 Instruction Manual, disponível no site: http://www.selinc.com.

[55] T35 Instruction Manual, disponível no site: http://www.gedigitalenergy.com.

[56] RET650 Instruction Manual, disponível no site: http://www.abb.com.

[57] 7UT612 Instruction Manual, disponível no site: http://www.siprotec.com.

[58] P642 Instruction Manual, disponível no site: http://www.alstomgrid.com.

[59] GRT100D Instruction Manual, disponível no site: http://www.toshiba-tds.com.

[60] THOMPSON, M. J., Percentage restrained differential, percentage of what?, IEEE Conference for Protective Relay Engineers, 2011.

[61] MiCOM PX4X Technical Manual - IEC 61850-9-2LE Interface, disponível no site: 
http://www.alstomgrid.com.

[62] HCX-2SB Series (datasheet), Hosonic, 2010.

[63] HCMOS 2.5x2.0mm 3.3V SMD Oscillator - Model: F230 Series (datasheet), FOX, 2011.

[64] Clock Oscillators Surface Mount Type - Clock “K” Series (datasheet), Kyocera, 2014.

[65] CARTRIGHT, J., Aging Performance in Crystals, Connor Winfield, 2008.

[66] KONKA, J., et al, Traffic Generation of IEC 61850 Sampled Values, IEEE First International Workshop on Smart Grid Modeling and Simulation (SGMS), 2011.

[67] BARANOV, P. F., et al, Software for Emulating the Sampled Values Transmission in Accordance with IEC 61850 Standard, 2nd International Symposium on Computer, Communication, Control and Automation, 2013.

[68] ZHAO, P., IEC 61850-9-2 Process Bus Communication Interface for Light Weight Merging Unit Testing Environment, Tese de Mestrado, KTH Electrical Enginnering, 2012.

[69] Ethernet 10/100/1000BASE-T Application Software - TDSET3, SR-ENET, DPO4ENET datasheet, Tektronix, 2014.

[70] DP83848C/I/VYB/YB PHYTER QFP Single Port 10/100 Mb/s Ethernet Physical Layer Transceiver datasheet, Texas Instruments, 2015.

[71] site: www.freeformatter.com/hmac-generator.html, acessado em julho/2015.

[72] LIMA, D. K., Transformadores Para Instrumentos Ópticos: Aspectos da Viabilidade do seu Uso Pelas Empresas do Setor Elétrico Brasileiro, Dissertação de Mestrado, EPUSP, 2009.

[73] SANTOS, J. C., Estudo e Desenvolvimento de Moduladores Eletro e Magnetoópticos e suas Aplicações como Transformadores de Medição (TP e TC Ópticos) em Sistemas Elétricos de Potência, Dissertação de Mestrado, EPUSP, 1993.

[74] METS et al, Combining power and communication network simulation for cost-effective smart grid analysis, IEEE Communication Surveys \& Tutorials, IEEE, 2014.

[75] DUALIBE, P., Subestações: Tipos, Equipamentos e Proteção (apostila), Centro Federal de Educação Tecnológica Celso Suckow da Fonseca, 1999.

[76] Subestações de 138, 69 e 34,5KV - Critério de Projeto (apostila), AMPLA, 2010.

[77] Diagrama unifilar da SE Altamira - Sistema Pará, Centro de Informações e Análise da Operação da Transmissão e Geração - Eletronorte, 2002. 
[78] Site de soluções Siemens para Smart Grid e Automação de Energia w3.siemens.com/smartgrid/global/en/products-systems-

solutions/protection/pages/overview.aspx, Siemens, acessado em janeiro/2016.

[79] Site de soluções ABB para automação de subestações - http://new.abb.com/substationautomation, ABB, acessado em janeiro/2016.

[80] Site de soluções GE para proteção e automação - http://www.gegridsolutions.com, GE, acessado em janeiro/2016.

[81] Site de soluções SEL para proteção e automação - http://www.selinc.com, SEL, acessado em janeiro/2016.

[82] SimPowerSystem for Use with Simulink - User’s Guide, Hydro-Québec TransÉnergie Technologies, 2003.

[83] SimEvents Getting Started Guide, MathWorks, 2015. 


\section{Anexo 1: Introdução aos Transformadores para Instrumentos com Tecnologia Não-Convencional}

Transformadores para instrumentos são utilizados em SASs para extrair informações das principais grandezas elétricas (tensão e corrente) presentes nos pontos mais importantes de um sistema elétrico [45] [72] [73]. Sua principal finalidade é reduzir o valor destas grandezas elétricas a níveis seguros e com isolação elétrica suficiente para que, posteriormente, possam ser enviadas para dispositivos secundários (relés de proteção, oscilógrafos, medidores, etc.) que irão processar lógicas de proteção e automação necessárias para o correto funcionamento do SAS. Existem basicamente dois tipos de TIs: o transformador de corrente responsável por reduzir a corrente medida no sistema de potência e o transformador de tensão responsável por reduzir a tensão medida no sistema de potência. Para o projeto de ambos podem ser utilizadas diferentes tecnologias, convencionais ou não convencionais. 


\section{Transformadores de Corrente Convencionais}

Os TCs convencionais são constituídos basicamente por um núcleo de ferro em formato toroidal e pelos enrolamentos primário e secundário isolados eletricamente um do outro, conforme ilustra a Figura 146, a seguir. O enrolamento primário normalmente é composto por uma única espira e é ligado em série com o circuito que se deseja medir o valor da corrente. $\mathrm{O}$ enrolamento secundário é composto por várias espiras distribuídas uniformemente pelo núcleo toroidal. Para sistemas de alta tensão todo este conjunto se encontra imerso em óleo. A redução do valor da corrente presente no primário ocorre no secundário por indução magnética. Posteriormente, esta corrente reduzida é transmitida para os dispositivos secundários através de um par de cabos elétricos.

Figura 146 - Transformadores de Corrente Convencionais fabricados pela ABB

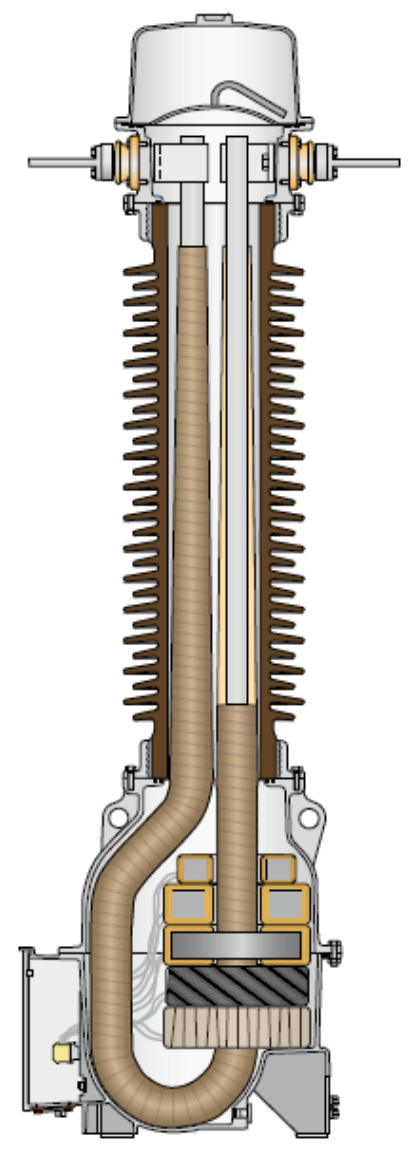

Hair-pin/Tank type

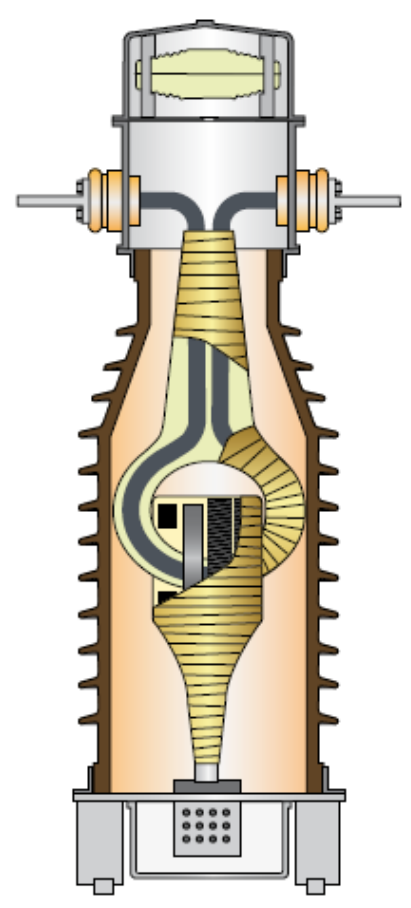

Cascade/Eye-bolt

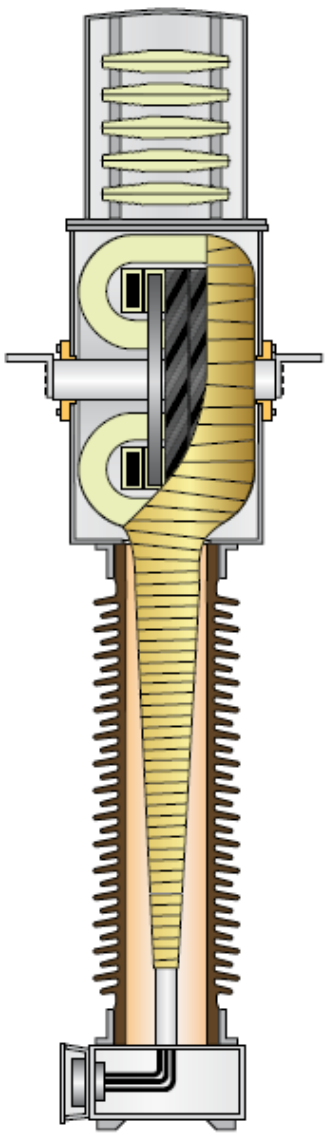

Top-core

Fonte: LIMA (2009)

Devido a estas características construtivas os TCs convencionais são projetados de forma diferente, de acordo com o tipo de aplicação desejada. Para aplicações de medição seu núcleo 
utiliza materiais de alta permeabilidade magnética com o objetivo de oferecer menor erro e menores perdas nas medições - em contrapartida ele satura com maior facilidade para correntes elevadas (em torno de 4 vezes a corrente nominal). Para aplicações de proteção seu núcleo utiliza materiais de menor permeabilidade magnética, saturando com correntes mais elevadas, típicas de curto-circuito (cerca de 20 vezes a corrente nominal). Portanto, numa situação onde, num determinado ponto de uma subestação, se deseja medir a corrente para fins de tarifação e de proteção, será necessário a instalação de dois TCs: um de medição e outro de proteção. 


\section{Transformadores de Potencial Convencionais}

Basicamente, existem duas arquiteturas utilizadas na construção de TPs convencionais: as baseadas em princípios indutivos e as baseadas em princípios capacitivos.

O TP indutivo é constituído de um transformador elétrico, com núcleo ferro magnético, cuja relação de transformação é definida pela relação de espiras entre os enrolamentos primário e secundário. Este modelo de TP é normalmente utilizado em tensões até 138KV. A Figura 147, a seguir, ilustra um modelo de TP indutivo fabricado pela ABB.

Figura 147 - TP indutivo fabricado pela $A B B$

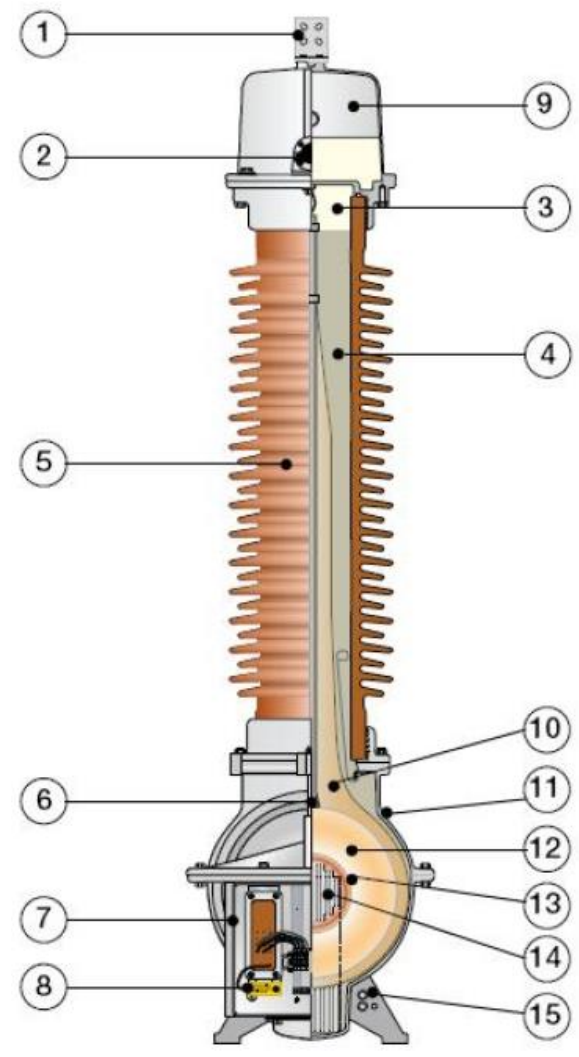

$$
\begin{array}{cl}
\text { Item } & \multicolumn{1}{c}{\text { Descriçäo }} \\
1 & \text { Terminal primário } \\
2 & \text { Visor de vidro do } \\
3 & \text { nível do óleo } \\
4 & \text { Enco } \\
5 & \text { quartzon } \\
6 & \text { Isolador } \\
7 & \text { Ponto para içamento } \\
7 & \text { secunde terminais } \\
8 & \text { Terminal de } \\
9 & \text { fechamento do neutro } \\
10 & \text { Isstema de expanão de papel } \\
11 & \text { Tanque } \\
12 & \text { Enrolamento primário } \\
13 & \text { Enrolamentos } \\
14 & \text { secundários } \\
15 & \text { Conexeo ão com terra }
\end{array}
$$

Fonte: SANTOS (2009)

O TP capacitivo é composto basicamente por uma associação de capacitores em série que realizam a função de divisor de tensão. A Figura 148, a seguir, ilustra um modelo de TP capacitivo fornecido pela Trafo. 
Figura 148 - TP capacitivo comercializado pela Trafo

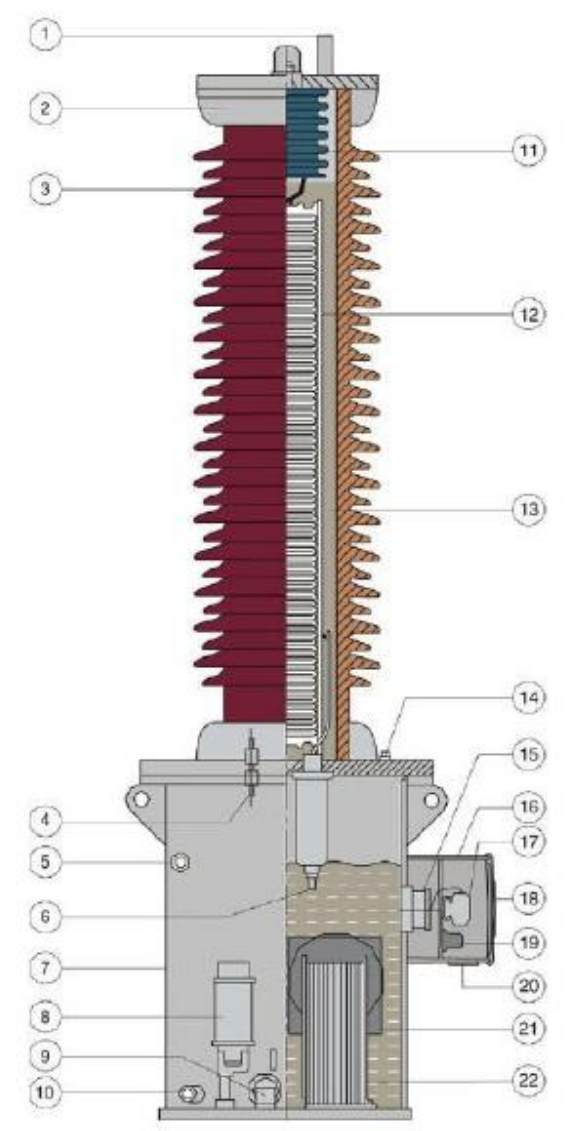

1 - Terminal primário
2 - Flange de liga de aluminio 3. - Isolador de porcelana 5 - Visor de nivel de deo - UEM 6 - Terminal de tensâo ntermediaria 7 - Tanque 8 - Reator de compensaçẫo 9. - Dispo sitivo amortecedor
10- Valivila de amostra de bleo - UEM 12. Unidade capacitiva 13. Oleo

14. Valvula de enchimento de oleo

15- Monobloco

16. Calxa terminal secundaria

17. Terminais secundarios

18. Placa de identíf́caça secundárie

19- Varistor

20- Placa de vedaçấ

21- Unidade Elotromagnotica-UEM

22. Transformador intermediarb de tens

Fonte: SANTOS (2009)

Tanto em operação normal quanto em situações de falha não existem grandes oscilações no valor da tensão medida por um TP, o que permite a utilização de um mesmo TP tanto para fins de medição quanto para fins de proteção, sem perdas de precisão na medição da tensão. 


\section{Transformadores de Corrente Não Convencionais}

Diversas pesquisas foram realizadas com o objetivo de melhorar as limitações tecnológicas inerentes dos projetos de TCs convencionais. Como resultado destas pesquisas foram desenvolvidos os Transformadores de Corrente Não Convencionais.

Em algumas frentes de pesquisa buscou-se melhorar a compatibilidade eletromagnética e a imunidade a ruídos externos dos condutores que transportam o sinal de corrente dos terminais secundários do TC para os dispositivos secundários. Uma das soluções propostas foi associar um conversor eletrônico ao TC convencional, capaz de gerar um sinal óptico de intensidade equivalente a corrente medida, e substituir os condutores metálicos por fibra óptica.

Em outras vertentes buscou-se substituir o elemento sensor por outras alternativas com características de performance superior e que eliminassem o problema de saturação do núcleo em altas correntes. Uma das soluções propostas foi utilizar a Bobina de Rugowsky, cujo núcleo de material não ferromagnético não apresenta saturação. Devido à baixa intensidade de seu sinal de saída é necessária a instalação de um conversor eletrônico, que pode amplifica-lo e gerar um sinal elétrico secundário com maior potência e imunidade a ruídos eletromagnéticos, ou transforma-lo em um sinal óptico equivalente e transportar esta informação através de um enlace óptico.

Uma das alternativas mais avançadas é aplicar sensores ópticos passivos diretos em substituição aos elementos sensores convencionais, como os sensores baseados no Efeito Faraday. Este efeito, ilustrado na Figura 149, a seguir, se manifesta quando um material magneto-óptico é submetido a um campo magnético H. Se um feixe de luz linearmente polarizado se propaga através desse sensor, numa direção paralela à do campo magnético, ocorrerá uma rotação do plano de polarização da luz, proporcional à intensidade do campo magnético aplicado. Posteriormente, esta luz transmitida é captada de forma adequada a medir esta rotação. 


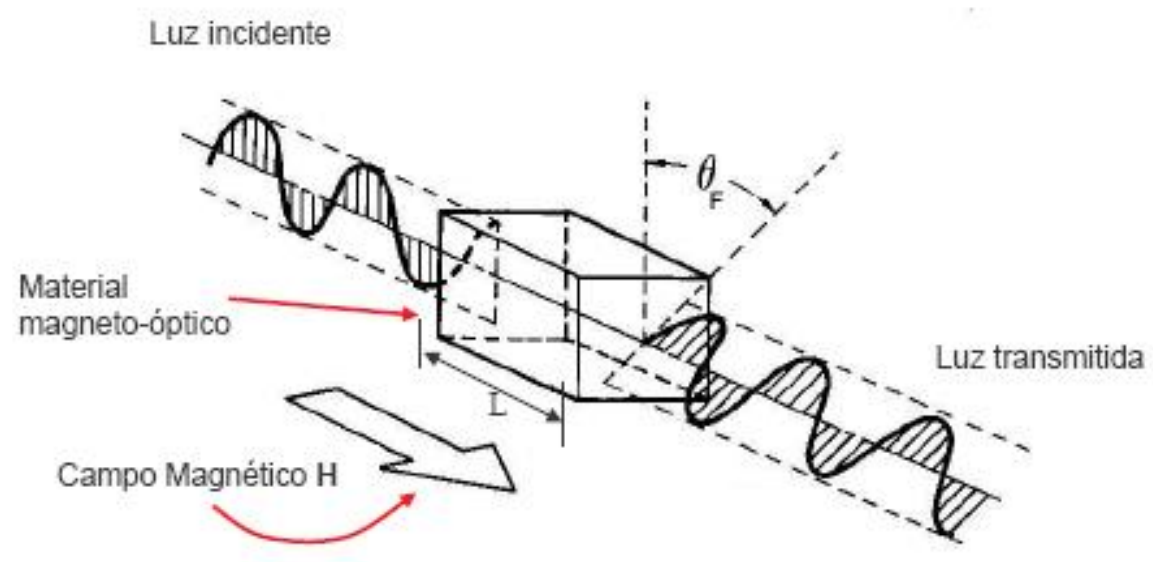

Fonte: LIMA (2009) A Figura 150, a seguir, ilustra um exemplo de TC óptico que utiliza o Efeito Faraday para medir a corrente elétrica [72]. Neste modelo a luz emitida por um LED é transportada através de fibras ópticas até um dispositivo polarizador. A partir deste ponto a luz polarizada circula por dentro de uma fibra com propriedades magneto-ópticas, onde sofrerá os efeitos do campo magnético gerado pela corrente a ser medida. Por fim, a luz é retirada por um dispositivo analisador e transportada através de fibra óptica até um foto-diodo, onde será convertida em sinal elétrico e amplificada. 
Figura 150 - Esquema de um TC óptico

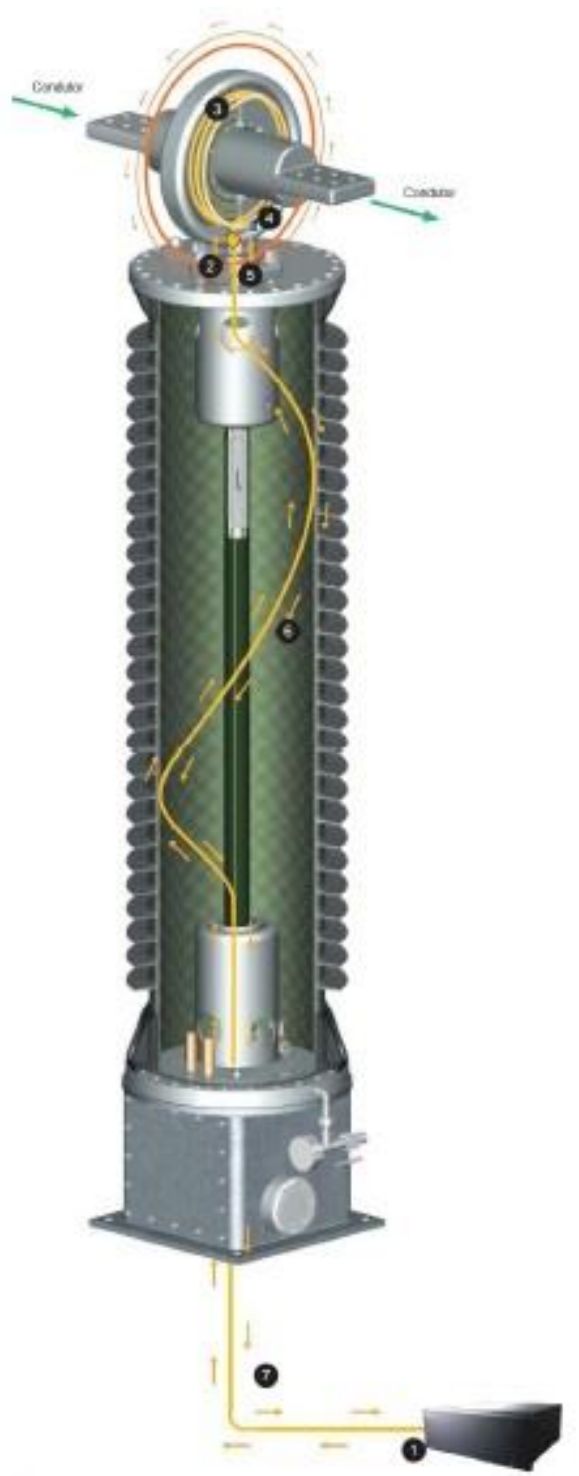

Fonte: LIMA (2009) 


\section{Transformadores de Potencial Não Convencionais}

A evolução dos TPs Não Convencionais ocorreu de forma semelhante aos TCs Não Convencionais. Em algumas linhas de pesquisas estudou-se a substituição dos cabos elétricos que transmitiam o sinal de tensão já reduzido para os equipamentos secundários por um link de fibras ópticas. Em outras linhas de pesquisa partiu-se para a substituição do elemento sensor, fundamentado agora em outro fenômeno físico, o Efeito Pockels.

O sensor de tensão que utiliza o Efeito Pockels se baseia no fenômeno da birrefringência que ocorre em alguns materiais anisotrópicos (que possuem propriedades físicas diferentes de acordo com a direção da polaridade da luz aplicada sobre ele) quando submetidos a um campo elétrico. A Figura 151, a seguir, ilustra este fenômeno.

Neste tipo de modulador eletro óptico utiliza-se um material birefringente que apresente dois índices diferentes de refração. Por exemplo, um índice de refração mais alto para um feixe de luz polarizado no sentido horizontal (eixo y - chamado de slow direction) e um índice de refração mais baixo para um feixe de luz polarizado no sentido vertical (eixo x - chamado de fast direction).

Quando um feixe de luz linearmente polarizado for aplicado com uma direção de polarização intermediária aos eixos horizontal e vertical as componentes horizontal e vertical deste feixe sofrerão um atraso na sua propagação, de acordo com o seu índice de refração, e emergirá elipticamente polarizado no outro lado do material. Este sinal a seguir passa por um analisador e é captado de forma adequada a medir a elipsidade do sinal. 


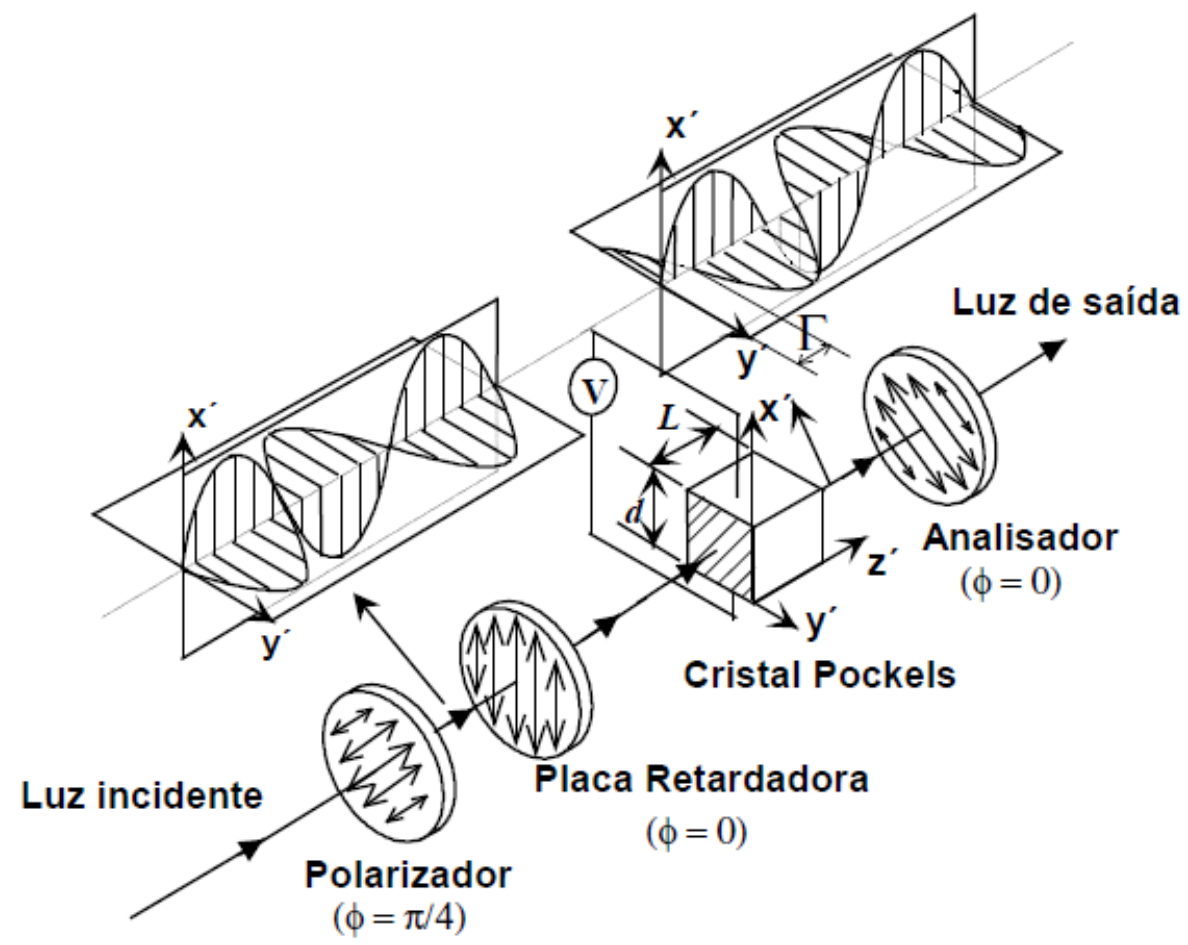

Fonte: SANTOS (2009) A variação da tensão aplicada sobre este material anisotrópico variará o campo elétrico a qual ele está submetido e fará com que suas propriedades físicas se alterem, por consequência, modificando a forma como a luz se propaga e a elipsidade da luz emergente. Esta variação é medida e relacionada diretamente com a variação da tensão.

A Figura 152, a seguir, ilustra um exemplo de sensor óptico de tensão baseado no Efeito Pockels [72]. Ele consiste de um cristal inserido entre a alta tensão e o terra. A luz emitida por uma fonte de luz é transmitida através de uma fibra óptica, polarizada através de um polarizador, e inserida no sensor, propagando-se na direção do campo elétrico gerado pela tensão a ser medida. Um prisma reflexivo posicionado na alta tensão reflete a luz de volta para o lado aterrado do sensor, onde é extraída e analisada por uma eletrônica que fará a conversão para tensão elétrica. 
Figura 152 - Esquema de um TP óptico

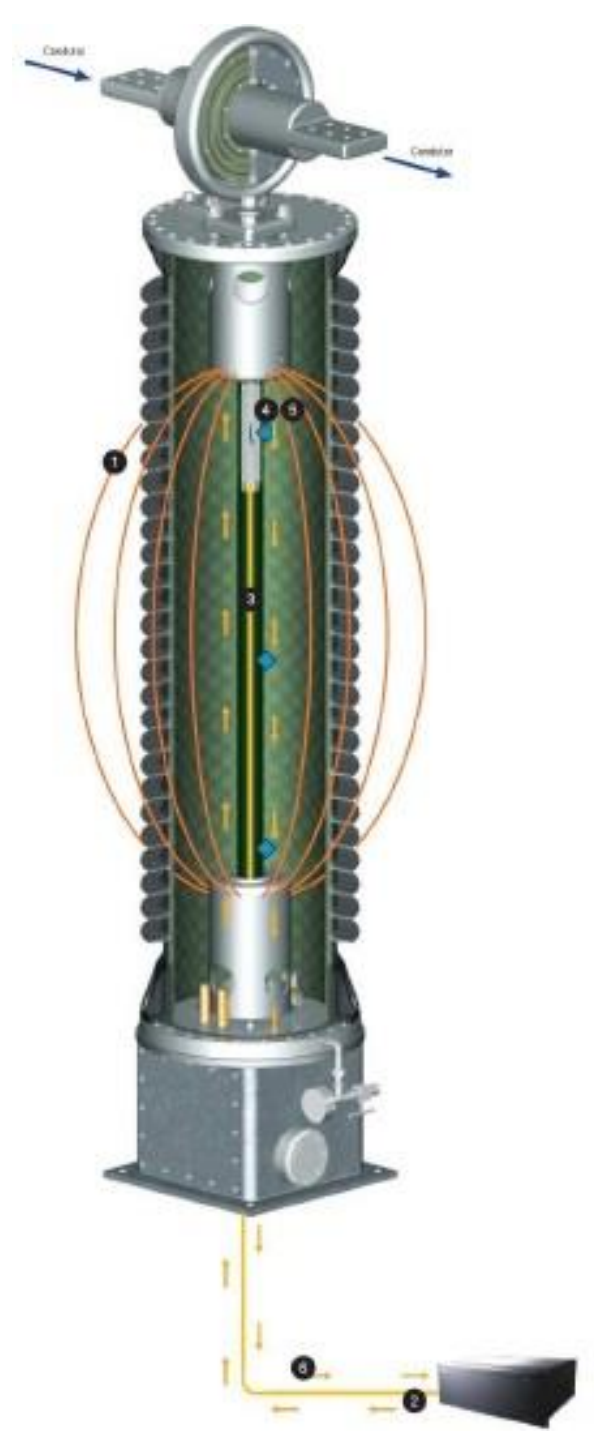

Fonte: LIMA (2009) 


\section{Anexo 2: Processo Pretendido para Calibração em Campo de Transformadores para Instrumentos}

O protótipo para a plataforma de TP óptico digital com interface IEC 61850-9-2 será desenvolvido utilizando como base outra plataforma, que se encontra em desenvolvimento no LSO, para a elaboração de um sistema para calibração em campo de TIs. A Figura 153, a seguir, ilustra o sistema pretendido.

Figura 153 - Plataforma para Calibração em Campo

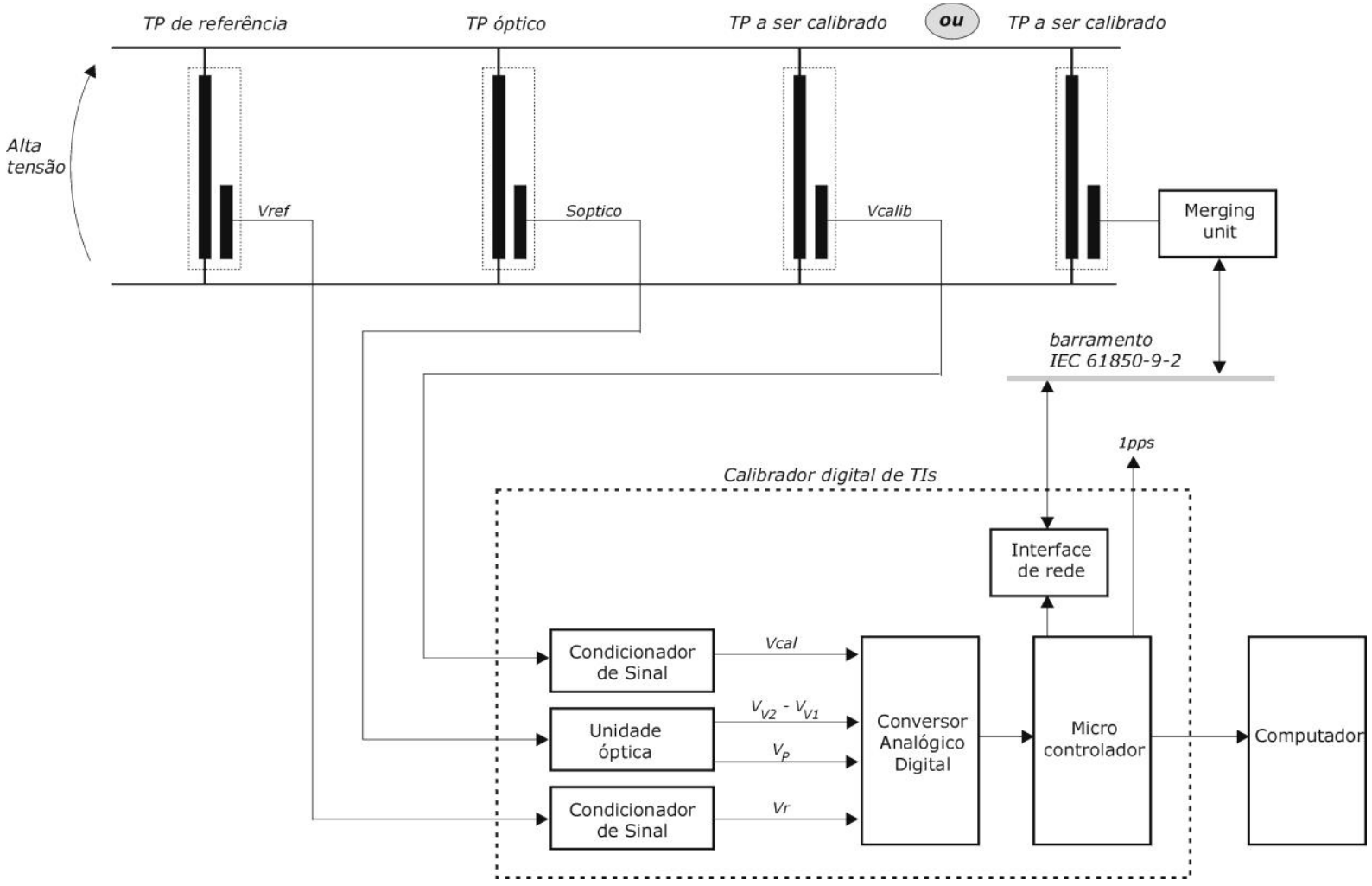

Fonte: o Autor

A Plataforma para Calibração em Campo é composta por um TP óptico e por um Calibrador digital de TIs. Este calibrador é constituído, basicamente, por um bloco Microcontrolador conectado a um bloco Conversor Analógico Digital capaz de amostrar, de forma simultânea, quatro sinais analógicos. Dois destes sinais $\left(V_{V 2}-V_{V 1}\right.$ e $\left.V_{P}\right)$ são oriundos do bloco Unidade Óptica e seguem os mesmos princípios do sistema apresentado na Figura 58. Outro sinal, denominado $V r$, é oriundo do sinal Vref do TP de referência, devidamente condicionado pelo bloco Condicionador de Sinal. O último sinal, denominado Vcal, é oriundo do sinal Vcalib de um TP a ser calibrado, devidamente condicionado pelo bloco Condicionador de Sinal. O objetivo de se medir estes quatro sinais é calibrar o TP óptico e o Calibrador digital de TIs de forma que estes atinjam exatidão suficiente para serem considerados, respectivamente, um TP 
de referência e um calibrador de referência para a calibração de outros TPs em campo.

Uma vez calibrado todo este sistema o próximo passo é levar o conjunto TP óptico + Calibrador digital de TIs para campo. O TP a ser calibrado em campo tem seu sinal de secundário (Vcalib) devidamente condicionado pelo bloco Condicionador de Sinal, tornandose o sinal Vcal. O TP óptico é conectado no mesmo barramento de alta tensão do TP a ser calibrado. A partir disto, o sistema poderá comparar a medição realizada por ambos e elaborar o relatório de calibração.

A plataforma deve contar ainda com um bloco Interface de rede que possibilitará a calibração de TPs com interface de rede para barramento de processo de acordo com a Norma IEC 61850-9-2. 